\title{
IV. Selbstbehauptung aus Glaubensgründen - Widerstand der Zeugen Jehovas bis Kriegsbeginn
}

\section{Bekennermut und konspirative Techniken: Intensivierung der mis- sionarischen Aktivitäten unter den Bedingungen des „totalen Staates“}

Nachdem im Anschluß an den gemeinsamen Auftakt vom 7. Oktober 1934 das Verkündigungswerk der Zeugen Jehovas in Deutschland ungeachtet des Verbotes wieder aufgenommen worden war, kamen die Bibelforschergemeinden in den nunmehr gebildeten Kleingruppen zumeist wöchentlich zur gemeinsamen Lektüre der Bibel und des „Wachtturms“ zusammen. Diese ungefähr einstündigen gottesdienstlichen Versammlungen der Zeugen Jehovas, die mit Gebeten eingeleitet und beschlossen wurden und die vom Gesang einiger „Königreichslieder“ begleitet waren, wurden in den Wohnungen der Gruppenangehörigen veranstaltet und oftmals nach außen hin als Kaffeekränzchen, Familientreffen, Kartenspielrunde oder Handarbeitskreis getarnt. Da unter den Angehörigen der Kleingruppen vielfach sowohl nachbarschaftliche oder enge freundschaftliche Bindungen als auch verwandschaftliche Beziehungen bestanden und die Zusammenkünfte somit auch tatsächlich einen gewissermaßen familiären Aspekt an sich hatten, war die Gefahr, entdeckt zu werden - solange die Gestapo keine gezielten Observationen unternahm -, relativ klein, zumal Außenstehende beziehungsweise Interessierte in aller Regel erst dann zu diesen gottesdienstlichen Versammlungen hinzugezogen wurden, wenn sie sich zuvor im persönlichen Bibelstudium mit einem „Verkündiger“ über eine längere Zeitspanne als vertrauenswürdig erwiesen hatten.

In der ersten Zeit trug auch die Unkenntnis der Gestapo über die Glaubensgewohnheiten der Bibelforscher dazu bei, daß die Zahl der Aufdeckungen sich in Grenzen hielt ${ }^{1}$. Zunächst konzentrierte sich die Gestapo bei den Ermittlungen auf den Nachweis der gemeinsamen Lektüre von „,verbotenen Schriften“, während das Zusammenkommen von mehreren Zeugen Jehovas sie noch nicht zum unmittelbaren Einschreiten veranlaßte. Als beispielsweise in Magdeburg am 7. Oktober 1934 eine Versammlung von Zeugen Jehovas polizeilich „überholt“ wurde, rückte die Gestapo unverrichteter Dinge wieder ab, weil sie in dem Raum nur eine Anzahl Personen angetroffen hatte, die ein von einem Klavier begleitetes Lied sangen, und auch sonst nichts Anstößiges feststellen zu können meinte ${ }^{2}$. Nachdem die Polizei gegangen war, führten die Zeugen Jehovas ihre Versammlung fort und beratschlag-

1 Polizeilicherseits verfügte man zunächst über keinerlei Kenntnisse hinsichtlich der Glaubensgemeinschaft. Um diesen Mangel zu beseitigen, ließ sich das Staatspolizeiamt Lübeck Anfang 1935 von dem im dortigen Gefängnis einsitzenden IBV-Bezirksdienstleiter eine Darlegung über die „Lehre und den Rythus [Ritus]“ der Bibelforscher schreiben (SLG HH, HSG 11 Js. Sond. 1617/34, Band III, BI. 345, Staatspolizeiamt Lübeck, Schreiben vom 4.2.1935 an die Hamburger Polizeibehörde; die Darlegung ebenda, Bl. 348ff.).

2 Vgl. Jahrbuch 1935, S. 86; EZA, 1/C3 Nr. 309, Kurt G., Eingabe vom 16.10.1934 an den Reichskanzler. Erst eine Woche nach der Versammlung erkannte die Gestapo - eventuell aufgrund der mittlerweile eingegangenen Protestschreiben -, daß sie es mit einer ,verbotswidrigen Zusammenkunft" der IBV zu tun gehabt hatte. Die erfolgte Namensfeststellung ermöglichte es ihr allerdings, der Teilnehmer im nachhinein habhaft zu werden. 
ten anschließend über das Protestschreiben an Hitler und über das weitere Vorgehen nach Wiederaufnahme der Aktivitäten.

Die Zusammenkünfte am 7. Oktober und damit die Neubildung der IBV-Organisation waren der Gestapo nicht nur in Magdeburg verborgen geblieben. In Hamburg, wo es zu der größten Anzahl von Festnahmen kam, war die dortige Staatspolizei erst zwei Wochen später durch ein Ersuchen des Dresdener Polizeipräsidiums um Amtshilfe in einer anderen Angelegenheit (Nachforschungen wegen der illegalen Einfuhr von Bibelforscherschriften, die über die deutsch-tschechische Grenze geschmuggelt worden waren) ${ }^{3}$ auf die Versammlungen am 7. Oktober 1934 und die Neuorganisation der Hamburger IBV-Gruppe aufmerksam geworden. Infolge der daraufhin ab dem 25. Oktober durchgeführten verschärften Postüberwachung bekam die Staatspolizei Kenntnis von Ort und Termin der wöchentlichen Zusammenkunft einer der in Hamburg gebildeten Stadtteilgruppen, obwohl der abgefangene Brief vom 28 . November verschlüsselt darüber berichtete: „Wenn Du Zeit hast, zu unserm Familienabend am Donnerstag zu kommen, würden wir uns sehr freuen; um $7^{1 / 2}$ abends beginnt der Schmaus.“4

Am Donnerstag, den 6. Dezember 1934, griff die Staatspolizei zu. Sie überraschte die Anwesenden bei der gemeinsamen „Wachtturm“-Lektüre. Bei der sich anschließenden Hausdurchsuchung und durch Verhöre gelang es den drei ermittelnden Gestapo-Beamten, weitere Einzelheiten zu erfahren. Am nächsten Tag wurde der Hamburger IBV-Gesamtleiter Max Grote verhaftet. Beamte der Staatspolizei fanden in seiner Wohnung ein Notizbuch, in dem die Namen der Leiter von 22 der insgesamt 24 Stadtteilgruppen verzeichnet waren. Diese Eintragungen boten der Staatspolizei ausreichende Anhaltspunkte für ihre weiteren Ermittlungen. Nun erfolgten in Hamburg zahlreiche Verhaftungen, die zur Einleitung von Strafverfahren gegen insgesamt 170 Teilnehmer der Versammlungen vom 7. Oktober 1934 führten. Außerdem gelang es der Staatspolizei, ein Bücherlager auszuheben und „ca. $30.000 \mathrm{~kg}$. Broschüren der Bibelforscher" zu konfiszieren.

Das Hamburger Beispiel zeigt zum einen, daß man auf seiten der IBV noch nicht hinreichend auf die Erfordernisse illegaler Arbeit eingestellt war - später wurde peinlich darauf geachtet, daß keine mit Namen versehenen schriftlichen Aufzeichnungen angefertigt wurden -, belegt zum anderen aber auch, daß man im Blick auf möglicherweise erfolgende Festnahmen Vorbereitungen und Absprachen getroffen hatte. So lassen die Aussagen vor der Staatspolizei vermuten, daß ein gemeinsamer Text verabredet worden war, den man gegebenenfalls bei der Gestapo anzugeben bereit war. Er lautete in etwa: „Am 7.10.1934 habe ich an der Zusammenkunft der Zeugen Jehovas bei X. teilgenommen. Es waren ungefähr 10 Personen anwesend, deren Namen ich nicht mehr genau angeben kann. " 5 Ein derartiger Text nötigte weder zu einer Lüge, noch gab er Namen und Einzelheiten preis, die andere Glaubensangehörige in Bedrängnis hätten bringen können.

3 SLG HH, HSG 11 Js. Sond. 1617/34, Band I, BI. 1, Polizeipräsidium in Dresden, Schreiben vom 23.10.1934.

4 SLG HH, HSG 11 Js. Sond. 1617/34, Band I, Anlage zu Bl. 12a.

5 Vgl. die Aussagen in: SLG HH, HSG 11 Js. Sond. 1617/34 und in den Anschlußverfahren $1617 / 34 a-34 f$. 
In den Verhören blieben die Zeugen Jehovas zumeist standhaft; sie beantworteten die Fragen zur Person, gaben sich aber sonst vollkommen unwissend. Am 7. Februar 1935 vermerkte der verantwortliche Sachbearbeiter bei der Hamburger Staatspolizei, daß sich die polizeilichen Ermittlungen trotz der großen Zahl von Verhaftungen sehr schwierig gestalten würden, „da einzelne Bibelforscher nicht zu bewegen waren, die hierzu erforderlichen Angaben zu machen"6.

Auch im benachbarten Altona mußte die dortige Außenstelle der Staatspolizeistelle für den Regierungsbezirk Schleswig, die am 24. Oktober 1934 die Anordnung erlassen hatte, „der Propagandatätigkeit der Bibelforscher größte Aufmerksamkeit zu schenken und dagegen einzuschreiten"7, am 12. Januar 1935 eingestehen, daß ,die polizeilichen Aktionen zur Durchführung des Verbots der Vereinigung der Ernsten Bibelforscher [...] keinen durchschlagenden Erfolg gebracht" haben. Zu dieser Zeit, d. h. um die Jahreswende 1934/35, befanden sich in Dresden ca. 40, in Berlin und Halle ca. je 20 Zeugen Jehovas in Schutzhaft ${ }^{9}$.

Der für die nächsten Monate feststellbare starke Anstieg der Festnahmen ${ }^{10}$ war allerdings nicht in erster Linie auf effizientere Ermittlungsmethoden der Polizeibehörden zurückzuführen, sondern vielmehr auf das hohe Risiko, das mit der Wiederaufnahme des Missionsdienstes verbunden war. Im Unterschied zu den $\mathrm{Zu}$ sammenkünften war hier die Entdeckungsgefahr sehr groß. Zwar versuchten die Zeugen Jehovas gewisse Vorsichtsregeln zu beachten. So gingen sie großteils nur mit der Bibel in der Tasche von Haus zu Haus beziehungsweise von Tür zu Tür, und erst wenn jemand Interesse signalisierte, führten sie bei „Rückbesuchen“ auch das Schrifttum der Watch Tower Society mit sich ${ }^{11}$. Beim ersten Klingeln an der Haustür wurden die Gespräche mit einigen unverbindlichen Worten eingeleitet, um an der Reaktion des Angesprochenen festzustellen, ob es sich um einen „Parteigänger Hitlers“ handelte oder ob sie jemanden vor sich hatten, dem sie die Königreichsbotschaft verkündigen konnten. Nur dann sprachen sie weiter. Wenn ihnen jedoch irgend etwas verdächtig vorkam, brachen sie das Gespräch unter einem Vorwand ab, verließen sogleich das Haus und setzten ihre Tätigkeit erst wieder in einer anderen Straße fort.

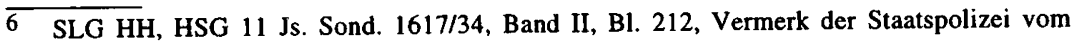
7.2.1935.

7 UaP Rolf Schwarz, Staatspolizeistelle für den Regierungsbezirk Schleswig in Altona, RdErl. vom 24.10.1934, in Abschrift als RdV des Landrates in Rendsburg vom 27.10.1934 an die Ortspolizeibehörden des Kreises.

8 UaP Rolf Schwarz, Staatspolizeistelle für den Regierungsbezirk Schleswig in Altona, RdErl. vom 12.1.1935, in Abschrift als RdV des Landrates in Rendsburg vom 17.1.1935 an die Ortspolizeibehörden.

9 Vgl. BA, R 43 IV/179, Bl. 268-272, Hans Dollinger, Eingabe vom 5.1.1935.

10 Lichtenegger, Bibelforscher, S. 182, und Pingel, Häftlinge, S. 88, nehmen einen kausalen Zusammenhang zwischen der Einführung der allgemeinen Wehrpflicht und dem Anstieg von Festnahmen respektive der verstärkten Einweisung von Bibelforschern in die Konzentrationslager an, der so nicht besteht. Der Anstieg der durch die Gestapo gegen Zeugen Jehovas verfügten Inschutzhaftnahmen ist auf die nach dem Beschluß von Basel - ungeachtet des Verbotes ab Oktober 1934 in vollem Umfang wiederaufgenommene Verkündigungstätigkeit zurückzuführen; die am 16.3.1935 wiederhergestellte „Wehrhoheit" des Reiches bedeutete für die praktizierenden Kriegsdienstverweigerer zwar das Heraufziehen einer neuen Gefahr, aber die Schärfe der gegebenen Auseinandersetzung beeinflußte sie vorerst nur mittelbar.

11 Vgl. Jahrbuch 1974, S. 141. 
Auch vermieden es viele Zeugen Jehovas, in ihrer unmittelbaren Nachbarschaft zu predigen, sondern übernahmen ein Gebiet in einem benachbarten Ort oder Stadtteil, in dem sie persönlich nicht bekannt waren. Teilweise fuhren größere Gruppen zu gemeinsamen Missionsaktionen in eine bestimmte Region, um zeitgleich an verschiedenen Orten tätig werden zu können. Über die Vorteile eines solchen Einsatzes heißt es in einem Bericht:

„Aber wir ließen keine Gelegenheit verstreichen, der Gestapo ein Schnippchen zu schlagen. Wir teilten uns auf in verschiedene Gebiete und gingen dann los. Alle zugleich begannen wir mit dem Predigen in irgend einer Straße in verschiedenen Ortschaften und Städten. Aber jeder besuchte nur einige Häuser. Wir lieferten die Schriften ab und verschwanden wieder. Inzwischen liefen in den Polizeistationen Anrufe aus allen umliegenden Ortschaften ein, die Zeugen seien da. Die Gestapo wußte kaum, wo sie zuerst einsetzen sollte. Und tauchten dann die Überfallkommandos auf, waren wir längst nicht mehr da." 12

Dennoch war der Predigtdienst in einer Zeit, in der das Denunziantentum Konjunktur hatte, höchst gefahrvoll ${ }^{13}$. Auf den Revierwachen gingen zahlreiche Anzeigen ein. In nicht wenigen Fällen wurden die „Königreichsverkündiger“ noch gleich im Hausflur oder auf der Straße von Hausbewohnern oder eilig herbeigerufenen Polizisten gestellt. In dem Bericht eines Hamburger Hauptwachtmeisters der Schupo-Revierwache 58 stellt sich ein derartiger Vorgang folgenderweise dar:

„Am 5.12.1934, um 15.30 Uhr, machte mich auf meinem Dienstgange im Elligersweg der Hauswart Carl S. [...] auf einen mir unbekannten Mann aufmerksam, der im Hause Elligersweg Nr. 53 ptr. bei Sch., ein Buch mit der Überschrift, Regierung' zum Preise von 0,20 verkauft hatte. Der Herausgeber des Buches ist die Internationale Bibelforscher-Vereinigung, Wachtturm Bibelund Traktat-Gesellschaft Magdeburg. Der Mann wurde von mir zur Wache gebracht. [...] Die Staatspolizei erhielt von mir im Vorwege teleph. Kenntnis." 14

Selbst Kinder wurden zu Aussagen verleitet. So berichtete beispielsweise eine 13jährige Schülerin der Polizei davon, daß ein ihr unbekannter Mann bei ihren Eltern gewesen sei: „Der Mann sprach von Gott und der Bibel und vom Krieg und Totschießen. Was im einzelnen gesprochen ist, kann ich nicht sagen. Der Mann übergab in meiner Gegenwart meinen Eltern drei Bücher. Um was für Schriften es sich handelte, weiß ich nicht, ich habe sie mir nicht angesehen. Was der Mann eigentlich bei uns wollte, weiß ich nicht. Wenn ich den Mann sehe, werde ich ihn wiedererkennen." 15 Daraufhin wurden dem Mädchen fünf Personen gegenübergestellt. Unter ihnen erkannte sie den Mann, den sie mit ihren Eltern hatte sprechen sehen.

12 Doyon, Hirten, S. 230.

13 In der NS-Presse erschienen entsprechende Aufforderungen, und Denunzianten wurden für ihre "vorbildliche Verhaltensweise“ belobigt: „Dieser wachsame Volksgenosse war erfreulicherweise pietätlos genug, den falschen Prediger sofort verhaften zu lassen." (VB, 25.7.1936)

14 SLG HH, HSG 11 Js. Sond. 1617/34, Band I, Bl. 10, Polizeibehörde Hamburg, Wache 58, Bericht vom 5.12.1934.

15 SLG HH, HSG 11 Js. Sond. 298/38, Gestapo II B 1, 2052/37, Staatspolizeistelle Hamburg, Vernehmungsprotokoll vom 23.7.1937. 


\section{Trotz Festnahmen Unerschrockenheit}

Doch weder die steigende Zahl von Festnahmen noch die zu gewärtigenden Folgen - seit Anfang 1935 wurden Hunderte von Zeugen Jehovas ${ }^{16}$ in die Konzentrationslager Esterwegen, Moringen und vor allem Sachsenburg eingewiesen ${ }^{17}$, und auch die Strafgerichte verhängten teilweise bereits drastische Urteile ${ }^{18}$ - schreckten die Aktivisten unter den Zeugen Jehovas von der Betätigung für ihr Verkündigungswerk ab. So stand Anfang November 1935 vor dem schlesischen Sondergericht ein Zeuge Jehovas, den das gleiche Gericht sechs Wochen zuvor, am 17. September, zu drei Monaten Gefängnis verurteilt hatte, und der bereits am Tag nach der ersten Urteilsverkündung erneut verhaftet worden war, weil er ,abermals für die Sekte geworben hatte"19.

$\mathrm{Zu}$ dieser Unerschrockenheit im Bekennen, die ihren tieferen Grund in einem festen Gottvertrauen und in der Glaubensgewißheit des baldigen Anbruches des Königreiches Christi auf Erden hatte, trug nicht unwesentlich die Erwartungshaltung der Brooklyner Zentrale der Watch Tower Society bei. So hatte schon der erste nach den Versammlungen vom 7. Oktober erschienene „Wachtturm“ die Zeugen Jehovas in Deutschland aufgefordert, als die von Gott zu seiner „Königreichsklasse“ erwählte „,kleine Herde“ treu zu bleiben und allen Gefahren zu trotzen: „Der Herr Jesus ermahnte seine Nachfolger, keine dieser Leiden zu fürchten, und gab ihnen dann diese Versicherung: ,Sei getreu bis zum Tode, und ich werde dir die Krone des Lebens geben. - Offenbarung 2:10."20 Neben die Herausstellung der Heilszusage für jene, die im „Dienste des Herrn“ ausharren, trat die Betonung der nun eingetretenen Prüfungssituation, in der es gelte, sich Gott gegenüber ,loyal“ zu verhalten und dadurch „Satan“ zu widerlegen. So erklärte das vermutlich im Oktober/November 1934 verfaßte Jahrbuch der Zeugen Jehovas: „Manche dieser treuen Nachfolger Christi Jesu wurden in Konzentrationslager oder andere Gefängnisse gebracht und elend mißhandelt, weil sie sich weigerten, für Hitler zu stimmen oder

16 Nicht selten findet sich selbst in der Fachliteratur die Angabe, daß Zeugen Jehovas erst 1936/ 37 in Konzentrationslager eingewiesen worden seien. So geht Dieter Kolbe von der falschen Annahme aus, daß bis zum weitflächigen Vorgehen gegen „Kriminelle“ und sogenannte „Asoziale“ im Jahre 1937 Schutzhaft nur über politische Gegner verfügt worden sei. Dabei verschlimmert er seinen Mißgriff noch durch eine angefügte Erläuterung, wonach zu „den ,Asozialen' [...] außer den Homosexuellen und Alkoholikern vor allem die ,Internationalen Bibelforscher"“ (Kolbe, Bumke, S. 281) gehörten.

17 Im Sommer 1935 sollen sich in Sachsenburg ca. 400 und in Esterwegen ca. 120 Zeugen Jehovas in der Gewalt der SS befunden haben (vgl. Erwachet!, 22.11.1992, S. 18; Zürcher, Kreuzzug, S. 150f.). Im Frauen-KZ Moringen, in das im Januar 1935 die ersten Bibelforscherinnen eingeliefert wurden, stellten sie schon bald nach den Kommunistinnen mit $22 \%$ die zweitgrößte Gruppe; ihre Gesamtzahl betrug bis Ende 1937 über 300 (Angabe der KZ-Gedenkstätte Moringen). In den Jahren 1935/36 war es durchaus noch üblich, daß die meisten Zeugen Jehovas nach mehrmonatigem Lageraufenthalt aus der KZ-Haft entlassen wurden.

18 Siehe S. 238f. Das Schöffengericht III in Dortmund verurteilte am 29.11.1934 einen Zeugen Jehovas wegen Zuwiderhandlung gegen das IBV-Verbot zu zwei Jahren, eine Frau zu einem Jahr, eine weitere zu neun Monaten Gefängnis (zit. in: LA SH, Abt. 352 Altona Nr. 8869). Den Aufzeichnungen von Syndikus Dollinger zufolge scheint es das zu dieser Zeit höchste verhängte Strafmaß gegen Bibelforscher gewesen zu sein (vgl. BA, R 43 IV/179, Bl. 271).

19 EZA, 7/Generalia XII Nr. 161, o. Bl., Pressenotiz vom 4.11.1935.

20 SLG HH, HSG 11 Js. Sond. 100/37, o. Bl., Bibelstudien, Ersatzzeitschrift für den „Wachtturm“, o. D. [November 1934], Nachdruck des am 15.10.1934 im „Wachtturm“ erschienenen Artikels „Zulassung der Christenverfolgung“. 
ihn als den Retter der Menschheit zu begrüßen. Die Treuen sind entschlossen, Jehova Gott treu zu bleiben und jede Strafe zu ertragen, die Gott über sie zu kommen duldet. Nur auf diese Weise kann der Mensch endgültig auf seine Rechenschaft Jehova gegenüber geprüft werden." 21 Im Blick auf die von den Zeugen Jehovas in Deutschland einzunehmende Haltung wurde im ,Wachtturm“ und den anderen Bibelforscherschriften herausgestellt, daß für Christen eine Gehorsamspflicht nur gegenüber der theokratischen Obrigkeit bestünde, nicht aber gegenüber „widergöttlichen“ Anordnungen der Hitler-Regierung; denn diese stehe „ohne Zweifel unter der Kontrolle der unsichtbaren Macht Satans und seiner ruchlosen Verbündeten, die zusammen gegen Jehovas Zeugen Krieg führen“. Ohne Umschweife wurde festgestellt: „Gesetze sind unnötig für gerechte Menschen (1. Tim. 1:9). Irgendein Gesetz, das mit dem besonderen Gesetze Jehovas im Widerspruch steht oder dem göttlichen Gesetz widerstreitet, ist ungerecht. " 22

Der Stärkung der Gläubigen durch die Zusicherung, bei Treue zu Gottes Geboten und aktivem Bekennen der Königreichsbotschaft das ewige Leben zu erlangen und als Mitregenten im kommenden Friedensreich reichlich belohnt zu werden, stand auf der anderen Seite die Androhung gegenüber: ,... und wenn sie verfehlen, Gottes Gesetz zu halten, so hat ihr Ungehorsam die ewige Vernichtung zur Folge."23

Zu dem psychischen Druck, der auf den Zeugen Jehovas dadurch lastete, daß ihnen vor Augen stand, „keine Wahl“ zu haben, trat die Sorge, von den Glaubensgeschwistern gemieden, aus der Vereinigung ausgeschlossen und mit dem gegenüber „Abgefallenen“ ausgesprochenen „Gemeinschaftsentzug“ belegt zu werden. Neben den aus dieser Zwangslage heraus Handelnden und den „,kämpferischen Bekennern" traten jene in Erscheinung, die sich zwar gleichfalls am Predigtwerk beteiligten, aber zur Besonnenheit mahnten. Nicht selten wurden allerdings ihre gegen

21 Jahrbuch 1935, S. 81.

22 UaP Rolf Schwarz, Wachtturm-Vervielfältigung (Titel „Verräter“, vermutlich 1935).

23 Zürcher, Kreuzzug, S. 31. Die Haltung der Watch Tower-Zentrale, die ohne Zweifel die Konfrontation verschärfte, gilt manchen Autoren als Beleg dafür, daß die Brooklyner Führung bewußt die deutschen Zeugen Jehovas dem Verfolgungsschicksal ausgesetzt habe, um dies für ihre Zwecke zu nutzen. Während Dietrich Hellmund noch einschränkend von „sehr gewichtigen Indizien“ spricht, die ihm darauf hinzudeuten scheinen, „daß die psychologisch sehr ungeschickt und weltfremd fernsteuernde Brooklyner Leitung manchen ZJ ganz unnötig ins Martyrium hineingetrieben hat" (Hellmund, Zeugen Jehovas, Kapitel IV, 2, Anm. 535), sieht Rolf Nobel eine absichtsvolle Strategie als gegeben an: Es habe sich um „ein eindeutiges, ja sogar ein mörderisches Kalkül“" gehandelt, denn nur „,ein Wort der Sektenführer“ hätte seiner Ansicht nach genügt, „das Blutbad zu verhindern. Aber die schwiegen. So starben 2.000 Sektenmitglieder in den Konzentrationslagern, brauchbare Märtyrer für den ,Göttlichen Kanal im fernen und sicheren New York, ,Beweise für die unbeugsame Haltung der Zeugen Jehovas“." (Nobel, Falschspieler Gottes, S. 192f.)

Läßt sich vielleicht noch darüber diskutieren, inwieweit die Brooklyner Führung die Konfrontation suchte, um die einsetzende Verfolgung als Bestätigung der von ihr propagierten Prophezeiungen deuten zu können, so bleibt andererseits festzuhalten, daß bereits 1933, als die Leitung noch auf den Verhandlungskurs setzte, oftmals in den Versammlungen, $d$. h. an der „Basis“, zu mehr Entschlossenheit und Entschiedenheit gedrängt wurde. Für den opferreichen Widerstand und den Weg des Martyriums bedurfte es, auch in den späteren Jahren, bei zahlreichen Zeugen Jehovas keiner „Anweisung aus Brooklyn“. Vielmehr waren die Maximen bereits so weit internalisiert, daß der Bibelforscherglaube selbst in ihnen die Bereitschaft zum Handeln bewirkte. 
eine bestimmte Aktion mit dem Hinweis geäußerten Bedenken, daß dieses Tun ein zu hohes Risiko aufweise, als „Zaudern“ und „mangelndes Vertrauen auf Jehova“ ausgelegt. Dabei waren jene eher Gemäßigten dort, wo sie ihr Gewissen gefordert sahen, beispielsweise in der Grußfrage, ebenso unbeugsam wie die anderen. Für sie kam es darauf an, ,den Gegner nicht unnötig zu provozieren, also sich weitgehendst anzupassen“, aber dort, wo die Grenze erreicht war, diese dann auch kompromißlos einzuhalten: „Dann muß Widerstand da sein, dann kann kein Kompromiß mehr erfolgen." 24

Einige Zeugen Jehovas nahmen hingegen die von der Watch Tower-Zentrale verbreiteten Aufforderungen zum unerschrockenen Bekenntnis sehr wörtlich. Sie legten in aller Öffentlichkeit ,Zeugnis“ ab und bevorzugten im Angesicht des ,,satanischen" Feindes demonstrative Handlungen. Ein Bibelforscher aus Itzehoe ging beispielsweise im Juli 1935 auf eine ihm unbekannte Frau zu und gab ihr unmißverständlich $\mathrm{zu}$ verstehen, daß ihm das von ihr getragene Abzeichen der NSFrauenschaft mißfalle ${ }^{25}$. Auch erklärte er ihr gegenüber die Wehrmacht zu einem Werkzeug des Teufels und verkündete in Anspielung auf die NS-Führung, daß ,alle, die heute das alte Testament verlästerten, hinweggefegt" würden. Die Offenheit gegenüber der sich in ihrer Ehre ,als Amtswalterin“ beleidigt fühlenden Frau brachte dem Mann drei Monate Gefängnis ein.

Die im Zusammenhang mit dem Missionsdienst stehenden Festnahmen steigerten noch die Bedeutung der bei den Zeugen Jehovas zwar nicht zahlreichen, dafür aber um so verpflichtenderen rituellen Bindungen. Von besonderer Bedeutung waren die Gedächtnismahlfeiern, die von den Zeugen Jehovas einmal jährlich in Erinnerung an das letzte Mahl Jesu mit seinen Jüngern, das der EvangelienÜberlieferung zufolge am Vorabend des Passahfestes stattfand, am jeweils gleichen Tag, dem 14. Nisan im jüdischen Kalender, nach Sonnenuntergang durchgeführt werden. Dies bedeutete, daß zu einem feststehenden und als nicht verlegbar geltenden Termin alle Bibelforschergemeinden zusammenzukommen versuchten. Der Gestapo waren wohl zunächst die genauen Hintergründe nicht bekannt, jedoch hatte sie Anfang März 1935 durch die Postuiberwachung von dem Datum, auf das das Gedächtnismahl im Jahr 1935 fiel, erfahren und die sich bietende Möglichkeit für einen polizeilichen „Zugriff“ erkannt. Am 5. März berichtete die Kieler Staatspolizeistelle nach Berlin: „Die Bibel- und Traktat-Gesellschaft sendet aus der Schweiz nach wie vor die bekannten Druckschriften und neuerdings auch die Schrift ,Die Schlacht Gottes ' vom 1.3.35 an bekannte Bibelforscher in Deutschland. Hierin wird aufgefordert, am 17.4.35 das Passahfest zu feiern."26 Zwei Wochen später, am 20. März, wandte sich das Geheime Staatspolizeiamt mit einem Runderlaß an alle preußischen Staatspolizeistellen ${ }^{27}$. Diesem Erlaß schlossen sich in der Folge auch die obersten Gestapo-Stellen der anderen Länder an. So teilte die Bayerische Politische Polizei am 8. April den dortigen Polizeibehörden mit, aus

24 Knöller, Erinnerungen, S. 18, 22.

25 Vgl. Möller, Steinburg, S. 209.

26 BA, R 58/1128, B1. 375, Staatspolizeistelle für den Regierungsbezirk Schleswig in Kiel, Allgemeine Übersicht über die politische Lage im Monat Februar 1935 vom 5.3.1935.

27 Vgl. BA, R 58/1074, Bl. 28. 
einer beschlagnahmten Bibelforscherschrift sei ersichtlich, „daß sich die ,Gruppen der Gesalbten“ voraussichtlich am 17. April 1935 nach 6 Uhr abends zu einer Gedächtnisfeier des Namen Jehovas und des Opfers Jesu Christi versammeln werden. Ein überraschender Zugriff bei den bekannten führenden Persönlichkeiten der Ernsten Bibelforscher zu dem angegebenen Zeitpunkt dürfte erfolgversprechend sein und ist zu veranlassen." 28

Nur der Tatsache, daß die IBV aufgrund einer Warnung von den Vorbereitungen der Gestapo Kenntnis erlangte und die Bezirksleiter die Gruppen noch von der Notwendigkeit besonders umfangreicher Vorsichtsmaßnahmen unterrichten konnten, war es zu verdanken, daß sich - obgleich zahlreiche IBV-Gruppen zur Gedächtnismahlfeier zusammentrafen - die Zahl der Festnahmen in Grenzen hielt ${ }^{29}$. Die Treffpunkte waren verlegt worden, so daß etwa die Gestapo Dortmund nur berichten konnte, man habe die Wohnungen überwacht, es sei aber in keinem Fall zu Zusammenkünften von Bibelforschern gekommen ${ }^{30}$. Einzelne Staatspolizeistellen konnten aber auch „Erfolgsnachrichten“ uibermitteln; Hannover meldete die Verhaftung von 13 Teilnehmern der Gedächtnismahlfeiern in der Leinestadt sowie von zwölf weiteren Personen in Hildesheim ${ }^{31}$. Die Kieler Gestapo hatte sich bereits im Vorwege zum Einschreiten veranlaßt gesehen und berichtete, daß in ihrem Amtsbezirk Festnahmen der „führenden Persönlichkeiten“ erfolgt seien, „die durch die Vorbereitung zu dem Fest, Beschaffung von Matze u. ä. aufgefallen waren“32.

Nachdem Paul Balzereit und andere Leitungsmitglieder der Wachtturm-Gesellschaft im Mai 1935 verhaftet worden waren, nahm zunächst für eine kurze Übergangsperiode Martin C. Harbeck vom Berner ,Zentraleuropäischen Büro“ die Leitungsaufgaben wahr. Im Anschluß an einige Sondierungen reiste Harbeck nach New York, um mit der Zentrale in Brooklyn über die Neuregelung der Leitung des deutschen IBV-Zweiges zu beraten. Nach seiner Rückkehr im Juli 1935 übertrug er dem bisherigen Bezirksleiter von Berlin, dem 36jährigen Versicherungsangestellten Fritz Winkler, die „Aufsicht“ über das Verkündigungswerk der Zeugen Jehovas in Deutschland und setzte ihn damit faktisch zum Nachfolger Balzereits ein ${ }^{33}$. Die Leitung erfolgte in enger Kooperation mit Harbeck, der weiterhin als Mittelsmann zur Brooklyner Zentrale fungierte. Zur Aufrechterhaltung der Kontakte scheint auch das amerikanische Generalkonsulat in der Berliner Bellevuestraße 8 beigetragen zu haben; so soll Winkler seine Berichte zur Weiterleitung nach Bern dorthin gegeben haben ${ }^{34}$. Unter Fritz Winkler, der seit seiner Ernennung in der Illegalität stand, fand eine Aufteilung des Reichsgebietes in dreizehn Bezirke statt. Im Rahmen der

28 BA, Sammlung Schumacher/267 I, BPP, RdErl. vom 8.4.1935.

29 Vgl. Imberger, Widerstand, S. 278f.

$30 \mathrm{Vgl}$. Jahrbuch 1974, S. 143.

31 Staatspolizeistelle Hannover, Lagebericht für den Monat April 1935 vom 4.5.1935, Gestapo Hannover, S. 358.

32 GStAPrK, Rep. 90 P/80, Staatspolizeistelle für den Regierungsbezirk Schleswig in Kiel, Allgemeine Übersicht über die politische Lage im Monat April 1935. Im folgenden Monat berichtete die Staatspolizeistelle Kiel, daß in Flensburg, Glücksburg, Schleswig und Umgebung insgesamt 69 Personen „zur Anzeige gebracht worden“ seien (BA, R 58/480, Bl. 53).

33 Die „offizielle“ Amtsenthebung Balzereits erfolgte erst durch einen Artikel in einem unter dem Titel „Diener“ 1936 erschienenen „Wachtturm“. Siehe auch S. 135.

34 Vgl. Gebhard, Zeugen Jehovas, S. 140f.; Hetzer, Augsburg, S. 627. 
Umorganisierung wurden an die Stelle der in Haft befindlichen IBV-Funktionäre neue „Bezirksdienstleiter“ gesetzt. Diese Neubesetzungen bedeuteten ebenso wie die Ernennung Winklers zugleich einen Generationswechsel in der Führung der Bibelforschervereinigung. So löste beispielsweise im Bezirk Pfalz-Baden der 26jährige Konrad Franke den um 30 Jahre älteren Dr. Franz Merk ab, in SchleswigHolstein übernahm der 44jährige Hermann Schlömer die Verantwortung an Stelle der beiden zum Kreis um Balzereit zählenden Leitungsmitglieder Arno Thümmler und Alfred Zimmer, und in Bayern rückte der 30jährige Otto Lehmann auf den Platz des altgedienten IBV-Funktionärs Konrad Glamann. Diese Entwicklung setzte sich in den nächsten Jahren fort. Generell ist festzustellen, daß in erster Linie „die Jungen“" (sowohl an Lebensalter als auch im Hinblick auf die Zeit der Zugehörigkeit zur IBV) die ,illegalen Kader“ bildeten, während zahlreiche frühere Funktionsträger - oftmals nach Verbüßung einer im Jahre 1935 gegen sie ausgesprochenen mehrmonatigen Haftstrafe - sich weitgehend zurückzogen und sich fortan nicht mehr an Aktionen beteiligten.

Winkler traf sich regelmäßig mit den jeweiligen Bezirksdienstleitern zu Unterredungen und zur Entgegennahme der aufgrund der Meldungen aus den einzelnen Ortsgruppen erstellten ,Dienstberichte“ 35 , beispielsweise mit den Verantwortlichen für den süddeutschen Raum alle vier Wochen um 16.00 Uhr im Stuttgarter Hindenburgbau, während als Treffpunkt mit nord- und ostdeutschen Bezirksdienstleitern zeitweilig ein von einem Glaubensbruder im Berliner Tiergarten geführter Stuhlverleih diente ${ }^{36}$. Mit der Zeit fanden die monatlichen Zusammenkünfte aus Tarnungsgründen zumeist in der Eisenbahn statt. Die jeweils wechselnden Termine und Streckenabschnitte wurden zu diesem Zweck eine Woche zuvor von Winkler verschlüsselt mitgeteilt. Der betreffende Bezirksdienstleiter stieg dann an dem genannten Bahnhof zu. Nach ein paar Stationen verließ einer der Gesprächspartner wieder den Zug. Da die Bezirksdienstleiter ihrerseits die Verbindungen zu den örtlichen Dienstleitern nur noch durch persönliche Kontakte aufrechterhielten - der Schriftverkehr barg ein zu hohes Risiko -, besaßen sie ebenso wie Winkler Netzkarten beziehungsweise Bezirkskarten der Reichsbahn.

\section{Vorsichtsmaßregeln und Raffinesse}

Im zunehmenden Maße bediente sich die illegale Organisation konspirativer Techniken, die von der Einrichtung fester Kurierdienste, der Anlage „toter“ Briefkästen bis hin zur Annahme von Decknamen reichten. Eine 1936 von der Gestapo abgefaßte „Denkschrift über die illegale Betätigung der Bibelforscher“ vermerkte nicht

$\overline{35}$ Die Dienst- bzw. Tätigkeitsberichte, die die Zahl der im Berichtszeitraum tätigen Verkündiger bzw. der im Predigtdienst geleisteten Stunden ebenso verzeichnen wie Angaben über den Umsatz an Bibeln, Bücher und Broschüren, wurden von Winkler zu einem Gesamtbericht zusammengestellt und an Harbeck weitergeleitet. Die Erstattung derartiger Berichte bedeutete keine Neueinführung - wie die Gestapo vermutete (vgl. beispielsweise SLG HH, SH SG 11 Son KMs 149/36, Bl. 1) -, sondern stellte die Beibehaltung einer unter den Zeugen Jehovas üblichen Praxis dar.

36 Vgl. Jahrbuch 1974, S. 151f.; John, Wewelsburg (1996), S. 147; Koch, M., Die kleinen Glaubensgemeinschaften, S. 421. 
ohne Respekt, daß alles „völlig geheim und unter Einhaltung aller nur möglichen Vorsichtsmaßregeln gehandhabt" ${ }^{* 37}$ worden sei. Auch auf der unteren Ebene entwickelte man Wege, um die verschärfte Postüberwachung, die für fast alle ,amtsbekannten Bibelforscher" seit ca. Ende 1934 angeordnet worden war, zu umgehen $^{38}$. So verabredeten Zeugen Jehovas für den Schriftverkehr über den ohnehin für Außenstehende oftmals kaum verständlichen Spezialwortschatz hinaus - beispielsweise der Bezeichnung des „Wachtturms" als ,geistiger Speise“ - ausgeklügelte Geheim-Codes ${ }^{39}$. Die Zeugen Jehovas arbeiteten mit Deckadressen, die als Postsammelstellen fungierten. Zumeist handelte es sich um gute Bekannte oder um Verwandte, die keine Zeugen Jehovas waren beziehungsweise als solche bislang nicht öffentlich in Erscheinung getreten waren. Dorthin wurde die Post geschickt, weil davon ausgegangen wurde, daß diese nicht im Verdacht einer illegalen Betätigung stehenden Personen von der Postzensur verschont wurden. Daraufhin nun selbst gar keine Briefe mehr zu erhalten, erschien allerdings nun wiederum auch verdächtig, wie einem Schreiben des Friedrichstädter Bürgermeisters vom 23. August 1935 zu entnehmen ist: „Von dem Herrn Landrat in Schleswig wurde über die eingehende Post der hiesigen Bibelforscher eine von hier durchzuführende Briefkontrolle angeordnet. Durch irgend welche Umstände ist dies den Bibelforschern bekannt geworden und seit einiger Zeit erhalten diese durch das hiesige Postamt keine Post mehr. Nun wurde festgestellt, daß der Bibelforscher Bäcker Buchholz aus Drage zur Nachtzeit nach Eiderstedt fährt und in Witzwort bei einer Frau Bove [...], die viel Post erhalten soll, offenbar Post für die hiesigen Bibelforscher abholt. Ich beantrage deshalb, über die ein- und ausgehende Post der Frau Bove in Witzwort die Briefkontrolle anzuordnen." 40

Inwieweit die Untergrundorganisation der Zeugen Jehovas den Bedingungen der Illegalität Rechnung zu tragen verstand, zeigen insbesondere die Aktivitäten, die unternommen wurden, um die Gruppen mit Bibelforscherschriften zu versorgen. Zwar konnte zu Predigtzwecken noch eine längere Zeit und im ausreichenden Maße auf ältere Bücher und Broschüren zurückgegriffen werden, die in jenen Verstecken und Depots lagerten, die dem Zugriff der Gestapo entgangen waren, und auch gelangten weiterhin auf dem Postweg Schriften der Watch Tower Society zu den Zeugen Jehovas in Deutschland, doch der Eigenbedarf der Gruppen an neuerer

37 IfZ, MA 554, 936279-87 (85), Denkschrift „Die Internationale Bibelforscher-Vereinigung“, als Anlage zum RdS der Staatspolizeileitstelle München vom 24.12.1936. Die vierzehn Tage zuvor mit Gestapa-Rundschreiben vom 12.12.1936 (vgl. die im RSHA geführte „Kurzzusammenstellung in Sektenangelegenheiten ergangener Erlasse“, in der das - nicht überlieferte Gestapa-Rundschreiben vom 12.12.1936 unter der lfd. Nr. 16/1BV verzeichnet ist, BA, R 58/1074, Bl. 29) an die Staatspolizei(leit)stellen versandte und nicht näher mit Verfasserangabe o. ä. gekennzeichnete „Denkschrift“ wurde vermutlich im Geheimen Staatspolizeiamt von Mitarbeitern des für die IBV zuständigen Referates II 1 B 1 angefertigt.

38 Elke Fröhlich berichtet davon, daß in Bayern aus Gründen der Arbeitsentlastung - bei den zuständigen Bezirksämtern hatte die Staatspolizei für jede zu überwachende Person einen Einzelantrag zu stellen - hinsichtlich der Zeugen Jehovas ebenso wie bei ehemaligen Schutzhäftlingen von dem Prinzip des Einzelantrages abgewichen und zu Sammelanträgen und gruppenbezogener Postüberwachung übergegangen worden sei. Es ist zu vermuten, daß in anderen Ländern analog verfahren wurde. Vgl. Fröhlich, Herausforderung, S. 138f.

39 Vgl. Kühl, Friedrichstadt, S. 175; Jahrbuch 1986, S. 150; EB Heinrich Markert, 5.6.1984.

40 Zit. nach Kühl, Friedrichstadt, S. 175. 
Bibelforscherliteratur ließ sich auf diese Weise nicht decken. Seit dem Herbst 1934 erfolgte deshalb der Schmuggel von Schriften zunächst vor allem über die deutschtschechische Grenze. Dabei war es allerdings gleich in der ersten Zeit zu einem Rückschlag gekommen: Von der sächsischen Polizei waren Anfang Oktober 1934 zehn Zeugen Jehovas verhaftet worden, die im Vormonat 1.500 bis 2.000 Bücher über die Grenze geschafft hatten ${ }^{41}$. Doch danach gelang es, über einen Zeitraum von annähernd zwei Jahren in großer Zahl Bibelforscherschriften unbemerkt über die Grenze zu bringen; die Koordination des Schriftenschmuggels und der anschlieBenden Verteilung übernahm der Bezirksdiener für Westschlesien und Sachsen, August Fehst. Die in Prag oder in Bern gedruckten Schriften wurden von Prag aus mit dem Zug nach dem 15 Kilometer von der Grenze entfernt liegenden Hohenelbe (Riesengebirge) gebracht, von wo aus sie weitertransportiert wurden nach Spindlermühle, einer grenznah gelegenen Sommerfrische ${ }^{42}$. In dem kleinen Ort diente der Heuboden eines Bauemhauses als Zwischenlager. Von dort aus brachen in der Regel zweimal wöchentlich kleine Gruppen mit dem Rucksack - im Winter auf Skiern und Rodelschlitten - auf, um gegen Mitternacht die Grenze zu überqueren. Noch im Morgengrauen wurden die Bücher mit dem Fahrrad nach Hirschberg gebracht und anschließend auf Depots in Breslau, Halle, Berlin und in weiteren Orten verteilt.

Auf ähnliche Weise wie über den Spindlerpaß wurde auch bei Warnstorf (Zittauer Gebirge) der Schmuggel bewerkstelligt. Außerdem erfolgten Einfuhren über die französische und niederländische Grenze sowie bis zum März 1935 aus dem Saarland. Von der Schweiz aus wurde Schriftenmaterial sogar eine Zeitlang von Kurieren über die regulären Grenzübergänge geschafft, ,entweder versteckt in ihren Schuhen, zwischen doppelten Sohlen, oder unter ihrer Kleidung verborgen" 43 . Die Konstanzer Wohnung einer Bibelforscherin diente dabei als Anlaufstelle und bildete eine Art Bindeglied zwischen dem Berner Büro und den süddeutschen Bezirksdienstleitern ${ }^{44}$.

Während die Versorgung mit Büchern und Broschüren fast ausschlieBlich auf diese Weise vom Ausland her erfolgte, wurde der eingeschmuggelte „Wachtturm" an mehreren Orten innerhalb des Reichsgebietes zusätzlich vervielfältigt beziehungsweise nachgedruckt. Die Vervielfältigung des von der Brooklyner Zentralleitung verfaßten "Wachtturms" wurde entweder durch Anfertigung mehrerer Abschriften mit einer jeweils möglichst großen Zahl von Durchschriften oder mittels Matrizen auf Umdruckapparaten und Abzugsgeräten vorgenommen. In diesen Ersatzschriften wurde nicht immer der gesamte Inhalt der jeweiligen Ausgabe wiedergegeben, sondern aufgrund von Schwierigkeiten bei der Papierbeschaffung mußte

41 Vgl. BA, R 43 II/179, Bl. 263; SLG HH, HSG 11 Js. Sond. 1617/34, Band I, B1. 1f., Polizeipräsidium in Dresden, Schreiben vom 23.10.1934.

42 Die Schilderung beruht auf: Bericht von Ernst Wiesner, in: Jahrbuch 1974, S. 141f.; EB Johannes Rauthe, Geschichtsbericht, S. 39; EB Richard Rudolph, 31.5.1986. Vgl. ferner das bei Gebhard, Zeugen Jehovas, S. 178, abgedruckte Gestapo-Protokoll vom 2.4.1937, in dem für einen nicht näher eingegrenzten Zeitraum eine Zahl von 40.000 aus der Tschechoslowakei eingeschmuggelten Büchern und Broschüren der IBV angegeben ist.

43 Jahrbuch 1987, S. 143.

44 Vgl. Hetzer, Augsburg, S. 629; StA M, Staatsanwaltschaften 8551, SG München 16 KMs So 45-47, 37 (37), Band I; EB B. Maurer, 6.6.1984. 
oft eine Auswahl getroffen werden. Jede Ausgabe des illegalen „Wachtturms“ umfaßte in der Regel sechs bis sieben eng mit Schreibmaschine beschriebene Doppelseiten. Eine Hinzufügung von in Deutschland selbstverfaßten Beiträgen erfolgte zumindest in den ersten Jahren nicht. Die Auflage der in der Regel 14tägig - und damit im gleichen Zeitrhythmus wie der reguläre „Wachtturm“, aber mit einer vierbis achtwöchigen Verzögerung - hergestellten Ausgaben wurde so bemessen, daß zumindest jede Kleingruppe beziehungsweise IBV-Zelle ein Exemplar erhielt. In Altona, wo der „Wachtturm“ zunächst vom dortigen Dienstleiter nachts in einem mühsamen Verfahren mit einem Handroller hergestellt wurde, bis im Frühjahr 1936 die Beschaffung eines Trommel-Vervielfältigers gelang, wurden 1935/36 pro Ausgabe zwischen 200 und 300 Exemplare gedruckt, die hauptsächlich für die Bibelforschergemeinden in Schleswig-Holstein bestimmt waren ${ }^{45}$. Für die Orte an der Ostküste wurden weitere 100 Abzüge in Kiel hergestellt. Der nordwestdeutsche Raum wurde von Bremen aus versorgt, bis im August 1936 eine Verhaftungsaktion der Bremer Gestapo dem Betrieb der dortigen illegalen Druckerei ein Ende machte ${ }^{46}$. Da sich die Hamburger IBV-Hauptgruppe, die zuvor einen Teil der 350 in Bremen gedruckten „Wachttürme“ erhalten hatte, im Sommer 1936 einen Abzugsapparat angeschafft hatte, konnte der Verlust teilweise ausgeglichen werden. Von den in Hamburg nunmehr hergestellten 250 Exemplaren wurden 150 nach außerhalb versandt beziehungsweise über ein eingespieltes Verteilernetz verbreitet. Außerdem steigerte man in Altona die Auflage, so daß dort 1936/37 jeweils ca. 500 Exemplare des „Wachtturms“ gedruckt wurden, von denen zur Weiterverteilung 200 nach Hannover, 70 nach Bremen und 140 nach Bielefeld abgegeben wurden ${ }^{47}$.

Ähnlich wie in Norddeutschland war die Verteilung auch in den anderen Gebieten des Reiches organisiert. So wurde der „Wachtturm" unter anderem in Berlin $\left(1936 / 37 \text {, ca. } 240 \text { Exemplare) }{ }^{48} \text {, in München (ca. } 500 \text { Exemplare }\right)^{49}$ und in Karlsruhe (bis Mai 1936) sowie zeitweilig als Ersatzort für Karlsruhe in Mannheim (bis August 1936, ca. 400 Exemplare) ${ }^{50}$ gedruckt. Insgesamt mögen in den ersten Monaten des Jahres 1936 vom „Wachtturm“ jeweils bis zu 3.000 Exemplare im Untergrund hergestellt und verbreitet worden sein ${ }^{51}$.

Obgleich eine große Zahl von Personen an dem Druck und der Verteilung des „Wachtturms“ beteiligt waren, bereitete es der Gestapo große Schwierigkeiten, genauere Kenntnis von den Vorgängen zu erlangen. Um die Gefahr zu mindern, wechselte man oftmals die Standorte der Vervielfältigungsgeräte, wobei darauf geachtet wurde, daß sie nicht bei Zeugen Jehovas untergebracht wurden, die bei der Gestapo bereits als Bibelforscher bekannt waren. Auch kannten die Kuriere in der

\footnotetext{
45 Vgl. Imberger, Widerstand, S. 320f.; Jahrbuch 1974, S. 139f.; Möller, Steinburg, S. 212; DCB, VGH, 8 J 20/38, Bl. 22-33, Staatspolizeistelle Hamburg, Bericht vom 21.12.1937.

46 Vgl. Marssolek/Ott, Bremen, S. 305f.; SLG HH, HSG 11 Js. Sond. 399/37.

47 Vgl. SLG HH, HSG 11 Js. Sond. 298/38, Gestapo II B 1, 2052/37.

48 Vgl. Gebhard, Zeugen Jehovas, S. 175.

49 Vgl. Jahrbuch 1974, S. 112.

50 Vgl. Koch, M., Die kleinen Glaubensgemeinschaften, S. 424.

51 Vgl. SLG HH, SH SG 11 Son KMs 149/36, B1. 1, Staatspolizeistelle Kiel, Vermerk vom 2.9.1936.
} 
Regel nur den Namen derjenigen Person, die ihnen die Schriften übergeben hatte, so daß sie im Falle der Verhaftung keine weiteren Angaben machen konnten.

Während die Kurieraufgaben vor allem Männern übertragen wurden, waren zunehmend Frauen an der Herstellung des „Wachtturms“ beteiligt. Sie fertigten oftmals die Matrizen an und bedienten in vielen Fällen die Vervielfältigungsapparate. Aufgrund der von ihnen in der illegalen Arbeit wahrgenommenen Aufgaben wuchsen sie, die bisher in der IBV-Organisation nur Randpositionen innehatten, zunehmend in Leitungsfunktionen hinein 52 .

Die für die Anschaffung von Vervielfältigungsgeräten und Schreibmaschinen sowie den fortlaufenden Bedarf an Farbe, Papier und Verpackungsmaterial notwendigen Mittel wurden aus den Erlösen des Bücher- und Broschürenvertriebes sowie aus Spenden aufgebracht. Diese über die Gruppen- und Bezirksdienstleiter eingezogenen Gelder waren Teil der sogenannten „Gute-Hoffnung-Kasse“, aus der neben der „Wachtturm"-Herstellung noch zahlreiche weitere Aufgaben zu finanzieren waren. So wurden Mittel aufgebracht, um den Unterhalt derjenigen zu bestreiten, die in der Illegalität lebten. Auch waren die Ausgaben, die durch die große Zahl an Reisen von den Kurieren und den Bezirksdienstleitern jetzt entstanden, beträchtlich. Die „Gute-Hoffnung-Kasse“ diente jedoch auch dazu, notleidende Glaubensgeschwister zu unterstützen. Frauen, deren Männer inhaftiert waren, wurden - soweit möglich - mit regelmäßigen Zuwendungen bedacht. Der für diese Zwecke unabdingbare Teil verblieb in den einzelnen IBV-Gruppen; über die Verteilung verfügte der die „Gute-Hoffnung-Kasse“ in der jeweiligen Gruppe verwaltende Dienstleiter. Obwohl zahlreiche Zeugen Jehovas aus ihrer beruflichen Stellung entlassen worden waren und die meisten Glaubensangehörigen ohnehin in bescheidenen Verhältnissen lebten, kamen in den Gruppen zuweilen beachtliche Beträge zusammen, da die Verzichtsbereitschaft und der Solidaritätswille unter den Zeugen Jehovas allgemeinhin stark ausgeprägt waren. Über die „Gute-Hoffnung-Kasse“ hinaus zeigten sich der Gemeinschaftsgeist und das Zusammengehörigkeitsgefühl durch die persönlich gewährte Unterstützung, zum Beispiel in der Zuwendung von Nahrungsmitteln und Bekleidung. Die gemeinsame Erfahrung von Unterdrückung und Verfolgung festigte die Beziehungen untereinander; das Schicksal des anderen wurde wie das eigene empfunden. Soweit es möglich war, versuchten die Glaubensangehörigen einander beizustehen.

\section{Neue Initiativen und Aktivitäten}

Während des Jahres 1935 führten die deutschen Zeugen Jehovas eine neue Methode des Predigtdienstes ein, mit der die Watch Tower Society im Vorjahr schon in anderen Ländern zu arbeiten begonnen hatte und die dort - allerdings unter den Bedingungen der Legalität - den Erfolg der religiösen Werbetätigkeit gesteigert hatte. Es handelte sich dabei um den Einsatz von tragbaren Grammophonen. Die Zeugen Jehovas hofften auf ein erhöhtes Interesse bei den von ihnen Aufgesuchten und die Bereitschaft, ihnen bei einem „Rückbesuch“ Einlaß zu gewähren, wenn sie 
ihnen das Vorspielen einer Schallplatte anzubieten vermochten. Auf den Schallplatten waren kurze ins Deutsche übersetzte Vorträge Rutherfords von fünf- bis zehnminütiger Spieldauer aufgenommen, mit denen die Botschaft vom kommenden Königreich Christi und die Weltsicht der Bibelforscher den Zuhörern in ihren Grundzügen vertraut gemacht werden sollte ${ }^{53}$. Der mitgeführte Sprechapparat wurde auf verschiedene Weise getarnt; ein Zeuge Jehovas aus Burg in Dithmarschen trug das Grammophon beispielsweise in einem unscheinbaren braunen Wellpappkarton mit der Aufschrift „Das selbsttätige Waschmittel-Kappus“ mit sich ${ }^{54}$.

Die Herstellung der zunächst ebenfalls aus dem Ausland eingeschmuggelten Schallplatten erfolgte seit 1935 in Hennigsdorf bei Berlin. Der bei der Allgemeinen Elektrizitätsgesellschaft (AEG) beschäftigte Georg Klohe hatte zu diesem Zweck über einen Radiogroßhändler Schneidgeräte, Wachsplatten und anderes Material besorgt. Auf dem Boden eines kleinen Abstellraums im Garten seines Hauses besprach Klohe mit Hilfe seines Sohnes die ungehärteten Platten mit Themen aus dem „Wachtturm“. Da er über mehrere Schneid- und Sprechaufnahmegeräte verfügte, konnten jeweils fünf Platten gleichzeitig mitgeschnitten werden. Anschließend wurden die weichen Wachsplatten in einem kleinen elektrischen Heizofen gehärtet. Bis Juli 1936 sollen auf diese Weise über 1.000 Sprechplatten produziert worden sein. 55. Die Anfertigung der erforderlichen Grammophonapparate fand in Erfurt statt. Für die NS-Behörden war der Einsatz von Grammophonen Beleg für die „,besonders rege Werbetätigkeit“ der Bibelforscher. Im November 1936 sah sich der Reichsminister der Finanzen in dieser Frage zur Herausgabe einer Anweisung an die Zollämter veranlaßt, in der es unter anderem hieß:

„Als Propagandamittel benutzen sie häufig Schallplatten, auf denen Vorträge des berüchtigten Leiters dieser Gesellschaft, Rutherford, wiedergegeben sind und deren Inhalt in der Hauptsache aus Angriffen gegen das Dritte Reich und den Nationalsozialismus besteht. Diese Hetzplatten werden teils in Deutschland hergestellt, zum größten Teil aber illegal aus dem Auslande eingeführt. Im staatspolizeilichen Interesse ist es dringend erforderlich, daB die Einfuhr solcher Platten mit allen zu Gebote stehenden Mitteln verhindert wird. Im Einvernehmen mit dem Herrn Reichsführer SS und Chef der Deutschen Polizei im Reichsministerium des Innern bestimme ich daher das Folgende: Schallplatten, die im Post- und Güterverkehr eingeführt werden und nicht an bekannte Musikhandlungen gerichtet sind, sind anzuhalten. Zugleich ist die nächste Dienststelle der Geheimen Staatspolizei unverzüglich, gegebenenfalls fernmündlich, zu benachrichtigen, damit sie die erforderlichen weiteren Maßnahmen veranlaßt."

Allen Widrigkeiten zum Trotz gelang es den Zeugen Jehovas, in den Jahren 1935/36 das Verkündigungswerk zu konsolidieren. Ideenreich wurden Möglichkeiten aufgetan, um auch in größeren Gruppen zusammenzukommen und Gottesdienst $\mathrm{zu}$ halten. So mieteten 30 Bibelforscher aus Itzehoe und Umgebung im Sommer 1935 ein Motorboot und führten bei einer „Dampferfahrt auf der Stör“ ihr

53 Vgl. Jahrbuch 1968, S. 17.

54 Vgl. SLG HH, SH SG 11 Son KMs 149/36, Bl. 25.

55 Vgl. die Schilderung über Georg Klohe bei John, Wewelsburg (1996), S. 145; ferner EB Addi Klohe, der gemeinsam mit seinem Vater an der Herstellung der Platten beteiligt war.

56 BA, R 58/405, Bl. 58, Der Reichsminister der Finanzen, RdS vom 4.11.1936. 
Bibelstudium durch ${ }^{57}$. In den Sommermonaten trafen sich viele zu Versammlungen an verborgenen Waldplätzen, wobei sie die Zusammenkünfte etwa als Picknick oder als Treffen eines Kleingärtnervereins tarnten.

Es kam auch zu einer Zahl von Neubekehrungen, wobei unter den für die IBV Geworbenen nicht wenige waren, die früher den Linksparteien angehört hatten und von der entschlossenen Haltung der Zeugen Jehovas gegen das NS-Regime beeindruckt waren ${ }^{58}$. $\mathrm{Zu}$ ihnen gehörte beispielsweise ein 31 jähriger Bauarbeiter aus Nesse (Landkreis Oldenburg), der als ursprünglicher SPD-Sympathisant infolge der sozialdemokratischen Haltung zum Panzerkreuzerbau KPD-Mitglied geworden war, 1933/34 erstmals in Kontakt mit Zeugen Jehovas gekommen war und sich ihnen im Jahre 1935 fest anschlo ${ }^{59}$. Ein zwei Jahre älterer sozialdemokratischer Seemann stieß zur gleichen Zeit in Hamburg zur IBV, weil er als ,ein erbitterter Gegner" des „Wehrzwanges" bei den Bibelforschern Gesinnungsfreunde fand ${ }^{60}$. Ein gleichaltriger Lagerarbeiter, der in Breslau in einer Eisenhandelsfirma mit zahlreichen jüdischen Arbeitskollegen zusammenarbeitete, hatte 1934 die Bibelforscherlehre kennengelernt. Wie seine Frau berichtete, stand am Anfang die Übergabe eines „Wachtturms“: „Es war ein Mann, der für die damals bereits verbotene Organisation der Zeugen Jehovas von Tür zu Tür ging, und dieser Mann hat ihn gewonnen für die Zeugen Jehovas. Bei dieser Werbung stellte sich nämlich heraus, daß die Zeugen Jehovas genau dasselbe hinsichtlich der Juden sagten, daß sie nämlich auch ihr Lebensrecht hätten, was mein Mann schon immer im Familienkreise geäußert hatte." 61

$\mathrm{Zu}$ einer gezielten Ansprache von Menschen, von deren Distanz zum Nationalsozialismus man wußte, hatte die IBV-Führung geraten, als sie die Zeugen Jehovas aufforderte, die bisherige Kolportagetechnik der gefahrvollen „Haus zu HausMission" und der Verkündigung vor wahllos Fremden durch ausgewählte Kontaktaufnahmen zu ersetzen. Deshalb wurde die Losung ausgegeben, sich mit jenen bekannt zu machen und sie für den Glauben zu gewinnen, „die bei Festlichkeiten oder Veranstaltungen keine Hakenkreuzfahne" zeigten ${ }^{62}$.

Mitte 1936 registrierten auch die von der Exil-SPD herausgegebenen „Deutschland-Berichte“, daß die IBV, vornehmlich in Sachsen und dem Rheinland, neue

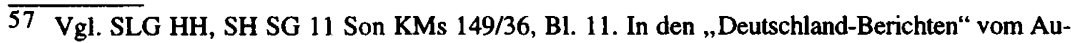
gust 1936 findet sich eine Notiz, der zufolge in Konstanz ,eine ganze Anzahl“ Bibelforscher verhaftet wurden, die auf dem Bodensee in einem großen Segelboot Gottesdienst abgehalten hatten und verraten worden waren. Vgl. Deutschland-Berichte 3 (1936), S. 1049.

58 Vgl. auch Wickert, Frauen, S. 202.

Zuweilen schlossen sich den Zeugen Jehovas aber auch Menschen anderer weltanschaulicher Herkunft an. So trat in Holzgerlingen, einem Dorf bei Stuttgart, ein ,,alter Kämpfer“ - Träger des Goldenen Parteiabzeichens und SA-Scharführer - im Oktober 1934 aus der NSDAP aus und wandte sich dem „Dienst für die Wahrheit“ zu. Vgl. Willi Wanner: Vom nationalsozialistischen Fanatiker zum christlichen Aufseher, in: Erwachet!, 22.4.1986, S. 13-16.

59 Vgl. Fahle, Verweigern, S. 156.

60 VVN HH, Komiteeakten P 4, Walter P., Lebenslauf vom 20.1.1947.

61 AfW HH, K 250702, B1. 83, Bericht der Witwe vom 17.7.1964.

62 Angabe der Bezirksdienerin für Schleswig-Holstein, Frieda Christiansen, laut Vernehmungsprotokoll vom 20.9.1937, zit. nach Imberger, Widerstand, S. 329. 
Anhänger gewinnen würde ${ }^{63}$. In einer Meldung wurde festgestellt, daß bei den Bibelforschern Menschen Zuflucht suchten, ,die innerlich nicht mehr ein noch aus wissen“. Selbst „unter den Genossen“, so wurde aus den kleinen Orten Ostsachsens berichtet, mache die religiöse Bewegung ,verheerende Fortschritte“. Die Redaktion kommentierte: „Jetzt hat es den Anschein, als ob die geistige Not der Zeit viele Menschen, die sich früher einer politischen Bewegung angeschlossen hatten, dazu bringt, sich dem religiösen Sektierertum zu verschreiben.“

Wenngleich die Missionserfolge angesichts der gegen die Zeugen Jehovas gerichteten Verfolgungen ausgesprochen bemerkenswert sind, so hatten die Zugewinne insgesamt doch eher ein bescheidenes Ausmaß. In Hamburg beteiligten sich, soweit ermittelbar, dreißig Personen an dem Verkündigungsdienst der Zeugen Jehovas, die nach 1933 zum Bibelforscherglauben bekehrt wurden ${ }^{64}$. Von ihnen wurden Ende 1936/Anfang $1937 \mathrm{ca}$. 18 bis 22 Männer und Frauen nach den üblichen Gepflogenheiten als Zeugen Jehovas getauft. Damit war zwar in Hamburg vermutlich jeder zehnte der im illegalen Predigtwerk aktiven Bibelforscher ein Neugeworbener, aber gemessen an der Zuwachsrate der Jahre zuvor kann allerdings von einem starken Anstieg der Gläubigenzahl insgesamt keine Rede sein ${ }^{65}$.

Die Berichte der Verfolgungsinstanzen belegen den Umfang der IBV-Aktivitäten in diesen Jahren recht deutlich. Ein vom Reichsführer-SS herausgegebener Bericht vom Februar/März 1935 verzeichnete ein „Anwachsen der Agitation“ und wies auf „große Mengen“ aus dem Ausland eingeschmuggelten „Propagandamaterials“ hin 66. Die Frankfurter Gestapo stellte ein Vierteljahr später fest: „Wie zahlreiche, gegen Anhänger der illegalen Bibelforschervereinigungen notwendige Maßnahmen zeigen, lassen sich diese durch das Verbot nicht abschrecken. [...] Ihre Methoden ähneln in vielen Beziehungen denen der Kommunisten, insbesondere bei der Schriftenverteilung, bei polizeilichen Vernehmungen und vor Gericht."67 Die Staatspolizeistelle in Hannover klagte Anfang 1936 über die „schwierige“ Überwachung68; in München registrierte man zur gleichen Zeit einen ,ans Unglaubliche grenzenden religiösen Fanatismus“, der dazu führe, daß die Zeugen Jehovas ,sich auch durch Inschutzhaftnahmen und Strafanzeigen nicht abschrecken lassen“. Die Leitung der Bayerischen Politischen Polizei hielt es für erforderlich, mit Runderlaß

63 Deutschland-Berichte 3 (1936), S. 922f. Vor allem aus Sachsen waren der Prager Redaktion Berichte über die IBV-Aktivitäten zugegangen. Dabei wurde die Unbeugsamkeit der Bibelforscher betont, die weder die Gestapo-Verfolgung noch die große Zahl von Gerichtsprozessen in die Knie zu zwingen vermöge. Bei der Darstellung der von der IBV im Untergrund angewandten Methoden klang Respekt und Hochachtung vor deren logistischen Fähigkeiten an.

64 Siehe S. $509 f$.

65 Die von dem 1938 in die USA emigrierten Syndikus des Deutschen Metallarbeiterverbandes, Ernst Fraenkel, in seinem drei Jahre später erschienenen Werk über den „Doppelstaat“ getroffene Feststellung über „die erstaunlich anwachsende Bewegung der Zeugen Jehovas in den letzten Jahren" (Fraenkel, Doppelstaat, S. 147) ist ein Beispiel für eine Deutung, die aufgrund der großen und angesichts der Zeitumstände besonders auffälligen Werbetätigkeit der Zeugen Jehovas unmittelbare Rückschlüsse auf deren tatsächliche Wirksamkeit glaubte ziehen zu können.

66 BA, R 58/233, Bl. 20, RFSS, Sonderbericht, Die Lage in der protestantischen Kirche und in den verschiedenen Sekten und deren staatsfeindliche Auswirkung, Februar/März 1935, S. 18.

67 Zit. nach Diamant, Gestapo Frankfurt, S. 85.

68 Staatspolizeistelle Hannover, Lagebericht für den Monat Februar 1936 vom 4.3.1936, Gestapo Hannover, S. 522. 
vom 1. Februar 1936 die Polizeidienststellen zu rügen, da festgestellt worden sei, „daß im Abwehrkampf gegen die als gefährliche Staatsfeinde bekannten Ernsten Bibelforscher nicht mit der nötigen Schärfe vorgegangen“ werde. Den Vollzugsbehörden wurde ,erneut zur Pflicht gemacht, [...] den Ernsten Bibelforschern größte Beachtung zu schenken"69. Zwar führten die verstärkten Bemühungen der Gestapo zu zahlreichen Festnahmen, die angestrebte „Zerschlagung“ der illegalen IBV-Organisation gelang jedoch nicht. Über die Zeit von der Wiederaufnahme des Verkündigungswerkes bis Mitte 1936 resümierte die bereits genannte Gestapo-Denkschrift: „Jeder Versuch der Betätigung wurde von der Geheimen Staatspolizei und den Gerichten geahndet, und dennoch nahm das illegale Treiben der Anhänger der Sekte von Monat zu Monat zu."70

In Berlin rüstete man jetzt zu einer Großoffensive gegen die Bibelforschervereinigung; am 24. Juni 1936 wurde bei der Geheimen Staatspolizei ein „Sonderkommando" gebildet. Bereits zwei Wochen darauf wies der zuständige Amtsleiter Heinrich Müller namens der Preußischen Geheimen Staatspolizei und des Politischen Polizeikommandeurs der Länder die Staatspolizeistellen im Reich an, „mit allen Mitteln gegen die Anhänger der Internationalen Bibelforscher-Vereinigung einzuschreiten"71.

\section{Organisierte Widerstandshandlungen: Zunehmende Repressalien} und der „fundamentalistische“ Widerstand der Zeugen Jehovas gegen das NS-Regime

Mitte 1936 begann eine neue Phase im Verhältnis zwischen Bibelforschern und NS-Regime: Die Zeugen Jehovas gingen zum offenen Gegenangriff auf den Staat über, der ihnen das elementare Menschenrecht verweigerte, ihren Glauben zu leben. Inzwischen war den Zeugen Jehovas im „Dritten Reich“ jede religiöse Betätigung untersagt, denn selbst die nichtöffentliche, gemeinsame Glaubenspflege galt den Justizorganen als Fortführung der Bibelforschervereinigung und damit als strafbare Zuwiderhandlung gegen das IBV-Verbot. Beispielsweise benannte der Oberstaatsanwalt beim Sondergericht Breslau im Oktober 1935 in einem Gerichtsverfahren gegen 17 Zeugen Jehovas als einzigen konkreten Anklagepunkt deren Beteiligung an einer am 26. April 1935 durchgeführten Versammlung: „Bei dieser

69 BHStA, Reichsstatthalter 638, BPP, RdErl. vom 1.2.1936. Gerhard Hetzer berichtet, daß nach Herausgabe dieses Erlasses in Bayern eine gezielte Verfolgung einsetzte. In Augsburg fanden daraufhin in der zweiten Februarwoche bei den amtsbekannten Bibelforschern Haussuchungen statt, die zur Aufdeckung eines Schriftenlagers mit 30 bis 35 Zentner Druckmaterial führten, das im Fehlboden (Hohlraum) eines Dachbodens verborgen worden war. Im Zuge der Aktion erfolgten noch weitere Schriftenfunde und zahlreiche Verhaftungen. Vgl. Hetzer, Augsburg, S. 628.

70 IfZ, MA 554, 936279-87 (83), Denkschrift „Die Internationale Bibelforscher-Vereinigung“, als Anlage zum RdS der Staatspolizeileitstelle München vom 24.12.1936.

71 BA, R 58/405, Bl. 55, Preußische Geheime Staatspolizei, Der Politische Polizeikommandeur der Länder, RdErl. vom 7.7.1936. 
Zusammenkunft wurde die Bibel behandelt, wurden Bibelstellen verglichen, ,Bibelstellen, die der Zeit entsprechen', behandelt, Gebete verrichtet, wobei der Angeschuldigte [...] Gebetsführer war."72 Die zuständigen Sondergerichte verurteilten eine große Zahl von Zeugen Jehovas wegen solcher oder ähnlicher „Vergehen" in der Regel zu mehrmonatigen Gefängnisstrafen; einzelne Sondergerichte griffen aber bereits im Jahre 1935 zu einem weit höheren Strafmaß. Das Weimarer Sondergericht verhängte beispielsweise im Juli 1935 gegen eine 45jährige Kinderpflegerin aus Hohenleuben bei Gera wegen fortgesetzter Teilnahme an Bibelforscherversammlungen ein Urteil von zwei Jahren und fünf Monaten Gefängnis; einen Monat später wurde eine 71jährige Frau wegen des gleichen Deliktes zu einem Jahr zwei Monaten Gefängnis verurteilt ${ }^{73}$. Von den Hamburger Zeugen Jehovas wurden allein im Jahre 1935 - soweit feststellbar - 198 in Schutzhaft genommen oder gerichtlich abgeurteilt; fünf wurden von der Staatspolizei in auswärtige Konzentrationslager eingewiesen ${ }^{74}$. Im Land Baden verurteilten im gleichen Zeitraum Sondergerichte insgesamt 197 Zeugen Jehovas ${ }^{75}$. Die Schuldsprüche erfolgten fast immer wegen Zuwiderhandlung gegen das IBV-Verbot, strafbar nach der „Verordnung des Reichspräsidenten zum Schutz von Volk und Staat“" vom 28. Februar 1933, aber in einigen Fällen auch wegen „Verächtlichmachung der Reichsregierung “, „Verbreitung von Greuelpropaganda“ und anderer nach dem „Gesetz gegen heimtückische Angriffe auf Staat und Partei“"76 strafbarer

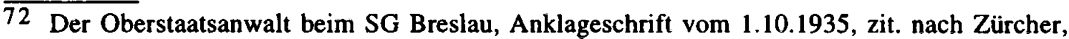
Kreuzzug, S. 94.

73 Vgl. VVN HH, Komiteeakten R 10; AfW HH 121189; Deutsche Frauenschicksale, S. 202. Die in dem Buch "Deutsche Frauenschicksale“, das 1937 von einer im Prager Exil lebenden Gruppe deutscher Antifaschistinnen und Antifaschisten herausgegeben wurde, im Anhang abgedruckte „unvollständige Statistik“ (S. 196-209), in der die gegen Frauen in Deutschland in den beiden Jahren 1935 und 1936 gefällten politischen Urteile aufgelistet werden, läßt erahnen, welchen Umfang die strafrechtliche Verfolgung von Zeugen Jehovas im Vergleich zu der anderer Regimegegner zu dieser Zeit einnahm. Die genannte Auflistung führt 319 Verurteilte auf, gegen die in 290 Verfahren verhandelt wurde. Davon waren 41 Bibelforscherinnen $(=12,9 \%)$; gegen sie wurde in 32 Verfahren verhandelt.

74 Siehe S. 510. Da in Hamburg die während der Zeit der polizeilichen Ermittlungen in Schutzhaft genommenen Personen in dem als Polizeigefängnis dienenden KZ Fuhlsbüttel untergebracht wurden, ist die Zahl der Zeugen Jehovas, die zumeist für einige Wochen oder Monate KZ-Bedingungen ausgesetzt waren, weitgehend identisch mit der Zahl der Festgenommenen und somit weit größer als die angegebene Zahl von fünf KZ-Einweisungen. Nicht etwa weil die Haftbedingungen weniger schlimm waren, sondern aus Gründen analytischer Klarheit wird in dieser Arbeit hinsichtlich der für Hamburg genannten Angaben generell die als eine Art „Vor-Untersuchungshaft" zu bezeichnende KZ-Haft in Fuhisbüttel, an die sich bei Erlaß eines richterlichen Haftbefehls die reguläre Untersuchungshaft anschloß, unterschieden von der nach offizieller Begründung zu „Präventionszwecken“ erfolgten Überstellung in ein Konzentrationslager. In diesen Fällen bildete die KZ-Haft ein vollkommen eigenständiges Strafinstrument der Gestapo, während die Inhaftierung im KZ Fuhlsbüttel der juristischen Strafverfolgung vorgeschaltet war, was auch darin zum Ausdruck kommt, daß die Schutzhaft in aller Regel auf die zu verbüßende Strafe angerechnet wurde.

75 Vgl. Mammach, Widerstand 1933-1939, S. 146.

76 Gesetz gegen heimtückische Angriffe auf Staat und Partei und zum Schutz der Parteiuniformen vom 20.12.1934, RGBI. 1934 I, S. 1269. Die Verurteilungen nach dem Heimtückegesetz nehmen prozentual allerdings nur einen sehr kleinen Anteil ein. Bei den in den Jahren 1933 bis 1938 vom Sondergericht München abgeurteilten 408 Bibelforschern erfolgte lediglich in zwei Fällen die Anklage aufgrund eines Verstoßes gegen das Heimtückegesetz (vgl. Kalous, Bibelforscher, S. 40); von den gegen Hamburger Zeugen Jehovas ausgesprochenen Sondergerichtsurteilen (ohne Freisprüche und Verfahrenseinstellungen) erfolgten, soweit ermittelbar, 383 we- 
Delikte. Die Strafverfahren gegen Bibelforscher fielen somit bis zur Schaffung neuer „Rechtsgrundlagen“ durch die Kriegsgesetze in die alleinige Zuständigkeit der Sondergerichte ${ }^{77}$.

Bezeichnend für eine Verfolgungspraxis, die auf die Ahndung mißliebiger Gesinnung orientiert war, ist der folgende Vorgang: Am 2. August 1935 wurden vier Hamburger Zeugen Jehovas wegen fortgesetzter Verkündigungstätigkeit zu Strafen zwischen vier und sechs Monaten Gefängnis verurteilt ${ }^{78}$. Während der Sitzungspause äußerte ein Besucher vor der Tür des Gerichtssaales im privaten Gespräch mit einer Bekannten, daß es eine Schande sei, wenn die Angeklagten verurteilt würden ${ }^{79}$. Diese Bemerkung wurde von einer anderen Frau, die vor Gericht als Zeugin geladen war, aufgeschnappt. Sogleich machte sie Justizbedienstete auf diese Äußerung aufmerksam und trug sie nach der Sitzungspause auch dem Gericht vor.

Aufgrund dieser Denunziation wurde der Besucher vor die Richter gerufen und zur Stellungnahme aufgefordert. Der Mann verwies darauf, daß er selbst bereits als Zeuge Jehovas in Schutzhaft gewesen sei und daß es sich bei den Angeklagten unter anderm um seine Ehefrau und seinen 24jährigen Sohn handele. Ohne Umschweife ließ das Gericht den 50jährigen Mann der Staatspolizei übergeben, die ihn noch am gleichen Tag abermals in Schutzhaft nahm. Der am folgenden Tag ausgestellte Schutzhaftbefehl nannte als Inhaftierungsgrund, daß der Betreffende dringend verdächtig sei, „Maßnahmen des Gerichts gegen die ,Internationale Bibelforscher-Vereinigung ' in abfälliger Weise kritisiert und dadurch das Ansehen des Staates öffentlich herabgesetzt zu haben" ${ }^{\prime 80}$.

Von dem Vorgang berichtete auch das „Hamburger Tageblatt“. Dort war in einem unvergleichlich zynischen Ton zu lesen:

„Einer, dem die Freiheit nicht bekommt, stand derweilen auf dem Flur des Strafjustizgebäudes und glaubte, sich verpflichtet zu fühlen, eine Philippika gegen den Staat und seine Rechtsprechung halten zu müssen. Es sei eine Schande vor Gott, wenn diese Märtyrer ihres Glaubens verurteilt würden. Vor dem Richter sollte er das wiederholen. Er windet sich. Er wird einer Zeugin gegenübergestellt und wird frech. Aber er muß zugeben: Er hat es gesagt. Das Gericht beschließt, auch diesen seltsamen ,Heiligen' gleich dazubehalten. Der Aufenthalt in einem Konzentrationslager, den man diesem ,Vorkämpfer aller verfolgten Bibelforscher' vor einiger Zeit verordnete, hat also offenbar nicht den gewünschten Erfolg gehabt. Aber man soll die Hoffnung nicht sinken lassen. Vielleicht wird er nach dem nächsten Mal ruhiger.“" 81

gen Vergehens gegen die VOSchVuS vom 28.2.1933 und fünf nach dem Heimtückegesetz. Die Angabe Katers, daß die „diversen Straftaten“ der Bibelforscher nach dem „Heimtückegesetz" geahndet worden seien (Kater, Bibelforscher, S. 197), ist deshalb für die überwiegende Mehrzahl der Fälle nicht zutreffend.

77 Den Sondergerichten war nach der VO über die Zuständigkeit der Sondergerichte vom 6.5.1933 (RGBI. 1933 I, S. 259) die Aburteilung der nach der VOSchVuS vom 28.2.1933 und der nach der VO des Reichspräsidenten zur Abwehr heimtückischer Angriffe gegen die Regierung der nationalen Erhebung vom 21.3.1933 (RGBI. 1933 I, S. 135) - abgelöst durch das genannte „Heimtückegesetz“ - unter Strafe gestellten Tatbestände vorbehalten.

79 Die Schilderung beruht auf dem anschließend eingeleiteten Ermittlungsverfahren (SLG HH, HSG 11 Js. Sond. 698/35).

80 SLG HH, HSG 11 Js. Sond. 698/35, Bl. 5, Schutzhaftbefehl vom 3.8.1935.

81 Hamburger Tageblatt, 3.8.1935 (,Seltsame ,Heilige“ vor Gericht“). 
Auch der Begriff der Betätigung für die verbotene Bibelforschervereinigung wurde exzessiv ausgelegt. Bei Bestattungen von Zeugen Jehovas schritten beispielsweise die zur Überwachung anwesenden Gestapo-Beamten gegen die Trauergemeinden ein, wenn der Redner am Grab auch nur den Namen Jehova erwähnte oder der Hoffnung auf das kommende Friedensreich Gottes Ausdruck zu geben versuchte. Selbst das Lesen von Trostworten aus der Bibel konnte gefährlich sein, wenn Textstellen gewählt worden waren, denen nach Ansicht der Gestapo ein „subversiver Charakter" anhaftete ${ }^{82}$. In Hamburg war bereits im Frühjahr 1934 ein gerichtliches Ermittlungsverfahren gegen Zeugen Jehovas eröffnet worden, weil auf drei Bestattungsfeiern für die Ziele der IBV geworben worden sei83. In einem Fall richteten sich die Anschuldigungen gegen den 57jährigen Ehemann einer am 27. April 1934 verstorbenen Bibelforscherin. Als dieser fünf Tage später am Grab seiner Frau die Traueransprache hielt, scheinen die Stapo-Beamten besonders hellhörig gewesen zu sein, handelte es sich doch bei der Verstorbenen mittelbar um das erste Todesopfer der NS-Verfolgung unter den Hamburger Zeugen Jehovas. Infolge der ,seelischen Aufregungen“ 84 nach mehrfachen Haussuchungen war die Frau einem Herzschlag erlegen.

Im Laufe des Jahres 1936 war die Gestapo, der es nicht gelang, die Aktivitäten der kleinen Glaubensgemeinschaft zu unterbinden, zu einer bis dahin bei der Verfolgung der Zeugen Jehovas in dieser Weise noch nicht gekannten Brutalität übergegangen. Bei den Verhören wurden nunmehr in zunehmendem Maße die gleichen Methoden wie gegenüber den politischen Regimegegnern angewandt; Quälereien und Folterungen häuften sich ${ }^{85}$. So waren in der "Steinwache“, dem Quartier der Dortmunder Gestapo, Mißhandlungen von Bibelforschern an der Tagesordnung. Dem Opfer eine Decke über den Kopf geworfen oder es geknebelt, um die Schreie zu ersticken, verlieh man den Vernehmungen den „nötigen Nachdruck“, wobei zum Folterarsenal Ochsenziemer, „Schiffsschaukel“ und Wagenradspeichen gehörten. In einem aus Deutschland herausgeschmuggelten Bericht schilderte ein im Juni 1936 verhafteter Zeuge Jehovas seine „Bekanntschaft“ mit dem berïch-

82 Zum Verbot der Durchführung bzw. zur Auflage von Beschränkungen für Bestattungsfeiern vgl. auch Jahrbuch 1989, S. 120f.; Zürcher, Kreuzzug, S. 176, 182.

83 SLG HH, HSG 11 Js. Sond. 774/34. Vgl. näher Garbe, Gott mehr gehorchen, S. 187f.

84 SLG HH, HSG 11 Js. Sond. 1617/34, Band IV, Anlage, o. B1., Erklärung des Sohnes vom 9.8.1948

85 Vgl. die bei Zürcher wiedergegebenen Berichte Betroffener (Zürcher, Kreuzzug, S. 114f., 138 $149,169-183$ ). Michael $\mathrm{H}$. Kater hat darauf hingewiesen, daß die Mißhandlungen , an sich unnötig“ gewesen seien; ,,denn in den meisten Fällen waren die Zeugen Jehovas sofort geständig, soweit sie nicht Gefahr liefen, Glaubensbrüder zu verraten" (Kater, Bibelforscher, S. 204). Katers Aussage ist insofern zutreffend, als die Zeugen Jehovas, soweit dies den Gestapo-Protokollen zu entnehmen ist, tatsächlich in der Regel bei der ersten Vernehmung die ihnen zur Last gelegte Betätigung als Bibelforscher zugegeben bzw. sich offen zu den Zeugen Jehovas und ihren Grundsätzen (Grußverweigerung, Ablehnung des Kriegsdienstes pp.) bekannt haben. Da sie aber die Nennung der Namen von Glaubensgeschwistern oder von Einzelheiten der Organisation des Verkündigungswerkes oftmals standhaft verweigerten und sich somit dort sperrten, wo die Gestapo ihre weiteren Ermittlungen anzusetzen beabsichtigte, wollten die Beamten genau jene Informationen gezielt aus ihnen herausprügeln. Daß die Gestapo-Mißhandlungen gegen die Zeugen Jehovas nicht nur Ausfluß der Exzeßtaten irgendwelcher beamteter Sadisten waren, sondern Bestandteil des polizeilichen Ermittlungsinstrumentariums, zeigen die Absprachen zwischen dem RJM und dem Gestapa über die Anwendung „verschärfter Vernehmungen“" bei Zeugen Jehovas (siehe S. 284f.). 
tigten dortigen Gestapo-Referenten für „Sektenangelegenheiten“, dem Kriminalassistenten Theiß, mit den folgenden Worten:

„Ohne vorherige Vernehmung peitschte mich Theiß durch. Hierzu gebrauchte er eine Reitpeitsche und einen Gummiknüppel. Nach dieser Prozedur wollte man mich zum Verräter an meinen Geschwistern machen. Ich lehnte jegliche Auskunft ab mit der Bemerkung, ich sei kein Judas und würde auch nichts verraten. Daraufhin wurde mein ganzer Körper und auch mein Kopf mit Schlägen der Reitpeitsche bedacht. [...] Unter den anhaltenden Peitschenhieben wurde ich schließlich bewußtlos. Als ich die Augen aufschlug, wurde ich mit schmutzigem Seifenwasser behandelt. Man goß mir einen Topf davon in den Mund, und an ihrem höhnischen Lachen konnte ich ihre Befriedigung an meinem Wiedererwachen feststellen. " 86

In den folgenden acht Tagen wurde dieser Mann drei- bis viermal täglich zum „Verhör" vorgeführt. Obgleich es Theiß und seinen Helfershelfern nicht gelang, ihn zum Verrat seiner Glaubensgeschwister zu bewegen, blieben ihre „Bemühungen“ nicht erfolglos. Am Ende hielten sie ein „Geständnis“ des Angeschuldigten in der Hand:

„Da nun aus mir nichts herauszukriegen war, wurde durch einen Kriminalbeamten ein Protokoll verfaßt, welches mich in jedem Satz belastete. Leider gab ich hierzu meine Unterschrift, um nicht länger diesen Folterknechten ausgesetzt zu sein. Ich sah meine Erlösung darin, wenn ich wieder in meine Zelle geführt wurde." 87

Die Mißhandlungen waren von Verhöhnungen der wehrlosen Opfer begleitet. Gerade jene unscheinbaren, aber glaubensstarken „Sektierer“, die aus der Sicht von Gestapo-Beamten „Verrückte“ oder „Phantasten“ waren, boten ihnen Gelegenheit, ihre „Allmacht“ herauszustellen: „Wo ist denn euer Jehova, der euch retten will? Er wollte euch doch helfen, aber der sch... euch was; ich habe Gewalt über euch, ich bin der Scharfrichter von Dortmund. Ihr lernt alle noch Heil Hitler sagen!" 88

Neben der direkten körperlichen Einwirkung standen bisweilen auch Drohungen mit Repressalien gegenüber Familienangehörigen und weitere Versuche, den Verhafteten psychisch zu brechen. Zeugen Jehovas berichten davon, daß GestapoBeamte ihnen in Verhören Revolver an den Kopf setzten und ihnen dabei angekündigten, sie sogleich zu erschießen, wenn sie nicht umgehend von ihrer Verweigerungshaltung abließen und die gewünschten Angaben machen oder Namen nennen würden ${ }^{89}$. In Einzelfällen ging die Gestapo auch dazu über, Angehörige in Geiselhaft zu nehmen. So wurde Anfang 1936 die Schwester des Bibelforschers Rudolf Meißner, der sich im Vorjahr der weiteren Verfolgung durch die Flucht über

$\overline{86}$ Zürcher, Kreuzzug, S. 139f.

87 Ebenda, S. 140.

88 Ebenda, S. 142. Die Praktiken der Dortmunder Gestapo führten schon bald auch zu Todesopfern unter den Zeugen Jehovas. Der 30jährige Stanislaus Schwarz aus Ahlen in Westfalen wurde wenige Tage nach seiner Festnahme im Dezember 1936 in der „Steinwache“, wo er von Theiß vernommen wurde, dabei ertappt, wie er im Hausgefängnis einem Glaubensgenossen einen Kassiber des Inhalts zusteckte, daß man sich gegenseitig nicht kennen wolle. Einige Tage später erhielten die Angehörigen die Nachricht übermittelt, Schwarz habe sich in der Zelle erhängt. Vgl. ebenda, S. $179 \mathrm{f}$.

89 Vgl. ebenda, S. 140, 142; VVN HH, Komiteeakten J 6. 
die Reichsgrenzen entzogen hatte, wegen der Haltung ihres Bruders im Ausland als Geisel in Haft genommen ${ }^{90}$. Auch Gertrud Franke, die Frau des Bezirksdienstleiters für Pfalz-Baden Konrad Franke, erlitt dieses Schicksal, als man nach ihrem Mann fahndete. Sie wurde im Frühjahr 1936 in Haft genommen und erst nach der fünf Monate später erfolgten Festnahme ihres Mannes wieder entlassen ${ }^{91}$.

Der Versuch einzelner Zeugen Jehovas, auf die Gestapo-Praktiken höheren Ortes aufmerksam zu machen und mit Eingaben an regionale Verwaltungsstellen, Ministerien oder den Reichskanzler um Abhilfe zu bitten, blieb ergebnislos und führte allenfalls zu Ermittlungen über den Absender. So erging es der Frau eines Zeugen Jehovas, die sich beschwerdeführend an die Regierung gewandt hatte, nachdem sie von der Mißhandlung ihres Ehemannes im KZ Sachsenburg erfahren hatte. Nach Eingang ihres Schreibens bei den Behörden wurde sie für sechs Monate inhaftiert, da ein solches Verhalten als Verbreitung von „Greuelpropaganda" gewertet wurde ${ }^{92}$.

\section{„Widerspenstigkeit“, „Fanatismus“, „Paranoia“}

Da die Sondergerichte in den Verfahren gegen Zeugen Jehovas in einigen Fällen die Einholung von psychiatrischen Gutachten zur Prüfung der Frage einer verminderten Schuldfähigkeit nach $\S 51$ StGB anordneten, befaßte sich neben Justiz und Polizei Mitte der dreißiger Jahre auch die im „Dritten Reich“ allgemeinhin eher dem Staats- als dem Krankenwohl verpflichtete Psychiatrie mit der Unbeugsamkeit und „Widerspenstigkeit“ der Bibelforscher. Nicht selten werteten die Gutachter das Verhalten der Angeschuldigten als einen durch ,religiösen Fanatismus“ hervorgerufenen „Verfolgungswahn“ und somit als „religiöse Paranoia“93. Teilweise wurde auch ein Beschluß auf Unterbringung in eine „Heil- und Pflegeanstalt“ befürwortet ${ }^{94}$. In der Folge wurden etliche Bibelforscher in eine Nervenheilanstalt eingewiesen; nach Überzeugung der Watch Tower Society wurde - wie es in einer Veröffentlichung aus dem Jahre 1938 heißt - „die Unterbringung geistig völlig gesunder Zeugen Jehovas in eine Irrenanstalt betrieben, um sie dort zugrunde gehen $\mathrm{zu}$ lassen" 95 .

Auf welche Weise und aufgrund welchen Erscheinungsbildes ein Bibelforscher in eine Nervenheilanstalt geraten konnte, zeigt das Beispiel des 46jährigen Invaliden Richard P., der Ende 1936 verhaftet worden war, weil er auf eine an inn gerichtete Aufforderung hin erklärt hatte, für eine Beteiligung am Luftschutz nicht zur Verfügung zu stehen. Bei der polizeilichen Einvernahme zeigte er sich gänzlich unbeugsam. Der vernehmende Beamte der Schutzpolizei München vermerkte im Protokoll:

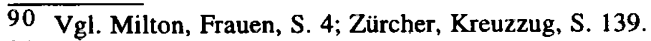

91 Vgl. Jahrbuch 1974, S. 117.

92 Vgl. Zürcher, Kreuzzug, S. 153.

93 Entsprechende Belege in den Akten der Sondergerichte, vgl. beispielsweise SLG HH, SH SG 11 Son KMs 19/37; SLG HH, HSG 11 Js. Sond. 298/38; StA M, Staatsanwaltschaften 8551, SG München $16 \mathrm{KMs}$ So 70-71, 37 (71), Band II, B1. $326 \mathrm{hh}$.

$94 \mathrm{Vgl}$. Koch, M., Die kleinen Glaubensgemeinschaften, S. 428; Kühl, Friedrichstadt, S. $187 f$.

95 Zürcher, Kreuzzug, S. 118. 
„Auf Vorhalt, daß die Tätigkeit der Bibelforscher doch gesetzlich verboten ist, erklärte er mir unumwunden, das kann niemand verbieten, weder das Dritte Reich noch Hitler. Die Menschheit wird in Deutschland noch schreckliche Tage erleben, sie steuert [auf] einen Abgrund zu, weil sie nicht an Jehova glaubt. “96

Angesichts derartiger Einlassungen sah sich der im Polizeibezirk 5 tätige Schupo-Hauptmann zu einer unmißverständlichen Kommentierung der Vernehmungsniederschrift aufgerufen:

„Ich halte den P. für einen der übelsten und gefährlichsten Subjekte. [...] P. ist ein ganz fanatischer Anhänger seiner Sekte und vollkommen unbelehrbar. Ich halte es für ein Unheil und für unverantwortlich, derartige Individien [!] unter anständigen Menschen herumlaufen zu lassen. Er scheut sich nicht im geringsten, sogar bei der Polizeibehörde seine wahnsinnigen Ansichten zu vertreten. Er wird daher in der Öffentlichkeit erst recht Propaganda treiben.“

Sechs Wochen später wurde der Bibelforscher aus der Schutzhaft in die Psychiatrische Abteilung des Strafgefängnisses München überstellt; der Gutachter attestierte eine ,schizophrene Reaktion“ und sah die Voraussetzungen des § 51 StGB Abs. 1 (Unzurechnungsfähigkeit) für gegeben an, da aufgrund der vorliegenden „,krankhaften Störung der Geistestätigkeit“ die Einsichtsfähigkeit in das Unerlaubte der begangenen Handlungen fehle ${ }^{97}$. Daraufhin stellte der Leiter der Anklagebehörde beim Sondergericht München das eröffnete Strafverfahren ein und befürwortete statt dessen die Unterbringung in einer Heil- und Pflegeanstalt.

Doch trotz der im „Dritten Reich“" verstärkt zu beobachtenden Tendenz, abweichendes Verhalten und weltanschauliche Divergenzen zum Nationalsozialismus als anormal - als in bezug auf die verbindlichen Regeln „verrückt“ - und somit als einen ,psychischen Defekt“ zu diagnostizieren, sank bei Juristen und Medizinern die Bereitschaft, auf Zuerkennung des $§ 51$ StGB zu plädieren, offenkundig weil im ,,autoritären Staat“ die Berücksichtigung von strafmildernden beziehungsweise strafausschließenden Gesichtspunkten als nicht oppurtun erschien.

In diese Richtung hatten auf der 25. Tagung der ,Deutschen Gesellschaft für gerichtliche und soziale Medizin", die vom 17. bis 19. September 1936 in Dresden stattfand, zwei an der Psychiatrischen und Nervenklinik der Universität Breslau tätige Dozenten plädiert, die in der „Bibelforscherfrage“ weniger die Psychiatrie als vielmehr die Strafverfolgungsbehörden gefordert sahen. Diese beiden Mediziner namens Sollmann und Wagner hatten unter Verantwortung des Klinikdirektors Professor Johannes Lange ${ }^{98}$ an der Breslauer Nervenklinik über einen längeren

96 StA M, Staatsanwaltschaften 8551, SG München 16 KMs So 70-71, 37 (71), Band I, B1. 65f., Polizeibezirk 5 (München), Vernehmungsniederschrift vom 15.12.1936.

97 Vom Landgerichtsarzt am 23.3.1937 erstattetes psychiatrisches Gutachten, ebenda, B1. 76.

98 Die von Lange, der sich auch selbst mit der Frage der strafrechtlichen Verantwortlichkeit von Zeugen Jehovas intensiver beschäftigt hat (vgl. Lange, Dienstverweigerung), und seinen Schülern Sollmann und Wagner, letzterer seit 1940 ebenfalls Professor (in Leipzig), herausgestellte These, da $B$ in aller Regel bei der Beurteilung der von Zeugen Jehovas begangenen, auf religiöser Motivation beruhenden Verweigerungsdelikte die Heranziehung des $\$ 51$ StGB ausscheidet, diese also regelmäßig strafrechtlich voll verantwortlich seien, erwies sich im Hinblick auf die Behandlung der Kriegsdienstverweigerungsfälle im Zweiten Weltkrieg als folgenschwer. Siehe näher S. 378f. 
Zeitraum elf dort eingewiesene Zeugen Jehovas beobachtet und mit ihnen bestimmte Untersuchungsreihen durchgeführt. Zum Bericht ihrer Ergebnisse erklärten sie, daß Geisteskranke unter den elf untersuchten Bibelforschern nicht feststellibar gewesen seien, jedoch habe es sich bei ihnen zumeist um ,eigenartige Persönlichkeiten“ gehandelt, wobei zwischen den eher "Stillen“ und den eher „Aktiven“ zu unterscheiden sei. Über einen 22jährigen, der sich bei seiner Einziehung zum Arbeitsdienst geweigert hatte, den Eid auf den „Führer“ zu leisten, aber den ihm aufgetragenen Arbeitsdienst „stets auf das Peinlichste“ erfüllte, befanden Sollmann und Wagner, daß er ,der menschlich Wertvollste der Sektenbrüder" gewesen sei. Und dann fügten sie eine Bemerkung an, die einen tiefen Einblick in das Selbstverständnis von in dieser Frage engagierten Psychiatern und ihre Begutachtungspraxis ermöglicht: „Seine gute Intelligenz und seine große Bibelkenntnis machten es schwer, ihn in die Enge zu treiben." 99

Nach Überzeugung der beiden Mediziner, für die das "Sektierertum“ der ,nationalsozialistischen Staatsidee" zuwiderlief und die es deshalb naheliegend fanden, „daß eine straffe Staatsführung Sekten verbietet, die in früheren Jahren gleichgültig geduldet worden" waren, handelte es sich „bei vielen der Zeugen Jehovas um ursprïnglich wertvolles Menschenmaterial“. Um aber zu verhindern, „daß solche, die auf der Suche nach echten Glaubenswerten sind, in Bahnen gelangen, die sie in unfruchtbare und zerstörende Konflikte treiben“, müsse „der Staat gegenüber den unbelehrbaren Aktivisten, denen es im wesentlichen um das Kämpfen geht [...], in seinen Forderungen an die Disziplin unerbittlich sein" ${ }^{100}$. Der Einschätzung, daß für unbeugsame Zeugen Jehovas in der Regel nicht die Nervenheilanstalt, sondern andere „Besserungseinrichtungen“ der richtige Ort seien, schlossen sich in den nächsten Jahren auch die Strafverfolgungsbehörden an.

Neben jenen, für die - zumeist Mitte der dreißiger Jahre - die Unterbringung in einer Heil- und Pflegeanstalt gemäß § $42 \mathrm{StGB}$ angeordnet worden war, kamen noch einige andere Zeugen Jehovas in Berührung mit der Psychiatrie beziehungsweise mit der von ihr mitverantworteten und unter den Begriff der Eugenik gestellten nazistischen Verfolgung von „Ballastexistenzen“. Unter Anwendung des „Gesetzes zur Verhütung erbkranken Nachwuchses“ vom 14. Juli 1933 ordneten die Erbgesundheitsgerichte auch gegen Zeugen Jehovas, wenngleich wohl insgesamt in einer nur geringen Anzahl von Fällen, die Zwangssterilisation an. So stellte ein begutachtender Kreisarzt im Fall eines 24jährigen Friseurs, der 1936 der Aufforderung zur Musterung nicht Folge geleistet hatte und sich auch nach zwangsweiser Vorführung der ärztlichen Untersuchung widersetzte, unter Angabe der Diagnose "Schizophrenie“ Antrag auf Sterilisation ${ }^{101}$. In Hamburg ordnete das Erbgesundheitsgericht im Fall eines 27jährigen den Zeugen Jehovas angehörenden Hilfsarbeiters die Zwangssterilisation an. Das Gutachten des Staatskrankenhauses Langenhorn vom 4. Februar 1936 hatte das Vorliegen von „Schwachsinn“ zwar ausdrücklich verneint, aber aufgrund einer „Erstarrung des Denkens“, das nur noch

99 Sollmann/Wagner, Bibelforscher, S. 437.

100 Ebenda, S. 444.

101 Vgl. ebenda, S. 433, 436f. 
um wenige ,überwertige Ideen“ kreise, eine beginnende Schizophrenie attestiert ${ }^{102}$. Der Eingriff wurde im folgenden Jahr im Wandsbeker Krankenhaus vollzogen.

\section{Erste reichsweite Verhaftungswelle}

Angesichts der massiven gegen die Glaubensgeschwister in Deutschland gerichteten Repressionen beschloß die Watch Tower Society nun, in verstärktem Maße die Öffentlichkeit in und außerhalb Deutschlands über die sich ereignende „Christenverfolgung“ aufzuklären und die bisherigen Proteste $\mathrm{zu}$ intensivieren. Zu diesem Zweck wurde unter anderem für den 4. bis 7. September 1936 ein internationaler Kongreß in Luzern (Schweiz) anberaumt. Für diese „Hauptversammlung“ sollten von den deutschen Zeugen Jehovas in großer Zahl Berichte über die Glaubensunterdrückung, Verhaftungen und Mißhandlungen erstellt werden. Soweit dies möglich war, sammelten die jeweiligen Gruppenleiter die Berichte ein und übergaben sie den Bezirksdienstleitern, die sie ihrerseits an Wilhelm Ruhnau, einen Danziger Bibelforscher, weiterreichten, der die Koordination und die Verantwortung dafür übernommen hatte, die Berichte über den Danziger Stadtstaat ins Ausland zu schaffen ${ }^{103}$.

Während diese Aktion unter Einhaltung größter Vorsichtsmaßnahmen durchgeführt wurde - und auch tatsächlich zahlreiche Berichte die Schweiz erreichten -, gelang dem zwei Monate zuvor gegründeten „Sonderkommando bei der Gestapo“ unter Beteiligung des Sicherheitsdienstes der SS ein folgenschwerer Schlag gegen die illegale IBV-Organisation. Am 24. August wurden Balzereit-Nachfolger Fritz Winkler sowie einige weitere Mitglieder der Berliner IBV-Gruppe verhaftet. Aufgrund der im Zusammenhang mit der Festnahme Winklers gewonnenen Erkenntnisse sahen die Gestapo-Sachbearbeiter die Chance, jetzt mit einem weitflächigen Zugriff die gesamte illegale Organisation der IBV ,im Zuge einer größeren Aktion“ zerschlagen zu können ${ }^{104}$. Reichsweit wurde eine Großfahndung eingeleitet, und die entsprechenden Referate wurden kurzfristig um weitere Beamte verstärkt. Unter Beifügung der Vernehmungsniederschrift von Winkler wies das Geheime Staatspolizeiamt am 28. August die Staatspolizeistellen an, gegen die genannten Funktionäre „Maßnahmen einheitlich am 31.8.1936 einzuleiten“105. An diesem letzten Augusttag des Jahres 1936 wurde eine größere Zahl leitender IBV-Funktionäre

$\overline{102}$ AfW HH, 181109 , Ärztliches Gutachten vom 4.2.1936; vgl. auch Garbe, Gott mehr gehorchen, S. 208f.

103 Vgl. UaP Günther Pape, Geheime Staatspolizei Darmstadt, Protokoll vom 9.9.1936; auszugsweise abgedruckt in: Gebhard, Zeugen Jehovas, S. 188-190. Vgl. auch ebenda, S. 193.

104 Fritz Winkler, der später ins KZ Sachsenhausen eingeliefert wurde, hatte - unter welchen Umständen auch immer - bereits im ersten Gestapo-Verhör ,ein volles Geständnis abgelegt“ und konnte von den vernehmenden Beamten in weiteren Verhören dazu bewegt werden, die Namen vieler Verantwortlicher und zahlreiche Einzelheiten preiszugeben. Die Gestapo veranlaßte ihn auch dazu, die Bezirksdienstleiter zur Aufgabe der Verweigerungshaltung aufzufordern und sie in einem Schreiben zu ersuchen, „die volle Wahrheit zu sagen“, da die Polizeibehörden über ihre Tätigkeit bereits informiert seien. Vgl. SLG HH, SH SG 11 Son KMs 149/36, B1. 1, Vermerk der Staatspolizeistelle Kiel vom 2.9.1936; StA M, Staatsanwaltschaften 8551, SG München $16 \mathrm{KMs}$ So 45-47, 37 (37), Band I, Bl. 1.

105 Geheimes Staatspolizeiamt, RdS vom 28.8.1936, abgedruckt in: Gebhard, Zeugen Jehovas, S. $171 \mathrm{f}$. 
festgenommen, so in Dresden der Bezirksdienstleiter für Schleswig-Holstein, der Techniker Georg Bär, ${ }^{106}$ in München der Postschaffner Johann Kölbl, der zusammen mit dem am folgenden Tag verhafteten Josef Zissler den bayerischen Bezirk leitete, und im Amtsbezirk der Staatspolizeistelle Mainz Konrad Franke, der Bezirksdienstleiter für Pfalz-Baden.

Am 1. September folgte auf dem Eilwege an die untergeordneten Polizeibehörden die Weisung, eine ,sofortige eingehende Durchsuchung und Vernehmung der dort als aktiv tätig bekannten Bibelforscher vorzunehmen“, da „die gesamte Zentralleitung der I.B.V. ausgehoben" 107 worden sei. Die Maßnahmen seien umgehend durchzuführen, da in vier Tagen in Luzern eine „Tagung“ stattfände, an der auch deutsche Funktionäre teilzunehmen beabsichtigten. Den Staatspolizeistellen wurde ein Fragenkatalog an die Hand gegeben, mit dessen Hilfe sie die Feststellungen über den ,illegalen Apparat nach unten hin“ zu treffen hatten.

Daraufhin setzte eine Verhaftungswelle ein, und es kam zur „Aufrollung“ zahlreicher IBV-Ortsgruppen, unter anderem in Berlin, Bremen und München. In einigen Bezirken, beispielsweise in Schleswig-Holstein und Bayern, waren die Mehrzahl der Bibelforscherversammlungen betroffen. Mehrere illegale „Wachtturm“-Druckereien wurden ,,ausgehoben“, und auch die „Schallplattenwerkstatt" in Hennigsdorf blieb nicht verschont. Die Gestapo hatte im Rahmen dieser Aktion mehr als die Hälfte aller Bezirksdienstleiter in ihre Gewalt bekommen können; von der Aushebung der ,gesamten Zentralleitung der I.B.V.“, die von den Sachbearbeitern des Gestapa-Sektenreferats erstmals schon am 28. August verkündet worden war ${ }^{108}$, konnte gleichwohl nicht die Rede sein. So entkam der Bezirksdienstleiter für Thüringen-Hannover, der Bäcker Walter Friese, dem Zugriff der Häscher. Er wurde ebenso wie einige andere leitende IBV-Funktionäre im „Deutschen Kriminalpolizeiblatt“ reichsweit zur Fahndung ausgeschrieben: „Deckname: Kfm. Karl Rößler, 27.4.98 Halle. Es ist nicht ausgeschlossen, daß Friese seine illegale Tätigkeit als Reisender für Autoöle ausübt. Er ist seit 29.8.36 flüchtig und wird wegen illegaler Betätigung für die ,Internationale Bibelforscher-Vereinigung • gesucht." 109 Vier Bezirksdienstleitern, die ebenfalls nicht gefaßt worden waren, und die in der folgenden Zeit die Hauptverantwortung für die IBV-Organisation in

106 Vgl. SLG HH, SH SG 11 Son KMs 149/36, Bl. 134. Der auf Seite 229 genannte Bezirksdienstleiter Hermann Schlömer hatte im April 1936 die Zuständigkeit für Schleswig-Holstein an Georg Bär abgegeben, um als Unterbezirksdienstleiter den Bezirk Rheinland zu übernehmen, da der für das Rheinland zuständige Albert Wandres das Saargebiet und das südliche Hessen mitzubetreuen hatte und den großen Bereich organisatorisch nicht allein bewältigen konnte. Bär, der sich bis zur Aufnahme seiner Tätigkeit in der Tschechoslowakei aufgehalten hatte, war vom Zentraleuropäischen Büro in Bern beauftragt worden, die Funktion des Bezirksdienstleiters für Schleswig-Holstein zu übernehmen.

107 Zit. nach Stokes, Eutin, S. 709. Vgl. auch Möller, Steinburg, S. 209.

108 Geheimes Staatspolizeiamt, RdS vom 28.8.1936, abgedruckt in: Gebhard, Zeugen Jehovas, S. $171 \mathrm{f}$.

109 DKBl. 9 (1936), Nr. 2643 (Ausgabe vom 23.12.1936), S. 1599. Friese konnte sich über ein Jahr lang verbergen; er wurde im Herbst 1937 verhaftet. Die ebenfalls im Kriminalpolizeiblatt zur Fahndung ausgeschriebenen IBV-Funktionäre Arthur Nawroth (Ostschlesien, Grenzmark) und August Fehst (Westschlesien und Teile Sachsens, zugleich einer der Hauptorganisatoren des Schriftenschmuggels) wurden im Frühjahr 1937 (Nawroth) bzw. vermutlich im Sommer 1939 (Fehst) verhaftet. Vgl. DKB1. 9 (1936), Nr. 2638 (Ausgabe vom 17.12. 1936), S. 1571; Gebhard, Zeugen Jehovas, S. 174. 
ihren Händen halten sollten - nämlich Georg Rabe (Ostpreußen), Albert Wandres (Rheinland, Südhessen), Heinrich Dietschi (Nordwestdeutschland) sowie Erich Frost (Sachsen) -, war sogar der Grenzübertritt in die Schweiz zur Teilnahme an der Luzerner Hauptversammlung gelungen.

Insgesamt hatten es $\mathbf{3 0 0}$ deutsche Zeugen Jehovas geschafft, die Grenze zu überwinden und nach Luzern zu kommen. Dabei hatte die Bayerische Politische Polizei am 20. August, also bereits einige Tage vor der Verhaftungsaktion, die Polizeibehörden darauf aufmerksam gemacht, daß die IBV die Abhaltung eines Kongresses in der Schweiz beabsichtige, und angeordnet, daß ,zur Verhinderung der Ausreise den betreffenden Personen der Reisepaß zu entziehen"110 sei. Daraufhin hatten die örtlichen Polizeistellen nicht nur die Ausweispapiere sichergestellt, sondern auch Bibelforscher, die nicht im Besitz eines Passes waren und bei den Behörden in der letzten Zeit um Ausstellung eines solchen vorstellig geworden waren, in Haft genommen.

Der vom 4. bis 7. September 1936 in Luzern veranstaltete Kongreß, der sich auch gegen die im Vorjahr in Danzig ${ }^{111}$ und Österreich ${ }^{112}$ ebenfalls verfügten Bibelforscherverbote richtete, bekam durch die kurz zuvor in Deutschland durchgeführten Massenverhaftungen nun eine besondere Brisanz. Es wurde unter anderem eine „Resolution“ verabschiedet, die für die Verfolgung der Zeugen Jehovas die Spitze der katholischen Kirche maßgeblich mitverantwortlich machte und die einen Appell zur Solidarität beinhaltete:

„Wir rufen alle gut gesinnten Menschen auf, davon Kenntnis zu nehmen, daß Jehovas Zeugen in Deutschland, Österreich und anderswo grausam verfolgt, mit Gefängnis bestraft, und auf teuflische Weise mißhandelt und manche von ihnen getötet werden. [...] Wir erheben scharfen Protest gegen die grausame Behandlung der Zeugen Jehovas durch die römisch-katholische Hierarchie und ihre Verbündeten in Deutschland und in allen anderen Erdteilen, aber wir überlassen gerne den Ausgang dieser Sache völlig der Hand des Herrn, unseres Gottes; denn nach seinem Worte wird er ihnen volle Vergeltung zuteil werden lassen. [...] Wir senden herzliche Grüße an unsere verfolgten

$\overline{110}$ BA, Sammlung Schumacher/267 I, BPP, RdErl. vom 20.8.1936.

111 In der unter der Aufsicht des Völkerbundes stehenden Freien Stadt Danzig, in der die NSDAP erstmalig bei den Volkstagswahlen am 28.5.1933 die absolute Mehrheit errungen hatte und seitdem die 330.000 Einwohner des Stadtstaates regierte, war das dortige Zweigbüro der Watch Tower Society am 28./29.3.1935 beschlagnahmt und ein Vierteljahr später, am 6.7.1935, die IBV durch Polizeiverfügung aufgelöst worden. Gegen das Verbot sowie die zunehmende Bedrängnis der Danziger Zeugen Jehovas - auch dort kam es zu Entlassungen, Haussuchungen und Mißhandlungen bei Polizeiverhören - protestierte die Watch Tower Society mit mehreren an den Hohen Kommissar des Völkerbundes gerichteten Petitionen. Zur Verfolgung der Zeugen Jehovas in Danzig vgl. Jahrbuch 1936, S. 101f.; Jahrbuch 1938, S. 189-192; Zürcher, Kreuzzug, S. 197-210.

112 Der österreichische Zweig der Watch Tower Society, der sich seit Anfang der zwanziger Jahre einer heftigen Gegnerschaft seitens der katholischen Kirche zu erwehren hatte und dessen Zeitschriften bereits unter der christlich-sozialen Regierung Dollfuß nach der von dieser im März 1933 vollzogenen Aufhebung der Verfassung der Zensur unterworfen waren, hatte zunächst eine am 10.9.1934 vom Bundessicherheitskommissär für Wien ausgesprochene Auflösungsverfügung erfolgreich anfechten können und beim Bundeskanzleramt deren Rücknahme erreicht. Gegen das ein dreiviertel Jahr später, am 17.6.1935, ergangene erneute Verbot blieb die Berufung allerdings ohne Erfolg; der Bundesgerichtshof erklärte es am 7.2.1936 für rechtens. Vgl. Maislinger, Die Zeugen Jehovas/Tirol, S. 369; Neugebauer, Wien, S. 161. 
Geschwister in Deutschland und bitten sie, guten Mutes zu sein und sich völlig auf die Verheißungen des allmächtigen Gottes, Jehova, und auf Christus zu verlassen." 113

Mit dieser „Resolution“, von der ca. zwei- bis dreitausend Exemplare an Regierungs-, Behörden- und Kirchenvertreter, allen voran Hitler und Papst Pius XI., verschickt wurden ${ }^{114}$, steigerte die Leitung der Watch Tower Society ihre antikatholische Stoßrichtung. Jetzt wurde der höhere katholische Klerus nicht nur als Drahtzieher der gegen die Zeugen Jehovas gerichteten Verfolgungskampagne 115 bezichtigt - wofür schließlich auch einige gewichtige Anhaltspunkte vorgebracht werden konnten -, sondern in Verkennung des Charakters der nationalsozialistischen Herrschaft wurde die Hitlerregierung als „,von den Jesuiten der römischkatholischen Hierarchie unterstützt und beeinflußt“ gedeutet und damit folglich zu einer Art „Agentur“ der römischen Kurie erklärt. Im Schrifttum der Watch Tower Society wurden nunmehr die Beamten der Geheimen Staatspolizei als die „Bluthunde der Hierarchie“116 bezeichnet, oder es war schlicht die Rede von der „,römischen Gestapo" 117 , wobei die vom NS-Regime angewandten Mittel mit den ,jesuitischen Schachzügen der Inquisition“118 verglichen wurden. Ihren deutlichsten Ausdruck fand diese Entwicklung in dem von Rutherford wenige Monate später veröffentlichten Buch „Feinde“; als solche erscheinen dort fast nur noch die „Religionisten“, die in der Lehre Rutherfords ebenfalls unter satanischem Einfluß stehenden Mächte „Kapital“ und „Politik“ treten demgegenüber zurück. Der Präsident der Watch Tower Society ordnete das Zeitgeschehen seinem dichotomischen Weltbild und der Vorstellung von der bereits begonnenen Entscheidungsschlacht vollkommen unter: Alles drehe sich nur noch um den einen großen Widerspruch, den zwischen Jehovas Organisation und den von der ,römisch-katholischen Hierarchie“ angeführten Organisationen Satans, wobei ,die Bewohner der Erde“ entweder „der einen oder der andern dieser beiden Organisationen untertan“ seien ${ }^{119}$. Unter dieser Prämisse steigerten sich die Verirrungen vollends. So hatten nach Rutherfords Überzeugung ,die Jesuiten“ nicht nur den Nationalsozialismus an die Macht gebracht, sondern zu diesem Zweck auch den Kommunismus gefördert, damit dieser als „Schreckgespenst“ Hitler die Massen zutreiben konnte. Der Grund für die Verfolgung der Zeugen Jehovas liege darin, daß ,diese verruchte Organisation“

113 Resolution des Mitteleuropäischen Kongresses der Zeugen Jehovas, 4.-7.9.1936, abgedruckt in: Zipfel, Kirchenkampf, S. 363-366.

114 Vgl. Jahrbuch 1974, S. 174, sowie die Erwähnung im Lagebericht des Generalstaatsanwaltes in Karlsruhe vom 30.10.1936: „Die schweizerische Zentrale hat es für notwendig gefunden, anfangs September ds. Js. einem großen Teil der badischen Staatsanwälte, auch mir selbst, von der Schweiz aus eine gedruckte Resolution zu übersenden." (BA, R 22/3133, Bl. 184)

115 Vgl. Zürcher, Kreuzzug, S. 37-58 (Kapitel „Die Verschwörung“); in dem 1938 erschienenen Buch von Franz Zürcher, des verantwortlichen Redakteurs der deutschsprachigen Ausgabe des „Goldenen Zeitalters", wurde die vermeintliche Komplizenschaft der katholischen Kirche mit dem NS-Regime zu belegen versucht, wobei die Verweise beispielsweise auf die Haltung des Bischofs von Osnabrïck und Preußischen Staatsrats Wilhelm Berning die Vorwürfe als nicht ganz berechtigungslos darstellten.

116 Jahrbuch 1937, S. 175.

117 „Alltägliches aus Deutschland“, Auszug aus dem „Goldenen Zeitalter“ vom 1.2.1937, abgedruckt in: Zipfel, Kirchenkampf, S. 412-417 (412).

118 Ebenda, S. 415.

119 Rutherford, Feinde, S. 71. 
einen jeden zu vernichten suche, der auf der Seite Jehovas stehe. Daß zur gleichen Zeit der NS-Staat inzwischen auch in mannigfacher Weise die Wirkungsmöglichkeiten der katholischen Kirche beschränkte und Priester jetzt ebenfalls wegen „Heimtücke“ vor die gleichen Sondergerichte wie die Zeugen Jehovas stellte, hinderte Rutherford nicht daran, die Hitler-Regierung ,in voller Übereinstimmung mit dem Vatikan in Rom"120 zu sehen.

\section{Flugblattaktionen}

Neben der verbalen Zuspitzung und der Titulierung Hitlers als „Willkürdiktator"121, der mit dem Papst im Bunde stehe, signalisierte vor allem der am Rande des Luzerner Kongresses gefaßte Beschluß, die „Resolution“ in Deutschland mittels einer groß angelegten Flugblattaktion zu verteilen, den Übergang zum offenen Gegenangriff auf das NS-Regime. Noch weitere für die illegale Arbeit in Deutschland wichtige Entscheidungen waren auf einer abseits vom eigentlichen - wohl auch von NS-Agenten beobachteten ${ }^{122}$ - Kongreßgeschehen angesetzten Beratung Rutherfords mit den anwesenden Bezirksdienstleitern und einigen anderen deutschen IBV-Funktionären getroffen worden. Nach dem Ausschluß Balzereits und der Verhaftung Winklers sowie der Mehrzahl der Bezirksleiter war eine Neuregelung der Leitung notwendig geworden. Zum neuen Verantwortlichen wurde der 35jährige Leipziger Kapellmeister Erich Frost ernannt, der die „Aufsicht“ über das deutsche Verkündigungswerk in enger Kooperation mit dem früheren Leiter der Magdeburger „Dienstabteilung“ und Prokuristen der Wachtturm-Gesellschaft, Heinrich Dwenger, wahrnehmen sollte, der sich inzwischen im Prager Exil befand und das dortige Zweigbüro leitete. Gleichzeitig bestimmte Rutherford - für den Fall, daß Frost verhaftet werden sollte - als dessen Nachfolger den 46jährigen Bochumer Schlosser Heinrich Dietschi. Des weiteren wurde zugleich mit der Neubesetzung der infolge von Festnahmen unbesetzten Posten der „Bezirksdiener“ - aus der Erkenntnis heraus, daß alle Zeugen Jehovas gleichermaßen „Diener“ des Wortes Gottes seien, waren die Bezeichnungen geändert worden - eine Umstrukturierung der IBV-Organisation verabredet. Ziel der Neuordnung war es, durch eine klarere Gliederung und den Aufbau gestaffelter Verantwortlichkeiten schneller und flexibler sowie den Bedingungen der Illegalität entsprechend reagieren $\mathrm{zu}$ können. Das Reichsgebiet wurde dazu erneut in dreizehn Bezirke aufgeteilt; in den größeren Bezirken wurden Unterbezirke mit entsprechenden „Unterbezirksdienern“ installiert. Jeder Bezirk- oder Unterbezirk wurde in Hauptgruppen und Gruppen unterteilt, die sich in Untergruppen und diese wiederum in Zellen gliederten ${ }^{123}$. Die

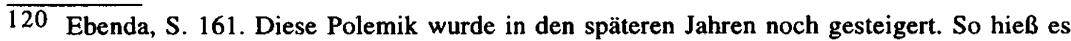
z. B. in der 1942/43 unter den Zeugen Jehovas verbreiteten Schrift „Verschwörung gegen die Demokratie“, daß die „Nazi-Faschisten-Diktatoren alle Früchte der katholischen Kirche“ seien, wobei zum Beleg darauf verwiesen wurde, daß von der ,römisch-katholischen Hierarchie [...] im Mai 1919 die Nazibewegung in Deutschland lanciert" worden sei. Zit. in: Der Generalstaatsanwalt bei dem Kammergericht, 12 OJs 549/44 (B), Anklageschrift vom 18.11.1944, abgedruckt in: Zipfel, Kirchenkampf, S. 527-533 (532).

121 Vgl. Rutherford, Tatsachen, passim; Rutherford, Faschismus oder Freiheit, S. 12ff.

122 Vgl. Jahrbuch 1987, S. 147.

123 Zur Neustrukturierung der IBV 1936/1937 vgl. näher Imberger, Widerstand, S. 308-318. 
Zellen bestanden in der Regel aus drei bis sechs Personen, von denen eine als ,Zellendiener“ eingesetzt wurde, die als Verbindungsperson zum „Untergruppendiener" beziehungsweise, wo es diesen mangels Anzahl nicht gab, zum „Gruppendiener" fungierte. Mit dieser neuen, aufgegliederteren Struktur sollte eine Zerschlagung der Organisation durch die Festnahme von Schlüsselfunktionären verhindert beziehungsweise erschwert werden. Da die Verbindungswege jeweils nur noch von einer organisatorischen Einheit zur nächsten reichten und dem einzelnen IBV-Angehörigen immer nur zwei oder drei „Funktionäre“ als direkte Ansprechpersonen bekannt waren, hoffte man zudem, die Aufdeckungsgefahr, vor allem infolge des Einschleusens von Spitzeln, verringern zu können. Für die im ländlichen Gebiet gelegenen kleinen Versammlungen ging die Neuordnung auch mit einer engeren Anbindung an das überregionale Organisationsgefüge einher ${ }^{124}$.

Nach Rückkehr vom Luzerner Kongreß wurden etliche der 300 deutschen Zeugen Jehovas, die am Kongreß teilgenommen hatten, verhaftet; oftmals erwartete sie bereits die Gestapo in ihrer Wohnung. Zwar hatten viele Paßinhaber ihre Ausweise vorsichtshalber „,verloren“, um nicht aufgrund des Sichtvermerkes überführt werden zu können, aber die Gestapo scheint über den Teilnehmerkreis gut unterrichtet gewesen zu sein ${ }^{125}$. Die NS-Presse konnte später frohlocken, daß es gelungen sei, ,eine Reihe dieser reisefreudigen ,Bibelforscher' festzunehmen, die auf allen möglichen Schleichwegen zur Teilnahme an dem Luzerner Hetzkongreß [...] über die Grenze gingen“126. Für den „Völkischen Beobachter" hatten die Bibelforscher in Luzern ihren „Zersetzungskampf gegen das nationalsozialistische Deutschland“ im Bunde mit anderen betrieben: „Hand in Hand mit Kommunisten und Emigranten besudelte und verleumdete man Deutschland in Wort und Bild."127

In den folgenden Tagen und Wochen wurden die Festnahmen weit über den Kreis der Kongreßteilnehmer hinaus ausgedehnt. Insgesamt fielen der Gestapo, die für die Verfolgung der kleinen Glaubensgemeinschaft einen großen Apparat aufbot ${ }^{128}$ und infolge des hohen Anteiles von Bibelforscherangelegenheiten an den staatspolizeilichen Maßnahmen ${ }^{129}$ ihre Sektenreferate entsprechend verstärkte, im

$\overline{124}$ In der Literatur ist zuweilen unter Bezugnahme auf das Organisationsgefüge und die Aktionsformen der IBV auf eine "frappierende Übereinstimmung" mit den Widerstandsformen der KPD, beispielsweise deren bis 1935 praktiziertes Konzept der Agitation in Fünfergruppen, hingewiesen worden (vgl. Imberger, Widerstand, S. 318, 375, Mann, Protest, S. 222; Marssolek/Ott, Bremen, S. 308). In einer vergleichenden Untersuchung über den ,religiösen und politischen Arbeiterwiderstand“ im Kreis Steinburg hat Reimer Möller herausgestellt, daß organisatorische Züge des Widerstandes der IBV „verblüffend der kommunistischen Widerstandskonzeption bis 1935“ ähnelten, wobei Möller auf den Zellenaufbau, die hierarchische Anleitung und die Flugblattpropaganda verweist (Möller, Steinburg, S. 227).

125 Vgl. Jahrbuch 1937, S. 175; EB Elise Kühnle, 23.11.1987. Im Jahrbuch 1987, S. 147, wird berichtet, die deutschen Teilnehmer seien in Luzern ,von Agenten der Nationalsozialisten heimlich fotographiert" worden.

126 VB, 2.6.1937.

127 VB, 25.4.1937.

128 Dabei wird zu berücksichtigen sein, daß Mitte der dreißiger Jahre nach der weitgehenden Unterdrückung des Widerstandes der Arbeiterparteien der Gestapo entsprechende Kräfte in Überzahl zur Verfügung standen und sie - nicht zuletzt zur Rechtfertigung des eigenen in den Jahren 1933/34 aufgeblähten Stellenplanes - eines anderen „Gegners“ bedurfte.

129 Für Bayern sind die Zahlen der im Zeitraum vom 30.3.-2.11.1936 insgesamt erfolgten Inschutzhaftnahmen bekannt. Danach wurden von den 1791 durch die Bayerische Politische Po- 
Rahmen der Verhaftungswelle im August/September 1936 weit über eintausend IBV-Angehörige in die Hände. Zwei Wochen nach dem Luzerner Kongreß, am 25. September, wurde in Danzig-Zoppot der für die Weiterleitung der Berichte ins Zentraleuropäische Büro nach Bern zuständige Wilhelm Ruhnau verhaftet. Offensichtlich handelten die dortigen Polizeibehörden auf Geheiß der deutschen Gestapo, denn Ruhnau wurde vier Tage später außer Landes geschafft, vermutlich über die Grenze nach Ostpreußen entführt und dann dort den reichsdeutschen Behörden ausgehändigt ${ }^{130}$. Die heimliche Auslieferung stellte einen groben Verstoß gegen die vom Völkerbund garantierte Verfassung der Freien Stadt Danzig dar ${ }^{131}$. Die Watch Tower Society wandte sich in den folgenden Monaten mit mehreren Petitionen an den polnischen Generalkommissar in Danzig und den Hohen Völkerbundkommissar, doch alle Bemühungen verliefen ergebnislos ${ }^{132}$. Ruhnau blieb verschollen; höchstwahrscheinlich wurde er von der Gestapo ermordet.

Trotz der gravierenden Verluste ${ }^{133}$, die der Organisation im Anschluß an den Luzerner Kongreß durch die erneuten Verhaftungen von Zeugen Jehovas aus dem Aktivistenkreis enstanden waren, konnte die dort beschlossene Umstrukturierung in den meisten Bezirken innerhalb weniger Wochen durchgeführt werden. Beispielsweise war der Bezirk Bayern, soweit feststellbar, seit Oktober 1936 in siebzehn Hauptgruppen und Gruppen unterteilt; in der Stadt München bestanden nunmehr 23 IBV-Zellen. In Hamburg gab es unter dem Hauptgruppendiener Max Grote vier Untergruppen, die sich in insgesamt 25 Zellen gliederten ${ }^{134}$.

lizei in Schutzhaft genommenen Personen 137 wegen verbotener Betätigung für die „Ernsten Bibelforscher" festgenommen $(=7 \%)$. Ein Vergleich mit den Zahlen der wegen Vorbereitung oder des Verdachts der Vorbereitung zum Hochverrat $(252=14 \%)$ und der wegen Betätigung oder Propaganda für die KPD oder SPD festgenommenen Personen $(156=8 \%)$ zeigt, welche Bedeutung dem Vorgehen gegen die IBV in der staatspolizeilichen Praxis mittlerweile zukam. Der Rest entfiel auf Personen, die wegen Gefährdung der öffentlichen Sicherheit, staatsabträglichen Verhaltens, staatsfeindlicher Äußerungen, Vergehen gegen $§ 175 \mathrm{StGB}$ und aus anderen nicht genau zuordbaren Gründen verhaftet wurden. Angaben nach Broszat, Konzentrationslager, S. 42.

130 Vgl. Zürcher, Kreuzzug, S. 201f.

131 Nach Artikel 76 Abs. 3 der Verfassung durfte kein Danziger Bürger einer fremden Regierung ausgeliefert werden.

132 Die Petitionen sind dokumentiert in: Zürcher, Kreuzzug, S. 197-203, 207-209. Mit einer am 15.1.1938 beim Hohen Völkerbundkommissar Carl Jacob Burckhardt eingereichten Eingabe forderte die Watch Tower Society den Völkerbund auf, gegen die Verfolgung der Zeugen Jehovas in Danzig einzuschreiten und wirksame Maßnahmen zu ihrem Schutz zu ergreifen (vgl. Jahrbuch 1938, S. 191). Eine konkrete Hoffnung darauf, daß der Völkerbund Abhilfe schaffen könne, scheint die Watch Tower Society allerdings nicht mehr gehegt zu haben. So erfolgte die Einreichung der umfangreichen Petitionen nicht zuletzt deshalb, ,damit der Völkerbund und die darin vertretenen Nationen keine Entschuldigung haben" (Zürcher, Kreuzzug, S. 197).

133 Die Tätigkeitsberichte der WTG weisen für das letzte Quartal 1936 gegenüber dem Monatsbericht Mai/Juni 1936 einen Rückgang der Verkündiger um 2.300 aus, vgl. Jahrbuch 1974, S. 156.

134 Vgl. Garbe, Gott mehr gehorchen, S. 193, 203. In Hamburg war die Neugliederung in ihren wesentlichen Zügen bereits ein dreiviertel Jahr vor der Luzerner Konferenz auf Anregung des norddeutschen Bezirksdienstleiters Heinrich Dietschi vollzogen worden (vgl. DCB, VGH, 8 J 20/38, Bl. 22-33, Staatspolizeistelle Hamburg, Abschlußbericht vom 21.12.1937; VVN HH, Komiteeakten Z 4). 
Abbildung 2: Aufbau der IBV-Hauptgruppen Hamburg und Altona (Stand: Ende 1936)

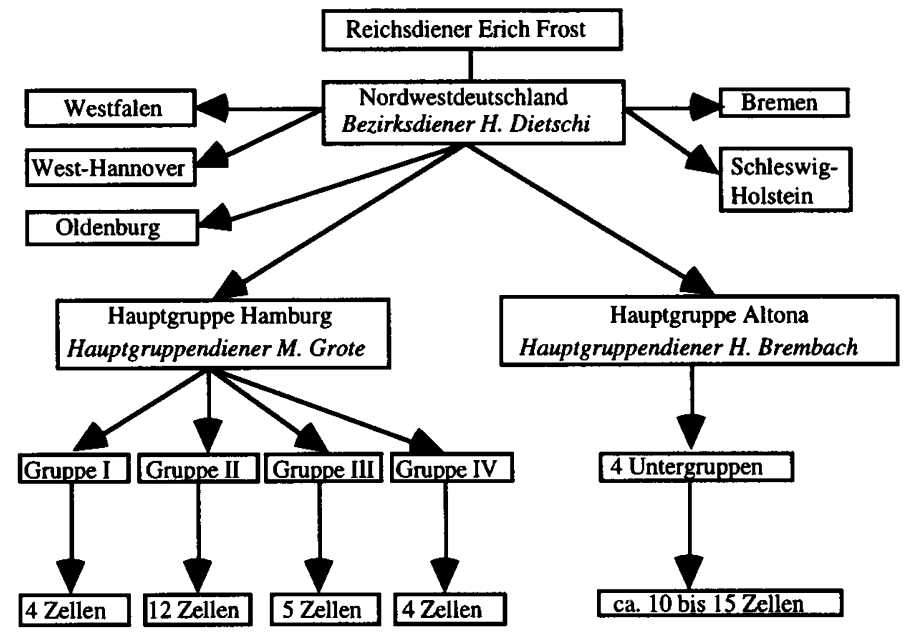

Die Gestapo, die die IBV zu diesem Zeitpunkt bereits so gut wie zerschlagen wähnte, war von der Regenerationsfähigkeit der Bibelforschervereinigung überrascht. In der Ende 1936 abgefaßten „Denkschrift“ des Geheimen Staatspolizeiamtes wurde beklagt, daß eine ,abschreckende Wirkung“ bisher nicht erreicht worden sei: „So konnte zum Beispiel in einem Bezirk festgestellt werden, daß nach der Aufdeckung des illegalen IBV-Apparates noch während der Untersuchung bereits eine Ersatzorganisation im Aufbau begriffen war."135

Gleichzeitig mit der Neuordnung wurden die Vorbereitungen für die in Luzern verabredete Flugblattaktion getroffen. In Hamburg wurde noch im September 1936 mit den Planungen begonnen. Beim ersten Treffen in einem Wellingsbütteler Gartenlokal informierte der Bezirksdiener Heinrich Dietschi ungefähr 15 leitende Zeugen Jehovas aus den Hauptgruppen Hamburg und Altona sowie aus einigen schleswig-holsteinischen Gruppen über die Beschlüsse von Luzern und verlas ihnen die dort verabschiedete und zur Verteilung vorgesehene Resolution. Wenige Tage später versammelten sich unter Leitung des Hauptgruppendieners Grote bei einem Wasserturm außerhalb der Stadt 60 bis 70 Hamburger Zeugen Jehovas, darunter alle Zellendiener, um konkrete Absprachen über den Ablauf der Verteilung zu treffen. Jede Zelle bekam ein bestimmtes Gebiet in Hamburg zugewiesen, das in einem anderen Stadtteil als dem eigenen Wohnbezirk lag. Die Verteilung sollte zeitgleich durchgeführt werden und nicht länger als 30 Minuten dauern. In den Häusern sollten jeweils nur ein oder zwei Exemplare in einen Briefkasten oder unter die Tür gesteckt und dann - wie mittlerweile im „Haus zu Haus“-Dienst bewährt - schnell eine andere Straße aufgesucht werden, um dort auf ähnliche

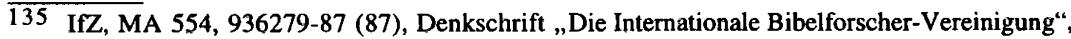
als Anlage zum RdS der Staatspolizeileitstelle München vom 24.12.1936. 
Weise vorzugehen. Mit den Zellenmitgliedern waren in der verbleibenden Zeit bis zum Beginn der Aktion die näheren Einzelheiten und zu treffende Vorsichtsmaßnahmen abzusprechen. Ähnlich wie in Hamburg wird auch in anderen Orten bei der Vorbereitung verfahren worden sein.

Als Zeitpunkt für die Aktion war reichsweit der 12. Dezember von 17.00 bis 19.00 Uhr vorgesehen. Insgesamt sollten im Deutschen Reich 300.000 Exemplare der in der Schweiz gedruckten „Resolution“ verteilt werden. Jedoch nur die über die deutsch-tschechische Grenze gebrachten „Resolutionen“ erreichten ihr Ziel, während die illegale Einfuhr der für Norddeutschland und Berlin bestimmten 100.000 Exemplare über die deutsch-niederländische Grenze mißlang. Durch den Nachdruck und die Umverteilung der über das Riesengebirge eingeschmuggelten Flugblätter wurde dieser Verlust kurzfristig zu kompensieren versucht.

Nachdem die Zellen die ihnen zugedachten Pakete und Päckchen erhalten hatten, wurden die „Resolutionen“ mit Handschuhen gefaltet und in neutrale Briefumschläge eingesteckt. Die für die Briefkastenverteilung vorgesehenen Umschläge blieben unbeschriftet, während andere, die anonym mit der Post verschickt werden sollten, vorrangig an Behördenbedienstete, Funktionsträger der Partei, Richter und Staatsanwälte sowie Pfarrer adressiert wurden. Obgleich alles gut organisiert war, drohte bis zuletzt die Gefahr, daß die Gestapo doch noch von der bislang vor ihr verborgenen Aktion Kenntnis erhielt. In Augsburg hatten Gestapo-Beamte am 10. Dezember, zwei Tage vor dem für die Verteilung vorgesehenen Termin, eine IBVZelle (nördliche Altstadt) bei den Vorbereitungen für die Flugblattverteilung überraschen können. Da die festgenommenen Frauen sich aber in Schweigen hüllten, vermochte die Augsburger Gestapo keine weitergehenden Schlüsse aus ihrer Entdeckung zu ziehen ${ }^{136}$.

An jenem zweiten Sonnabend im Dezember begannen, wie vorgesehen, Punkt 17.00 Uhr schlagartig und nahezu im ganze Lande über 3.000 Zeugen Jehovas mit der Verteilung der „Resolution“137. Kuverts mit Exemplaren der „Resolution“ wurden in Hausbriefkästen gesteckt, mit Heftzwecken an Hauseingängen oder Gartenpforten befestigt, unter Fußmatten geschoben, in Telefonzellen oder auf Parkbänke gelegt sowie an parkenden Autos angebracht. Auf diese Weise wurden viele zehntausende Exemplare verbreitet ${ }^{138}$.

Die Polizei war auf eine derart koordiniert und zügig vorgenommene Flugblattverbreitung nicht eingestellt. Die ersten Meldungen liefen zwar bereits nach

$\overline{136 \text { Vgl. Hetzer, Augsburg, S. } 631 .}$

137 Die Watch Tower Society nennt auf der Grundlage von Dienstberichten und später erstellten Berechnungen eine Zahl von 3.450 an der Verteilaktion beteiligten Zeugen Jehovas. Vgl. Jahrbuch 1974, S. 155; Bergman, Jehovah's Witnesses, S. XXI.

138 Unter der Annahme, daß jeder Beteiligte wie vorgesehen zwanzig bis vierzig Exemplare in dem ihm zugeteilten Gebiet verbreitet hat, kann von ungefähr 100.000 direkt verteilten Flugblättern ausgegangen werden. Hinzu kommen die per Post versandten Exemplare. In der WTG-Literatur wird die Zahl der insgesamt verbreiteten Exemplare mit 300.000 angegeben (vgl. Jehovas Zeugen in Gottes Vorhaben, S. 164; Jahrbuch 1974, S. 155f.). Von Hetzer sind Zweifel angemeldet worden; er hält die Zahl von 300.000 in Deutschland zur Verteilung gebrachten „Resolutionen“ für überhöht (vgl. Hetzer, Augsburg, S. 631, Anm. 60). Die von der Gestapo in den einzelnen Orten ermittelten Zahlen (z. B. für Augsburg 1.500-2.000, für Hamburg 1.800-3.000 und für München 1.800-2.400 Flugblätter) deuten darauf hin, daß die Aktion nicht in dem geplanten Umfang abgeschlossen werden konnte. 
wenigen Minuten auf den Revierwachen ein, doch ehe ein Überblick über das Ausmaß der Aktion hergestellt war und die entsprechenden „Gegenmaßnahmen“ eingeleitet werden konnten, war diese bereits beendet. Unmittelbar bei der Verteilung erfolgten nur ganz wenige Festnahmen ${ }^{139}$. In München wurde davon allerdings der dortige Gruppendiener Martin Pötzinger betroffen, der beim Verbreiten ,auf frischer Tat" gestellt wurde. Ein SS-Mann hatte, nachdem ein Umschlag mit der Resolution bei ihm in den Briefkasten eingeworfen worden war, sofort die Verfolgung aufgenommen. Obgleich Pötzinger die Flucht ergriff, konnte er unter Mithilfe eines hinzugerufenen SA-Mannes überwältigt und von den beiden ,eifrigen“ Parteigenossen um 18.20 Uhr den diensthabenden Beamten der Revierwache 1 im Polizeibezirk München 9 ,zugeführt“ werden ${ }^{140}$. In der „Hauptstadt der Bewegung" erging wenig später durch Rundspruch Alarm an alle Polizeidienststellen, $\mathrm{da} B$,in verschiedenen Stadtteilen Flugzettel mit gemeinem Inhalt gegen die Regierung verteilt" ${ }^{\text {"1 } 141}$ würden. Um $0.30 \mathrm{Uhr}$ übermittelte die Geheime Staatspolizei in Würzburg ein Fernschreiben, mit dem die Dienststellen vor der „Flugblattverteilung durch illegale Bibelforscher Überschrift ,Resolution ““ gewarnt wurden: „Die Polizeistreifen werden angewiesen heute Nacht noch ihr Augenmerk auf die Flugblattverteilung zu richten. Die Verteiler sind festzunehmen und das Material zu beschlagnahmen. Durchsuchungen bei den Bibelforschern sind vorzunehmen."142

Der „Reichsdiener“ Erich Frost konnte wenig später bei einem seiner Aufenthalte in Prag dem dortigen Zweigbüro melden, daß sich die Verteilung der „Resolution“ in Deutschland ,als ein gewaltiger Schlag gegen die Regierung und die Gestapo erwiesen " 143 habe. Auch die Staatsanwaltschaft beim Schleswig-Holsteinischen Sondergericht befand, daß die Aktion „so geschickt durchgeführt“ worden sei, „daß nur in wenigen Fällen die Täter ermittelt werden konnten"144. Über die eingeleiteten Polizeiaktivitäten heißt es in einem, die große Genugtuung der Zeugen Jehovas über ihren Erfolg widerspiegelnden Bericht: „Die Polizei durchkämmte ganze Häuserviertel und forderte an jeder Tür die Herausgabe des Traktats. Da nur sehr wenige Leute einen solchen besaßen, ja die meisten nicht einmal etwas davon wußten, hatte man den Eindruck, daß die ganze Bürgerschaft mit den Bibelforschern ,unter einer Decke stecke" und ihnen durch die Ableugnung eine Art Solidarität und Schutz gewähre. Dieser Eindruck [...] hatte eine verheerende Wirkung." 145

139 Vgl. Imberger, Widerstand, S. 334f.

140 Vgl. StA M, Staatsanwaltschaften 8551, SG München 16 KMs So 70-71, 37 (71), Band III, Bl. 1f., Polizeibezirk München 9, Wache 1, Vorführungsnote vom 12.12.1936.

Der gerade erst im Vormonat als Gruppendiener für den Bereich „München-Stadt“ eingesetzte Pötzinger, der bis 1936 als „Pionier" der Zeugen Jehovas in Prag, Sofia und Budapest tätig war, stieg nach dem Krieg in höchste Führungspositionen der Watch Tower Society auf. Als bislang einziges deutsches Mitglied wurde er 1978 in die 18köpfige "Leitenden Körperschaft" berufen, der er bis zu seinem Tode im Jahre 1988 angehörte.

141 Ebenda, Band IV, Bl. 1. Nach Bergman, Jehovah's Witnesses, S. XXI, soll um 18.15 Uhr über die deutschen Rundfunkanstalten vor den Flugblattverteilern gewarnt worden sein.

142 BA, Sammlung Schumacher/267 I, Fernschreiben der Geheimen Staatspolizei Würzburg.

143 Zit. nach Jahrbuch 1974, S. 155.

144 LA SH, Abt. 358 Nr. 409, Staatsanwaltschaft beim SH SG, Anklageschrift vom 13.11. 1937.

145 Jehovas Zeugen in Gottes Vorhaben, S. 164. Vgl. auch Jehovas Zeugen - Verkündiger des Königreiches Gottes, S. 449. 
Zahlreiche „Resolutionen“ wurden von „pflichtbewußten Volksgenossen“ auch selbst bei den Revierwachen abgeliefert beziehungsweise direkt der Staatspolizei zugestellt. So gingen beispielsweise allein in Flensburg - ausweislich der den staatsanwaltschaftlichen Ermittlungsakten beigefügten Asservaten - mindestens 23 Schreiben bei der dortigen Außenstelle der Kieler Staatspolizeistelle ein ${ }^{146}$. Bei den Absendern, denen in der Regel die „Resolution“ postalisch zugegangen war, handelte es sich um die Flensburger Stadtverwaltung, den Oberbürgermeister, eine Ortsgruppe der NSDAP, eine Firma, die Verwaltungsstelle der „Allgemeinen Ortskrankenkasse“, sowie um Einzelpersonen, zum Beispiel einen Studienrat, einen Facharzt für Orthopädie, Polizeibeamte und den Kreistierarzt, der sich noch am Sonnabendabend an die Schreibmaschine gesetzt hatte: „Anliegendes Schreiben ist mir heute ca. 171/2 Uhr in den Briefeinwurf meiner Haustür von einer unbekannten Person eingeworfen worden. Wegen seines hochverräterischen Inhalts gebe ich es zuständigkeitshalber ab." 147

Das Geheime Staatspolizeiamt rüstete nach zwei Tagen zum „Gegenschlag“. Am Abend des 14. Dezember wurde mit dem Vermerk „Dringend - sofort vorlegen“ den unteren Behörden von den Staatspolizeistellen beziehungsweise den übergeordneten Verwaltungsinstanzen ein Telegramm übermittelt, in dem mitgeteilt wurde:

„Die Art und Weise der Ausführung hat gezeigt, daß die I.B.V. trotz der Aktion vom 28.8.36 noch weiterbesteht. In allen Bezirken der Stapo-Stellen, in denen eine Verteilung dieser Flugblätter festgestellt wurde, ist auf Anweisung der Geheimen Staatspolizei - Geheimes Staatspolizeiamt Berlin - am 15.12.36 morgens 4 Uhr schlagartig bei allen der Betätigung oder Anhängerschaft für die I.B.V. verdächtigen Personen eine Haussuchung zu unternehmen. Dabei sind alle Personen in Schutzhaft zu nehmen, die auf Grund der Haussuchung verdächtig sind, sich illegal für die I.B.V., insbesondere aber an der Flugblattverteilung vom 12.12 .36 beteiligt zu haben. [...] Es ist anzustreben, daß auf Grund der neu durchzuführenden Aktion auch der Restbestand der illegalen I.B.V.Leitung erfaßt wird. “148

Obgleich die Polizei mit einem größeren Aufgebot an Kräften im Einsatz war und es an einigen Orten auch zu erneuten Verhaftungen kam - so sollen im Laufe des 15. Dezember in Kassel 33 Zeugen Jehovas festgenommen worden $\operatorname{sein}^{149}$-, erwies sich die reichsweit durchgeführte Gestapo-Aktion dieses Mal weitgehend als Fehlschlag. Wie einem Bericht der Staatspolizeistelle München zu entnehmen ist, waren die Zeugen Jehovas auf das polizeiliche Einschreiten vorbereitet: „Die Suchungen [!] verliefen infolge der von den Anhängern der Internat. Ernsten Bibelforscher befolgten Taktik ergebnislos. Die Anhänger dieser Vereinigung verwahrten in

146 Vgl. die im Verfahren gegen die Flensburger IBV-Gruppe anliegende Zusammenstellung der „bei der Dienststelle abgelieferten Flugblätter ,Resolution“", SLG HH, SG Kiel, 11 Son KMs 19/37. In Düsseldorf sind Reinhard Mann zufolge neun Briefe „pflichtbewußter Bürger“ mit Hinweisen über die Verteilung der „Resolution“ bei der politischen Polizei eingegangen (Mann, Protest, S. 222).

147 SLG HH, SH SG 11 Son KMs 19/37, o. Bl., Schreiben des Flensburger Kreistierarztes vom 12.12.1936.

148 IfZ, MA 554, 936288-91, Der Regierungspräsident von Oberbayern, Telegramm vom 14.12. 1936 an das Bezirksamt Friedberg.

149 Vgl. Kammler, Kasseler Soldaten, S. 138-141 (139). 
ihren Wohnungen nicht das geringste illegale Material, das für sie belastend werden könnte. Die Praxis hat ergeben, daß sie solches Material entweder verbrennen oder außerhalb ihrer Wohnung unterbringen." 150

Nach der Flugblattverbreitung erhöhten Justiz und Gestapo ihre Anstrengungen zur Bekämpfung der IBV. Der Generalstaatsanwalt in Karlsruhe berichtete am 20. Dezember dem Reichsjustizministerium, daß er als Reaktion auf die IBVAktion umgehend angeordnet habe, ,daß der Strafvollzug gegen die wenigen abgeurteilten ,Ernsten Bibelforscher", die sich nicht in Haft befanden, sofort" 151 durchzuführen sei. Die Sondergerichte verhängten im folgenden Frühjahr über FlugblattVerteiler Haftstrafen, die in der Regel auf sechs bis zwölf Monate, teilweise aber auch auf zwei Jahre Gefängnis lauteten ${ }^{152}$. Das Schleswig-Holsteinische Sondergericht sah in einem Urteil vom 27. Februar 1937 in der Verteilung der „Resolution“ zugleich ein Vergehen gegen das „Heimtückegesetz“, da nach Überzeugung der Richter die Behauptungen über eine in Deutschland stattfindende Verfolgung als wahrheitswidrig einzustufen seien: „Die Resolution enthält unwahre Behauptungen, die geeignet sind, das Wohl und das Ansehen des Reiches und der Reichsregierung schwer zu schädigen."153

Im gleichen Sinne äußerte sich auch die Ende 1936 abgefaßte Gestapa-Denkschrift: „In Deutschland werden Nachrichten über angebliche berufliche oder sonstige Benachteiligungen von Bibelforschern gesammelt und den ,Glaubensbrüdern * im Auslande übersandt. Auf Grund dieser Meldungen wird dort die übelste Greuelpropaganda betrieben und berichtet, in Deutschland würden die wahren Christen verfolgt, nur wegen ihres Glaubens würden die Zeugen Jehovas in Konzentrationslager und Gefängnisse geschleppt, dort gemartert und zum Teil auch getötet."154 Die Maßnahmen der Gestapo zeigten zur gleichen Zeit eine zunehmende Brutalisierung der angewandten Methoden ${ }^{155}$. Dies spiegelt sich auch in der Zunahme der Fälle, in denen Zeugen Jehovas durch Verfolgungsmaßnahmen den Tod fanden. Waren bis Mitte 1936 drei Opfer zu beklagen, so lag ein Jahr später die Zahl der Todesfälle, die von der Gestapo in der Regel als „Selbstmord durch Erhängen“ deklariert beziehungsweise getarnt wurden, bei mindestens siebzehn. Aufgrund der in die Schweiz übermittelten Berichte waren dem "Zentraleuropäischen Büro“ in Bern bis Mitte 1937 folgende ,unnatürliche Todesfälle“156 bekannt:

150 StA M, Staatsanwaltschaften 8551, SG München $16 \mathrm{KMs}$ So 70-71, 37 (71), Band I, Bl. 27, Staatspolizeistelle München, Bericht vom 19.2.1937.

151 BA, R 22/3133, BI. 209f., Generalstaatsanwalt in Karlsruhe, Lagebericht vom 20.12.1936.

152 Vor dem SG München wurden im April/Mai 1937 in acht Verfahren insgesamt 60 Flugblattverteiler abgeurteilt; das Strafmaß bewegte sich zwischen 21 Monaten und drei Wochen Gefängnis (vgl. StA M, Staatsanwaltschaften 8551). Das SH SG verhängte im Februar 1937 im Fall der Flensburger Flugblattverteiler Haftstrafen von durchschnittlich 10,8 Monaten; in Düsseldorf sind in der Regel Haftstrafen von circa einem Jahr Gefängnis ausgesprochen worden (Mann, Protest, S. 222). Das Kasseler Sondergericht verurteilte am 5.5.1937 zu zwei Jahren Gefängnis (Kammler, Kasseler Soldaten, S. 136).

153 SLG HH, SH SG 11 Son KMs 19/37, B1. 120-132 (129), Urteil vom 27.2.1937.

154 IfZ, MA 554, 936279-87 (82), Denkschrift „Die Internationale Bibelforscher-Vereinigung“, als Anlage zum RdS der Staatspolizeileitstelle München vom 24.12.1936.

$155 \mathrm{Vgl}$. Zürcher, Kreuzzug, S. 138ff., insbes. S. 177ff.

156 Zusammengestellt nach den Angaben bei Zürcher, Kreuzzug, S. 114, 169ff. Bei Zürcher findet sich nach dem Hinweis auf die in der SS-Presse (Das Schwarze Korps) geforderte ,ge- 
- elf Zeugen Jehovas bei Gestapo-Verhören (Mißhandlungen) und in der Polizeihaft (Erhängungen, aufgeschnittene Pulsadern), davon vier in der zweiten Jahreshälfte 1936 und sieben in der ersten Jahreshälfte 1937,

- ein 52jähriger Invalide, der an den ihm durch einen SA-Trupp zugefügten Mißhandlungen im Juli 1934 verstarb,

- ein Zeuge Jehovas, der Mitte 1935 im KZ Esterwegen beim Überschreiten der Postenkette erschossen wurde,

- ein ca. 35jähriger Zeuge Jehovas, der am 5. Dezember 1935 während der Strafhaft im Gefängnis Ichtershausen angeblich Selbstmord beging,

- ein Zeuge Jehovas, der drei Wochen nach seiner Festnahme im August 1936 in einer Nervenheilanstalt verstarb,

- ein Zuckerkanker, der einige Tage nach seiner Festnahme infolge der Verweigerung von lebenswichtigen Injektionen verstarb,

- ein 31jähriger Zeuge Jehovas, der 1937 an den Folgen von Mißhandlungen, die ihm im KZ Dachau zugefügt worden waren, verstarb.

Selbst wenn diese Angaben nur einen Teil der Realität und vermutlich nicht das ganze Ausmaß wiedergeben ${ }^{157}$, so können sie doch einen Eindruck von der Eskalation des Terrors gegen die Zeugen Jehovas in den Jahren 1936/37 vermitteln.

Im Februar/März 1937 wurde in einigen Orten - anscheinend ohne überregionale Koordination - die Verteilaktion vom 12. Dezember 1936 wiederholt. So verteilten Zeugen Jehovas in Augsburg am 11. Februar 1937 - als am gleichen Tag gegen Augsburger Glaubensgeschwister vor dem Sondergericht verhandelt wurde - erneut 1.200 bis 1.400 ,Resolutionen“158. Am 20. Februar fand auch im Ruhrgebiet eine erneute Flugblattaktion statt; in Essen kam es dabei zu Festnahmen, weil die dortige Stapostelle im Vorwege von einer ,unbedingt zuverlässigen V-Person“ aus Bibelforscherkreisen über die beabsichtigte Verteilung in Kenntnis gesetzt worden war ${ }^{159}$. Im Bezirk Rottenburg wurden einige „Resolutionen“ auch als Plakate angeschlagen ${ }^{160}$. Ebenfalls im Februar erfolgte in Hamburg unter der Leitung von Bezirksdiener Dietschi eine erneute Verteilung, an der auch Lübecker Zeugen Jehovas mitwirkten, weil einige Hamburger Bedenken gegen eine nochmalige Durchführung der Aktion hatten ${ }^{161}$.

setzliche“ Todesstrafe für Zeugen Jehovas die treffende Bemerkung: „Bis es so weit ist, verkriechen sich die Mörder hinter der Lüge: ,Er hat sich erhängt. ““ (Zürcher, Kreuzzug, S. 170)

157 In den Arbeiten von Kuno Bludau und Hans-Josef Steinberg wird der in der Auflistung des Berner ,Zentraleuropäischen Büros“ nicht aufgeführte Fall des Zeugen Jehovas Ignatz Lesniewski erwähnt, der am 23. Juni 1937 im Duisburger Polizeigefängnis „,nach einer offenbar grauenvollen Folterung durch die Gestapo freiwillig in den Tod" ging (Bludau, Duisburg, S. 224). Da ein Gefängnisarzt von sich aus tätig wurde, über die Leichenbesichtigung einen Bericht abfaßte und die angefertigten photographischen Aufnahmen Rückschlüsse auf schwere Mißhandlungen zuließen, wurde in diesem Fall ausnahmsweise das Motiv für die Selbsttötung sogar aktenkundig. Vgl. Steinberg, Essen, S. 22.

$158 \mathrm{Vgl}$. Hetzer, Augsburg, S. 631. Manfred Koch berichtet davon, daß in Mannheim im Frühjahr 1937 ein als Frau verkleideter Bibelforscher 500 Broschüren verteilte (vgl. Koch, M., Die kleinen Glaubensgemeinschaften, S. 426).

159 Vgl. Wickert, Frauen, S. 219.

$160 \mathrm{Vgl}$. Die kirchliche Lage in Bayern/Niederbayern und Oberpfalz, S. 118.

161 Vgl. SLG HH, HSG 11 Js. Sond. 173/38, Urteil vom 11.4.1938, S. 18; DCB, VGH, 8 J 20/38, B1. 31. Auch andernorts waren Vorbehalte gegen die Flugblattaktionen geäußert worden. So verteilten beispielsweise im Stadtgebiet von Duisburg Zeugen Jehovas aus dem be- 
Zur gleichen Zeit führten die Ermittlungen der Gestapo andernorts zu zahlreichen neuen Festnahmen. Die unmittelbar nach der Aktion vom 12. Dezember ausgebliebenen „Erfolge“ stellten sich nun ein. Mitte Februar befanden sich in München 60 Flugblattverteiler in Haft. Mit Bericht vom 19. Februar 1937 meldete die Staatspolizeistelle, daß ,die in München rechts der Isar bestandene illegale Organisation aufgerollt" 162 worden sei.

Vermutlich ein oder zwei Wochen später wurde der mittlerweile für den vergröBerten Bezirk Ost- und Westpreußen, Pommern und Mecklenburg zuständige Bezirksdiener Georg Rabe verhaftet. Am 4. März folgte die Festnahme des bayerischen Bezirksdieners und wohl etwa zur gleichen Zeit auch die der beiden für Ostschlesien sowie für Berlin und die Mark Brandenburg zuständigen Bezirksdiener. Der unter dem Tarnnamen „Meindl“ reisende Reichsdiener Erich Frost fiel der Gestapo am 21. März in die Hände ${ }^{163}$. Beim Sicherheitsdienst des ReichsführersSS wurde von dem Beginn einer ,zweiten Aktion gegen die IBV“ gesprochen und „Zur erfolgreichen Bekämpfung der IBV“ die Bildung eines ressortübergreifenden Sonderkommandos angeregt, zu dem ,aus den einzelnen Stapostellen sachkundige Beamte" und ,mit der Materie vertraute Sachbearbeiter der SD-Oberabschnitte" zusammengezogen werden sollten, da ,die Erfahrungen aus den beiden Aktionen“ gezeigt hätten, ,daß Beamte, die keine Sachkenntnis auf diesem Gebiete haben, für derartige Aktionen ungeeignet sind“164. Mit ,allen Mitteln und mit aller Energie“" sollte die zweite Aktion zum Abschluß gebracht werden; mittlerweile wußte man um die innerorganisatorische Rekrutierungskraft der Bibelforschervereinigung: „Solange noch ein Hauptfunktionär der illegalen I.B.V. auf freiem Fuß ist, muß mit der sofortigen Neuorganisation der I.B.V. gerechnet werden.“

In den nächsten Monaten stieg die Zahl der Verhaftungen weiter an. Auf einer am 18. Juni 1937 im Reichsjustizministerium durchgeführten Besprechung nannte der Dresdener Generalstaatsanwalt für seinen Amtsbezirk eine Gesamtzahl von 1.300 bis 1.500 Festnahmen ${ }^{165}$. Im Gegensatz zu Sachsen war die Zahl in Pommern der Einwohnerzahl entsprechend zwar kleiner, aber den Stettiner Generalstaatsanwalt stellten die dort vorgenommenen 500 bis 600 Verhaftungen von Zeugen Jehovas vor organisatorische Probleme, da die Gestapo wegen des Fehlens eines Konzentrationslagers in Pommern die Verhafteten in die Gefängnisse gebracht habe, so daß jene ,völlig überfüllt" waren ${ }^{166}$.

nachbarten Hamborn den im Juni 1937 verbreiteten „Offenen Brief“, da Duisburger Bibelforscher eine Beteiligung abgelehnt hatten. Vgl. Bludau, Duisburg, S. 292.

162 StA M, Staatsanwaltschaften 8551, SG München 16 KMs So 70-71, 37 (71), Band I, Bl. 10, Staatspolizeistelle München, Bericht vom 19.2.1937.

163 Vgl. Gebhard, Zeugen Jehovas, S. 173-187; Cole, Jehovas Zeugen, S. 192; FGN, NHS 137-04, Erich Frost, Schreiben vom 15.7.1969; Der Spiegel, 19.7.1961, S. 38f. (,Väterchen Frost“). Erich Frost wurde am 29.10.1937 vom SG Berlin zu drei Jahren und sechs Monaten Gefängnis verurteilt; nach der Haftverbüßung wurde er in das KZ Sachsenhausen eingeliefert. Seine Befreiung aus der KZ-Haft erfolgte am 5.5.1945.

164 SD, Aktenvermerk vom 2.4.1937, abgedruckt in: Gebhard, Zeugen Jehovas, S. 174; vgl. auch Imberger, Widerstand, S. 305.

165 BA, R 22/4277, B1. 186.

166 Generalstaatsanwalt Staecker berichtete ferner, daß die Staatspolizei „, für jeden eine Einzelzelle“ verlangt habe. Dieses - offensichtlich zur Verhinderung gemeinsamer Absprachen unter 
Doch trotz der großen Zahl von Festnahmen war der Gestapo und dem SD die beabsichtigte ,Zerschlagung“ der IBV noch nicht gelungen. Wenngleich die Namen der ,Spitzenfunktionäre“ bekannt waren und entsprechende Fahndungen mit Nachdruck betrieben wurden, konnte die Gestapo ihrer nicht habhaft werden ${ }^{167}$. Nach der Verhaftung von Erich Frost hatte - wie in Luzern abgesprochen - der norddeutsche Bezirksdiener Heinrich Dietschi den Posten des „Reichsdieners“ übernommen. Dietschi reorganisierte die Bezirkseinteilung bei Beibehaltung der sonstigen Struktur abermals; dabei setzte er nun auch erstmals Frauen zu „Bezirksdienerinnen“ ein. Waren zuvor in der Geschichte der Bibelforschervereinigung die leitenden Ämter ausschließlich den Männern vorbehalten gewesen, wobei die Zeugen Jehovas auf die entsprechenden Aussagen des Apostel Paulus über die nachgeordnete Stellung der Frau in der christlichen Gemeinde (1 Kor 11, 3; 14, 34) verwiesen, so rückten ab etwa Mitte 1936 verstärkt Frauen in führende Positionen, zum Beispiel als Gruppendienerin, nach ${ }^{168}$. Mit großer Entschlossenheit nahmen sie die ihnen übertragenen Aufgaben wahr, wobei sie an Mut und Unerschrockenheit den Männern nicht nachstanden, sondern eher im Gegenteil aufgrund des bei ihnen oftmals sehr ausgeprägten Bekenntniseifers die Radikalität des Einsatzes forcierten ${ }^{169}$. Nach der Verhaftungsaktion des Frühjahres 1937 waren für den Bezirk Baden-Saar-Pfalz Auguste Schneider aus Bad Kreuznach (Deckname: Paula), für Schleswig-Holstein Frieda Christiansen aus Flensburg (Deckname: Hermine Friedrichs bzw. Minchen), für Bayern Elfriede Löhr aus München (Deckname: Gertrud bzw. Nelly) und für Schlesien Gertrud Pötzinger zuständig. Daneben waren mittlerweile zahlreiche Ämter eines „Gruppendieners“ mit Frauen besetzt.

den Zeugen Jehovas sowie aus Sorge über deren Missionsbestrebungen gegenüber Mitgefangenen - vorgetragene Begehren habe sich ,technisch einfach nicht durchführen“ lassen.

Zumeist liefen die entsprechenden Fahndungen bereits seit langer Zeit. Heinrich Dietschi war seit dem 23.5.1936 von der Gestapo Dortmund zur Fahndung ausgeschrieben (SLG HH, HSG 11 Js. Sond. 88/37, B1. 20f.); nach dem Bezirkdiener für das Rheinland Albert Wandres soll die Gestapo bereits seit dem Jahr 1934 gefahndet haben (vgl. Jahrbuch 1974, S. 145148). Neue Fahndungsersuchen ergingen z. B. im Fall des Unterbezirksdieners Hermann Schlömer und des in der Nacht zum 7.2.1937, ,aus dem Polizeigewahrsam entwichenen“ IBVFunktionärs Michael Hilgers. Vgl. DKBl. 10 (1937), Nr. 2707 (Ausgabe vom 12.3.1937); DKBl. 10 (1937), Nr. 2699 (Ausgabe vom 3.3.1937), S. 255f.

168 Im WTG-Geschichtsbericht wird dies mit den Worten beschrieben, daß die „Glaubensschwestern" nach der Verhaftung der Mehrheit der Bezirksdienstleiter gebeten worden seien, ,in die Bresche zu springen“. Sie hätten daraufhin ,freudig die Lücken“ ausgefüllt, ,die durch die Verhaftung der Brüder entstanden waren" (Jahrbuch 1974, S. 160, 179).

169 Vgl. Garbe, Kompromißlose Bekennerinnen; Lichtenegger, Wiens Bibelforscherinnen, S. 166ff. Auch die Entwicklung der gerichtlichen Aburteilungen kann als Beleg für die zunehmende Aktivität von Bibelforscherinnen im Widerstand gelten. So hat Erika Kalous in ihrer Arbeit über die vor dem SG und OLG München geführten Bibelforscherverfahren herausgestellt, daß der prozentuale Anteil der Frauen an der Zahl der Abgeurteilten von 1935 bis 1945 konstant angestiegen ist. Während vor dem Sondergericht (Untersuchungszeitraum 1933 bis 1938) $52,7 \%$ der Urteile gegen Männer verhängt wurden, waren es beim OLG (Untersuchungszeitraum 1943 bis 1945) deutlich mehr Frauen, die abgeurteilt wurden (114 Frauen gegenüber 41 Männern, d. h. 73,5 \% zu 26,5\%). Während in den Jahren 1935 bis 1937 vor dem Sondergericht "Frauen wesentlich milder bestraft" worden seien als Männer, habe sich dies in den Verfahren vor dem OLG in den Jahren 1943 bis 1945 so geändert, daß „das Strafmaß der Frauen auf etwa demselben Niveau“" gelegen habe wie das der Männer. 


\section{„Barbarei in einem Lande der, Christenheit“"}

Obgleich die Reihen der IBV mittlerweile stark gelichtet waren, gelang nochmals eine Großaktion, an deren Vorbereitung in erster Linie neben dem neuen Reichsdiener Heinrich Dietschi und dem westdeutschen Bezirksdiener Albert Wandres die genannten Bezirksdienerinnen beteiligt waren. Mit einem „Offenen Brief“ sollten - noch umfassender und wesentlich detaillierter als dies die eher allgemein gehaltene Luzerner „Resolution“ tat - die Verfolgungspraktiken der Gestapo und die Zustände in den Gefängnissen und Konzentrationslagern scharf angegriffen werden. $\mathrm{Zu}$ diesem Zweck setzte man sich mit dem Berner Büro in Verbindung und schlug vor, eine Auswahl der von den Bezirksdienern gesammelten und anschließend nach Bern übermittelten Berichte verfolgter Zeugen Jehovas zu einem Aufklärungsflugblatt zusammenzustellen ${ }^{170}$. Nachdem Rutherford seine Zustimmung zu der Aktion erteilt hatte, verfaßte der Leiter des Büros in Bern, Martin Harbeck, den auf den Berichten beruhenden Text, in dem auch in längeren Ausschnitten Nazi-Quellen dokumentiert wurden - unter anderem ein Schreiben der NSDAP-Kreisleitung Waldenburg (Schlesien) ${ }^{171}$ vom 5. April 1937 und ein in der Zeitschrift „Der deutsche Justizbeamte“ erschienener Artikel über „Bibelforscher im Strafvollzug“172. Im Text des Flugblattes wurde die Verfolgung der Zeugen Jehovas im „Dritten Reich" mit den Folterungen der Inquisitionszeit verglichen. Unter Nennung von Ort und Namen der beteiligten Gestapo-Beamten berichtete das Flugblatt über Mißhandlungen mit Knüppeln und Ochsenziemern und über gewaltsame Tötungen. In Kursivschrift hervorgehoben wurde der Satz: „Bei der Mißhandlung haben sich unter anderen besonders der Kriminal-Assistent Theiss aus Dortmund, Tennhoff und Heimann von der Geheimen Staatspolizei Gelsenkirchen und Bochum hervorgetan."173 Über den Zeugen Jehovas Peter Heinen heißt es, daß er „von Beamten der Geheimen Staatspolizei im Rathaus zu Gelsenkirchen erschlagen“174 wurde.

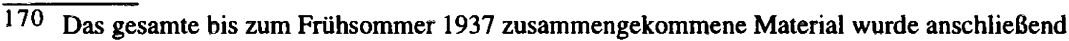
im Berner ,Zentraleuropäischen Büro“ zu einer umfangreichen Dokumentation verarbeitet, die 1938 unter dem Titel „Kreuzzug gegen das Christentum“ im Züricher „Europa-Verlag“" publiziert wurde (siehe auch S. 35, Anm. 108). Der im folgenden Jahr in Paris veröffentlichten französischen Übersetzung wurden Pressestimmen und Stellungnahmen bekannter Persönlichkeiten zu der Erstausgabe vorangestellt. Beispielsweise bekundete Thomas Mann seine tiefe Bewegtheit und sprach von einem ,eindringlichen Ruf an das Gewissen der Welt" (Rückübersetzung aus Zürcher, Croisade, o. S.). Die angestrebte Wirkung auf die internationale Öffentlichkeit und Solidaritätserweise traten zwar nicht in dem erhofften Maße ein, gleichwohl blieben die Appelle der WTG nicht ungehört. So berichteten vor allem in den USA, in Frankreich und der Schweiz Presseorgane über die Verfolgung der Zeugen Jehovas in Deutschland. Vgl. beispielsweise Humanité Paris, 20.5.1937 („Hitler persécute les Protestants"); weitere Presseberichte aus französischen und schweizerischen Zeitungen sind abgedruckt in: Zürcher, Kreuzzug, S. 107, 111, 124.

171 Das Schreiben ist im ungekürzten Wortlaut bei Zürcher, Kreuzzug, Abdruck nach S. 192, wiedergegeben.

172 Vgl. Strafabteilungsvorsteher Liesche: Der Bibelforscher im Strafvollzug, in: Der deutsche Justizbeamte, 21.3.1937, S. 140.

173 „Offener Brief - An das bibelgläubige und Christus liebende Volk Deutschlands“, abgedruckt in: Bludau, Duisburg, S. 289f.

174 Der 34jährige Heinen wurde zwei Tage nach seiner Festnahme am 9.10.1936 bei einem Verhör im Rathausgebäude, in dem sich seinerzeit auch das dortige Polizeigefängnis befand, 
Der Text legt auch davon Zeugnis ab, daß die Zeugen Jehovas sich als Märtyrer des christlichen Glaubens verstanden und trotz der Härte der NS-Verfolgung nicht gewillt waren, sich zu beugen:

„Seit vielen Jahren haben wir, Jehovas Zeugen, früher Bibelforscher genannt, in Deutschland unseren Volksgenossen die Bibel und ihre trostreichen Wahrheiten gelehrt und dabei in selbstloser Weise zur Linderung materieller und geistiger Not Millionen verausgabt. Als Dank dafür sind Tausende von Zeugen Jehovas in Deutschland aufs grausamste verfolgt, mißhandelt und in Gefängnisse und Konzentrationslager eingespert worden. Trotz größtem seelischen Druck und trotz sadistischer körperlicher Mißhandlung, auch an deutschen Frauen, Müttern und an Kindern im zarten Alter, hat man in vier Jahren nicht vermocht, die Zeugen Jehovas auszurotten; denn sie lassen sich nicht einschüchtern, sondern fahren fort, Gott mehr zu gehorchen als den Menschen, wie es seinerzeit die Apostel Christi auch taten, als man ihnen verbot, das Evangelium zu verkündigen.“

Das engbeschriebene und im DIN A3 Format gehaltene doppelseitige Flugblatt wurde in 200.000er Auflage in Bern gedruckt. Doch dieses Mal mißlangen alle Versuche, die Exemplare über die Grenze nach Deutschland zu schaffen. Daraufhin mußte die Herstellung im Inland organisiert werden. Nachdem die Vorlagen für die Druckplatten eingeschmuggelt worden waren, wurden auf einer von einem Zeugen Jehovas in Lemgo (Lippe) betriebenen Schnellpresse ca. 69.000 Stück des mit dem Titel „Offener Brief - An das bibelgläubige und Christus liebende Volk Deutschlands“ versehenen Flugblattes gedruckt.

Am Sonntag, den 20. Juni 1937, fand mittags zwischen 12.00 und $13.00 \mathrm{Uhr}$ wiederum zeitgleich in vielen Orten Deutschlands die Verbreitung des „Offenen Briefes“ statt ${ }^{175}$. Ebenso wie bei der Verteilaktion ein halbes Jahr zuvor hatte die Gestapo von den konkreten Vorbereitungen keine Kenntnis erlangt, so daß die Verteilung auf gleiche Weise wie bei der „Resolution“ vorgenommen werden konnte. In Hamburg waren an der Verteilung ca. 70 Personen beteiligt, denen für die Aktion mehrere tausend Flugblätter zur Verfügung gestanden haben. Auch dieses Mal wurden Flugblätter zugleich mit der Post verschickt, allerdings scheinen neben Amtspersonen bei dieser Aktion auch solche Menschen gezielt angeschrieben worden zu sein, von denen angenommen wurde, ,daß sie derartige Flugblätter auch lesen und sich über den Inhalt Gedanken machen und Flugblätter nicht achtlos beiseite werfen" 176 .

Den Zeugen Jehovas ging es allerdings auch mit dieser Flugblattaktion in erster Linie um ein offen vorgetragenes Bekenntnis zu Jehova Gott und damit verbunden um die Anklage der „Barbarei in einem Lande der ,Christenheit““"177. Der Öffent-

durch Beamte der Gelsenkirchener Gestapo-Außendienststelle zu Tode geprügelt. Vgl. Zürcher, Kreuzzug, S. 180-183.

175 In einigen Orten scheint der „Offene Brief“ nicht am 20. Juni, sondern einen Tag zuvor bzw. danach verteilt worden zu sein. So berichtet Hans-Josef Steinberg davon, daß in Essen am 19. Juni 300 Exemplare verteilt worden seien (vgl. Steinberg, Essen, S. 165). In einigen Ortschaften im Bezirk der Staatspolizeistelle Augsburg wurde der „Offene Brief" am Montag, den 21. Juni, in den Abendstunden verbreitet. Vgl. IfZ, MA 554, 936260, Staatspolizeistelle Augsburg, Schreiben vom 9.7.1937.

176 DCB, VGH, 8 J 20/38, Bl. 32, Staatspolizeistelle Hamburg, Abschlußbericht vom 21.12.1937.

177 Zürcher, Kreuzzug, S. 194. 
lichkeit sollte mit diesem Flugblatt, wie zuvor mit der „Resolution“, signalisiert werden: Schaut her, nunmehr ist für jeden klar erkennbar, wer das wahre Volk Gottes ist und wer Gottes Feinde sind! Insofern war die Aktion der Zeugen Jehovas auch eine Aufklärungskampagne über die Verbrechen des Naziregimes, aber das Ziel war nicht die Mobilisierung der Bevölkerung für den antifaschistischen Kampf. Die Kampagne wollte die Menschen in Deutschland zwar ebenfalls dazu bewegen, dem „,barbarischen Hitler-Staat“ die Loyalität aufzukündigen; dieses sollte aber vor allem deshalb geschehen, um an deren Stelle noch vor dem herannahenden „Harmagedon“ die Loyalität zur göttlichen Autorität zu setzen. Die Handlungsaufforderung in dem „Offenen Brief“ lautete, sich in der noch verbleibenden Zeit ,gänzlich auf die Seite Gottes und Christi Jesu“ zu stellen. Dieser Widerstand galt dem Kampf um das Gottesreich, nicht dem Sturz der nationalsozialistischen Machthaber. Denn diesen - davon waren die Zeugen Jehovas überzeugt - würde Jehova Gott schon allein bewerkstelligen.

Nach der Verteilung des „Offenen Briefes“, der für die Nationalsozialisten Beweis einer „Hetze“ war, „wie sie sonst nur noch in jüdischen Emigrantenblättern oder in der kommunistischen Lügenpresse des Auslands zu finden ist"178, wurden die Aktivitäten der Gestapo zur Bekämpfung der IBV nochmals intensiviert. Die Teilnahme deutscher Zeugen Jehovas an einer vom 21. bis 23. August 1937 im Pariser „Maison de la Mutualité“ unter Anwesenheit Rutherfords veranstalteten Hauptversammlung, bei der ähnlich wie im Vorjahr in Luzern im Beisein möglichst vieler deutscher Glaubensgeschwister über die weiteren Schritte beraten werden sollte ${ }^{179}$, konnte fast vollständig verhindert werden. Bereits fünf Wochen zuvor hatte die Geheime Staatspolizei die Polizeibehörden entsprechend instruiert und um Mitteilung gebeten, ,falls Paßanträge von Anhängern der IBV gestellt werden sollten"180; eine Woche vor Kongreßbeginn war von der Staatspolizeileitstelle München angeordnet worden, diejenigen Bibelforscher, bei denen der Verdacht bestehe, daß sie trotz Entzug des Reisepasses an der Hauptversammlung teilzunehmen beabsichtigen, schon im Vorwege „vorübergehend in Schutzhaft zu nehmen“181.

Unter diesen Voraussetzungen war es nur fünf Zeugen Jehovas gelungen, die Grenze zu überwinden und an der Konferenz teilzunehmen. Unter diesen fünf Personen war auch der Reichsdiener Heinrich Dietschi. Als er nach der Rückkehr in

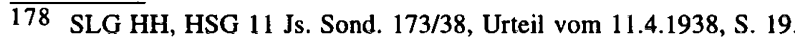

179 Der Bericht im Jahrbuch 1938 (S. 194f.) gibt keinen Aufschluß über die bei der Pariser Konferenz im einzelnen verhandelten Themen, auch in der anderweitigen Literatur findet die Konferenz keine größere Aufmerksamkeit.

180 BA, Sammlung Schumacher/267 I, Staatspolizeistelle Darmstadt, RdS vom 16.7.1937. Ein Vierteljahr vor dem Pariser Kongreß hatte die Staatspolizeileitstelle München verfügt, zukünftig eine „Ausstellung von Reisepässen für die als Bibelforscher bekannten Personen [...] zu verhindern". In den Fällen, in denen Pässe bereits ausgestellt worden seien, sollten sie eingezogen werden. (BA, Sammlung Schumacher/267 I, Staatspolizeileitstelle München, RdErl. vom 19.5.1937). Vermutlich liegt der von der Stapo München angeordneten $\mathrm{PaBsperre} \mathrm{ein}$ Gestapa-Runderlaß vom 28.4.1937 zugrunde (vgl. BA, R 58/1074, Bl. 29).

181 IfZ, MA 554, 936259, Staatspolizeileitstelle München, RdErl. vom 14.8.1937. Die Stuttgarter Staatspolizeileitstelle wies am 20.8.1937 hingegen die ihr unterstellten Polizeibehörden , lediglich' an, bei ,,allen im dortigen Bereich als IBV-Anhänger bekannten Personen vertraulich nachzuprüfen, ob sie über die Zeit des Kongresses ortsabwesend sind" (UaP J. E. Straßer/Sammlung zur historischen Dokumentation, Staatspolizeileitstelle Stuttgart, RdErl. vom 20.8.1937). 
Berlin seinen geheimen Aufenthaltsort aufsuchte, wartete die Gestapo dort bereits auf ihn. Albert Wandres, der aufgrund seines großen Wirkungsgebietes im Westen und Südwesten - nach der Verhaftung anderer Bezirksdiener hatte er deren Bezirke zeitweilig mit übernommen ${ }^{182}$ - von der Gestapo auch als stellvertretender Reichsdiener bezeichnet wurde ${ }^{183}$, wurde eine Woche später, am 3. September 1937, in Dresden festgenommen ${ }^{184}$.

Infolge der zur Festnahme des Reichsdieners und seines „Vertreters“ führenden Ermittlungen wurden innerhalb kurzer Zeit nahezu alle leitenden IBV-Funktionäre verhaftet: Bereits Ende August, noch vor Dietschi, war in Berlin die bayerische Bezirksdienerin Elfriede Löhr festgenommen worden. Einige Tage später wurde in Dresden Gertrud Pötzinger, die Verantwortliche für die Arbeit in Schlesien, verhaftet. Am 13. September um 9.00 Uhr morgens nahmen in Hamburg GestapoBeamte die Bezirksdienerin Frieda Christiansen in Empfang, als diese zu einem mit Wandres verabredeten Treffen norddeutscher Gruppendiener erschien ${ }^{185}$. Das gleiche Schicksal widerfuhr Mitte September in Bingen auf dem Bahnhof der Bezirksdienerin Auguste Schneider ${ }^{186}$. In jenen Tagen wurden auch der Bezirksdiener für Thüringen und Hannover Walter Friese, der Unterbezirksdiener für Württemberg Ludwig Stickel sowie weitere Bezirksverantwortliche in Haft genommen. Im Anschluß an die Festnahmen kam es zur „Aufrollung“ zahlreicher IBV-Gruppen, so in Pforzheim, Freiburg, Baden-Baden und Karlsruhe.

Auch die Hamburger IBV-Organisation, die sowohl die Verhaftungswelle Ende August 1936 als auch die nach der Verteilung der ,Resolution“ im Frühjahr 1937 nahezu unbeschadet überstanden hatte, wurde nun betroffen. Zwar war bereits zwei Tage nach der in der Hansestadt besonders umfangreichen „Offenen Brief"-Aktion die erste Verteilerin ermittelt worden, und Ende Juni waren einige weitere Festnahmen erfolgt; da aber die Aufklärungsarbeit - wie es in einem Gestapo-Vermerk heißt - ,schwierig und schleppend [verlief], weil die Festgenommenen z. T. bestritten bzw. keine Aussagen machten“187, war der Gestapo zunächst ein nachhaltiger „Erfolg“ versagt geblieben. Noch am 29. August 1937 konnte in Rönneburg

$\overline{182}$ Der Wiesbadener Bezirksdiener Wandres war zeitweilig für den gesamten südwest- und westdeutschen Raum zuständig (Rheinland, Südhessen, Pfalz-Baden, Württemberg und Saarland). In dieser Zeit unterstanden ihm circa 65 IBV-Gruppen. Vgl. Billstein, Krefeld, S. 306; Koch, M., Die kleinen Glaubensgemeinschaften, S. 422; Steinberg, Essen, S. 164.

183 DCB, VGH, 8 J 20/38, Bl. 22-33 (26), Staatspolizeistelle Hamburg, Abschlußbericht vom 21.12.1937.

184 Vgl. auch den Bericht von Albert Wandres, in: Der Wachtturm, 15.11.1965, S. 696-702.

185 DCB, VGH, 8 J 20/38, B1. 22-33 (26), Staatspolizeistelle Hamburg, Abschlußbericht vom 21.12.1937. Über die Art, wie Wandres seine Treffen mit den Gruppendienern arrangierte, hatte die Staatspolizeistelle Darmstadt die Polizeibehörden bereits mit einem Rundschreiben vom 8.7.1937 informiert: „Seine Treffpunkte mit den örtlichen Leitern der IBV. im Westen bestimmt er auf die folgende Weise: Er schreibt eine Postkarte mit harmlosem Inhalt und fremder Unterschrift. Auf der Postkarte gibt er ein Datum an, an dem er mit dem Kartenempfänger an dem angegebenen Treffpunkt zusammenkommen will. Dieses Datum ist aber nur fixiert [!]. In Wirklichkeit trifft Wandres schon eine Woche vorher am Treffpunkt ein." (BA, Sammlung Schumacher/267 I) Treffpunkt der regelmäßig jeden Monat durchgeführten Zusammenkünfte zwischen der Bezirksdienerin und dem Reichsdiener bzw. einem Vertreter war der Hamburger Bahnhof. Vgl. Imberger, Widerstand, S. 308.

186 Vgl. Jahrbuch 1974, S. 162.

187 DCB, VGH, 8 J 20/38, Bl. 25. 
(bei Harburg) eine größere Zusammenkunft von Gruppen- und Zellendienern aus Hamburg und Schleswig-Holstein arrangiert werden. Getarnt als Treffen eines Schrebergärtner-Vereins traf man sich in der Gaststätte „Rönneburger Park“ zu einer gemeinsamen Kaffeetafel. Nachdem die Anwesenden sicher waren, nicht beobachtet zu werden, brachen sie zu einem Spaziergang auf. Bei einer kleinen Waldlichtung machten sie halt. Dort berichtete ein auswärtiger Zeuge Jehovas den 52 vermeintlichen Kleingärtnern über den in der Vorwoche in Paris veranstalteten Kongreß. Anschließend wurden Absprachen über das weitere Vorgehen getroffen.

Zwei Wochen nach dieser Zusammenkunft gelang der Gestapo die „Zerschlagung “ der Hamburger IBV-Organisation. Nach der Festnahme des Hauptgruppendieners Max Grote am 11. September und zwei Tage später der Bezirksdienerin Christiansen wurden die Gruppen von oben nach unten ,aufgerollt“188. Der Verhaftung der führenden Personen Mitte September folgten im Oktober und November weit über 100 Festnahmen von Zellenmitgliedern. Bis zur Überstellung an die Justiz wurden die Zeugen Jehovas in das „Polizeigefängnis Fuhlsbüttel“" (so die 1936 „zur Abwehr von Hetz- und Greuelpropaganda“ eingeführte amtliche Bezeichnung des KZ Fuhlsbüttel) eingeliefert. Dort bildeten die Zeugen Jehovas nun für Monate die größte Gruppe unter den von der Gestapo eingelieferten Schutzhaftgefangenen. So waren beispielsweise im Oktober 1937 mindestens 122 von insgesamt 234 Schutzhaftgefangenen der Gestapo im KZ Fuhlsbüttel Zeugen Jehovas; im Januar 1938 waren es mindestens 132 von insgesamt 258 Gestapohäftlingen ${ }^{189}$. Im Frühjahr 1938 verhandelte das Hanseatische Sondergericht in acht Verfahren gegen insgesamt 187 Hamburger Zeugen Jehovas ( 77 Männer und 110 Frauen), von denen $55 \mathrm{zu}$ Gefängnisstrafen von über einem Jahr bis vier Jahren verurteilt wurden ${ }^{190}$. Mit Genugtuung konnte die Hamburger Staatspolizeileitstelle im November 1938 feststellen, daß ,die IBV seit der Aktion 1937 im hiesigen Sondergerichtsbezirk vollständig zerschlagen " 191 sei.

Von der Verhaftungswelle 1937 konnte sich die IBV-Organisation auch andernorts für lange Zeit nicht beziehungsweise überhaupt nicht mehr erholen ${ }^{192}$. Die

188 Max Grote, der am 11.4.1938 vom HSG zu vier Jahren Gefängnis verurteilt wurde, verstarb 58jährig noch während der Strafhaft im Gefängnis Wolfenbüttel am 21.10.1940 (UaP Walter Todt). Frieda Christiansen wurde am 18.2.1938 vom SH SG ebenfalls zu vier Jahren Gefängnis verurteilt.

189 Die hier angegebene jeweilige Mindestzahl der inhaftierten Zeugen Jehovas ist durch den Verf. aufgrund eines Abgleiches der Namenslisten des Polizeigefängnisses Fuhlsbüttel (Sta HH, Justizverwaltung I, Verzeichnis der entstandenen Schutzhaftkosten, Generalakte 451 a E, Bd. 1, Forts. Bd. 1c) mit den ihm bekannten Namen Hamburger Zeugen Jehovas erschlossen worden. Da die Namenslisten keinen Haftgrund nennen, kann die Zahl auch noch höher sein.

190 SLG HH, HSG 11 Js. Sond. 173/38; 179/38; 297/38; 298/38; 369/38; 373/38; 385/38; ein weiteres Verfahren war abgetrennt worden.

191 SLG HH, HSG 11 Js. Sond. 298/38, GnH 3659/42, Staatspolizeileitstelle Hamburg, Bericht vom 21.11.1938.

192 In einigen Orten fand die Aufdeckung der IBV-Gruppen erst Ende 1937/Anfang 1938 statt. Reimer Möller schildert in seiner Studie über den Kreis Steinburg im einzelnen die stufenweise „Zerschlagung“ der dortigen IBV-Zellen (vgl. Möller, Steinburg, S. 215-217). Im Zeitraum vom 10.12.1937 bis 2.3.1938 wurden nacheinander die Zellen in Neuenkirchen, Itzehoe, Wilster, Glückstadt und Kellinghusen ,,aufgerollt“, wobei die örtlichen Polizeistellen zeitweise durch Gestapo-Bedienstete aus Kiel und Neumünster angeleitet wurden. Insgesamt wurden in Schleswig-Holstein bei der ,Zerschlagung der IBV“ Ende 1937/Anfang 1938 mindestens 267 Zeugen Jehovas in Haft genommen. Vgl. Imberger, Widerstand, S. 349. 
Aktivisten saßen zumeist in den Gefängnissen und Konzentrationslagern ein; die nicht verhafteten Zeugen Jehovas zogen sich zum Teil verängstigt, zum Teil führungslos zurück. Ein überregionales Organisationsgefüge bestand seit dem September 1937 nicht mehr. Die in einzelnen Orten noch bestehenden Gruppen traten zunächst nicht mehr öffentlich in Erscheinung ${ }^{193}$. Der zusammengeschmolzene Stamm von unentwegten Anhängern versuchte, soweit es möglich war, die religiösen Zusammenkünfte im kleinen Kreis fortzuführen, wobei nun oftmals nur noch auf die Bibel zurückgegriffen werden konnte, da der Bezug von ,Wachttürmen" vorübergehend fast vollständig zum Erliegen gekommen war.

Die Verfolgungsinstanzen glaubten, daß ihr Kampf gegen die Bibelforschervereinigung damit im wesentlichen als beendet betrachtet werden könne. Am 18. Oktober 1937 berichtete der Karlsruher Generalstaatsanwalt nach Berlin, daß in seinem Amtsbezirk ,die Tätigkeit der Bibelforscher [...] nachgelassen" 194 habe; ein Vierteljahr später konnte sich die Zentralabteilung II 1 des SS-Sicherheitshauptamtes in einem Lagebericht in bezug auf die IBV mit der Feststellung begnügen: „Die internationalen Bibelforscher sind nicht sonderlich in Erscheinung getreten."195 Zwar registrierten die SD-Spitzel im Laufe des Jahres 1938 wieder vermehrte Aktivitäten, und die Staatspolizeistellen nahmen erneut eine nicht unbeträchtliche Zahl von Festnahmen vor, doch dieser Entwicklung wurde nicht mehr die Dramatik der zurückliegenden zwei Jahre beigemessen. Der Jahreslagebericht 1938 des Sicherheitshauptamtes resümierte:

„Von den verbotenen Sekten trat lediglich wieder die ,Internationale Bibelforscher-Vereinigung (IBV) merklich in Erscheinung. Da jedoch durch das energische Vorgehen des Staates ihre Organisation vollkommen zerschlagen wurde, blieben auch die neuerlichen Aktionen der IBV ohne größere Wirkung. Die illegale Einfuhr von Schriften der IBV über die schweizerische und französische Grenze wurde fast völlig unterbunden. Im ganzen Reich wurden im Jahre 1938 rund 700 Bibelforscher in Schutzhaft genommen. Hierunter befanden sich zahlreiche Personen, die am 10.4.1938 in aller Öffentlichkeit die Teilnahme an der Wahl verweigert und gegen den Führer gehetzt hatten."196

In dem anschließenden ersten Vierteljahreslagebericht für das Jahr 1939 wurde vermerkt: „Die ,Bibelforscher“ sind nur noch vereinzelt in Erscheinung getreten. Die Durchführung der illegalen Propaganda und der illegale Zeitschriftenvertrieb aus der Schweiz zeigen eindeutig, daß jetzt im Reich keine einheitliche Leitung der IBV vorhanden ist."197

193 Dies bestätigen ausnahmslos die Angaben in den Lokalstudien. Vgl. beispielsweise Hetzer, Augsburg, S. 640; Koch, M., Die kleinen Glaubensgemeinschaften, S. 423; Mann, Protest, S. 222; Steinberg, Essen, S. 165.

194 Der Generalstaatsanwalt in Karlsruhe, Lagebericht vom 18.10.1937, abgedruckt in: Verfolgung und Widerstand unter dem Nationalsozialismus in Baden, S. 260.

195 Lagebericht der Zentralabteilung II 1 des Sicherheitshauptamtes des RFSS für Januar 1938, Berichte des SD und der Gestapo, S. 278.

196 Jahreslagebericht 1938 des Sicherheitshauptamtes, Meldungen aus dem Reich, Band 2, S. 7214 (52).

197 Sicherheitsdienst der SS, 1. Vierteljahreslagebericht 1939, Meldungen aus dem Reich, Band 2, S. 237. 
Nach den drei Verhaftungswellen vom August/September 1936, März/April 1937 und August/September 1937 war der Bibelforschervereinigung als umfassende reichsweite Organisation das Rückgrat gebrochen; der Bekennermut und die Entschlossenheit der Zeugen Jehovas ließen sich hingegen nicht unterdrücken. Ihre Kraft reichte aus, nochmals zu einem organisatorischen Neubeginn anzusetzen.

\section{Konflikte zwischen Justiz und Polizei beim Vorgehen gegen die Internationale Bibelforscher-Vereinigung}

In einem höchst bemerkenswerten Maße entzündeten sich Konflikte zwischen Polizei und Justiz im „Dritten Reich“ wiederholt an der Frage der Strafverfolgung der Zeugen Jehovas. Als im Jahre 1934 in größerer Zahl Freisprüche in „Bibelforscherverfahren“ ergingen, weil Gerichte die in den einzelnen Ländern erlassenen IBV-Verbote für rechtsunwirksam erklärten, hatten die damit von der Rechtsprechung errichteten Verfolgungshindernisse auf seiten der Gestapo schnell den Entschluß heranreifen lassen, in derartigen Fällen gegebenenfalls mit eigenen Mitteln das verbotswidrige Handeln von Zeugen Jehovas zu ahnden. Zu diesem Zweck nutzte die Gestapo das den polizeilichen Exekutivorganen seit Erlaß der „Verordnung des Reichspräsidenten zum Schutz von Volk und Staat" vom 28. Februar 1933 zur Verfügung stehende Instrument der Schutzhaft, das es erlaubte, nach eigenem Ermessen bei „Gefährdung der öffentlichen Sicherheit und Ordnung“ eine zeitlich unbefristete, vorbeugende Inhaftnahme vorzunehmen ${ }^{198}$. Gegen den „Schutzhaftbefehl“, der zugleich die Einweisungsverfügung in die seit März 1933 eingerichteten Konzentrationslager darstellte, konnten im Unterschied zum richterlichen Haftbefehl keine Rechtsmittel eingelegt werden. Das primär zur unmittelbaren Ausschaltung politischer Gegner dienende Instrument der Schutzhaft verschaffte somit den Polizeiorganen die Möglichkeit, unter Ausschaltung der Justiz gegen alle Gegnergruppen vorzugehen.

In der Zweckbestimmung dazu war allerdings betont worden, daß der Schutzhaft - von der die Staatspolizei, aber auch die Kriminalpolizei exzessiven Gebrauch machte - ein rein präventiver Charakter zukomme und von daher die der Justiz vorbehaltene Funktion der Ahndung strafbarer Handlungen unbeeinträchtigt bleibe. Von Anfang an erwies sich in der Praxis dieser Versuch einer genauen Abgrenzung von Haftfunktionen jedoch als eine artifizielle, problembeladene Konstruktion einer Arbeitsteilung von Justiz und Polizei, denn die nun gegebene Doppelgleisigkeit von normativer und außernormativer Gewalt enthielt Reibungsflächen und mußte über kurz oder lang zu Konflikten führen. Schon früh gab es Beschwerden über eine „zweckwidrige“ Anwendung der Schutzhaft.

198 Die juristische Grundlage für den Erlaß der Schutzhaft bot die in der VOSchVuS vom 28.2.1933 erfolgte Aufhebung des Artikels 114 der Reichsverfassung, der die Unverletzlichkeit der persönlichen Freiheit garantierte. Damit hatten die Nationalsozialisten jene rechtliche Schranke ausgeräumt, die der von ihnen sogleich in den ersten Wochen nach der ,Machtergreifung" entfachten Jagd auf Regimegegner entgegenstand. 
Aus diesem Grunde sah sich der Reichsminister des Innern Anfang 1934 veranlaßt, den mit der Schutzhaft beabsichtigten Zweck der Gefahrenabwehr in Erinnerung zu rufen und ihre ausschließliche Zulässigkeit als polizeiliche Präventivmaßnahme festzustellen. In einer am 9. Januar 1934 an die Landesregierungen ergangenen Anweisung von Minister Frick heißt es klarstellend: „Dagegen darf die Schutzhaft nicht als ,Strafe', d. h. als Ersatz für eine gerichtliche oder polizeiliche Strafe, zudem mit von vornherein begrenzter Dauer verhängt werden. Es ist daher grundsätzlich nicht angängig, daß an Stelle der Einleitung eines Strafverfahrens Schutzhaft angeordnet wird."199

Im Jahre 1934 und zumindest noch im ersten Halbjahr 1935 kam es oftmals vor, daß Zeugen Jehovas, die von der Gestapo festgenommen und zur Einleitung eines Verfahrens wegen Zuwiderhandlung gegen das Bibelforscherverbot dem Haftrichter vorgeführt worden waren, von diesem nicht in Untersuchungshaft genommen wurden. In solchen Fällen war entweder die Beweislage als nicht ausreichend eingestuft worden - zum Beispiel wenn Richter in der Teilnahme an einer gottesdienstlichen Zusammenkunft anders als die Gestapo keine Fortführung der verbotenen IBV zu erkennen vermochten -, oder der Haftrichter hatte unter Hinweis auf die Einschätzung des Sondergerichts Darmstadt und anderer Gerichte, die dem IBV-Verbot wegen Fortbestand der in der Verfassung niedergelegten und nicht suspendierten Religionsartikel keine Rechtskraft zubilligten, erklärt, daß eine Aburteilung unter den gegebenen Voraussetzungen nicht zu erwarten sei. Hatte die Gestapo schon mit Unmut registrieren müssen, daß Zeugen Jehovas in Gerichtsverhandlungen freigesprochen worden waren, so schien sie es schon gar nicht akzeptieren zu wollen, einen nach dem Ergebnis der staatspolizeilichen Ermittlungen einer Straftat gegen „Volk und Staat“ überführten und sich in den Vernehmungen als „unbelehrbar" zeigenden Bibelforscher, der dem Richter zur weiteren Veranlassung aus der Schutzhaft zugeführt wurde, nach der Ablehnung eines Haftbefehls aus der eigenen Verfügungsgewalt entlassen zu sollen.

Die Staatspolizeistellen institutionalisierten daraufhin eine Praxis, die im offenen Widerspruch zu der ministeriell verfügten Zweckbestimmung der Schutzhaft stand. In einem Runderlaß vom 12. Januar 1935, mit dem die Staatspolizeistelle für den Regierungsbezirk Schleswig (in Altona) die Ortspolizeibehörden davon in Kenntnis setzte, daß ,in letzter Zeit“" verstärkt Aktivitäten der Bibelforscher registriert worden seien, hatte der Leiter der Gestapo-Stelle einräumen müssen: „Durchweg sind die diesbezüglichen Feststellungen jedoch nicht ausreichend, strafrechtlich gegen die

199 BA, R 58/264, B1. 16, RMdI, Schreiben vom 9.1.1934 an die Landesregierungen. Der ein Vierteljahr später herausgegebene Grundsatz-"Erlaß des Reichsinnenministeriums über die Verhängung und Vollstreckung der Schutzhaft" schrieb diese Regelung fest und bestimmte unter dem Punkt III, Absatz 3: „Die Verhängung der Schutzhaft ist ferner nicht zulässig zur Ahndung strafbarer [...] Handlungen. Strafbare Handlungen sind durch die Gerichte abzuurteilen." (BA, Sammlung Schumacher/271, RMdl, RdErl. vom 12.4.1934) Auch die vier Jahre später durch den RMdI ergangene Neuregelung der Schutzhaftbestimmungen hielt an dieser Regelung fest; sie bestimmte in $\S 1 \mathrm{Abs}$. 1 , daß Schutzhaft „nicht zu Strafzwecken oder als Ersatz für Strafhaft angeordnet werden“ dürfe (BA, R 58/1027, Bl. 2, RMdI, RdErl. vom 25.1.1938). 
Täter vorzugehen und Haftbefehl gegen sie zu erwirken."200 Da die Ermittlungsergebnisse ein juristisches Vorgehen nicht erlaubten, wurde deshalb ein Weg eingeschlagen, der dem Einfluß der Justiz entzogen blieb: „Ich habe mich daher entschlossen, durch Schutzhaftmaßnahmen die staatsfeindliche Tätigkeit der Bibelforscher zu unterbinden und ersuche, sofort in eingehende Nachprüfungen einzutreten, welche Personen durch ihre Tätigkeit für die Vereinigung der Bibelforscher eine unmittelbare Gefahr für den nationalsozialistischen Staat hervorrufen und mir dieselben unter Beifügung eines erschöpfenden Berichts zu melden.“

Für die Betroffenen bedeutete dies, daß sie nicht einem Gericht zur Aburteilung zugeführt wurden, sondern - in den Jahren 1935/36 zumeist noch für eine befristete Dauer - in Konzentrationslager eingewiesen wurden. So wurden im AnschluB an den genannten Erlaß beispielsweise allein drei Angehörige der Altonaer IBV-Gruppe in das KZ Esterwegen eingewiesen: vom 19.2. bis 20.10.1935 ein 30jähriger Brauereiarbeiter, vom 12.3. bis 9.6.1935 ein 31 jähriger Fabrikarbeiter und vom 10.5. bis 22.10.1935 ein 49jähriger Zigarrenmacher ${ }^{201}$.

In den Bezirken anderer Staatspolizeistellen beschritt man im Laufe des Frühjahrs 1935 einen ähnlichen Weg wie in Altona. Dabei bildete sich ein festes Schema heraus: Nach Abschluß der polizeilichen Ermittlungen wurden die Zeugen Jehovas zunächst dem Richter vorgeführt. Erließ dieser einen Haftbefehl, so erfolgte die Abgabe des oder der Gefangenen an die Justiz zur weiteren Strafverfolgung. War dies aufgrund einer schlechten Beweislage oder aus anderen Gründen nicht der Fall, stand die Fortführung der Schutzhaft und damit die Überstellung in ein Konzentrationslager als mögliche Alternative bereit ${ }^{202}$. Der polizeilichen Schutzhaft kam als einer Art „Vor-Untersuchungshaft“ 203 fortan eine Selektionsfunktion zu: jene Fälle, die justitiabel waren, wurden an die Justizorgane abgegeben, während die anderen von der Gestapo in eigener Zuständigkeit und auf ihre Weise ,bearbeitet" wurden. Die Schutzhaft wurde damit zu einem Korrektiv mißliebiger juristischer Entscheidungen.

Beispielsweise wurden in Hildesheim im April 1935 zwölf Bibelforscher, wie der dortige Regierungspräsident dem Reichsminister des Innern berichtete, „von der Staatspolizeistelle in Schutzhaft genommen, nachdem - wie nicht selten - das

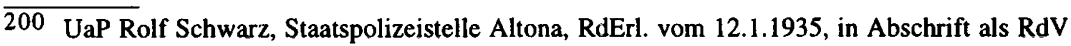
des Landrates in Rendsburg vom 17.1.1935 an die Ortspolizeibehörden.

201 VVN HH, Komiteeakten B 19, H 9, M 6.

202 Der im Mai 1937 zur „Schutzhaft gegen Bibelforscher“ herausgegebene Grundsatzerla $\beta$ der Staatspolizeileitstelle München bestätigte die beschriebene und bereits seit langem praktizierte Verfahrensweise. Der Erlaß ordnete zwar an, daß in Schutzhaft genommene Bibelforscher ,unverzüglich dem Gericht zum Erlaß eines richterlichen Haftbefehls vorzuführen" seien. Wenn aber „ein richterlicher Haftbefehl nicht erlassen oder später wieder aufgehoben“ wurde, war von den Gestapodienststellen ,die Überstellung in ein Konzentrationslager zu veranlassen“. (BA, R 58/264, BI. 306, Staatspolizeileitstelle München, RdErl. vom 19.5.1937)

203 Bereits mit der Praxis, bei Strafsachen entgegen der Vorschrift der Strafprozeßordnung, nach der ein Beschuldigter unverzüglich, spätestens am Tag nach der Festnahme, dem Richter vorzuführen war (\$114 b StPO), die Festgenommenen für die Zeit der polizeilichen Ermittlungen in Schutzhaft zu nehmen, hatte die Gestapo in die Strafverfolgungskompetenzen der Justiz eingegriffen. Häufig wurde die auf diese Weise zur „Vor-Untersuchungshaft“ ausgestaltete Schutzhaft monatelang ausgedehnt, bevor die Strafsache an die Justizorgane mit dem Antrag auf Erlaß eines richterlichen Haftbefehles abgegeben wurde. 
Amtsgericht den Erlaß eines Haftbefehls abgelehnt hatte"204. In den im September 1935 von der Bayerischen Politischen Polizei an die Polizeibehörden übermittelten Richtlinien bezüglich „Schutzhaft gegen Bibelforscher“ wurde angeordnet: „Personen, die zum ersten Mal wegen Betätigung für die ,Internationale BibelforscherVereinigung ' betroffen werden, sind, falls kein richterlicher Haftbefehl erlassen wird, bis zu sieben Tage in Schutzhaft zu nehmen und dann nach erfolgter strenger Verwarnung und einer eventuellen Auflage der Meldepflicht zu entlassen. Handelt es sich um Führer der IBV, so kann die Schutzhaft bis auf zwei Monate ausgedehnt werden."205 Solche Regelungen unterstrichen, daß die Schutzhaft zum Substitut für die Strafhaft wurde; die Gestapo betätigte sich als eine Art „Polizeijustiz“ und legte in eigener Kompetenz das jeweilige Strafmaß fest.

Aber auch wenn Zeugen Jehovas bereits an die Justiz übergeben worden waren, dann jedoch - etwa aufgrund von im staatsanwaltschaftlichen Ermittlungsverfahren zu Tage getretenen Entlastungsmomenten oder weil kein Fluchtverdacht bestand der Haftbefehl wieder aufgehoben und die Entlassung aus der Untersuchungshaft angeordnet wurde, setzte erneut der Zugriff der Gestapo ein. Gemäß eines Runderlasses der Bayerischen Politischen Polizei vom 26. Juni 1935, wonach ,bei Aufhebung richterlicher Haftbefehle gegen Anhänger der ,Internationalen Vereinigung Ernster Bibelforscher' Schutzhaftbefehle zu erlassen" 206 waren, erfolgte diese Praxis sogar im Einvernehmen mit dem Reichsministerium des Innern und dem Reichsjustizministerium.

Neben die Anordnung von Schutzhaft - in jenen Fällen, in denen die Justiz keine ausreichende Grundlage für einen Haftbefehl gegeben sah - und somit neben die ,Ahndung strafbarer Handlungen“ mit polizeilichen Mitteln traten Einwirkungsversuche der Gestapo auf die Rechtsprechung, um diese zu einem härteren Vorgehen zu veranlassen. Nach Ansicht der Gestapo mangelte es der Justiz in weiten Teilen an der gebotenen Entschlossenheit bei der Aburteilung von Regimegegnern aller Richtungen. Das Berliner Geheime Staatspolizeiamt hatte aus diesem Grunde in einem Runderlaß vom 26. April 1935, in dem Klage darüber geführt wurde, „daß Staatsfeinde von einzelnen Gerichten nicht mit der notwendig erscheinenden Schärfe behandelt oder bestraft werden“, die Staatspolizeistellen zur Überwachung der Rechtsprechung aufgefordert und angeordnet, zukünftig ,darauf zu achten, ob die von den Gerichten getroffenen Maßnahmen auch tatsächlich zur Niederkämpfung der Staatsfeinde geeignet sind“207.

Insbesondere in Verfahren gegen Zeugen Jehovas blieben die von den Rechtsprechungsorganen verhängten Strafen weit hinter den Erwartungen der Gestapo zurück. Selbst nachdem ab Mitte 1935 in der Judikatur - wohl nicht zuletzt aufgrund der vom Reichsjustizministerium geübten Richterschelte - die Rechtsgültigkeit der IBV-Verbote nirgends mehr in Frage gestellt wurde und von daher eine nachgewiesene Betätigung für die Bibelforschervereinigung grundsätzlich der straf-

204 Der Regierungspräsident in Hildesheim, Lagebericht an den RMdI für die Monate April/Mai 1935 vom 1.6.1935, Gestapo Hannover, S. 381.

205 BA, R 58/264, B1. 162, BPP, RdErl. vom 23.9.1935.

206 BHStA, Reichsstatthalter 638, BPP, RdErl. vom 26.6.1935.

207 Geheimes Staatspolizeiamt, RdErl. vom 26.4.1935, zit. nach Rürup, Topographie, S. 98. 
rechtlichen Ahndung unterlag, ergingen nicht wenige Urteile in Bibelforscherverfahren, die im Strafmaß als bemerkenswert ,milde" zu bezeichnen sind. So wurden in einem im August 1935 gegen 43 Zeugen Jehovas aus dem Kreis Göppingen wegen fortgesetzter Teilnahme ,an Zusammenkünften mit ihren Glaubensgenossen“ angestrengten Proze $\beta$ der Hauptangeklagte zu 300 RM Geldstrafe, zwei Angeklagte zu 200 RM sowie 30 weitere Angeklagte zu der gesetzlichen Mindeststrafe von 150 RM verurteilt, während die restlichen Angeklagten aus Mangel an Beweisen auf Kosten der Staatskasse freigesprochen wurden ${ }^{208}$. Derartige Urteile stießen bei der Gestapo und auch auf seiten der vorgesetzten Justizbehörden auf Unverständnis. Die Staatspolizeistelle Frankfurt am Main befand im November 1935: „Die Gefährlichkeit der Arbeit der Bibelforscher wird im allgemeinen zu gering eingeschätzt, wie es scheint, insbesondere auch bei den Gerichten."209

Der in den staatspolizeilichen Lagebeurteilungen und in der NS-Presse verbreiteten Ansicht, daß es sich bei den Bibelforschern um ,gefährliche Staatsfeinde“ handele, mochten sich viele Gerichte aufgrund des tatsächlichen Persönlichkeitsbildes der einzelnen Beschuldigten und der Art der zur Aburteilung anstehenden Tatbestände - etwa einer Zusammenkunft zum Bibelstudium oder der zu Missionszwecken erfolgten Weitergabe von Bibelforscherschriften - nicht einfach anschlieBen. Beispielsweise erklärten die Richter in einer in einem Berufungsverfahren vor dem Landgericht Dortmund am 16. Januar 1935 gefällten Entscheidung, daß ,eine wesentliche Herabsetzung der vom Vorderrichter verhängten Strafen umso mehr angebracht [sei], als die Angeklagten nach ihrem gesamten Eindruck in der Hauptverhandlung vor dem erkennenden Gericht keineswegs als Rechtsbrecher im gewöhnlichen Sinne angesprochen werden können"210. Das Sondergericht Frankenthal charakterisierte in einem Verfahren gegen Angehörige der IBV-Gruppe Bad Dürkheim die Beschuldigten als „,durchweg kleine Leute“ und „nicht eigentlich vom bösen Willen beseelt" 211 ; in dem genannten Prozeß gegen die Göppinger Bibelforscher hatte selbst der Staatsanwalt eingeräumt, daß es sich bei den Angeklagten um ,harmlose, anständige Menschen“ handele.

Da die vor dem Richtertisch stehenden Zeugen Jehovas oftmals in keiner Weise mit dem Bild des ,heimtückischen Staatsfeindes“ in Einklang zu bringen waren, befürchteten zuweilen sogar höhere Justizbehörden einen Autoritätsverlust der Sondergerichte. In einem Bericht des Karlsruher Generalstaatsanwalt vom März 1937 heißt es zu diesem Problem: „Daß unter den ,Ernsten Bibelforschern“ nicht selten alte, teilweise auch gebrechliche Männer und Frauen, nach manchmal weiter Reise, vor dem Sondergericht erscheinen müssen, drückt wohl gelegentlich die Bedeutung dieser Einrichtung herab.“ In Sorge um den Ruf der Sondergerichte, deren Glaubwürdigkeit als Organe zur Bekämpfung gefährlicher Staatsfeinde nach Dafürhalten des Generalstaatsanwaltes in diesen Fällen gefährdet zu sein schien, schlug der oberste Ankläger in Baden vor, die Sondergerichte zukünftig nicht mehr

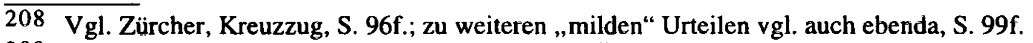

209 Staatspolizeistelle Frankfurt (Main), Allgemeine Übersicht über die innenpolitische Entwicklung im Berichtsmonat November 1935 vom 30.11.1935, abgedruckt in: Die Lageberichte der Geheimen Staatspolizei über die Provinz Hessen-Nassau, S. 516.

210 LA SH, Abt. 352 Altona Nr. 8869, Anlage, LG Dortmund, 10 M 69/34, Urteil vom 16.1.1935.

211 Zit. nach: Warmbrunn, Strafgerichtsbarkeit, S. 374. 
mit solchen Prozessen zu belasten: „Es wäre wünschenswert, wenn derartige Verfahren, denen auf den ersten Blick anzusehen ist, daß die Angeklagten harmlose Mitläufer sind, zum ordentlichen Verfahren abgegeben werden dürften."212

Auch andere Staatsbedienstete und anscheinend selbst Gestapo-Beamte hielten die Zeugen Jehovas gelegentlich eher für eine „harmlose Sekte“, als in ihnen eine oppositionelle Gruppierung zu sehen. Davon zeugen nicht zuletzt die sich in den Gestapo-Erlassen immer wieder findenden wortreichen Beteuerungen über die dem Staat durch die Aktivitäten der Bibelforscher erwachsenden Gefahren. Die Bayerische Politische Polizei beklagte in einem Runderlaß vom 1. Februar 1936, „daß im Abwehrkampf gegen die als gefährliche Staatsfeinde bekannten Ernsten Bibelforscher nicht mit der nötigen Schärfe vorgegangen" werde, und warnte davor, die von der IBV ausgehende „Gefahr“ zu unterschätzen ${ }^{213}$. Die Staatspolizeileitstelle München belehrte, daß es sich bei den Bibelforschern ,nicht um harmlose Sektierer [handele], sondern um gefährliche Staatsfeinde, die in stiller und zäher Arbeit die deutschen Volksgenossen für ihre internationalen volksfeindlichen Ansichten und Bestrebungen zu gewinnen und auf dem Wege über eine angebliche Religion zu Feinden des Staates zu erziehen versuchen“214. In der Ende 1936 den Polizeibehörden übermittelten vertraulichen Gestapa-Denkschrift wurde festgestellt, „daß auch heute noch in weiten Kreisen des Volkes und selbst bei Behörden des Staates und der Bewegung der Eindruck vorherrscht, daß die IBV nur eine harmlose Sekte darstelle und ihre Anhänger nur irregeleitete ,Gottsucher' seien“215.

\section{„Aufklärungsaktion" der NS-Propagandisten}

Um diesen ,Mißstand“ zu beseitigen, erhöhten die Gestapo-Sektenreferate in $\mathrm{Zu}$ sammenarbeit mit dem Sicherheitsdienst der SS ihre Bemühungen um „Aufklärung“ über „die politischen Ziele der IBV“. Zu diesem Zweck wurden zum einen interne Hintergrundmaterialien und Denkschriften erstellt ${ }^{216}$, die den am Vorgehen gegen die Bibelforscher beteiligten Behörden vertraulich zugingen; im Falle der Gestapa-Denkschrift wurde die ,geeignete Unterrichtung der Sachbearbeiter“ zur

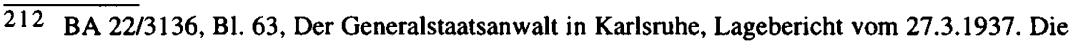
Anregung des Generalstaatsanwalts ist vom RJM nicht aufgegriffen worden. Strafsachen wegen Zuwiderhandlung gegen das IBV-Verbot wurden weiterhin nur vor den Sondergerichten verhandelt; eine Abgabe von Verfahren an die ordentlichen Strafgerichte ist nicht belegt.

BHStA, Reichsstatthalter 638, Bayerische Politische Polizei, RdErl. vom 1.2.1936.

214 StA M, Staatsanwaltschaften 8551, SG München 16 KMs So 45-47, 37 (37), Band I, Bl. 55, Staatspolizeileitstelle München, Bericht vom 17.11.1936.

215 IfZ, MA 554, 936279-87 (79), Denkschrift „Die Internationale Bibelforscher-Vereinigung“, als Anlage zum RdS der Staatspolizeileitstelle München vom 24.12.1936.

216 Dazu zählen unter anderem die bereits mehrfach zitierte Gestapa-Denkschrift „,Die Internationale Bibelforscher-Vereinigung" (siehe S. 230, Anm. 37), ferner die von Kriminalkommissar Müller vermutlich ebenfalls Ende 1936 verfaßte Abhandlung „Die ,Internationale Ernste Bibelforschervereinigung ' (IBV.), deren Grundsätze und Organisation", die hauptsächlich den organisatorischen Aufbau der IBV schilderte (StA M, Staatsanwaltschaften 8551, SG München $16 \mathrm{KMs}$ So 70-71, 37 (71), Band VII, Anlage, o. B1.), und der von einem SS-Hauptsturmführer namens Kolrep in den Schulungsmaterialien für die „Gegnerbekämpfung“ verfaßte Teil über „Das Sektenwesen“, der sich in großen Teilen mit der IBV auseinandersetzte (BA, R 58/779, Bl. 141-147). 
Pflicht gemacht ${ }^{217}$. Zusätzlich zu derartigen Informations- und Schulungsmaterialien wurden den unteren Dienststellen auch Selbstzeugnisse der Bibelforscher zur Kenntnis gegeben, die belegen sollten, ,um welch gehässige und absolut staatsfeindliche Elemente es sich bei den Ernsten Bibelforschern handelt" ${ }^{218}$. Beispielsweise übermittelte die Staatspolizeileitstelle München einen dem „Goldenen Zeitalter" vom 1. Februar 1937 entnommenen Artikel, der nach Auffassung der bayerischen Gestapobeamten ,,in der Gehässigkeit und beispiellosen Unverschämtheit nicht mehr übertroffen werden [könne]. Nicht nur, daß der Führer als ,Raubtier bezeichnet wird, sind auch die übrigen Ausführungen in derselben hetzerischen Tendenz gehalten und erinnern an bolschewistische Ausfälligkeiten. Der Auszug ist den unterstellten Beamten zur Kenntnis zu geben; daher ist ihnen erneut zur Pflicht zu machen, auf diese Staatsfeinde ein besonderes Augenmerk zu richten." 219

Zum zweiten wurden die Parteigliederungen verstärkt für den Kampf gegen die Bibelforscher mobilisiert. Im Oktober 1936 befaßte sich eine Ausgabe der vom „Beauftragten des Führers für die Überwachung der gesamten geistigen und weltanschaulichen Erziehung der NSDAP“ herausgegebenen „Mitteilungen zur weltanschaulichen Lage“ mit den „politischen Hintergründen“ der Bibelforschervereinigung. Das Schulungsblatt aus dem Hause Rosenbergs stellte - unter Verwendung der von dem Antisemiten Hans Jonak von Freyenwald vorgelegten „Forschungen" - die Verwurzelung der bibelforscherischen Glaubenslehre im jüdischen Gedankengut in den Mittelpunkt seiner Ausführungen. Aufgrund dieser Betrachtungsweise sei es nunmehr gelungen, „die direkte Verbindungslinie zwischen ,Ernsten Bibelforschern' einerseits, Marxismus und Freimaurertum andererseits einwandfrei nachzuweisen" 220 . Nach Wiedergabe einiger Passagen zur Eschatologie der Bibelforscher, die den Glauben an ein zukünftiges, alle Völker „ungeachtet der gegenwärtigen nationalen Unterschiede“ umfassendes Gottesreich auf Erden zum Gegenstand hatten, resümierte das Mitteilungsblatt:

„Wird in diesen angeführten Gedankengängen nicht mit geradezu erschreckender Deutlichkeit ausgesprochen, was im Weltbolschewismus bereits grauenvolle Wirklichkeit geworden ist? Die Unterwerfung der Welt unter die jüdische Diktatur - blutige Vernichtung - Aufhebung aller nationalen Unterschiede, wie sie die Bibelforscher in obigen Ausführungen verkünden, was ist das anderes als jüdischer Weltbolschewismus? Es ist demnach kein Zweifel, daß die ,Ernsten Bibelforscher' geistige Schrittmacher für den Weltbolschewismus sind."

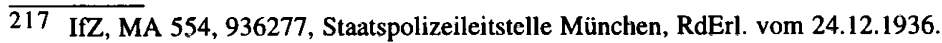

218 IfZ, MA 554, 936269, Staatspolizeileitstelle München, RdErl. vom 22.5.1937.

219 Ebenda. Der Artikel, der den Titel „Alltägliches aus Deutschland“ trug, wurde anscheinend deshalb von der Gestapo als eine besondere Infamie empfunden, weil in ihm die wirtschaftliche und soziale Lage Deutschlands mit den nationalsozialistischen Verheißungen kontrastiert wurde. Jeder der einzelnen Absätze, die Themen wie Leistungsdruck, Dienstverpflichtung, Lohnabbau, , Kraft durch Freude“-Propaganda, Parteibonzenwirtschaft sowie die „klassischen" Bibelforscherthemen Kindererziehung, Gruß- und Wahlzwang behandeln, endet mit einem spöttischen „Heil Hitler!“ (IfZ, MA 554, 936271-74; auch abgedruckt in: Zipfel, Kirchenkampf, S. 412-417).

220 IfZ, MA 603, 20474-20480, Mitteilungen zur weltanschaulichen Lage, Nr. 34 (2. Jahr), 2.10.1936. 
Das Rosenbergsche Schulungsblatt, nun angelangt bei der von seiten der NSPropagandisten stets strapazierten These von der ,jüdisch-bolschewistischen Weltverschwörung", sah in den Bibelforschern nicht nur geistige, sondern auch ganz handfeste Bündnisgenossen jenes „Komplottes“. Da „das Judentum“ sich mit der Bibelforschervereinigung einer ,geradezu phantastisch aufgebauten Organisation" bediene, seien die Auswirkungen im Weltgeschehen bereits zu spüren. So seien etwa im Hinblick auf die Vorgänge in Spanien ${ }^{221}$, wo die Bibelforscher eine besonders rege Werbetätigkeit entfaltet hätten, ,die Zusammenhänge [...] mit Händen zu greifen“. Damit stünde - und mit diesen Worten schloß der Beitrag in den „Mitteilungen“ - „die Bibel im Dienst der Weltrevolution“.

Auch die „Hintergrundberichte“, die in der vom Reichsorganisationsleiter der NSDAP Robert Ley herausgegebenen Funktionärszeitschrift „Der Hoheitsträger“ erschienen, beschäftigten sich ausführlich mit der Bibelforschervereinigung und den Gefahren, die dem nationalsozialistischen Staat angeblich von seiten der IBV drohten ${ }^{222}$. In dem amtlichen Informationsorgan der NSDAP, das zur vertraulichen Unterrichtung und Schulung der „Hoheitsträger“ und „Politischen Leiter“ diente, wurde die Partei zum rücksichtslosen Kampf gegen die Bibelforscher aufgerufen. Anscheinend entsprach die bisherige Mithilfe der NSDAP-Gliederungen bei der Verfolgung der Zeugen Jehovas nicht ganz den an höherer Stelle gehegten Erwartungen, denn nachdrücklich und wiederholt wurde den „Parteigenossen“ eingebläut, daß es nicht genüge, wenn allein die Polizei diesen Kampf führe; ,,an der Ausmerzung der für die positive Mitarbeit am Staat verlorenen Anhänger der Bibelforschervereinigung“ - so forderte die Funktionärszeitschrift - „muß jeder mithelfen. Er hilft dann einen Volks- und Staatsfeind vernichten." 223

Neben die Unterweisung derjenigen, denen die Verfolgung der IBV dienstlich oblag, und die Mobilisierung der Parteigliederungen trat zum dritten eine öffentliche „Aufklärungsaktion“, die darauf abzielte, die Akzeptanz für ein unnachsichtiges Vorgehen gegen die Zeugen Jehovas zu erhöhen. SS-Hauptsturmführer Kolrep, Verfasser einschlägigen Schulungsmaterials, befand, daß eine intensive Öffentlichkeitsarbeit „Hand in Hand“ mit den staatspolizeilichen „Abwehrmaßnahmen“ zu gehen habe: „Wenn die Volksgenossen immer wieder durch aufklärende Zeitungsar-

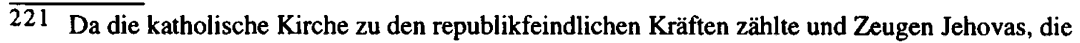
sich weigerten, auf seiten Francos im Bürgerkrieg zu kämpfen, hingerichtet wurden, bezog die Watch Tower Society in ihren Publikationen unzweideutig gegen den spanischen Faschismus Stellung (vgl. näher Jahrbücher 1934ff.; Zürcher, Kreuzzug, S. 44ff.). Interpretationen in der wissenschaftlichen Literatur, die deshalb die Zeugen Jehovas ,auf der Seite der Republik“ (Koch, M., Die kleinen Glaubensgemeinschaften, S. 419) oder gar auf der "Seite der antinationalsozialistischen, antifaschistischen Kräfte in der Welt“ (Struve, Zeugen Jehovas, S. 293) verorten, verkennen allerdings den Charakter deren Engagements.

222 Vgl. Ernst Ludwig Illinger: Die Ernsten Bibelforscher als Sendboten des jüdischen Bolschewismus, in: Der Hoheitsträger, Folge VI, Juni 1938, S. 12-15; „Verblendete“ Volksgenossen und ,harmlose" Menschen [o. V.], in: Der Hoheitsträger, Folge VIII, August 1938, S. 1216. Die Berichte erschienen in der Reihe „Hoheitsträger, kennst du diese?“, mit der - auf einschlägigen Informationen des Sicherheitsdienstes der SS oder der Gestapo beruhende „Hintergrundkenntnisse“ für die Gegnerbekämpfung vermittelt wurden. 
tikel auf den Sektenschwindel hingewiesen und von der Richtigkeit der staatlichen Maßnahmen überzeugt werden, wird der Erfolg dieser Arbeit nicht ausbleiben. "224

In der Presse, die zumeist anläßlich von Sondergerichtsverfahren über die IBV berichtete ${ }^{225}$, wurde die Diktion verschärft, und zum Zwecke der ,Entlarvung“ der Bibelforscher wurde auf die in der antisemitischen Propaganda eingesetzten und dort bereits erprobten Diffamierungstechniken zurückgegriffen. So wurden die Zeugen Jehovas nun nicht nur der Verbindung mit dem Kommunismus bezichtigt, wobei man sie zugleich auch als Agenten im Dienste US-amerikanischer Drahtzieher bezeichnete, sondern über den propagandistischen Kampf gegen die Lehre und Betätigung der IBV hinaus schürten die NS-Schriftleiter jetzt auch den persönlichen Haß: Die Zeugen Jehovas wurden auch als Personen verächtlich gemacht, der Lächerlichkeit preisgegeben, mit rassistischen Urteilen bemessen und als „minderwertig“ befunden. In enger Anlehnung an die im „Hoheitsträger“ im Blick auf die Parteifunktionäre angeschlagene Gangart wurde auch der allgemeinen Öffentlichkeit mit allen Mitteln publizistischer Suggestion das Horrorgebilde einer Verbrechergesellschaft präsentiert, die sich „unter dem Deckmantel der Religion“226 tarne und „,deren Staatsgefährlichkeit“, wie die SS-Zeitung „Das Schwarze Korps“ ihren Lesern erklärte, „der Laie gar nicht übersehen“ 227 könne. Für den „Westdeutschen Beobachter“, der unter der Überschrift „Die Ernsten Bibelforscher: Sendboten des jüdischen Bolschewismus“ eine bebilderte ganzseitige Reportage veröffentlichte, waren die Urheber der Bibelforscherlehre ,niederträchtige Verbrechernaturen“, die „rücksichtslos ausgemerzt werden“228 müßten. In Richtung auf die Zweifler und Zaudernden wurde hinzugefügt: „Die Verfolgung der ,Ernsten Bibelforscher" ist keine Verfolgung einer religiösen Gemeinschaft, keine Verhinderung ungestörter Religionsausübung, sondern der lebensnotwendige Kampf gegen einen gefährlichen Staats- und Menschheitsfeind." Für diesen Kampf bedienten sich die Nazi-Propagandisten des „Stürmer“-Stiles; im „Westdeutschen Beobachter" lautete beispielsweise die Bildunterschrift unter den dort abgebildeten Porträtsfotos von 15 Zeugen Jehovas: „Diese Anführerköpfe der ,Bibelforscher' illustrieren am besten das Bestreben dieser Gesellschaft, das Untermenschentum im Interesse des jüdischen Bolschewismus zu organisieren. So will man an die Stelle einer völkischen und sittlichen Weltordnung das Chaos einer Bastardrasse mit jüdischer

$\overline{224}$ BA, R 58/779, B1. 147, Schulungsmaterial „Das Sektenwesen“, S. 13.

225 Einige Presseartikel zu Bibelforscherprozessen sind veröffentlicht bei Zürcher, Kreuzzug, S. 95-110. Der Berichterstattung, in der durchgängig herausgestrichen wurde, daß die Zeugen Jehovas keineswegs ,harmlose, religiöse Fanatiker“ seien, ist deutlich das Bemühen anzumerken, derartigen Einschätzungen, die sich anscheinend in der Bevölkerung aller Propaganda zum Trotz hielten, entgegenzutreten. So urteilte der „Völkische Beobachter“ über die Zusammenkünfte der Bibelforscher: „In Wirklichkeit haben ihre ,Bibelstunden“ jedoch weder mit unserem Herrgott, noch mit der Seligkeit etwas zu tun, sondern nur mit einem raffiniert ausgestreuten Defaitismus.“ (VB, 4.3.1937, „Narren! ,Ernste Bibelforscher“ vor dem Gericht“)

226 VB, 16.1.1937 („Energische Maßnahmen gegen Staatsfeinde. Zwei Jahre Gefängnis für einen aufhetzenden Ernsten Bibelforscher").

227 Das Schwarze Korps, 11.2.1937, S. 14 („,Besuch beim Sondergericht: Die Kleinen läßt man laufen“).

228 P. E. Rings: Die Ernsten Bibelforscher: Sendboten des jüdischen Bolschewismus. Das nationale Denken ist für sie eine „Versündigung gegenüber Jehova“, in: Westdeutscher Beobachter, 21.8.1938. 
Spitze setzen." Doch eine derartige Sichtweise beherrschte nicht nur die Parteipresse. Auch im renommierten „Meyers Lexikon“ war zu lesen, die „besondere Gefahr“ der Internationalen Bibelforscher-Vereinigung liege darin, „daß sie sich mit ihren Phantastereien an rassisch, charakterlich $u$. geistig Minderwertige wendet und diese zur Sabotage an Volk und Staat aufruft" 229.

Um der öffentlichen Diffamierung der Zeugen Jehovas mehr Glaubwürdigkeit zu verleihen, wurde entsprechendes „Beweismaterial“ zitiert. So findet sich in zahlreichen Artikeln und Darstellungen ein Verweis auf einen am 5. September 1936 im Rahmen der Postüberwachung beschlagnahmten Brief aus Winnipeg in Kanada, der an die Wachtturm Bibel- und Traktat-Gesellschaft, Magdeburg, gerichtet war $^{230}$. Aus diesem ominösen Schreiben - laut Presseberichterstattung handelte es sich bei dem Absender um einen „,amerikanischen Bibelforscher“ namens Hope Slipachuk - wurde in der Regel die folgende Passage wiedergegeben: „Die gegenwärtigen üblen Regierungen sind nun zu Ende, und bald wird eine ehrliche, rechtmäßige Regierung errichtet werden zu Gunsten der Menschheit unter der Oberaufsicht des großen Messias, unseres Heiligen Vaters Joseph Stalin von Neu-Rußland - Union der Sowjetrepubliken."231 Dieser Brief galt nicht nur der NS-Presse als hinreichender Beleg dafür, daß von den Bibelforschern ,Stalin als der Stellvertreter Jehovas anerkannt" 232 werde, sondern er wurde auch - und dies wirft ein bezeichnendes Licht auf die Art der Rechtsfindung im ,Dritten Reich“ - in einem Berliner Sondergerichtsverfahren als Beweis zugelassen ${ }^{233}$.

Die Propagandisten konnten sich bei ihrer „Aufklärungsaktion“ auch auf sogenannte „wissenschaftliche Abhandlungen“ berufen ${ }^{234}$, so beispielsweise auf ein vom Herausgeber des antisemitischen „Welt-Dienstes“, Oberstleutnant a. D. Ulrich Fleischhauer, erstattetes „Sachverständigengutachten“, das jener 1935 dem Berner Gerichtshof vorlegte zur Frage der Echtheit der sogenannten „Protokolle der Weisen von Zion“ (erstmals 1901 in Rußland publizierte „Protokolle“ von „Geheimsit-

229 Meyers Lexikon, 6. Band, 8. Auflage 1939, Sp. 297f.

230 Vgl. Hamburger Tageblatt, 14.5.1938; weitere Nachweise bei Zürcher, Kreuzzug, S. 63-65.

231 IfZ, MA 554, 936279-87 (83), Denkschrift „Die Internationale Bibelforscher-Vereinigung“. Das Berner Zentraleuropäische Büro bezeichnete im März 1937 in einer in 68 Tageszeitungen der Schweiz veröffentlichten Erklärung Presseberichte über eine Verbindung der Zeugen Jehovas mit dem Kommunismus als „Nazilügen“: Ein solcher Satz über Stalin sei „mit der Lehre und dem Glauben der Bibelforscher völlig unvereinbar" (Zürcher, Kreuzzug, S. 64). Eine von der Brooklyner Watch Tower-Zentrale angeordnete Untersuchung der Briefangelegenheit ergab, daß aus dem kanadischen Winnipeg im August 1936 tatsächlich ein Brief an die Adresse des Magdeburger Zweigbüros abgesandt worden war, jedoch von einer Person, die mit den Zeugen Jehovas in keinerlei Verbindung stand. Für die Gestapo - so befand die Watch Tower-Zentrale - sei der Brief ein ,gesuchtes und willkommenes Mittel zu den schlimmsten Verfolgungen“ (ebenda, S. 65).

232 Hamburger Tageblatt, 13.4.1938 (,200 staatsfeindliche ,Bibelforscher ‘ gefaßt - Stalin als ,Jehovas Stellvertreter"“).

233 Vgl. Jonak, Bibelforscher, S. 69f.

234 Hier ist auch auf die Ausführungen über die IBV in dem seinerzeit als „wissenschaftlich“ deklarierten „Handbuch der Judenfrage“ zu verweisen (vgl. Fritsch, Handbuch der Judenfrage [1933], S. 264ff.), das im „Dritten Reich“ eine Auflage von über eine Viertelmillion Exemplaren erreichte. In der nach dem Tode (1933) des Verfassers Theodor Fritsch erfolgten Neubearbeitung wurde nachdrücklich begrüßt, daß , im Kampf gegen die Seelenverjudung [...] auch der eine Weltherrschaft des , auserwählten` Volkes predigende ,Bund Ernster Bibelforscher" verboten" worden sei (zitiert nach der 49. Auflage, Leipzig 1943, S. 543). 
zungen" eines die Weltbeherrschung anstrebenden ,jüdischen Ältestenrates“) 235 . Der elfte Abschnitt des 400seitigen Gutachtens, der mit der Überschrift „Die Echtheit der Protokolle bewiesen durch das Weltherrschaftsprogramm der ,Internationalen Vereinigung Ernster Bibelforscher" " 236 versehen war, galt der Offenlegung der von den Bibelforschern angeblich betriebenen „Pläne“, da sich in ihnen die „wahren Absichten“ des Judentums zeigten: „Noch nie bisher ist mit solcher Deutlichkeit der Weltherrschaftsplan des auserwählten Volkes enthüllt worden: Entnationalisierung aller Völker, Beseitigung aller Staaten, Aufteilung aller Völker auf zwölf Verwaltungsgebiete nach dem Muster der zwölf israelitischen Stämme und deren Verwaltung durch eine 100prozentig jüdische Regierung ist das Programm der Ernsten Bibelforscher, das sie unter Berufung auf die den Juden gegebenen göttlichen Weissagungen und unter dem Vorwande, die verdorbene Christenheit retten zu wollen, vertreten." 237 Für Fleischhauer waren die Zeugen Jehovas nichts anderes als eine Kampforganisation „,im Dienste Judas“, die sich lediglich äußerlich als christliche Gemeinschaft getarnt habe.

Große Bedeutung im nationalsozialistischen „Abwehrkampf“ gegen die Zeugen Jehovas erlangte ein 1936 verfaßtes Werk des Wiener Antisemiten Dr. Hans Jonak von Freyenwald, der von der Gestapo als ,ausgezeichneter Kenner der Bibelforscherfrage“ 238 geschätzt wurde. In seiner Schrift über die ,Zeugen Jehovas“, die den Untertitel „Pioniere für ein jüdisches Weltreich“ trug und mit „Imprimatur“ der katholischen Kirche erschien, hatte dieser „Experte“ die Diffamierungstechniken vorexerziert: Zitate aus Bibelforscherschriften wurden aus dem Zusammenhang gerissen, die Begriffe umgedeutet und sich auf obskure Briefe irgendwelcher ,amerikanischer Freimaurer" berufen, die die Lenkung der Bibelforscher durch „das Judentum“ beweisen würden. Wortreich interpretierte Jonak von Freyenwald die Prophezeiung des Weltenendes durch die Zeugen Jehovas als einen Aufruf zum völligen Umsturz der ,sozialen Ordnung der Dinge“ und damit zur Weltrevolution: „Vernichtung der Regierungen aller Länder ist somit das Programm der Ernsten Bibelforscher, und ein solches Programm nennt man ein politisches. Daran wird auch nichts geändert, daß Rutherford das von ihm aufgestellte Programm unter krasser Verfälschung biblischer Texte als ein gottgewolltes hinzustellen und damit

235 Das Gerichtsverfahren war von dem Schweizerischen Israelitischen Gemeindebund angestrengt worden, nachdem in Bern antisemitische Schmähschriften in großer Zahl vertrieben worden waren. Die Berner Richter schlossen sich im Mai 1935 vollständig denjenigen Gutachtern an, die die Echtheit der Protokolle bestritten. Danach handelte es sich bei den Protokollen, deren Inhalt vom Gericht als „lächerlicher Unsinn“ charakterisiert wurde, um eine höchstwahrscheinlich um die Jahrhundertwende von russischen Geheimpolizeikreisen angefertigte Fälschung, die den Beweis eines ,jüdischen Komplottes“ erbringen sollte, um den Judenhaß zu steigern.

236 Fleischhauer befand, daß sich „, auch an Hand der Bibelforscherschriften“ der Nachweis führen lasse, „daß die Protokolle keine Fälschung, daß sie keine den Juden unterschobene Kampfschrift sind, sondern daß sie aus der gleichen Gedankenwelt geboren wurden, die die Bibelforscherlehre beseelt" (Fleischhauer, Protokolle, S. 119). Fleischhauer wurde im Zuge einer Gegenklage vom „Zentraleuropäischen Büro" der Zeugen Jehovas wegen falscher Begutachtung und wegen Ehrverletzung angezeigt. Zu einem Prozeß kam es nicht, da der Beklagte sich dem Verfahren in der Schweiz nicht stellte. Vgl. Zürcher, Kreuzzug, S. 68.

237 Fleischhauer, Protokolle, S. 117.

238 IfZ, MA 554, 936279-87 (83), Denkschrift „Die Internationale Bibelforscher-Vereinigung“, als Anlage zum RdS der Staatspolizeileitstelle München vom 24.12.1936. 
die Verantwortung für diese umstürzlerischen Ideen von sich auf Jehova zu überwälzen versucht. Leute mit solchen Plänen gehören, je nachdem man ihren Geisteszustand beurteilt, entweder wegen religiösen Wahnsinns in eine Irrenanstalt oder als Hetzer gegen Staat und Kirche in eine Strafanstalt.“239 Auch auf die Judikatur hatte die Schrift von Jonak von Freyenwald Einfluß; in den Urteilsschriften der Sondergerichte wurde sie zur Darstellung und Bewertung der Bibelforscherlehre oftmals herangezogen 240 .

\section{Umstrittene Urteile und Gerichte}

Doch es blieb nicht bei dieser flankierenden Maßnahme einer „Aufklärungskampagne", die allgemein die Verfolgungsmotivation erhöhen sollte. Die Gestapo versuchte auch direkt auf die Rechtsprechung in Strafsachen gegen Bibelforscher einzuwirken. Ein Mittel dazu war die Herausstellung als beispielhaft geltender Urteile. So gab die Bayerische Politische Polizei mit Rundschreiben vom 17. Dezember 1935 den Polizeidirektionen, Staatspolizeistellen und Bezirksämtern den Abdruck eines Urteiles des thüringischen Sondergerichtes vom 27. August 1935 zur Kenntnis, wobei die darin enthaltenen Ausführungen der Weimarer Richter als ,in allen Punkten zutreffend" bezeichnet wurden. Gleichzeitig ordnete die Bayerische Politische Polizei an, ,mit den örtlichen Staatsanwaltschaften Fühlung zu nehmen und darauf hinzuwirken, daß auch diese den Standpunkt des Sondergerichts in Weimar einnehmen"241. Am 1. April 1936 übersandte der Politische Polizeikommandeur der Länder an die ihm unterstellten Staatspolizeistellen der außerpreußischen Länder eine vervielfältigte Urteilsschrift des gleichen Sondergerichtes vom 24. Januar des Jahres. Auch dieses Mal sollten, wie anläßlich der zuvor ergangenen Rundverfügung der Bayerischen Politischen Polizei, die Polizeibehörden bei den Staatsanwaltschaften vorstellig werden, um diese zur Einnahme des ,gleichen Standpunktes“ zu veranlassen ${ }^{242}$. In dem betreffenden Urteil des Weimarer Sondergerichtes war die Notwendigkeit zu „strengen Strafen“ sowohl im Blick auf die „Täter“ betont worden, als auch zur Warnung jener, , die Gefahr laufen, den Lehren

$\overline{239}$ Jonak von Freyenwald, Zeugen Jehovas, S. 96. Vgl. auch die Ausführungen über die IBV in dem fünf Jahre später erschienenen Werk des gleichen Autors „Jüdische Bekenntnisse aus allen Zeiten und Ländern“, S. 250ff. Unter dem Namen Dr. Hans von Jonak veröffentlichte derselbe im März 1937 einen Beitrag in dem in Wien herausgegebenen Korrespondenzblatt für den katholischen Klerus Österreichs, in dem er seine Thesen auch für das katholische Publikum des Nachbarlandes aufbereitete. Vgl. Jonak, Bibelforscher, S. 69f.

240 Als Beispiel sei die Urteilsschrift des Hanseatischen Sondergerichts in dem Verfahren vom 11.4.1938 gegen die Gruppe „Hamburg I“ mit dem Hauptgruppendiener Grote als Hauptangeklagten genannt. In einer achtseitigen Darlegung der Bibelforscherlehre erscheint dort der Name Jonak von Freyenwald nicht weniger als sechsmal. Vgl. SLG HH, HSG 11 Js. Sond. $173 / 38$.

241 IfZ, Fa 119/2, Bl. 204, BPP, RdS vom 17.12.1935. In dem betreffenden Urteil des Weimarer Sondergerichts, das in einer in Zella-Mehlis gegen sieben Zeugen Jehovas geführten Verhandlung ergangen war, hatte dieses die Rechtsgültigkeit des IBV-Verbotes uneingeschränkt bejaht und zu Strafen zwischen drei Monaten und zwei Jahren Gefängnis verurteilt (IfZ, Fa 119/2, Bl. 186-193, SG Weimar, So. G. 40/35, Urteil vom 27.8.1935).

242 BA, R 58/405, B1. 24, Der Politische Polizeikommandeur der Länder, RdS vom 1.4.1936. 
der Internationalen Bibelforscher-Vereinigung sich zuzuneigen“243. Die Folgerung des Gerichtes, daß aus diesem Grunde in Bibelforscherverfahren „Abschreckungszweck und Abschreckungswirkung der Strafe [...] bei der Strafzumessung in den Vordergrund treten" müssen, wird ebenso zu der Herausstellung des Urteiles durch die Gestapo beigetragen haben wie die Feststellung der Richter, daß im nationalsozialistischen Staat allein der Wille des „Führers“ gelte und dieser es nicht wolle, „daß sein Ziel durchkreuzt wird, auch nicht von der Internationalen BibelforscherVereinigung“.

Das Geheime Staatspolizeiamt beklagte sich mehrfach beim Reichsjustizministerium über die Nachsicht vieler Gerichte in Bibelforscherverfahren und drängte auf Strafverschärfung. Auch im Ministerium herrschte über die Rechtsprechung auf „dem Gebiete der Bekämpfung der Bibelforscher“ offensichtlich Unzufriedenheit. In einer am 23. September 1935 geführten Besprechung mit dem Oberreichsanwalt und den Generalstaatsanwälten klagte das Ministerium vor allem über die ,auffälligen Unterschiede im Strafmaß“244. Für Straftaten gleicher Art und Schwere seien von den Gerichten Strafen „von ganz verschiedener Höhe“ ausgesprochen worden. Nach einer den Generalstaatsanwälten präsentierten Gegenüberstellung der Strafzumessungspraxis von drei verschiedenen Gerichten schwankte das durchschnittlich verhängte Strafmaß gegen die „Leiter“ der IBV zwischen 4 3/4 Monaten und 3 Jahren 3 Monaten Gefängnis. Während ein Gericht gegen ,Mitläufer“ zumeist auf Geldstrafe zwischen 150 bis 300 RM erkenne und überhaupt ,nur“, wie beklagt wurde, zu 23 Prozent Freiheitsstrafen aussprechen würde, die sich auf durchschnittlich $23 / 4$ Monate erstreckten, verurteilten die beiden anderen Gerichte ausschließlich zu Freiheitsstrafen (davon das eine im Durchschnitt zu 4 1/4, das andere zu 15 Monaten) ${ }^{245}$. Da die Strafen in der Regel weitgehend den Anträgen der Staatsanwaltschaft entsprochen hätten, trug das Ministerium den obersten Anklagevertretern auf, ihren Einfluß auf die ihnen unterstellten Staatsanwaltschaften entsprechend geltend zu machen. Diese müßten künftig durch „,Kontrolle der Straf-

$\overline{243}$ BA, R 58/405, Bl. 25-38 (32), SG Weimar, So. G. 4/36, Urteil vom 24.1.1936; das Urteil ist mit unwesentlichen Kürzungen veröffentlicht bei Zipfel, Kirchenkampf, S. 352-358.

244 BA, R 22/4277, Bl. 128f., Protokoll der Besprechung mit dem Oberreichsanwalt und den Generalstaatsanwälten im RJM am 23.9.1935. Vgl. auch Angermund, Richterschaft, S. 153.

245 Die vom RJM genannten Zahlen über die Durchschnittsstrafen in Bibelforscherverfahren vermitteln insgesamt gesehen ein verzerttes Bild. Die Rechtsprechung an dem Gericht, das die höchsten Strafmaße verhängte (durchschnittlich 15 Monate, Funktionäre bis 3 Jahre 3 Monate), ist - bezogen auf den Zeitpunkt Mitte 1935 - als gänzlich atypisch zu bezeichnen; das Beispiel wurde offensichtlich gewählt, um die Erwartungen des Ministeriums zum Ausdruck zu bringen. Nach der Gestapa-Denkschrift über die IBV aus dem Jahre 1936 lagen die Strafen hingegen im allgemeinen „,selbst bei Funktionären nur im Rahmen von 4-8 Monaten Gefängnis"; lediglich bei „,vereinzelten, besonders schwer gelagerten Fällen" seien Gefängnisstrafen von 1 bis 2 Jahren verhängt worden (IfZ, MA 554, 936286). Wenn auch bei der Gestapa ein Interesse bestanden haben mag, die Angaben möglichst niedrig anzusetzen, um die Justiz ihrer Versäumnisse wegen schelten zu können, kommen die Gestapa-Zahlen gleichwohl der Realität näher. So wurden im Jahre 1935 gegen Hamburger Zeugen Jehovas vor dem Hanseatischen SG durchschnittlich 3,1 Monate Gefängnis verhängt; beim Altonaer SG lautet der entsprechende Wert 2,2 Monate (siehe S. 281). Das SG München verhängte 1935 in Bibelforscherverfahren eine Durchschnittsstrafhöhe von 4 Monaten Gefängnis (vgl. Kalous, Bibelforscher, S. 35 und Anhang 4). 
anträge“ darauf hinwirken, „daß solche untragbaren Unterschiede ausgeglichen werden".

Wurde bei der Besprechung im September 1935 das Verlangen nach einer härteren Strafverfolgung von Zeugen Jehovas noch nicht explizit zum Ausdruck gebracht, sondern das Erfordernis einer einheitlicheren Rechtsprechung in den Vordergrund gerückt, so wurde im folgenden die Weisungsgebundenheit der Staatsanwaltschaften offen benutzt, um in Strafsachen gegen Zeugen Jehovas die gewünschten höheren Urteile zu erreichen. Am 5. Dezember 1936 richtete das Reichsjustizministerium an die Staatsanwaltschaften eine Verfügung, in der betont wurde, daß von den Sondergerichten gegen die Bibelforscher ,mit den schärfsten Mitteln vorgegangen werden muß“ 246 . Geldstrafen seien grundsätzlich, auch bei bloßer Mitgliedschaft, angesichts des „staatsgefährlichen“ Charakters der Bibelforschervereinigung nicht angemessen. Bei Funktionären solle „der durch das $\mathrm{Ge}$ setz zugelassene Strafrahmen voll ausgenutzt“ werden ${ }^{247}$. Um die Notwendigkeit härterer juristischer Zwangsmittel zu unterstreichen, ließ das Reichsjustizministerium den Staatsanwaltschaften zugleich die im Geheimen Staatspolizeiamt im Herbst 1936 erstellte Denkschrift über die illegale Betätigung der Internationalen Bibelforscher-Vereinigung zur vertraulichen Kenntnisnahme zukommen ${ }^{248}$. Ein Vierteljahr später, am 2. März 1937, sah das Ministerium sich veranlaßt, bei den Anklagebehörden die Verfügung vom Dezember 1936 in Erinnerung zu rufen, weil „einige Gerichte sich noch nicht haben entschließen können, mit der nötigen Strenge vorzugehen" 249 . Bei diesen massiven Einwirkungsversuchen handelte es sich um mehr als die Wahrnehmung des ministeriellen Weisungsrechtes gegenüber den Staatsanwaltschaften; es handelte sich um den Versuch, den Rechtsprechungsorganen das Strafmaß zu diktieren und damit die - laut Verfahrensrecht auch im „Dritten Reich“ gewahrte - Unabhängigkeit der Gerichte zu beschneiden.

Als ein besonders markantes Beispiel für das von einigen Gerichten in Strafverfahren gegen Zeugen Jehovas gezeigte „Widerstreben“ kann die Rechtsprechung am Altonaer Sondergericht gelten, das sich in Verfahren gegen andere „Staats-

246 RJM, RdV vom 5.12.1936, zit. nach Johe, Justiz, S. 122.

247 Nach § 4 der VOSchVuS vom 28.2.1933 waren Zuwiderhandlungen mit Geldstrafe oder Gefängnis zu bestrafen, d. h. der Strafrahmen bewegte sich zwischen der Mindeststrafe von $150 \mathrm{RM}$ und der Gefängnishöchststrafe von fünf Jahren.

248 Auch andere, in den folgenden Jahren vorgetragene Appelle von höheren Justizvertretern lassen erkennen, daß diese einen ,Aufklärungsbedarf" bei den Gerichten als gegeben ansahen. So belehrte im September 1938 der Berliner Landgerichtsdirektor Burczek in einer in der ,Juristischen Wochenschrift" erschienenen Abhandlung die Fachöffentlichkeit über den - so Burczek - oft verkannten „staatsgefährlichen“ Charakter der Bibelforscher. Wenn sie auch um ihrer „vermeintlichen Ideale willen handeln“, so gelte es nichtsdestoweniger, ihnen mit Entschlossenheit entgegenzutreten: „Hier darf kein Mitgefühl abhalten [...] Auch die sonst tadelfrei lebende alte Frau, die als Mitglied der IBV angehört, vergeht sich schwer gegen Volk und Staat, weil sie durch ihre Teilnahme an der Vereinigung überhaupt mit die Möglichkeit setzt, daß die Vereinigung ihr Leben im Staate zu dessen Schaden fortführen kann. Diese Tatsache wird noch in weiten Kreisen verkannt, ist aber von ausschlaggebender Bedeutung für die Würdigung anscheinend harmlosen, in Wirklichkeit staatsgefährlichen Tuns in staatspolitischer und strafrechtlicher Hinsicht." (Burczek, Staatsbürgerpflichten, S. 2378; vgl. auch die ähnliche Argumentation bei Crohne, Strafrechtspflege, S. 9, und bei Freisler, Strafrechtspflege, S. 367)

RJM, RdV vom 2.3.1937, zit. nach Johe, Justiz, S. 122. 
feinde“ keineswegs durch „Milde“ auszeichnete ${ }^{250}$. Obgleich dieses für den Oberlandesgerichtsbezirk Kiel zuständige Gericht infolge der freisprechenden Entscheidung vom 3. April 1935, die sich auf die Formfehler des preußischen IBVVerbots und damit auf dessen Rechtsunwirksamkeit berief, von der Gestapo und dem Reichsjustizministerium heftigst gerügt worden war ${ }^{251}$, ließen die Altonaer Richter in Bibelforscherverfahren auch in der Folgezeit keine den Berliner Vorstellungen entsprechende ,geläuterte Urteilspraxis“ erkennen ${ }^{252}$. Zwar wurde nach den Richterschelten und Stellungnahmen der vorgesetzten Stellen auch beim Schleswig-Holsteinischen Sondergericht die Gültigkeit des IBV-Verbotes und die damit gegebene Strafbarkeit der Betätigung als Bibelforscher nicht mehr in Frage gestellt, doch im Strafausspruch zeigte das Gericht in der Regel eine vergleichsweise große Zurückhaltung ${ }^{253}$. In der für den betreffenden Regierungsbezirk Schleswig zuständigen Kieler Staatspolizeistelle registrierte man dies mit deutlichem Unmut. So klagte diese Stelle im Lagebericht über den Monat Januar 1936 erneut: „In den letzten Wochen wurden wiederum verschiedene Prozesse gegen Bibelforscher durchgeführt, wobei jedoch die erkannten Strafen in keinem Verhältnis zu dem unheilvollen und die Wehrkraft des Volkes schädigenden Treiben dieser kommunistisch verseuchten Fanatiker standen. “254

Beispielsweise hatte das Altonaer Sondergericht in einer am 11. November 1935 geführten Verhandlung die Leiter der IBV-Ortsgruppen Wandsbek und Bad Oldesloe zu relativ geringen Haftstrafen von ein und zwei Monaten Gefängnis verurteilt ${ }^{255}$. Gegen „Mitläufer“ wurden in der Regel nach wie vor Geldstrafen verhängt ${ }^{256}$; nicht selten ergingen „mangels Beweises“ Freisprüche ${ }^{257}$. Teilweise

250 In dem Prozeß um die Geschehnisse des sogenannten „Altonaer Blutsonntags“ hatte das SG Altona am 2.6.1933 die ersten politischen Todesurteile im „Dritten Reich" verhängt. Die Richter schickten vier Kommunisten wegen Beihilfe zum Mord aufs Schafott, obgleich ein konkreter Schuldnachweis nicht erbracht worden war. Vgl. Meyer, Nacht über Hamburg, S. $34 \mathrm{ff}$.

251 Siehe S. $150 \mathrm{f}$.

252 Weitere Belege für eine widerstrebene Urteilspraxis des Altonaer Sondergerichtes in Bibelforscherverfahren nennen Imberger, Widerstand, S. 292f.; Möller, Steinburg, S. 214, 224f. Möller hat darauf aufmerksam gemacht, daß sich das Sondergericht zur Begründung der relativ kurzen Haftstrafen bei ersten Verurteilungen einer festen Argumentationsfigur bediente. Dabei wurde herausgestellt, da $B$ dem betreffenden Angeklagten der , staatsgefährdende Charakter" der IBV , nicht voll zum Bewußtsein gekommen" sei, vielmehr sei er in seiner Einstellung zum Staat ,in mißverständlicher, vom Ausland her gepredigter Auslegung des Bibelwortes ,man müsse Gott mehr gehorchen als den Menschen' [...] irregeleitet worden".

253 In späterer Zeit bzw. nach Verlegung des Sitzes des Schleswig-Holsteinischen Sondergerichtes im Frühjahr 1937 nach Kiel paßte sich die Strafzumessungspraxis des Gerichtes nicht nur dem allgemeinen Reichstrend an, sondern scheint diesen sogar noch überboten zu haben. Klaus Bästlein berichtet davon, daß dieses in Verfahren gegen Bibelforscher ,außergewöhnlich hohe Freiheitsstrafen von bis zu vier Jahren verhängt" habe (Bästlein, Sondergericht Kiel, S. 166).

254 BA, R 58/570, Bl. 47-54 (54), Staatspolizeistelle für den Regierungsbezirk Schleswig in Kiel, Allgemeine Übersicht über die politische Lage im Monat Januar 1936.

255 Vgl. LA SH, Abt. 352 Altona Nr. 8928, SH SG, 11 Son KMs 70/35, Urteil vom 11.11. 1935.

256 Das Schleswig-Holsteinische Sondergericht (11 Son KMs 3/37) verurteilte noch im Frühjahr 1937 einen Zeugen Jehovas aus Wewelsfleth, dem vorgeworfen wurde, auswärtige Bibelforscher in seiner Wohnung empfangen und Kontakte zu Glaubensbrüdern in Wilster unterhalten zu haben, , nur' zu einer geringfügigen Geldstrafe von 300 RM, obwohl eine vom Gericht 
blieb das ausgesprochene Strafmaß in Bibelforscherverfahren vor dem SchleswigHolsteinischen Sondergericht deutlich unter der von der Staatsanwaltschaft beantragten Höhe ${ }^{258}$. Während in Prozessen gegen Hamburger Zeugen Jehovas vor dem Hanseatischen Sondergericht im Jahre 1935 die Durchschnittsstrafhöhe 3,1 Monate und im Jahre 1936 schon 10 Monate Gefängnis betrug, fanden die IBV-Angehörigen aus den preußischen Nachbarstädten Altona und Wandsbek beim drei Kilometer entfernten Altonaer Gericht mildere Richter. Dort betrugen die entsprechenden Durchschnittswerte 2,2 Monate (1935) und 2,5 Monate (1936) 259 .

Als am 3. September 1936 das Schleswig-Holsteinische Sondergericht gegen neun Angehörige der IBV-Gruppe Altona verhandelte, wurden von seiten eines Angeklagten die Vernehmungsmethoden der Gestapo offen kritisiert. Ein Bibelforscher erklärte, der Kriminalangestellte Willy T., der als Zeuge der Verhandlung beiwohnte, habe ihn beim Verhör stark unter Druck gesetzt und mit einem Stock malträtiert ${ }^{260}$. Der betreffende 23jährige Sachbearbeiter der Außendienststelle der Kieler Gestapo in Altona bestritt dies auf die Nachfrage des Gerichts hin rundum. Das Gericht selbst bemängelte zwar die Oberflächlichkeit der im Ermittlungsverfahren gefertigten polizeilichen Protokolle und bezweifelte in zwei Fällen auch deren Zuverlässigkeit - was einen Freispruch und gegenüber einem weiteren Beschuldigten eine Verfahrenseinstellung zur Folge hatte -, aber den Mut, den Gestapo-Ermittler wegen der offenkundig unter Drohungen und Zwang zustandegekommenen Geständnisse zur Rede zu stellen, fand es dennoch nicht. Allerdings wurde im Urteil ausdrücklich festgehalten, daß der Kriminalangestellte als Zeuge zu seiner Aussage vereidigt wurde.

Drei Wochen später, am 24. September, verhandelte die Kammer des Schleswig-Holsteinischen Sondergerichtes unter Vorsitz des Landgerichtsdirektors Dr. Gohlke-Kasten mit Ausnahme eines Beisitzers in der gleichen Besetzung abermals in einer Bibelforscherangelegenheit. Vor der Richterbank standen dieses Mal sechs Angeklagte, die zur IBV-Zelle Altona-Stellingen gehörten und denen die Teilnahme an „verbotenen Zusammenkünften“ vorgeworfen wurde. Es schien ein ganz normaler Bibelforscherprozeß zu werden. Im Abschlußbericht der Gestapo war das Urteil präjudiziert; nach den dortigen Feststellungen handelte es sich samt und sonders um „fanatische“ und „unbelehrbare“ Anhänger der Ernsten Bibelforscher,

eingeholte Beurteilung des Wewelsflether Amtsvorstehers den Beschuldigten als unbeugsamen NS-Gegner auswies. Vgl. Möller, Steinburg, S. 214.

257 Vgl. beispielsweise SLG HH, SH SG 11 Son KMs 19/37; dieses Verfahren richtete sich unter anderem wegen Teilnahme an der Flugblattaktion vom 12.12.1936 (Verbreitung der Luzerner „Resolution“) gegen acht Angehörige der IBV-Gruppe Flensburg, von denen drei mit Urteil vom 27.2.1937 freigesprochen wurden.

$258 \mathrm{Vgl}$. beispielsweise SLG HH, SH SG 11 Son KMs 149/36. In diesem gegen fünf Angehörige der IBV-Gruppe Itzehoe geführten Verfahren verhängte das Gericht in vier Fällen jeweils ,nur' eine Strafe in halber Höhe des staatsanwaltschaftlichen Antrages.

259 Die Geldstrafen wurden analog zur jeweils verfügten Ersatzhaftstrafe umgerechnet (fünf Reichsmark, ein Tag Haft); Freisprüche wurden miteinbezogen, während Verfahrenseinstellungen unberücksichtigt blieben. Die Angaben beziehen sich auf die Verfahren gegen Hamburger Zeugen Jehovas (IBV-Hauptgruppen Altona und Hamburg).

260 Vgl. LA SH, Abt. 352 Altona Nr. 9194, Bl. 70-79, SH SG, 11 Son KM 130/36, Urteil vom 3.9.1936; SLG HH, SH SG 11 Son KMs 139/36, Handakten, o. B1., Einvernahmeprotokoll des Willy $\mathrm{T}$. vom 14.10 .1936$. 
bei denen „eine exemplarische Strafe angebracht“ sei261. Doch das Verfahren verlief anders, als es der Gestapo-Ermittler, auch dieses Mal der Altonaer Kriminalangestellte Willy $T$., offensichtlich vorgedacht hatte.

Die Angeklagten äußerten während der Verhandlung, daß die bei der Gestapo abgefaßten Vernehmungsprotokolle nicht der Wahrheit entsprächen, da sie zu ihren Geständnissen gezwungen worden seien. Die 36jährige Angeklagte Annemarie B. erklärte den Richtern, wie ihre Unterschrift unter die von dem vernehmenden Gestapo-Mitarbeiter formulierte Aussage gekommen sei. Dieser habe ihr nämlich, wie die Urteilsschrift vermerkt, ,in Aussicht gestellt, daß er sie schlagen würde und daß er mit ihr in den Keller gehen würde. [...] Dort müßte sie sich nackend ausziehen und würde verprügelt; wenn sie dann dicke Striemen hätte, dürfte sie sich beschweren.“262 Ihr Mann gab an, jener Gestapo-Mann habe ihm ebenfalls Prügel angedroht und hinzugefügt, wenn er das Vernehmungsprotokoll nicht unterschreibe, dann könne er mit dem bereitstehenden Spaten gleich anfangen, sein eigenes Grab zu schaufeln.

Auf diese Angaben hin nahmen die Richter den als Zeugen geladenen Kriminalangestellten ins Verhör. Zuerst leugnete Willy T. alles, doch auf die Frage, ob er das beschwören könne, erklärte er, ,er könne sich nicht mehr so genau erinnern. Auf weiteren Vorhalt räumt er ein, daß wohl die Möglichkeit bestände, daß er etwas derartiges gesagt habe.“ Unter diesen Umständen erklärte das Gericht sich außerstande, die im Ermittlungsverfahren erhobenen Bekundungen „zur Grundlage seiner tatsächlichen Feststellungen zu machen“, und sprach alle sechs Angeklagten „mangels ausreichender Beweise" frei.

Auch persönliche Beweggründe hatten den 23jährigen Gestapo-Mann in diesem Verfahren zu großem Verfolgungseifer getrieben ${ }^{263}$. Die Mehrzahl der Mitglieder der IBV-Zelle Stellingen war ihm, der ebenfalls in diesem Stadtteil wohnte, aus der Nachbarschaft bereits zuvor bekannt; so war er mit einem 35jährigen Postboten, zu dessen Zustellbezirk seine Wohnung gehörte, bei der Überbringung eines Wechsels kräftig aneinandergeraten. Da Willy T. in dem Postbeamten den Verantwortlichen für ihm aufgebürdete Gebühren sah, gab er ihm zu verstehen, daß er es schon heimzuzahlen wisse. Vor diesem Hintergrund wird verständlich, warum die Richter in diesem ansonsten keineswegs außergewöhnlichen Fall eine Gelegenheit sahen, nun ihrerseits einmal gegenüber der Staatspolizeistelle Stärke zu beweisen. Der Vorwurf der Amtspflichtverletzung konnte sich in diesem Fall nicht allein auf die

261 LA SH, Abt. 352 Altona Nr. 9201, Bl. 59, Geheime Staatspolizei, Außendienststelle Altona, Abschlußbericht vom 21.9.1936.

262 LA SH, Abt. 352 Altona Nr. 9201, Bl. 65-71 (70), SH SG, 11 Son KMs 138/36, Urteil vom 24.9.1936; die folgenden Zitate ebenda. Nach den im Antrag auf Ausstellung eines Verfolgtenausweises niedergelegten Angaben eines Betroffenen, der im Zusammenhang mit diesem Verfahren vom 28.8.1936 bis 24.9.1936 inhaftiert worden war, ist es nicht - wie die Urteilsschrift vermuten läßt - bei Drohungen geblieben. Der Zeuge Jehovas gibt an, daß er von dem Gestapo-Mann T. im Verhör mißhandelt worden ist. Vgl. VVN HH, Komiteeakten M 20, Paul M., Antrag vom 18.3.1946.

263 Der Kriminalangestellte verdankte seine Stellung einer für Gestapo-Beamte dieses Ranges typischen Parteikarriere. Als Siebzehnjähriger war er 1930 zur SA gestoßen; am 1.10.1931 folgte der Eintritt in die NSDAP und im folgenden Jahr in die SS. Dies waren die Voraussetzungen, die ihn am 20.4.1933 zum Hilfspolizisten werden ließen und ihn für seine spätere Übernahme in den regulären Polizeidienst qualifizierten. 
Anwendung von Gewalt zur Erzwingung von Geständnissen berufen, sondern auch auf den Mißbrauch amtlicher Befugnisse für persönliche Zwecke sowie auf die niedrigen Rachegelüste eines heißspornigen Gestapo-Vertreters. So beließ man es nicht bei dem Freispruch für alle sechs Angeklagten, sondern verfügte noch am gleichen und am darauffolgenden Tag einige Maßnahmen, die bei der Kieler Gestapo-Spitze zu heller Empörung führten.

Nachdem durch die Gerichtsverhandlung vom 24. September der Verdacht entstanden war, daß die durch den zuständigen Gestapo-Sachbearbeiter vorgenommenen Ermittlungen ,unter Anwendung unzulässiger Mittel“ erfolgten, ordnete die Staatsanwaltschaft auch die Überprüfung weiterer beim Gericht anhängiger Bibelforscherverfahren an. Um zu gerichtsverwertbaren Beweisen zu gelangen, wurde veranlaßt, daß alle Angeschuldigten im Zuge der „Nachprüfung“ durch einen vom Sondergericht beauftragten Richter erneut vernommen wurden ${ }^{264}$. In einem Verfahren gegen sechs Angehörige der IBV-Zelle Wandsbek, für das der Termin zur Hauptverhandlung auf den 1. Oktober anberaumt war, wurde am 25. September die Entlassung der in Haft sitzenden Angeklagten veranlaßt und der Prozeßtermin aufgehoben ${ }^{265}$. Ebenfalls am Tag nach der Gerichtsentscheidung wurde der Leiter der IBV-Gruppe Itzehoe, gegen den in einem anderen Verfahren ermittelt wurde, aus der Untersuchungshaft entlassen.

Der letztgenannte Vorgang erzürnte die Kieler Staatspolizeistelle besonders. Ende Oktober legte sie förmlich Beschwerde beim Kieler Generalstaatsanwalt dagegen ein, daß vom Altonaer Sondergericht die Aufhebung des Haftbefehles verfügt worden war, ohne daß die Gestapo über die Entlassung des 29jährigen Itzehoer IBV-Funktionärs vom Gericht in Kenntnis gesetzt wurde. In dem Beschwerdebrief forderte die Kieler Gestapo den Generalstaatsanwalt auf, „darauf hinzuwirken, daß der Staatspolizeistelle von der Aufhebung von Haftbefehlen gegen Bibelforscher rechtzeitig Mitteilung gemacht wird"266.

Gleichzeitig richtete die Kieler Staatspolizeistelle an die Adresse des Oberstaatsanwalts beim Sondergericht in Altona eine umfassendere Protestnote, in der vorgebracht wurde, ,daß die Art der Vernehmung des Krim. Angestellten T. und die Urteilsbegründung seitens des Sondergerichts zu erheblichen Bedenken Anlaß geben. Das angewandte Verfahren ist geeignet, das Ansehen einer Staatsbehörde in der Öffentlichkeit herabzusetzen. [...] Ich werde aus diesen Gründen pflichtgemäß in dieser Angelegenheit weitere Schritte unternehmen müssen.“267

Diese „weiteren Schritte“ führten zu einer Beschwerde des Geheimen Staatspolizeiamtes beim Reichsjustizministerium und zu einem Schriftwechsel zwischen dem Ministerium und dem Reichsführer-SS, in dem - so die Feststellung in einem

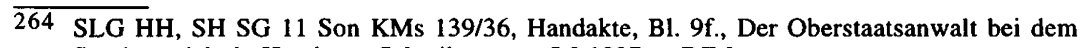
Sondergericht in Hamburg, Schreiben vom 5.8.1937 an RJM.

265 SLG HH, SH SG 11 Son KMs 139/36, danach verbunden mit HSG 11 Js. Sond. 298/38.

266 SLG HH, SH SG 11 Son KMs 149/36, Handakte, B1. 25, Staatspolizeistelle Kiel, Schreiben vom 22.10.1936 an den Kieler Generalstaatsanwalt.

267 LA SH, Abt. 352 Altona Nr. 9201, Handakte, Bl. 1f., Staatspolizeistelle Kiel, Schreiben vom 15.10 .1936 . 
Bericht des Hanseatischen Oberlandesgerichtes - „der RFSS das Verhalten des Gerichts kritisieren zu müssen glaubte" 268 .

Noch in einer anderen Beziehung führte die Altonaer Gerichtsentscheidung zu Erörterungen auf höheren Ebenen. Gegen den Kriminalangestellten war von seiten der Staatsanwaltschaft beim Landgericht Altona ein Ermittlungsverfahren ,wegen Verbrechens gegen $\S 343$ StGB“" (Aussageerpressung) eingeleitet worden ${ }^{269}$. Aufgrund der schwerwiegenden Vorwürfe und des Verdachtes des Amtsmißbrauches für persönliche Zwecke sah sich selbst die Kieler Staatspolizeistelle im Handlungszwang; im Oktober wurde der Gestapo-Mann ,einstweilen von seinen Dienstgeschäften entbunden“. Nachdem das staatsanwaltschaftliche Ermittlungsverfahren - vermutlich nach entsprechenden Interventionen - ein Vierteljahr danach sangund klanglos eingestellt worden war, konnte Mitte Januar 1937 der Altonaer Kriminalangesellte Willy T. erneut seinen Dienst antreten, allerdings hielt man es jetzt für angebracht, ihn zur Staatspolizeistelle Kiel zu versetzen.

Die auch bei anderen Staatsanwaltschaften im Zusammenhang mit verschiedenen Tatkomplexen gegen folternde Gestapo-Bedienstete wegen des Verdachtes von „Amtsverbrechen“ vereinzelt geführten Ermittlungsverfahren erzeugten einen gewissen Klärungsbedarf. Zur „Beseitigung aufgetretener Schwierigkeiten“ kamen am 4. Juni 1937 führende Beamte des Geheimen Staatspolizeiamtes und des Reichsjustizministeriums zu einer Besprechung zusammen ${ }^{270}$. Das Justizministerium verlangte eine die Fälle ,zulässiger Einwirkung“ bei polizeilichen Verhören genau umschreibende Regelung, um den Staatsanwaltschaften Richtlinien an die Hand geben zu können, nach denen sie die Frage der Zulässigkeit von Aussageerzwingungen beurteilen könnten. Wie der vortragende Referent des Reichsjustizministeriums bemerkte, wäre es schließlich ,widersinnig“, die ausführenden GestapoBeamten wegen Amtsverbrechens zu verfolgen, wenn zugleich die Anwendung „,verschärfter Vernehmungen“ von Amts wegen als „erforderlich und unerläßlich“ betrachtet würde.

Die Beamten des Justizministeriums votierten in dieser Besprechung für ,verschärfte Vernehmungen“ in jenen Fällen, ,in denen der Sachverhalt unmittelbare Staatsinteressen berührt". Während die Justizvertreter dabei in erster Linie an Hoch- und Landesverrat dachten, gaben die Gäste von der Gestapo - wie das Protokoll vermerkt - ,der Meinung Ausdruck, daß möglicherweise auch in Bibelforscher-, Sprengstoff- und Sabotagesachen eine verschärfte Vernehmung in Frage kommen könnte". Eine Entscheidung über die in die Regelung einzubeziehenden Delikte und Personengruppen wurde noch nicht herbeigeführt; die Gestapo-Vertreter baten sich eine Rücksprache mit dem Reichsführer-SS aus. Sodann folgten

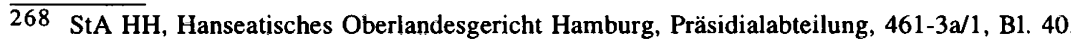
Die Feststellung ist enthalten in einer Zusammenstellung von polizeilichen Urteilskorrekturen, die OLG-Präsident Rothenberger Ende 1938 anfertigen ließ. (Der Schriftwechsel RJMRFSS konnte nicht ermittelt werden.)

269 SH SG 5 Js 166/36, zit. in: SLG HH, SH SG 11 Son KMs 139/36, Handakte, BI. 5.

270 Ein von dem Düsseldorfer Oberstaatsanwalt Dr. Steimer gefertigter Bericht über die Besprechung (übermittelt mit Schreiben vom 8.6.1937 an den Generalstaatsanwalt in Düsseldorf) ist veröffentlicht in: Beweisdokumente für die Spruchgerichte, S. 279f., Dokument G.J. 144. (Die folgenden Zitate entstammen diesem Protokoll.) 
detaillierte Erörterungen, in welcher Form die amtlich verordneten Mißhandlungen vorzunehmen seien: „Grundsätzlich sind bei ,verschärften Vernehmungen“ nur Stockhiebe auf das Gesäß, und zwar bis zu 25 Stück, zulässig. Die Zahl wird von [der] Gestapo vorher bestimmt. Vom 10. Stockhieb an muß ein Arzt zugegen sein. Es soll ein ,Einheitsstock' bestimmt werden, um jede Willkür auszuschalten.“

Später angeordneten Erlassen ist zu entnehmen, daß die Vornahme von „,körperlichen Einwirkungen“ bei Verhören von Zeugen Jehovas in ,geregelten Formen“ durchgeführt werden konnte 271 . Die Gestapo-Beamten brauchten jedenfalls, wenn sie die Form wahrten, staatsanwaltschaftliche Ermittlungsverfahren nicht mehr zu fürchten; sie konnten mit Duldung der Justiz prügeln ${ }^{272}$. Eine am 12. Juni 1942 vom Chef der Sicherheitspolizei und des SD verfügte Neuregelung, die den Kreis der Betroffenen auf „Kommunisten, Marxisten, Bibelforscher, Saboteure, Terroristen, Angehörige der Widerstandsbewegungen, Fallschirmagenten, Asoziale, polnische oder sowjetrussische Arbeitsverweigerer oder Bummelanten“" ausweitete, nannte neben der „Verabreichung von Stockhieben“ als weitere zulässige Mittel der Einwirkung ,einfachste Verpflegung (Wasser und Brot), hartes Lager, Dunkelzelle, Schlafentzug, Ermüdungsübungen“ ${ }^{273}$.

\section{Standhaftes Schweigen, erfolglose Strafen}

Nachdem die IBV seit dem Herbst 1936 in ihren Aktionsformen neue offensive Akzente setzte, wuchs im Berliner Geheimen Staatspolizeiamt die Unzufriedenheit mit den Ergebnissen justitieller Einwirkung auf die Bibelforscher. Sowohl ein zu geringes Strafmaß als auch die mangelnde Wirkung des Strafvollzuges wurden kritisiert. Angesichts von zunehmenden Aktivitäten der Zeugen Jehovas gelangte man im Gestapa zu der Überzeugung, daß die bisherigen Strafen keine ,,abschreckende Wirkung“ gezeigt hätten: „Wenn die Bibelforscher nach Verbüßung ihrer meist nur wenige Monate dauernden Gefängnisstrafen entlassen wurden, so waren sie nicht etwa bekehrt, sondern fühlten sich vielmehr als Märtyrer und hielten noch stärker fest am ,Werk des Herrn“."274

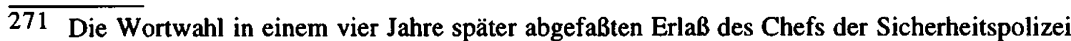
und des SD, der auf eine am 1.7.1937, d. h. einen Monat nach der Besprechung, angeordnete Regelung Bezug nimmt, läBt erkennen, $\mathrm{da} B$ die Gestapo-Vertreter auf ihrer Position mit Erfolg beharrten. In dem Erlaß vom 6.10.1941 heißt es, bei Reichsdeutschen bleibe die Anwendung der verschärften Vernehmung „, beschränkt auf kommunistische bzw. marxistische Funktionäre, Bibelforscher und Saboteure" (BA R 58/243, Bl. 326-328, Der Chef der Sicherheitspolizei und des SD, Erlaß vom 6.10.1941). Der Wortlaut jenes Erlasses vom 1.7.1937 ist nicht erhalten. Er wurde durch die Neuregelung vom 12.6.1942 ersetzt und war ,unter Beachtung der Verschlußvorschriften zu vernichten“. Vgl. Gruchmann, Justiz, S. 718, Anm. 98.

272 In der Besprechung vom 4.6.1937 war festgelegt worden, daß beim Verdacht unzulässiger Aussageerpressung zunächst von der Staatsanwaltschaft bei der Gestapo nachzufragen war, ob eine Genehmigung für eine „verschärfte Vernehmung“ vorlag. War dieses der Fall, waren die Ermittlungen niederzuschlagen. Lothar Gruchmann bemerkt zutreffend, da $B$ die GestapoFührung es damit , in der Hand hatte, auch , wilde' Mißhandlungen untergeordneter Organe durch nachträgliche Genehmigung zu decken" (Gruchmann, Justiz, S. 717).

273 BA, R 58/243, Bl. 337-340, Der Chef der Sicherheitspolizei und des SD, Erlaß vom 12.6. 1942.

274 IfZ, MA 554, 936279-87 (86), Denkschrift „Die Internationale Bibelforscher-Vereinigung“, als Anlage zum RdS der Staatspolizeileitstelle München vom 24.12.1936. 
Wie wenig mit dem herkömmlichen Instrumentarium der Strafverfolgung bei Menschen auszurichten war, die ihr Schicksal als gottgewollte Prüfung verstanden, in der es den Glauben ohne Kompromisse standhaft gegen alle Anfechtungen und Gefahren zu bewahren galt, mag ein Beispiel verdeutlichen: Ein Hamburger Zeuge Jehovas, der nach einer mehrwöchigen Fahndung am 24. März 1937 in Glückstadt festgenommen wurde, gab noch am gleichen Tag bei seiner ersten „Vernehmung“ nur einen Satz von sich: „Jesus wurde vor seine Richter geführt und er schwieg. Auch ich werde schweigen." 275 In den folgenden fünf Monaten, in denen er im Polizeigefängnis Fuhlsbüttel und anschließend im Untersuchungsgefängnis eingesperrt war, verweigerte dieser Zeuge Jehovas bei Gestapo-Verhören buchstäblich jede Antwort, so daß im betreffenden Vernehmungsprotokoll dann lediglich notiert werden konnte: „Wiederum gab er auf die ihm gestellten Fragen keine Antwort, weder zur Sache noch zur Person."276 Auf dem ihm zur Unterschrift vorgelegten „Personal- und Erkennungsblatt“ unterzeichnete er mit „Zeuge Jehovas“. Was sich alles abgespielt haben mag, bis er schließlich doch seinen Namen unter das Dokument setzte, ist nicht bekannt.

Doch selbst in der anschließenden Verhandlung vor dem Hanseatischen Sondergericht, das ihn am 17. August 1937 zu einem Jahr Gefängnis verurteilte, schwieg der Mann beharrlich. Nur durch schriftliche Äußerungen auf kleinen Notizzetteln beteiligte er sich am Prozeßverlauf. Auf einen schrieb er: „Als Zeuge Jehovas laut Jes. 43:10-12 bin ich durch meinen Führer und Heiland an die Heilige Schrift mit meinem Gewissen gebunden, und wenn ich 10 Jahre kriege, ich kann nicht anders, Jehova Gott helfe mir." Auf einem anderen Zettel notierte er die Worte des Propheten Amos: „Amos 5:13 - So spricht Jehova - Der Einsichtige schweigt - es ist eine böse Zeit.“"

Im Urteil wurde festgehalten, daß der Angeklagte kein Wort sprach: „Durch schriftliche Aufzeichnungen, die er überreichte und die verlesen wurden, gab er zu verstehen, daß ihm Jehova am 24. März 1937 das Gebot des Schweigens auferlegt habe." Etwaige Zweifel an der Zurechnungsfähigkeit - der vom Gericht bestellte Verteidiger versuchte auf diesem Weg, für seinen Mandanten ein möglichst mildes Urteil zu erwirken - sah das Gericht als nicht begründet an, da der Angeklagte „den Vorgängen in der Hauptverhandlung ohne alle Schwierigkeiten folgen konnte und auf die ihm vorgelegten Fragen sofort durch Anführung von Bibelstellen, die er aufschrieb, zu antworten in der Lage war." Während das Gericht sich durch die Haltung des Angeklagten nicht aus der Ruhe bringen ließ, sie sogar - im deutlichen Gegensatz zu den Gestapo-Beamten im Vorermittlungsverfahren - als ,harmlos“ einstufte, fiel insbesondere eine schriftliche Willensbekundung des Angeklagten auf kein Verständnis: „Gefährlich ist es aber, daß er, wie alle fanatischen Bibelforscher, in völliger Verkennung des wahren Sinnes des Gebotes: ,Du sollst nicht töten' den Heeresdienst, wie er zu verstehen gegeben hat, im Ernstfall verweigern und sich auf das Beten beschränken würde.“"277

275 SLG HH, HSG 11 Js. Sond. 96/37, BI. 8, Gestapo Hamburg, Vermerk vom 25.3.1937.

276 SLG HH, HSG 11 Js. Sond. 96/37, Bl. 10.

277 SLG HH, HSG 11 Js. Sond. 96/37, Urteil vom 17.8.1937. 
Die Justizverwaltungen und insbesondere die Gefängnisleitungen mußten oftmals das Scheitern ihrer „Bemühungen“ eingestehen; es gelang ihnen zumeist nicht, die Standhaftigkeit der Zeugen Jehovas zu brechen. So berichtete der Generalstaatsanwalt aus Zweibrücken, daß bei nahezu allen Bibelforschern „der Strafvollzug ohne Wirkung" bleibe ${ }^{278}$. Auch Vollzugspraktiker teilten diese resignative Sicht. In einem im März 1937 in der Zeitschrift „Der deutsche Justizbeamte“ veröffentlichten Beitrag über den „Bibelforscher im Strafvollzug“ befand ein Strafabteilungsvorsteher, daß nur wenige unter ihnen seien, ,die durch die Strafverbüßung zur Einsicht gelangen“279. Obgleich, wie der Leiter der Eisenacher Gefängnisse, Dr. Brandstätter, berichtete, „sämtliche Register gezogen [wurden], die im Strafvollzug gezogen werden können“280, habe nur bei einer Minderheit der Zeugen Jehovas der „Vollzugszweck“ erreicht werden können. In Eisenach war durch die Einrichtung eines ,Sonderunterrichtes“ für Bibelforscher versucht worden, „diese Gefangenen durch richtige Schulung und Behandlung von der Falschheit ihrer Irrlehre zu überzeugen, ihnen nationalsozialistisches Gedankengut nahe zu bringen und sie dadurch für das Dritte Reich zu gewinnen“281. Die „Schüler“ sperrten sich in ihrer Mehrheit gegen derartige Einwirkungsversuche und waren keineswegs zu einer „Bejahung des Dritten Reiches“ zu bewegen. Der Unterweisende mußte zur Kenntnis nehmen: „Der totale Staat, die gewünschte richtige und ideale Staatsform, ist für sie die Utopie des Tausendjährigen Reiches. “282

Um den Zeugen Jehovas das „Rüstzeug“ für ihre Verweigerungshaltung zu nehmen, hatte bereits 1935 der Vorsitzende des Jenaer Sondergerichtes gegenüber dem Reichsjustizministerium angeregt, eine Anweisung herauszugeben, nach der den in Gefängnissen einsitzenden Zeugen Jehovas die Bibel nicht mehr - wie sonst bei Strafgefangenen üblich - ausgehändigt werden solle, da diese ihre staatsgefährdenden Ansichten ,aus planvoll zusammengesetzten Bibelstellen“ 283 gewinnen würden. Der Reichsjustizminister sah aber vorerst keinen Anlaß, eine derartige Anordnung zu erlassen. In seiner Antwort vom 21. November 1935 befand er, daß es ,Sache der Vollzugsbehörde“ sei, ,zu verhindern, daß das Studium der Bibel zu Aufzeichnungen führt, die in staatsgefährlicher Weise verwendet werden können“. Im übrigen gehe er davon aus, daß die Bedenken ,zum guten Teil dadurch beseitigt werden können, daß den Ernsten Bibelforschern nicht die ganze Bibel, sondern nur

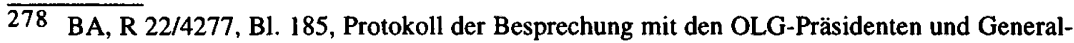
staatsanwälten im RJM am 18.6.1937.

279 Liesche, Bibelforscher, S. 140.

280 Brandstätter, Strafvollzug, S. 53.

281 Ebenda, S. 48. Nach den Angaben von Brandstätter folgte „nur etwas über ein Drittel“ den im Unterricht vorgetragenen Gedanken und ,erwärmte sich, wenn auch nur langsam, für sie“. Lediglich zwei von 16 einer besonders ,intensiven Beschulung“ ausgesetzten Zeugen Jehovas hätten sich von der IBV vollständig gelöst; als „Gegenpol“ stünden ihnen ,zwei ganz verbissene Menschen gegenüber". Die anderen, so glaubte der Gefängnisdirektor feststellen zu können, hätten ihre innere Sicherheit verloren und könnten für das „Dritte Reich“ noch gewonnen werden. Diese dürften aber - so Brandstätter - nach einer Haftentlassung nicht den „Weg überall versperrt“ finden: „Man muß ihnen die Möglichkeit geben, mitzumarschieren, sei es zunächst auch nur in der allerletzten Reihe." 
das Neue Testament ausgehändigt" 284 werde. Diese Empfehlung erschien Vollzugspraktikern als nicht ausreichend. Sie warnten auch vor einer nur teilweisen Überlassung biblischer Schriften, da es dem Haftzweck widersprechen würde, den Zeugen Jehovas ,diejenigen Bücher (Bibel und Neues Testament) zu verabfolgen, aus denen sie für ihre innere Zugehörigkeit zu ihrer verbotenen Sekte [...] fortdauernd neue Nahrung und Ermunterung entnehmen könnten“285.

Die in den Diensten der Justiz stehenden Lehrkräfte klagten über die ,außerordentlichen Schwierigkeiten", die die Bibelforscher in Strafhaft bei dem Versuch der „weltanschaulichen Umformung“ bereiten würden. Ein im Strafgefängnis Ichtershausen tätiger Oberlehrer berichtete beispielsweise über anhaltenden Widerstand gegen das Vorhaben, durch Unterricht und Zellenbesuche „Zug um Zug die Lehre der IBV als das, was sie ist, nämlich als eine Irrlehre und als einen Mißbrauch der Religiosität aufzudecken“. Aufgrund seiner Erfahrungen müsse er feststellen, „daß von aller weltanschaulichen Schulungsarbeit an politischen Gefangenen, die an den Bibelforschern zu der schwierigsten, langwierigsten und undankbarsten gehört" 286 .

Neben der Indoktrination versuchten die Gefängnisdirektionen, mit Zwangsmitteln, insbesondere mit Zellenarrest, die Bibelforscher von ihrer Haltung abzubringen. Eine Unterbringung in Einzelzellen sollte den Zeugen Jehovas nicht nur die Möglichkeit zur gegenseitigen Stärkung nehmen, sondern auch die von ihnen in bezug auf andere Mitgefangene eifrig entfalteten Missionsversuche unterbinden. Eine Anordnung des Reichsjustizministeriums aus dem Jahre 1940, die bestimmte, „daß Gefangene, die dazu neigen, im Sinne ihrer staatsfeindlichen oder sonst abzulehnenden Anschauungen andere Gefangene zu beeinflussen, zum Beispiel Ernste Bibelforscher, von Mitgefangenen streng getrennt gehalten werden müssen“ 287 , bestätigte insofern nur eine bereits zuvor in den Haftanstalten - soweit die Belegungskapazitäten es erlaubten - weitgehend geübte Praxis.

\section{Falsche Vertraute und Bekehrte}

Da sie jede Weiterverbreitung der Bibelforscherlehre grundsätzlich zu unterbinden versuchten, hielten die Vollzugsbehörden ein äußerst scharfes Einschreiten gegen Missionsbemühungen für erforderlich. Dabei handelte es sich jedoch keineswegs nur um ein allgemeines Anliegen. Vielmehr gab es nicht selten auch konkrete Anlässe dazu, denn vergleichsweise häufig fanden inhaftierte Zeugen Jehovas unter ihren Mitgefangenen Resonanz, und teilweise kam es auch zu Bekehrungen ${ }^{288}$.

$\overline{284}$ BA, R 22/1422, Bl. 29, RJM, Schreiben vom 21.11.1935. Die Anregung, den Zeugen Jehovas „nur das Neue Testament“ auszuhändigen, mag auch daher motiviert sein, daß unter "Jehova“ allgemeinhin der Gott des Alten Testamentes verstanden wurde, mithin die Belassung des Neuen Testamentes als nicht „gefährlich“ galt. Zugleich spiegelt sich darin die in der NS-Zeit allgemein verbreitete Ablehnung des Alten Testamentes, das als ein Glaubensdokument jüdischen Ursprungs nur widerstrebend als Teil des christlichen Bekenntnisses anerkannt wurde.

285 Liesche, Bibelforscher, S. 140.

286 Herr, Bibelforscher, S. 87f.

287 BA, R 22/4371, o. B1., RJM, Verfügung vom 21.11.1940.

288 Vgl. beispielsweise Jahrbuch 1974, S. $128 f$. 
Diese Missionserfolge bereiteten allerdings nicht nur den Vollzugsorganen, sondern zuweilen auch den Zeugen Jehovas selbst schwere Probleme, wie das folgende Beispiel ${ }^{289}$ zeigt: Eine schon mehrere Male wegen Diebstahls und Betruges vorbestrafte Frau, die 1936 in der Haft im Hamburger Untersuchungsgefängnis ihre Zelle mit einer Bibelforscherin teilte, hatte sich von dieser viel von dem kommenden Königreich Gottes und den darin herrschenden paradiesischen Zuständen erzählen lassen. Schließlich gab sie zu erkennen, daß sie jetzt ebenfalls von der Richtigkeit der Bibelforscherlehre überzeugt wäre. Daraufhin bot die Zeugin Jehovas der mittel- und obdachlosen Frau an, sie könne doch nach beider Haftentlassung auch mit in ihre Wohnung einziehen, die dazu groß genug sei. Dies geschah später auch tatsächlich. Die in der Haft missionierte Frau wurde sogleich mit zu Widerstandsaktivitäten herangezogen. Ende 1936 beteiligte sie sich auch an der Verteilung der Flugblätter „Resolution“.

Doch bald stellte sich heraus, daß die Hamburger IBV mit der „Neuerwerbung“ keinen Glücksgriff getan hatte. Nachdem die Quartiergeberin feststellte, daß die Frau unter Vorspiegelung falscher Tatsachen Geldbeträge von ihr zu erschwindeln versuchte, löste sich die Verbindung abrupt. Kurz darauf ging bei der Hamburger Polizei eine Anzeige ein; die um ihren Erfolg gebrachte Schwindlerin schwärzte ihre ehemalige Haftgefährtin nun wegen erneuter Betätigung für die verbotenene Bibelforschervereinigung an. Doch die Denunziantin hatte sich dabei wohl selbst verkalkuliert; als man von ihrer eigenen „Tatbeteiligung“" an der Flugblattaktion erfuhr, wurde auch sie wegen Bibelforscherbetätigung abgeurteilt.

Häufig versuchte die Gestapo, auf diese und ähnliche Art Spitzel in die IBVOrganisation einzuschleusen ${ }^{290}$. Man legte V-Leute zu Bibelforschern in die Zelle. Nach kurzer Zeit heuchelten die auf der Lohnliste der Gestapo Stehenden Interesse für den Bibelforscherglauben und begannen ihre Rolle als ,zur Wahrheit Bekehrte“ zu spielen. Doch in den meisten Fällen scheinen die IBV-Zellen nicht so unbedacht gehandelt zu haben wie die im geschilderten Fall betroffene Zelle Wandsbek/ Bramfeld. So prüfte man im Regelfall sehr genau die Glaubwürdigkeit des Bekehrungsakts und ob man es mit einem ,unsicheren Kantonisten“ zu tun habe. Die Strategie der von außen hineingeschleusten V-Leute, die auch nicht immer über das bei religiösen Dingen erforderliche Einfühlungsvermögen verfügt zu haben scheinen, erwies sich mit der Zeit für die Sektenreferate der Staatspolizeistelle als weitgehend unergiebig. Man wählte einen anderen Weg: die Rekrutierung von Zuträgern aus den Reihen der Bibelforscher ${ }^{291}$.

289 Die Darstellung beruht auf den Verfahrensakten SLG HH, HSG 11 Js. Sond. 298/38.

290 Am 18. Juli 1937 waren auf einer Tagung des Sicherheitsdienstes der SS zur Frage, wie zukünftig mit nachrichtendienstlichen Mitteln dem „,konfessionellen Gegner“ und dem ,Sektenwesen“ entgegenzutreten sei, , Richtlinien zur Bekämpfung des Sektenwesens“ an die „Oberund Unterabschnittsreferenten“ ausgegeben wurden, in denen zum verstärkten Einsatz von „VMännern“ aufgefordert wurde. Vgl. Neuhäusler, Kreuz, S. 376.

291 Der Einsatz von SD- und Gestapo-Spitzeln zur Aushorchung von IBV-Gruppen und die Rekrutierung von Bibelforschern, denen für die Auslieferung ihrer Glaubensgeschwister Haftverschonung gewährt wurde, sind mehrfach belegt (vgl. Imberger, Widerstand, S. 351; Jahrbuch 1974, S. 150, 179f.; Jahrbuch 1986, S. 127; Steinberg, Essen, S. 165f.; Wickert, Frauen, S. 218f.). Damit kann die These von Weyrauch, Gestapo V-Leute, S. 64-66, 78f., der zufolge die Gestapo die Zeugen Jehovas generell zu den „Typen der Nichtmitarbeiter“ gerechnet habe, als widerlegt gelten. 
Wie die Gestapo dabei vorging, zeigt das Beispiel des Mitte 1937 verhafteten Hamburger IBV-Zellendieners X.292, der nach einer Aburteilung zu zwei Jahren Gefängnis in ein ernsländisches Strafgefangenenlager eingewiesen worden war. Der ungefähr 50jährige Mann war den dort bei der Moorkultivierung herrschenden harten Arbeitsbedingungen nicht gewachsen; sein gesundheitlicher Zustand verschlechterte sich rapide. Da selbst bei widrigem Wetter „bis zur völligen Durchnässung " gearbeitet wurde, litt der Zeuge Jehovas an ständiger fiebriger Erkältung. Bald stellten sich Darm- und Magenblutungen ein; nach einem halben Jahr kam es schließlich zum „völligen Zusammenbruch“. Es folgte ein mehrmonatiger Lazarettaufenthalt. Das Sektenreferat II B 1 der Hamburger Staatspolizei, das bereits einige Monate zuvor anläßlich eines von Frau X. wegen des Gesundheitszustandes ihres Mannes gestellten Gnadengesuches die Frage eines Einsatzes dieses Zeugen Jehovas als V-Mann erwogen hatte, teilte der Staatsanwaltschaft jetzt mit, daß eine „recht baldige Entlassung des in Strafhaft befindlichen X. aus staatspolizeilichen Gründen erwünscht“ sei, denn es sei „,beabsichtigt, X. in Zukunft als Vertrauensperson für IBV-Angelegenheiten in Hamburg zu verwenden“. Dieses Begehren fand im Unterschied zu dem von Frau X. eingereichten Gnadengesuch auf seiten der Justiz volles Verständnis. Bereits fünf Tage später teilte der Oberstaatsanwalt dem Gefängnisvorsteher mit, daß der Strafvollzug vorläufig unterbrochen werde. Der kurz zuvor aus dem Lazarett zurückverlegte Gefangene sei jedoch nicht auf freien Fuß zu setzen, da er ,von der Geheimen Staatspolizei abgeholt“ werde. Auf den Papieren solle als Entlassungsgrund der schlechte Gesundheitszustand angegeben werden.

Ein halbes Jahr später nahm die Gestapo zu dem trotz gewährter Strafunterbrechung noch nicht entschiedenen Gnadenverfahren Stellung. Die Hamburger Staatspolizeistelle erklärte, daß X. eines Gnadenerweises für „würdig“ befunden werde, da er seit seiner vorläufigen Entlassung aus der Strafhaft „mit der hiesigen Dienststelle als Vertrauensmann in engster Fühlungnahme gestanden“ habe: „Er weiß das ihm geschenkte Vertrauen zu schätzen und hat der Dienststelle in dieser Hinsicht gute Dienste geleistet." Mitte 1939 wurde die ausstehende Reststrafe von elf Monaten bei Auferlegung einer dreijährigen Bewährungsfrist erlassen.

Da sich die Maßnahmen „,zur Bekämpfung der IBV“ - abgesehen von gelegentlichen Denunziationen und Einsätzen von V-Leuten wie in dem geschilderten Fall im allgemeinen jedoch großteils als wirkungslos erwiesen, suchte die Gestapo seit Ende 1936 nach effizienteren Wegen. Die Gestapa-Denkschrift, die das Erfordernis

292 Die Darstellung beruht auf: SLG HH, HSG 11 Js. Sond. 298/38, GnH 3659/42; VVN HH, Komiteeakten XZ 1; AfW HH R 231191. Nach 1945 gaben etliche Hamburger Zeugen Jehovas in Entschädigungsanträgen an, da $\beta$ ihre Verurteilung auf einer Denunziation durch den ehemaligen Leiter der IBV-Jugendgruppe Erwin Z. beruhte. Bei diesen Belastungen wird eine nicht unwesentliche Rolle gespielt haben, daß sich Erwin Z. 1940 von der IBV lossagte und auch nach 1945 nicht in ihre Reihen zurückkehrte. Man glaubte, in dem „Abtrünnigen“ den Schuldigen für den damaligen Verrat gefunden zu haben. Von demjenigen, der statt dessen seit Ende 1938 tatsächlich die Gestapo mit Informationen über die IBV-Organisation in Hamburg versorgte, ist den Glaubensgeschwistern hingegen allem Anschein nach nie etwas bekannt geworden, wie die geführten Gespräche mit damaligen Beteiligten der Hamburger IBVGruppe vermuten lassen. Aus diesem Grunde wurde auf die Angabe von personenbezogenen Informationen weitgehend verzichtet, das unverfängliche $X$. anstatt des Initials gewählt und einige zeitliche und örtliche Angaben verfremdet. 
einer härteren Vorgehensweise begründen sollte, bezeichnete es als „eine zwingende Notwendigkeit, daß der Staat jegliche Betätigung für die verbrecherischen Ziele der Internationalen Bibelforscher-Vereinigung so ahndet, daß der Betreffende für lange Zeit von der menschlichen Gesellschaft ferngehalten wird und keine Gelegenheit hat, sein Treiben fortzusetzen" ${ }^{293}$. Der Einsatz aller zur Verfügung stehenden Mittel gegen die IBV sei geboten, „um sie wenigstens in Deutschland für immer zu vernichten".

Die Beobachtung, daß ,die Bibelforscher in den meisten Fällen nach ihrer Entlassung aus der Strafhaft ihr verwerfliches Treiben mit verstärktem Fanatismus“ erneut aufnahmen, war für das Geheime Staatspolizeiamt ein eindeutiger Beleg, ,daß die bisher von den Gerichten verhängten Strafen wegen illegaler Betätigung für die Internationale Bibelforscher-Vereinigung ihren Zweck verfehlt haben“294. Aus diesem Grunde forderte die Gestapo von der Justiz eine deutliche Heraufsetzung des bislang üblichen Strafmaßes. Da die Reichspräsidentenverordnung zum Schutz von Volk und Staat vom 28. Februar 1933 als Rechtsgrundlage den Strafrahmen begrenzte und dies im Höchstfalle Strafen von fünf Jahren Gefängnis ermöglichte, drängte das Geheime Staatspolizeiamt das Reichsjustizministerium, die Strafbestimmungen in Bibelforscherverfahren zu ändern. Das Gestapa schlug vor, entweder die Strafvorschriften über hochverräterische Betätigung ( $\$ \$ 80-84$ StGB) in Anwendung zu bringen, da ,die Betätigung der Bibelforscher der Wühlarbeit der Kommunisten und Marxisten gleichzustellen" sei, oder eine neue gesetzliche Bestimmung zu erlassen, ,wonach die Funktionäre der illegalen IBV mit Zuchthaus und Mitläufer mit Gefängnis nicht unter 6 Monaten bestraft werden“295.

Neben den Erwartungen, die die Gestapo an die Justiz richtete, weitete sie selbst ihre Schutzhaftpraxis in bezug auf IBV-Angehörige aus. Diente die Schutzhaft bei Bibelforschern bis dahin im wesentlichen als ein Strafersatz mit zumeist befristeter Dauer, so wurde sie nun hauptsächlich zu einem strafergänzenden und strafverschärfenden Instrument mit dem Ziel der „Dauerverwahrung“ aller unbeugsamen Zeugen Jehovas. Nachdem bereits 1936 in vielen Fällen Zeugen Jehovas unmittelbar nach erfolgter Strafverbüßung von der Gestapo in Konzentrationslager eingewiesen worden waren, wurde diese Praxis im Frühahr 1937 institutionalisiert und für Zeugen Jehovas, insofern diese nicht ,abschworen“, die Schutzhaft als polizeilich verfügte „Nachhaft“ generell angeordnet. Der diesbezügliche Gestapa-Erlaß vom 22. April 1937 wurde den Polizeibehörden von den Staatspolizeistellen im folgenden Wortlaut bekanntgegeben: „Sämtliche Anhänger der IBV, die nach Beendigung der Strafhaft aus den Gefängnissen entlassen werden, sind unverzüglich in Schutzhaft zu nehmen; ihre Überführung in ein Konzentrationslager ist unter Darlegung des Sachverhaltes zu beantragen." 296

293 IfZ, MA 554, 936279-87 (86), Denkschrift „Die Internationale Bibelforscher-Vereinigung“, als Anlage zum RdS der Staatspolizeileitstelle München vom 24.12.1936.

294 Geheimes Staatspolizeiamt, Lagebericht für die Zeit vom 1.10.1936 bis zum 28.2.1937, zit. nach Steinberg, Essen, S. 160, Anm. 8.

295 Ebenda.

296 Niedersächsisches Hauptstaatsarchiv Hannover, Hann 80, Lün. II - 94b, Geheimes Staatspolizeiamt, RdErl. vom 22.4.1937. 
Die Staatspolizeileitstelle Stettin setzte den dortigen Generalstaatsanwalt drei Wochen später von dem am 22. April ergangenen Runderlaß des Geheimen Staatspolizeiamtes in Kenntnis. Der Generalstaatsanwalt wurde um Mithilfe gebeten und ersucht, Anhänger der IBV nach Strafverbüßung ,nicht zu entlassen, sondern sie der hiesigen Staatspolizeileitstelle zu überstellen und die Einlieferung in das hiesige Polizeigefängnis zu veranlassen" ${ }^{297}$. Der von der Gestapo um Amtshilfe gebetene Generalstaatsanwalt setzte sich daraufhin freilich mit dem Reichsjustizministerium in Verbindung, wodurch dieses erstmals überhaupt von der Existenz des Gestapa-Erlasses erfuhr. Im Ministerium hielt man sich bedeckt; eine ministerielle Regelung über die Verfahrensweise bei bevorstehenden Strafentlassungen von Bibelforschern wurde nicht in Aussicht gestellt ${ }^{298}$. Daraufhin erließ der Stettiner Generalstaatsanwalt in eigener Vollmacht für seinen Geschäftsbereich die notwendigen Anweisungen 299.

Oft wartete die Gestapo nicht erst den Entlassungstermin ab, sondern verfügte schon Monate vor dem Haftende eine anschließende Inschutzhaftnahme. So teilte die Außendienststelle Flensburg der Staatspolizeistelle für den Regierungsbezirk Schleswig dem Oberstaatsanwalt in Kiel mit Schreiben vom 4. Juni 1937 mit, daß gegen vier Flensburger Zeugen Jehovas, die vom Schleswig-Holsteinischen Sondergericht ein Vierteljahr zuvor bei Anrechnung der erlittenen Schutz- und Untersuchungshaft zu Gefängnisstrafen zwischen zehn und achtzehn Monaten verurteilt worden waren - und deren Entlassungstermine somit noch in weiter Ferne lagen -, „die Inschutzhaftnahme angeordnet worden“ sei. Ohne Bedenken, daß dieser Beschluß der Justiz bereits im Vorwege die Nichterfüllung des Vollzugszweckes bescheinigte, bat man den Oberstaatsanwalt, der das Urteil gegen die Bibelforscher erwirkt hatte, um Amtshilfe: „Die Schutzhaft beginnt mit dem Tage ihrer Entlassung aus der Strafhaft. Aus diesem Grunde wird um Mitteilung gebeten, wann folgende Personen aus der Strafhaft entlassen werden [...] Ferner wird um entsprechende Verständigung der zuständigen Gefängnisverwaltungen gebeten, damit von hier aus die Abholung der Gefangenen rechtzeitig in die Wege geleitet werden kann. “300

\section{Inschutzhaftnahme von Zeugen Jehovas}

Die von der Gestapo-Spitze verfügte Inschutzhaftnahme von Zeugen Jehovas nach deren Haftentlassung und damit die regelmäßige Anordnung einer polizeilichen „Nachhaft“ traf in Justizkreisen zum Teil auf erhebliche Vorbehalte, da die Verhän-

297 BA, R 22/1467, Bl. 286, Staatspolizeileitstelle Stettin, Schreiben vom 13.5.1937.

298 Im Fall von „Hoch- und Landesverrätern“ hatte das RJM einige Monate zuvor mit Erlaß vom 18.1.1937 die Strafvollzugsbehörden angewiesen, daß die Staatspolizei(leit)stellen rechtzeitig von einer bevorstehenden Strafentlassung in Kenntnis zu setzen seien. Vgl. Dokumente zur Gleichschaltung, S. 228.

299 Vgl. BA, R 22/1467, B1. 286, Der Generalstaatsanwalt in Stettin, Schreiben vom 4.6.1937. Die Besprechung im Ministerium fand zwei Tage zuvor, am 2.6.1937, statt. Vgl. Gruchmann, Justiz, S. 620-622.

300 SLG HH, SH SG 11 Son KMs 19/37, B1. 160, Außendienststelle Flensburg der Staatspolizeistelle für den Regierungsbezirk Schleswig, Schreiben vom 4.6.1937. Die Daten der Haftentlassung waren in den vier betreffenden Fällen: 13.10.1937, 26.10.1937, 5.11.1937 und 25.4.1938. 
gung von Schutzhaft zur Verstärkung gerichtlicher Strafen als offene Diskriminierung der ordentlichen Gerichtsverfahren empfunden wurde ${ }^{301}$. Eine derartige Praxis bedeutete einen weiteren Eingriff in die Strafverfolgungskompetenzen der Justiz, denn de facto bestimmte bei „Tätern“, die wegen Zuwiderhandlung gegen das IBV-Verbot abgeurteilt wurden, fürderhin nicht mehr der Richterspruch die Haftzeit respektive das reale „Strafmaß“, sondern dies lag nun in der Hand der damit befaßten Gestapo-Beamten. Jetzt verhängte die Geheime Staatspolizei häufig völlig selbständig zusätzliche Schutzhaft.

Besondere Kritik rief das Vorgehen der Gestapo bei den Vollzugspraktikern hervor. Sie erlebten unmittelbar, welche Farce jenes Verfahren darstellte, wenn zuweilen Bibelforscher, die ihre Freiheitsstrafe verbüßt hatten und aus der Strafhaft entlassen wurden, trotzdem vorübergehend - bis zur endgültigen Überstellung in ein $\mathrm{KZ}$ - im gleichen Gefängnis oder gar der gleichen Zelle verblieben, nun aber als Schutzhaftgefangene der Gestapo. Grundsätzliche Bedenken kamen hinzu. Der Direktor der Gefängnisse in Freiburg befürchtete, daß durch die „unterschiedslose Inschutzhaftnahme“ nach Strafverbüßung ,die bessernde und abschreckende Wirkung des Strafvollzugs an den ernsten Bibelforschern in Frage gestellt“302 werde. Sein Kollege aus Eisenach betonte, daß die Gefängnisleitung während der Dauer des Strafvollzuges ausreichend Erkenntnisse darüber erlange, „wer bei der Entlassung noch Staatsfeind ist“. Dabei stand auch für ihn außer Frage, daß in bezug auf diejenigen, die während der Gefängnishaft nicht „,von der Bibelforscheridee abgekommen“ seien, ,keinerlei Rücksicht“ geübt werden dürfe. Während der Gefängnisdirektor im Fall der „Unbelehrbaren“ die Überstellung ,ins Konzentrationslager“ guthieß, plädierte er nachdrücklich für eine andere Verfahrensweise gegenüber den „Gebesserten“: Diese gehörten ,,in Freiheit, auf daß sie den Weg ins Dritte Reich gehen. Versperrt man ihnen schon gleich beim Ablauf der regulären Strafe diesen Weg, so war alle Mühe im Strafvollzug umsonst." 303

Jene, die aktiv an einer ,weltanschaulichen Umformung“ der Bibelforscher arbeiteten und an dem Gedanken der Spezialprävention festhielten, fürchteten - angesichts von pauschalen Maßnahmen - um die Erfolge ihres ,zähen Kampfes“. Sie sprachen sich gegen eine ins polizeiliche Ermessen gestellte Entscheidung über die Frage der Haftentlassung aus. Nach den Worten eines in diesem Bereich tätigen Oberlehrers verdienten die Strafvollzugsanstalten das Vertrauen, „daß sie nur diejenigen zur Entlassung in Vorschlag bringen, die tatsächlich im Interesse der Volksgemeinschaft dieser Entlassung würdig sind“304. In derartigen Worten spiegelt sich

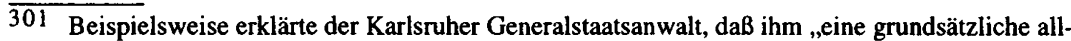
gemeine Inschutzhaftnahme aller Ernsten Bibelforscher nach Verbüßung der Strafhaft [...] unerwünscht" erscheine (BA, R 22/3136, Bl. 131, Der Generalstaatsanwalt in Karlsruhe, Lagebericht vom 18.10.1937).

302 BA, R 22/3136, BI. 157, zitiert im Lagebericht des Karlsruher Generalstaatsanwalts vom 16.12.1937.

303 Brandstätter, Strafvollzug, S. 55.

304 Herr, Bibelforscher, S. 88. Der seit Mai 1938 im Gefängnis Ichtershausen tätige Oberlehrer Rudi Herr vertrat ein vollständig an Selektionsgesichtspunkten ausgerichtetes Konzept, das die „Gemeinschaftsfähigen“ unter den Bibelforschern für die „Volksgemeinschaft" zurückgewinnen wollte, während es die „Unbelehrbaren“ und „Gemeinschaftsunfähigen“ auszuscheiden suchte und in ihrem Fall „grundsätzlich“ für eine „Unterbringung in den Konzentrationsla- 
das bei den Justizbediensteten weitverbreitete Gefühl, durch selbstherrliche Entscheidungen der Gestapo bei KZ-Überstellungen von Personen, bei denen nach Urteil der Haftanstalt der „Vollzugszweck“ durchaus erreicht schien, um die Früchte der eigenen Arbeit gebracht zu werden und so als kompetenzlos dazustehen.

Angehörige der Bibelforschervereinigung wurden von der Gestapo aber nicht nur nach erfolgter Strafverbüßung in Konzentrationslager überstellt, sondern nicht selten auch dann, wenn sie von Sondergerichten freigesprochen worden waren respektive diese Gerichte ihre Strafe durch Anrechnung von vorhergehenden Schutzund Untersuchungshaftzeiten für verbüßt erklärt hatten. In solchen Fällen konnten in der Regel die Betreffenden zwar den Gerichtssaal als ,freie Bürger'verlassen, wurden dann aber zumeist gleich an der Tür von der Gestapo in Empfang genommen oder kurz danach unter Vorlage eines Schutzhaftbefehles verhaftet.

Diese Vorgehensweise stie $\beta$ in Justizkreisen auf scharfen Widerspruch. Mit Schreiben vom 21. Mai 1937 übermittelte der Frankfurter Oberlandesgerichtspräsident dem Reichsminister der Justiz ,mit Rücksicht auf die der Sache zukommende allgemeine Bedeutung" einen Bericht des Vorsitzenden Richters am Sondergericht in Frankfurt am Main, in dem dieser über die Begleitumstände von drei am dortigen Sondergericht geführten Hauptverfahren, in denen gegen insgesamt 62 Angeklagte wegen Betätigung für die IBV verhandelt worden war, Klage führte. Bei einem Teil der Angeklagten hatte das Gericht Strafen zwischen zwei und sieben Monaten Gefängnis für ausreichend erklärt. Da diese durch die erlittene Schutz- und Untersuchungshaft als verbüßt galten, war in diesen Fällen der Haftbefehl aufgehoben worden und Entlassungsanordnung ergangen. Über die dem richterlichen Urteilsspruch folgenden Ereignisse berichtete der Vorsitzende des Frankfurter Sondergerichtes mit merklicher Verbitterung:

„Jeweils unmittelbar nach Verkündung des Urteils hat der mit der Durchführung der Ermittlungen von der Geheimen Staatspolizei beauftragte Kriminalassistent im Gerichtsgebäude die Anweisung zu erneuter Festnahme von Angeklagten gegeben, deren Haftentlassung das Sondergericht [...] angeordnet hatte. Das Sondergericht erblickt in diesem Vorgehen eine Schädigung des Ansehens der Justiz und eine Erschütterung des Vertrauens in die Rechtspflege. Es wird dadurch der Anschein der Korrektur eines unmittelbar vorangegangenen Richterspruches erweckt. Insbesondere wird durch dieses Verfahren die nach sorgfältiger Beratung erfolgte Abwägung und Abstufung des Strafmaßes zunichte gemacht. Das Sondergericht hält sich für verpflichtet, diese Vorgänge zur Kenntnis der Justizverwaltung zu bringen und auf die daraus erwachsenden Gefahren aufmerksam zu machen."305

gern“ plädierte. Der Oberlehrer entwickelte dazu Kategorien, mit deren Hilfe er die „Sichtung des vorhandenen Menschenmaterials“ bzw. die „Auslese unter den vorhandenen Bibelforschern" vornahm.

305 BA, R 22/1467, B1. 285, zitiert im Schreiben des OLG-Präsidenten in Frankfurt am Main vom 21.5.1937 an den RJM. In der in den RJM-Akten überlieferten Abschrift des Berichtes, den der Vorsitzende Richter des Frankfurter Sondergerichtes dem dortigen Landgerichtspräsidenten am 10.5.1937 erstattet hatte, lautet die Stelle, an der im obigen Zitat vom Verf. eine Auslassung vorgenommen wurde, folgendermaßen: Der Gestapo-Beamte habe „Anweisung zu erneuter Festnahme von Angeklagten gegeben, deren Haftentlassung das Sondergericht nicht angeordnet hatte“. In Anbetracht des gesamten Kontextes - sowohl des Berichtes als auch der durch ihn bewirkten Aktenvorgänge - scheint es sich jedoch offensichtlich um einen ein- 
Die bewußte Ignorierung richterlicher Entscheidungen durch ,polizeiliche Urteilskorrekturen" 306 wurde als Verlust an eigener Existenzberechtigung empfunden und scheint die Sonderrichter in ihrem Selbstverständnis als Elite der nationalsozialistischen „Rechtswahrer“, die mit ausreichender Härte den „Staatsfeinden“ zu begegnen meinte, tief gekränkt zu haben.

\section{Das Reichsjustizministerium und die „Bibelforscherfrage“}

Aufgrund des Unmutes in Justizkreisen über die Schutzhaft-Praxis der Gestapo sah sich das Reichsjustizministerium veranlaßt, das Thema „Schutzhaft und Bibelforscher" auf die Tagesordnung einer für den 18. Juni 1937 im Ministerium anberaumten Tagung zu setzen, zu der - wie auch bei den vorangegangenen sogenannten „Chefpräsidentenbesprechungen“ - die Oberlandesgerichtspräsidenten, die Generalstaatsanwälte, der Präsident des Reichsgerichtes, der Oberreichsanwalt, der Präsident des Volksgerichtshofes und der Reichsanwalt beim VGH geladen waren 307 .

Im Verlauf der an jenem Freitag, den 18. Juni, vormittags ab 10.00 Uhr in der Berliner Wilhelmstraße ausgerichteten Tagung erörterten die Spitzen des Ministeriums mit den genannten Herren ausgiebig die der Justiz durch die GestapoPraxis erwachsenen Probleme und die Folgen für das weitere Vorgehen bei der Strafverfolgung der Zeugen Jehovas ${ }^{308}$. Der Reichsminister der Justiz, Dr. Franz Gürtner, gab in seinen Einleitungsworten zu diesem Tagesordnungspunkt zu erkennen, daß er die in den Berichten einiger Oberlandesgerichtspräsidenten und Generalstaatsanwälte geäußerten Bedenken weitgehend teile. Wie sie beklagte er ebenfalls die mit der Schutzhaft für die Justiz oftmals verbundenen Schwierigkeiten. In diesem Zusammenhang sprach er von „gewissen Anwendungsformen, die auf die Dauer nicht erhalten werden können“. Die Schutzhaft werde vielfach nicht mehr aus Gründen der Prävention verhängt, sondern zu anderen Zwecken, „,z. B. um jemanden vergleichsbereit zu machen oder einen Freigesprochenen oder zu gering Bestraften noch festzuhalten“. Da dieser Aspekt „zur Zeit eine mißliche Rolle auf dem Gebiet der Internationalen Bibelforscher" spiele, hielt der Reichsjustizminister eine diesbezügliche Absprache für vordringlich.

Nachdem das Ministerium durch die von den Generalstaatsanwälten erstatteten Berichte auf die zunehmende Zahl von Inschutzhaftnahmen nach gerichtlichem

fachen Übertragungsfehler zu handeln, der infolge der zweimaligen Abschrift entstanden sein wird.

Die Gestapo weitete die ihr mit dem Instrument der Schutzhaft zu Zwecken der Gefahrenabwehr eingeräumte Machtbefugnis zu einem umfassenden Mittel der Korrektur der Rechtspflege aus: Neben der Schutzhaft vor bzw. anstelle einer gerichtlichen Bestrafung trat die Schutzhaft nach verbüßter Freiheitsstrafe, d. h. nach einer als zu gering empfundenen Strafe. In noch offenkundigerer Weise nahm die Schutzhaft einen die Justizorgane korrigierenden Charakter an, wenn sie nach gerichtlichem Freispruch oder nach einer verfügten Gnadenentscheidung erfolgte. Zur Praxis der „Urteilskorrektur“ durch Schutzhaftverhängung vgl. Gruchmann, Justiz, S. 583-631; Johe, Justiz, S. 138-143, 155-166.

307 BA, R 22/4277, B1. 145, RJM, Schreiben vom 12.6.1937.

308 BA, R 22/4277, B1. 149-191, Protokoll der Besprechung mit den OLG-Präsidenten und Generalstaatsanwälten im RJM am 18.6.1937. Die folgenden Zitate entstammen diesem Protokoll. 
Freispruch aufmerksam gemacht worden sei, habe man sich, wie der für Fragen der Strafrechtspflege und der Strafvollzugsverwaltung zuständige Abteilungsleiter, Ministerialdirektor Dr. Wilhelm Crohne, den Anwesenden dann höflich versicherte, „,sofort mit der Gestapo in Verbindung gesetzt“. Zu Beginn seines Berichts eröffnete Crohne den Anwesenden mit der Bitte um Vertraulichkeit gleich den Inhalt des am 22. April 1937 vom Geheimen Staatspolizeiamt an die Staatspolizeistellen im Reichsgebiet ergangenen Erlasses, wonach sämtliche Anhänger der IBV nach Beendigung der Strafhaft in Schutzhaft zu nehmen seien. Nachdem diese allgemeine Anweisung ,nun einmal“ ergangen sei, bleibe der Justiz nur, sie hinzunehmen: „Da es sich bei den in der genannten Anordnung behandelten Maßnahmen lediglich um solche polizeilicher Art handelt, können wir gegen die Anordnung nichts machen. Uns wurde ausdrücklich zugesichert, daß es sich nicht um eine Kritik der Urteile handeln solle." Mit dieser beschwichtigenden Auskunft aus der Prinz-AlbrechtStraße hatte das Reichsjustizministerium sich zufriedengegeben. Dem unverblümten Eingeständnis, selbst keine weiteren Handlungsmöglichkeiten zu besitzen, folgte die Bekanntgabe von einigen kleinen kosmetischen Korrekturen, die vom Gestapa den Vertretern des Justizministeriums zugesagt wurden. So hatte das Gestapa zugesichert, daß die Staatspolizeistellen angewiesen würden, Festnahmen von Freigesprochenen unmittelbar im Gerichtssaal zu unterlassen.

Insgesamt ließ sich jedenfalls schon nach diesen ersten Ausführungen schließen, daß die Unterrichtung des Kreises der Anwesenden über die mittlerweile vom Reichsjustizministerium mit dem Geheimen Staatspolizeiamt in Grundzügen bereits erzielte Übereinkunft der eigentliche vom Ministerium und von Dr. Crohne verfolgte Zweck der Besprechung sein mußte.

Zur Bedeutung der IBV führte Crohne dann dem Protokoll zufolge aus ${ }^{309}$ : „Es darf nicht mehr vorkommen, daß die Bibelforscher als eine religiöse Sekte angesehen werden. Sie sind eine absolut staatsgefährliche Vereinigung geworden, die z. T. vom Auslande aus geleitet wird. Sie haben auf ihre Fahne u. a. die Verweigerung des Wehrdienstes geschrieben, darüber hinaus aber auch die Verweigerung der Mitarbeit in den für die Wehrmacht arbeitenden Betrieben. Die Tragweite ist deutlich daraus erkennbar, daß sie z. B. auch die Tätigkeit bei der Eisenbahn und der Post im Kriegsfalle ablehnen." Neben die ,wehrkraftzersetzende“ Wirkung der Bibelforscher trete aber noch eine größere Gefahr ${ }^{310}$ : „Wir haben von der Gestapo Nachrichten, wonach der Kommunismus mit Gewalt in die I.B.V. hineindringt.“ Der Umfang der Organisation ${ }^{311}$ verdeutliche die ganze Dimension des von seiten der IBV gegen den nationalsozialistischen Staat gerichteten Angriffes: „Es wurde

$\overline{309}$ In ähnlicher Weise hatte Crohne bereits ein halbes Jahr zuvor in der „Deutschen Justiz“ zu den Aktivitäten der IBV Stellung genommen. Vgl. Crohne, Strafrechtspflege, S. 9.

310 Bereits am 13.1.1937 hatte das Reichsjustizministerium dem Sondergericht in Darmstadt mitgeteilt, daß man ,wegen dieses Problems des Zusammenhangs zwischen KPD und IBV mit der Geheimen Staatspolizei sehr eng zusammenarbeite“ (zit. nach: Warmbrunn, Strafgerichtsbarkeit, S. 375, Anm. 195.

311 In einer als Teil der SD-Schulungsmaterialien für die „Gegnerbekämpfung“ vermutlich 1938 von SS-Hauptsturmführer Kolrep verfaßten Ausarbeitung über „Das Sektenwesen“ wurde die Anhängerschaft der Bibelforschervereinigung auf 350.000 beziffert. Die Gesamtzahl der Sektenanhänger in Deutschland schätzte Kolrep auf ,heute bereits [...] mehrere Millionen“ (BA, R 58/779, Bl. 143 Rs). 
mir bei der Gestapo gesagt, daß die Zahl der Internationalen Bibelforscher in Deutschland 5 bis 6 Millionen betrage. Ich selbst rechne mit 1 bis 2 Millionen.“

Nachdem Crohne noch durch einen Hinweis auf die erfolgten ,umfangreichen Flugblattverteilungen durch Bibelforscher" deren wachsende Bedeutung unterstrichen hatte, kam er zu der Aufgabe, die der Justiz im Kampf gegen die Zeugen Jehovas nun zukomme: „Wir müssen immer wieder feststellen, daß von der Möglichkeit, in der Gefängnisstrafe bis zu 5 Jahren hinaufzugehen, wenig Gebrauch gemacht wird. Herr Staatssekretär Freisler hat kürzlich in einer Rundverfügung ausdrücklich hervorgehoben, daß hier die nötige Strenge anzuwenden sei. [...] Ich bitte darauf hinzuwirken, daß die Weichheit in dem Vorgehen gegen die Internationalen Bibelforscher zurückgestellt wird." 312 Crohne verband seine Rüge der bisherigen Urteilspraxis, die den mit der Verordnung zum Schutze von Volk und Staat gegebenen Strafrahmen nicht genügend ausschöpfe, zudem mit einer namentlichen Aufzählung jener Gerichtsbezirke, in denen das von den jeweiligen Sondergerichten verhängte Strafmaß ,auffällig milde“ ausfallen und weit hinter den Erfordernissen zurückbleiben würde. Die anwesenden Oberlandesgerichtspräsidenten erfuhren, daß man im Justizministerium Breslau, Celle, Düsseldorf, Naumburg, Stettin und Zweibrücken zu den ,milden Bezirken“ rechnete. Und obendrein wurde dem Kollegenkreis gleichfalls kundgetan, daß man namentlich in Darmstadt, Dresden, Jena und Königsberg jene Scheu eben nicht kannte ${ }^{313}$.

Crohne berichtete den Anwesenden auch, daß der Reichsführer-SS die den Sondergerichten in Bibelforscherverfahren gegebenen gesetzlichen Möglichkeiten im Strafmaß ohnehin für nicht ausreichend halte. Der Reichsführer-SS habe deshalb dem Justizministerium vorgeschlagen, in einer Novelle Zuchthaus anzudrohen. Dem könne man jedoch momentan noch nicht entsprechen. Zugleich verwies Crohne aber darauf, daß im Entwurf des neuen Strafgesetzbuches, das gerade abschließend beraten werde ${ }^{314}$, entsprechende Möglichkeiten bereits vorgesehen

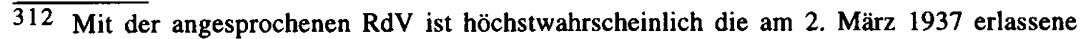
Verfügung des RJM (siehe S. 279) gemeint.

313 Die Angaben Crohnes über die Urteilspraxis bei Bibelforscherverfahren in den genannten OLG-Bezirken werden bestätigt durch die Dokumentation des ,Zentraleuropäischen Büros“ der Watch Tower Society: Laut den bei Zürcher, Kreuzzug, S. 93ff., wiedergegebenen Berichten wurde die fünfjährige Höchststrafe von dem sächsischen Sondergericht in Leipzig (OLGBezirk Dresden), dem thüringischen Sondergericht in Rudolstadt (OLG-Bezirk Jena) sowie den Sondergerichten Königsberg, Dresden und Darmstadt verhängt. Die der Dokumentation zugrundeliegenden Pressemeldungen und Berichte der Betroffenen gehen bis Mitte 1937, decken also ungefähr den gleichen Zeitraum ab.

314 Die unter Leitung von Reichsjustizminister Gürtner im November 1933 eingesetzte ,, amtliche Strafrechtskommission“, deren Aufgabe die Erarbeitung eines neuen „Deutschen Strafgesetzbuches“ war, das im Rahmen einer grundlegenden „Strafrechtsreform" an die Stelle des geltenden, von den Nationalsozialisten wegen seiner „Liberalität“ gescholtenen Strafgesetzbuches von 1871 treten sollte, hatte den Entwurf dieses Gesetzeswerkes Ende Oktober 1936 fertiggestellt; Anfang Dezember 1936 wurde er dem Kabinett zur Beschlußfassung vorgelegt. Trotz mehrfacher Beratung in den Kabinettssitzungen wurde das „Deutsche Strafgesetzbuch“ jedoch nicht verabschiedet. Über die Gründe der Nicht-Verabschiedung heißt es bei Martin Broszat: „Ohne Zweifel wünschte Hitler zumindest für längere Zeit keine Bindung an ein bis in die Einzelheiten hinein kodifiziertes Strafrecht, und zwar auch dann und gerade dann nicht, wenn es sich um sogenanntes nationalsozialistisches Recht handelte, von dem man sich nicht mehr mit dem Hinweis auf ,überholte liberalistische Rechtsnormen " leicht wieder hätte distanzieren können." (Broszat, Strafjustiz, S. 393) 
seien $^{315}$. Danach könnten ,die Bibelforscher in Zukunft mit Zuchthaus bestraft werden wegen Teilnahme an einer wehrfeindlichen Verbindung“. Bis zum Inkrafttreten dieses neuen Gesetzeswerkes heiße es vorerst, die geltenden Möglichkeiten voll auszuschöpfen. Crohne fügte dann hinzu: „Daß eine Geldstrafe nicht mehr am Platze ist, brauche ich wohl nicht mehr hervorzuheben." Der Ministerialdirektor und spätere Vizepräsident des Volksgerichtshofes gab anschließend die ihm bei der Gestapo mit auf den Weg gegebene Parole aus: „Der Kampf gegen die Internationalen Bibelforscher muß schärfer und schärfer werden.“

In der folgenden Aussprache wurden dann allerdings doch weit auseinandergehende Ansichten geäußert. Generalstaatsanwalt Schnöring aus Düsseldorf, einem der als ,mild“ gescholten OLG-Bezirke, mochte in den Bibelforschern nur zum Teil gefährliche Staatsfeinde erkennen, da nach seinem Empfinden ,der größte Prozentsatz [...] aus mehr trottelhaften Typen“ bestehe. Schon der äußere Eindruck zeige vielfach, daß die Täter ,geistig nicht ganz normal“ seien. Dieser Einschätzung widersprach sein Kollege Windhausen aus dem benachbarten Gerichtsbezirk Köln. Er berichtete, daß insbesondere der im Saargebiet feststellbare Zuwachs bei den Bibelforschern auch auf ,politische Momente“ zurückgeführt werden müsse, und verwies in diesem Zusammenhang darauf, daß die IBV vor der Saarabstimmung dafür geworben habe, nicht für den Anschluß an das Deutsche Reich zu stimmen.

Auf die Beweggründe der Bibelforscher wies der Stettiner Generalstaatsanwalt Staecker hin. Seiner Ansicht nach würde es sich in gewissem Sinne auch um eine Nachwirkung des Ersten Weltkrieges handeln: „Zahlreiche Menschen, die innerlich zerbrochen sind, haben für ihr religiöses Bedürfnis keine Befriedigung mehr gefunden und sind so auf diese Sekte gestoßen." Doch dies ändere nichts daran, daß die IBV eine ,außerordentliche Gefahr“ darstelle. Besonders ihre „pazifistischen Ideen“ seien geeignet, ,,im Sinne des Kommunismus ausgebeutet zu werden“. Da aber sehr verschiedene Menschen Rückhalt in den Gruppen von Bibelforschern gefunden hätten, hielt Generalstaatsanwalt Staecker eine differenzierte Bewertung in Gerichtsverfahren für erforderlich. Es gebe ,eine ganze Reihe von Personen, die lediglich Mitläufer sind und eine Naivität zeigen, die milde Strafen verständlich erscheinen läßt.“

Der Marienwerder Generalstaatsanwalt Jantzen teilte mit, daß innerhalb seines Bezirkes Elbing als Hochburg der IBV bezeichnet werden könne. Dort sei die Sekte „sehr stark verbreitet“, auch der „,kommunistische Einfluß“ sei ,sehr erheblich“. Allerdings registriere man in der letzten Zeit ,unzweifelhaft ein erhebliches Abflauen“. Dies sei - so Jantzen - sicherlich eine Folge der in seinem Bezirk verhäng-

315 Die im Rahmen der Arbeiten der „, amtlichen Strafrechtskommission“ im Mai 1934 von dem Ministerialrat im RJM Fritz Grau vorgelegten Vorschläge zum Abschnitt „Angriffe gegen die Wehrmacht" enthielten eine Strafbestimmung über die „Teilnahme an einer wehrfeindlichen Verbindung“, die sich nach den Worten Graus gegen ,die pazifistischen Vereinigungen [richtete], die es als ihre Aufgabe betrachten, die Wehrbereitschaft des Volkes zu untergraben oder lächerlich zu machen“ (BA, R 22/962). In einer leicht veränderten Fassung sollte diese Bestimmung als $\S 147$ Eingang in das neue „Deutsche Strafgesetzbuch“ finden. Da dieses nicht verabschiedet wurde, erfolgte nach Kriegsbeginn mit dem $\S 3$ der am 25.11.1939 erlassenen Wehrkraftschutzverordnung die Inkraftsetzung einer entsprechenden Strafbestimmung, die den Gerichten bei „Teilnahme an einer wehrfeindlichen Verbindung" die Verhängung einer Zuchthausstrafe ermöglichte. Siehe S. $345 f$. 
ten „drakonischen Strafen“, die bis zu 3 oder 4 Jahre Gefängnis betragen würden. Der Meinung, daß es eine Abnahme der IBV-Aktivitäten gebe, mochte sich Dr. Sturm, Generalstaatsanwalt in Breslau, jedoch nicht anschließen. Seinem Eindruck nach habe sich die Betätigung der Bibelforscher ,,eher versteift, als daß sie zurückgeht“. Um deren Widerstand zu brechen, schlug der Dresdener Generalstaatsanwalt Jung eine unterschiedliche Behandlung der Bibelforscher in den Gefängnissen vor. Die „Funktionäre“ solle man ausschließlich in Einzelhaft nehmen. Jung hoffte, mittels dieser Isolierung einige Zeugen Jehovas dem Einfluß ihrer „Wortführer“ entziehen zu können: „Unter den Mitläufern gibt es viele, die nur ganz lose mit der I.B.V. in Verbindung stehen. Diese müssen wir beim Strafvollzug von dieser Bewegung wegholen."

Zum Abschluß der Aussprache zog Staatssekretär Dr. Roland Freisler ein vorläufiges Resümee: Es sei deutlich geworden, daß unter den Anwesenden ,über das richtige Maß und die Art der Strafe" keine einhellige Meinung bestehe. Dies finde nicht zuletzt in der Uneinheitlichkeit der verhängten Höchststrafen in den einzelnen OLG-Bezirken seinen Ausdruck. Freisler warnte dann nochmals eindringlich vor einer Verharmlosung der dem Reich von seiten der IBV erwachsenden Bedrohung: „Vielfach sieht man den Bibelforscher als jemanden an, der einer Sekte angehört, über deren geistige Grundlage man lächelt, der man aber nicht mit Gefängnisstrafen entgegentreten will.“ Wer so denke, verkenne die Lage: „Es ist für das Volk eine außerordentliche Gefahr, wenn der Wehrdienst und die Grundlagen unserer Rassengesetzgebung verneint werden. Dieser Gefahr muß in allen Bezirken Rechnung getragen werden."

Falls es der Justiz nicht gelinge, so Freisler, eine Strafzumessungspraxis herbeizuführen, die den Erwartungen aller beteiligten Stellen entspreche, dürfe sie sich nicht wundern, „daß dann das andere Sicherheitsorgan sagt, es habe auch das Seinige zu tun". Mangelnde Entschlossenheit könne die unerwünschte Folge haben, daß ,die Aufgabe der Justiz, Rechtspflege zu üben, von anderen Stellen mitergriffen wird." Damit lenkte Freisler die Aufmerksamkeit der anwesenden Spitzenbeamten auf das Kernproblem der Justiz im nationalsozialistischen Deutschland. In dem Maße, in dem die Gestapo - und niemanden anders meinte Freisler mit den „anderen Stellen“ - sich durch polizeiliche Maßnahmen zum Korrigieren von Entscheidungen, die den Gerichten vorbehalten waren, aufgerufen fühlte, sich also Kompetenzen der Rechtspflege anmaßte und im Sinne einer „Polizeijustiz“ agierte, wuchs der Eindruck, daß die Justiz selbst zunehmend nicht mehr im Stande sei, die ihr ,im totalen Staat“ übertragenen Aufgaben zu bewältigen und damit ihren Beitrag zur Bekämpfung der Staatsfeinde zu leisten. Damit stand letztlich nicht nur das Monopol der Rechtsprechung auf dem Spiel, vielmehr geriet die Justiz als Institution tendenziell in Gefahr, schließlich jede Existenzberechtigung zu verlieren.

Vor diesem Hintergrund ist Freislers Plädoyer für eine klare Abgrenzung der Verantwortlichkeiten zu sehen. Zum einen müsse der Gestapo signalisiert werden, daß die Rechtspflege ,immer Aufgabe der Justiz“ sei. Deshalb dürften keine Vermengungen erfolgen: „Es ist nicht gut, wenn jemand wegen einer Tat, für die er verurteilt worden ist, nach Verbüßung der gerichtlichen Strafe, ohne daß irgendetwas anderes hinzugekommen ist, weiter in einer Haft verbleibt, die ihm als verlän- 
gerte Strafhaft erscheint. Ganz unmöglich ist es, daß sich so etwas in unseren Strafanstalten abspielt. [...] Es ist ausgeschlossen, daß die Strafanstalten dulden oder begünstigen, daß jemand, der bisher als Strafhäftling in einer Zelle saß, nach dieser Strafhaft als Schutzhäftling in der Zelle bleibt.“ Mit der anschließenden Bemerkung, daß für ,polizeiliche Präventivhaft", die im Anschluß an eine Strafhaft erfolge, „die dafür zuständige Stelle auch allein in Frage kommen“ müsse, stellte Freisler dann klar, daß man im Reichsjustizministerium fortan nicht mehr gewillt sei, die den Justizbehörden unterstehenden Hafteinrichtungen den Polizeiorganen für Zwecke der Schutzhaft - jedenfalls insoweit es sich um die sogenannte Nachhaft handelte - zur Verfügung zu stellen. Damit forderte der Staatssekretär folglich von der Gestapo, in diesen Fällen grundsätzlich nur noch Überstellungen in solche Haftstätten vorzunehmen, die ihrem eigenen Zugriff unterlagen, also - letztlich - in die Konzentrationslager der SS.

Dem gegenwärtig erweckten Eindruck, daß ,Stellen außerhalb der Justiz gewissermaßen die Strafzumessungsgründe vorschreiben", müsse andererseits aber auch durch entschlossene Maßnahmen begegnet werden. Freislers Schlußbemerkung wirkte gleichsam nochmals wie ein Appell an die versammelten Spitzenbeamten der Justiz, sich zu vergegenwärtigen, was auf dem Spiele stehe, wenn man die Bekämpfung der Bibelforscher der Gestapo allein überlasse: „Wir können und dürfen von uns aus nirgends den Anschein erwecken, als wären wir nicht der Meinung, daß wir in der Lage sind, gegenüber dem Verbrechertum das Schlußwort des Staates zu sprechen und zu vollziehen.“

Nachdem die Oberlandesgerichtspräsidenten und die Generalstaatsanwälte nun von der im Vorwege zwischen dem Geheimen Staatspolizeiamt und dem Reichsjustizministerium zumindest in Grundzügen bereits festgelegten Übereinkunft unterrichtet worden waren und man ihnen $\mathrm{zu}$ verstehen gegeben hatte, daß ihnen selbst nichts anderes übrigbleibe, als die vereinbarte Verfahrensweise zu akzeptieren, ergingen in rascher Folge die betreffenden nötigen Anordnungen. Mit Runderlaß vom 2. Juli 1937 ordnete der Reichsminister der Justiz an, daß der jeweils zuständigen Staatspolizeistelle die bevorstehende Entlassung von Bibelforschern aus der Strafhaft anzuzeigen und die Gefangenen mit Ende der Justizhaft der Gestapo „zur Verfügung zu stellen“ seien. Über die der Staatspolizei zu gewährende Amtshilfe sollten die Oberstaatsanwälte und die Leiter der Vollzugsanstalten entsprechend in Kenntnis gesetzt werden ${ }^{316}$. Vier Tage später, am 6. Juli, erklärte der Reichsjustizminister in einem Schreiben an den Reichsführer-SS und Chef der Deutschen Polizei sein grundsätzliches Einverständnis mit der Inschutzhaftnahme von Bibelforschern nach Beendigung der Strafhaft in den Fällen, in denen diese sich nicht glaubhaft von der IBV getrennt hätten ${ }^{317}$. Am nächsten Tag schon folgte ein Erlaß, mit dem jenen Bedenken Rechnung getragen wurde, die die Justizbediensteten am nachhaltigsten geäußert hatten: ,Schutzhaft, die gegen Ernste Bibelforscher wegen ihrer Betätigung im Anschluß an eine Freiheitsstrafe, die sie deswegen

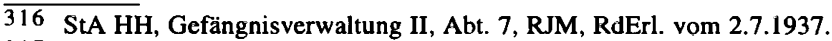

317 Ausweislich der Angabe im Schreiben des RFSS an den RJM vom 8.2.1939, in dem davon die Rede ist, daß das Ministerium sich seinerzeit mit Schreiben vom 6.7.1937 „grundsätzlich mit dieser Sachbehandlung einverstanden erklärt" habe (BA, R 22/1467, Bl. 326). 
verbüßt, oder an eine Untersuchungshaft, die sie deswegen erlitten haben, verhängt wird, ist nicht, und zwar auch nicht vorübergehend, in einer Justizvollzugsanstalt zu vollziehen." ${ }^{318}$ Die Serie der Erlasse beschloß am 8. Juli eine Rundverfügung des Reichsjustizministeriums über die „Ausgestaltung des Strafvollzuges an Ernsten Bibelforschern“319.

Das Geheime Staatspolizeiamt unterrichtete seinerseits am 5. August die Staatspolizeistellen von den getroffenen Abmachungen. Um den örtlichen Repräsentanten der Gestapo zu verdeutlichen, daß sie sich keineswegs durch die in Justizkreisen geäußerte Kritik irritieren zu lassen brauchten, hob der Leiter der Abteilung Innere Politische Polizei, Kriminalrat Heinrich Müller, ausdrücklich hervor, der „Herr Reichsminister der Justiz“ habe ihm mitgeteilt, „,aß er die verschiedentlich von den ihm nachgeordneten Behörden geäußerte Meinung, die Inschutzhaftnahme der Bibelforscher nach Strafverbüßung gefährde die Autorität der Gerichte, nicht teile“ und daß ihm „die Notwendigkeit staatspolizeilicher Maßnahmen auch nach Strafverbüßung [...] durchaus verständlich" sei. Da der Minister jedoch darum gebeten habe, ,die Verbringung der Bibelforscher in Schutzhaft nicht unter Begleitumständen vorzunehmen, die dem Ansehen der Gerichte abträglich sein könnten“, wies Müller im Gestapa-Erlaß vom 5. August 1937 die Staatspolizeistellen zur Beachtung folgender Verfahrensregelungen an:

„1.) Wenn ein Bibelforscher in einem Strafverfahren freigesprochen oder die erkannte Freiheitsstrafe durch die Untersuchungshaft für verbüßt erklärt wird, so hat eine auf Grund meines RdErl. vom 22.4.1937 - II B 2/326/37 S - etwa erforderliche Inschutzhaftnahme im Gerichtssaal selbst zunächst zu unterbleiben. 2.) Wird von den Strafvollstreckungsbehörden über die bevorstehende Entlassung von Bibelforschern aus der Strafhaft Mitteilung gemacht, ist umgehend meine Entscheidung über Anordnung staatspolizeilicher Maßnahmen gemäß meinem vorbezeichneten RdErl. vom 22.4.37 einzuholen, damit die Überführung in ein Konzentrationslager unmittelbar im Anschluß an die Strafverbüßung erfolgen kann. Solange die Überführung in ein Konzentrationslager nicht unmittelbar nach der Strafverbüßung erfolgen kann, sind die Bibelforscher in Polizeigefängnissen unterzubringen. “320

Da nach der Strafverbüßung die weitere Unterbringung in Vollzugsanstalten der Justiz nunmehr grundsätzlich zu unterbleiben hatte, quartierten die Staatspolizeistellen die Zeugen Jehovas, wenn deren Gefängnisstrafe verbüßt, aber von dem Geheimen Staatspolizeiamt noch keine Entscheidung über die Schutzhaft getroffen worden war ${ }^{321}$, vorübergehend - zumeist für einige Wochen - in Polizeigefängnissen, in Verwahranstalten oder Arbeitshäusern ein. In Ausführung des Erlasses

318 BA, R 22/4371, o. Bl., RJM, RdV an alle Generalstaatsanwälte vom 7.7.1937.

319 BA, R 22/1261, Bl. 93, zitiert im Schreiben des Generalstaatsanwalts in Naumburg/Saale vom 22.1.1938 an das RJM.

320 Geheimes Staatspolizeiamt, RdErl. vom 5.8.1937, abgedruckt in: Der Prozeß gegen die Hauptkriegsverbrecher, Band XXXI, S. 13f., Dokument 084-D.

321 Mit dem ,Schutzhafterlaß“ des RMdI vom 25.1.1938 (BA, R 58/1027) wurde die Kompetenz zur Anordnung und Aufhebung der Schutzhaft weiter zentralisiert. Sie lag seitdem ausschließlich bei dem Gestapa in Berlin, d. h. Schutzhaftbefehle waren nur noch von dort auszufertigen. Die Befugnisse der einzelnen Staatspolizei(leit)stellen wurden auf die Anordnung einer „vorläufigen Festnahme“" beschränkt. Vgl. näher Broszat, Konzentrationslager, S. 74f. 
vom 5. August 1937 entwickelte die Gestapo eine bestimmte, einem festen Grundmuster folgende Verfahrensweise, für die das Vorgehen der Staatspolizeileitstelle Karlsruhe im Fall eines Sattlers aus Heidelberg als exemplarisch gelten kann: Gegen diesen Zeugen Jehovas, der nach Verurteilung durch das Sondergericht Mannheim bis zum 21. Oktober 1937 eine achtmonatige Haftstrafe im Bezirksgefängnis Wiesloch zu verbüßen hatte, verfügte die Karlsruher Gestapo im Vorgriff zwei Wochen vor Strafende ,Schutzhaft". Am Tage der Haftentlassung erfolgte dann wie vorgesehen die ebenfalls angeordnete „einstweilige Verschubung nach dem Bewahrungslager Kislau“322. Nach der Bestätigung des Schutzhaftbefehles durch das Geheime Staatspolizeiamt wurde der Sattler am 4. November vom badischen Verwahrungslager Kislau zum Polizeipräsidium München ,zur Einlieferung in das Konzentrationslager Dachau“ überstellt.

Wenn auch die Schutzhaft nach Strafverbüßung sich als direkte Fortsetzung der Haft darstellte, so fand infolge dieser Regelung gleichwohl am Tag des nominellen Haftendes stets die Entfernung aus dem Strafgefängnis statt. Das Justizministerium gab sich damit zufrieden, auf diese Weise wenigstens den Schein gewahrt zu haben. Für die Betroffenen erfolgte am „Entlassungstag“ die Überstellung aus der Verfügungsgewalt der einen Verfolgungsinstanz in die der anderen, also aus den bereits harten Bedingungen des ,geregelten Vollzugs“ in die Ungewißheit der KZs.

\section{Die Funktion der „Reverse“}

Die Gestapo überstellte jedoch keineswegs alle Bibelforscher nach Haftverbüßung in ein Konzentrationslager ${ }^{323}$. Vor dem Erlaß eines Schutzhaftbefehles prüfte sie in eigener Kompetenz, ob die betreffende Person sich weiterhin zu den Zeugen Jehovas bekannte beziehungsweise sich von der IBV als vollständig losgelöst erklärte. Diesem Zweck diente die Vorlage einer ,Verpflichtungserklärung“. Derartige „Reverse“ legten einzelne Gestapo-Stellen nachweislich schon seit 1935 den in Schutzhaft genommenen Bibelforschern bei Haftprüfungen ${ }^{324}$ von Zeit zu Zeit zur Unterschrift vor. Dabei wurden zunächst in den verschiedenen Lagern und Polizeigefängnissen unterschiedliche Textfassungen verwendet, die die förmliche Zusicherung verlangten, sich nicht weiter für die IBV zu betätigen ${ }^{325}$. Wenn die Zeugen Jehovas dies bescheinigten, wurden sie nach Hause entlassen. Die Gestapo verband die Entlassung aus der Schutzhaft allerdings mit der Warnung, daß sie bei Rückfälligkeit nicht mehr mit „Milde“ rechnen könnten.

322 DdW, Schutzhaftakte Julius R., Verwahrungslager Kislau; vgl. auch GBr, Akte/Schutzhäftling, Nr. 1120.

323 In der Literatur wird häufig nicht beachtet, daß die Gestapo nach Haftverbüßung zunächst prüfte, ob eine „Läuterung“" eingetreten war oder ob es sich um einen „unbelehrbaren“ Bibelforscher handelte. So geht Möller, Steinburg, S. 217, unter Bezug auf den Gestapa-Erlaß vom 22.4. 1937 davon aus, daß grundsätzlich , alle zu Gefängnisstrafen verurteilten IBVAngehörigen im Anschluß an die Strafhaft in ein Konzentrationslager überführt" wurden.

324 Der Erlaß des RMdI über die „Verhängung und Vollstreckung der Schutzhaft" vom 12.4.1934 (BA, Sammlung Schumacher/271) schrieb vierteljährliche Haftprüfungstermine vor, mit denen festgestellt werden sollte, ob die Voraussetzungen für die Inhaftierung weiter gegeben waren. Spätere Neufassungen der Schutzhaftbestimmungen ließen diese Regelung unberührt. Vgl. Imberger, Widerstand, S. 299; Zipfel, Kirchenkampf, S. 193. 
Die zuweilen auch bei Verhören vorgelegten Erklärungen ${ }^{326}$ forderten in den ersten Jahren noch nicht die offene Distanzierung vom Glauben der Zeugen Jehovas. So hatte beispielsweise die von der Hamburger Staatspolizeistelle in den Jahren 1937/38 verwendete „Verpflichtungserklärung“ folgenden Wortlaut:

„Ich [...] verpflichtete mich hierdurch, in Zukunft jeden Verkehr mit Angehörigen oder Anhängern der ,Internationalen Bibelforscher-Vereinigung ' (Zeugen Jehovas) zum Zwecke des Bibel-, Wachtturm- und sonstigen Bibelforscherstudiums aufzugeben und mich jeder Betätigung als Zeuge Jehovas zu enthalten.

Ich bin darauf hingewiesen worden, daß jegliches Zusammenkommen mit anderen Zeugen Jehovas, auch wenn diese Treffs in Form von Kränzchen oder Familienfeiern stattfinden, unter das Verbot der Fortführung der Bibelforschervereinigung fällt.

Ich bin bereit, alles Bibelforscher-Schriftenmaterial, das mir in Zukunft zugehen sollte, der Staatspolizeistelle zu übergeben. Evtl. Wahrnehmungen, aus denen zu schließen ist, daß sich andere Personen zum Zwecke des organisatorischen Zusammenhalts der Zeugen Jehovas erneut zusammenfinden, will ich ebenfalls sofort der Staatspolizei anzeigen." 327

Die Unterschrift unter diesen oder einen ähnlichen Revers konnte bei Angehörigen der IBV, denen nur geringfügige Vergehen vorgeworfen wurden, auch dann die unmittelbare Freilassung aus der Schutzhaft zur Folge haben, wenn gegen sie ein Strafverfahren lief, so daß die Beschuldigten bis zum Prozeßtermin von weiteren Haftmaßnahmen verschont blieben.

Unter den Zeugen Jehovas war es umstritten, ob man eine derartige Erklärung unterzeichnen dürfe; da sie aber keine Verleugnung des Glaubens forderte und im Blick auf ihre anderen Forderungen in Bibelforscherkreisen teilweise für die Einnahme eines eher taktischen Verhältnisses votiert wurde, leisteten nicht wenige Zeugen Jehovas - wenn auch mit Skrupeln - die Unterschrift ${ }^{328}$. Von jenen, die den Revers als eine das Gewissen nicht bindende Nötigung empfanden, wurde etwa die Position vertreten, daß man ein solches Schreiben unterzeichnen könne, weil man ,den Teufel ruhig belügen“ dürfe, wenn man „dadurch wieder frei würde, um Jehova draußen noch besser dienen zu können“"329. Auch kam es zum Teil in den Familien zu Absprachen, wer den Widerstand aufgebe und „unterschreibe“,

$\overline{326}$ In der Literatur werden die Verpflichtungserklärungen vielfach lediglich im Zusammenhang mit ihrer Vorlage in den Konzentrationslagern erwähnt und infolgedessen ausschließlich als eine Art „Entlassungsangebot“ gedeutet (vgl. etwa Kater, Bibelforscher, S. 190). Über ihre Verwendung im KZ hinaus wurden die Reverse jedoch mit unterschiedlichen Funktionen auch ansonsten von der Gestapo eingesetzt. Dies reichte vom präventiv vorgelegten Loyalitätsrevers bei einer Gestapo-Vorladung bis zur seit 1937 institutionalisierten Praxis für die Verhängung von „Nachhaft“, bei der die Entscheidung über den Erlaß eines Schutzhaftbefehles nach Haftverbüßung - unter anderem - von der Unterschriftsleistung abhängig gemacht wurde. SLG HH, HSG 11 Js. Sond. 298/38, Verpflichtungserklärung.

329 Jahrbuch 1974, S. 170. Die NS-Propagandisten warfen den Zeugen Jehovas deshalb vor, dem "Grundsatz einer relativen Wahrheitspflicht“" (VB 25.4.1937) zu huldigen; die Gestapo befand: „Das Verbot der IBV in Deutschland hat dazu geführt, daß den Anhängern sogar gestattet ist, zu lügen. Das Gewissen wird damit beruhigt, daß ihnen gesagt worden ist: Ihr braucht der Polizei, dem Gericht, nicht die Wahrheit zu sagen, weil diese Einrichtungen nicht von Gott geschaffen, sondern Satansorganisation sind, und Satan braucht man nicht die Wahrheit zu sagen." (DCB, VGH, 8 J 20/38, Bl. 24, Stapo Hamburg, Abschlußbericht vom 21.12.1937) 
damit ein Elternteil den Kindern erhalten blieb, um diese dadurch vor dem Zugriff der NS-Behörden zu schützen. In einigen Fällen schien es den IBV-Angehörigen deshalb möglich zu unterschreiben, weil in der betreffenden Textfassung nur von „Bibelforschern“, nicht aber von „Zeugen Jehovas“ gesprochen wurde ${ }^{330}$. Andere, die unterschrieben, waren zwar tatsächlich bereit, sich nicht mehr für die IBV zu betätigen, ihren Glauben wollten aber auch sie auf keinen Fall verleugnen ${ }^{331}$.

Am Fall von 49 Angehörigen der IBV-,,Gruppe Hamburg II“, die im Herbst 1937 verhaftet und ins Polizeigefängnis Fuhlsbüttel eingeliefert worden waren, läßt sich die Verfahrensweise verdeutlichen ${ }^{332}$. Der mit dem Vorgang befaßte GestapoZuständige legte nach Abschluß der Vorermittlungen in den Tagen zwischen dem 28. Januar und dem 4. Februar 1938 die Verpflichtungserklärungen denjenigen Beschuldigten zur Unterschrift vor, die als „Mitläufer“ eingestuft worden waren. Erfolgte die Unterschrift, so wurde der oder die Betreffende in der Regel noch am gleichen Tag aus der Schutzhaft entlassen; bis zum Prozeßbeginn blieb er oder sie auf freiem Fuß. Wurde die Unterzeichnung verweigert, so verblieben die Betreffenden vorerst in Schutzhaft, nach einigen Tagen erfolgte die Vorführung beim Haftrichter zwecks Erlaß eines Haftbefehles. Grundsätzlich wurde ein Haftbefehl bei den ,Funktionären“ (Zellen- und Gruppendienern) und bei schwerer Beschuldigten erwirkt. Insgesamt ergibt sich folgendes Bild:

Tabelle 3: Abgabe von „Verpflichtungserklärungen“ am Beispiel eines Anfang 1938 durchgeführten Ermittlungsverfahrens gegen die IBV-Gruppe „Hamburg II"

Gestapo-Akten:

49

$(100 \%)$

Revers unterschrieben/Entlassung aus der Schutzhaft:

Erlaß eines Haftbefehls:

Entlassung aus der Schutzhaft aufgrund Krankheit

oder hohen Alters vor Ende der Vorermittlungen:

Während der Vorermittlungen verstorben:

330 Vgl. Jahrbuch 1974, S. 170. Diese Haltung ist in den Verhören in den ersten Jahren oftmals eingenommen worden und schlug sich in den Protokollen etwa wie folgt nieder: „Ich bekenne mich nicht zu der IBV, sondern als Zeuge Jehovas" (SLG HH, SH SG 11 Son KMs 149/36, B1. 63, Aussage vor der Ortspolizeibehörde Itzehoe vom 28.9.1936). Da die Gläubigen sich seit der Neuorientierung von 1931 als von Jehova berufene Zeugen verstanden, bereitete es für sie keine unüberwindlichen Schwierigkeiten, eine Mitgliedschaft bei den „,Bibelforschern“ in Abrede zu stellen, während eine Zugehörigkeit zu den „Zeugen Jehovas“ von ihnen in den seltensten Fällen verleugnet wurde.

$331 \mathrm{Vgl}$. beispielsweise die von einem Krefelder Bibelforscher gegenüber der Gestapo am 20.9. $1938 \mathrm{zu}$ Protokoll gegebene Aussage: „Ich habe jetzt meine zweite Strafe verbüßt und verpflichte mich, niemals mehr illegal für die IBV tätig zu sein, bleibe aber meiner Gesinnung treu. Im Falle eines Krieges will ich jede Arbeit verrichten, aber nicht mit der Waffe in der Hand kämpfen." (Zit. nach Billstein, Krefeld, S. 307)

332 SLG HH, HSG 11 Js. Sond. 298/38. Die Angaben sind hier möglich, da in diesem Fall den staatsanwaltschaftlichen Ermittlungsakten bis auf zwei Ausnahmen noch die jeweiligen Gestapo-Personalakten beilagen, die üblicherweise nach Abschluß des Verfahrens an die Staatspolizeistelle zurückgereicht wurden. Neben Beschuldigtenbogen, Erkennungsblatt, Vernehmungsprotokollen etc. befanden sich in ihnen auch die Verpflichtungserklärungen. 
Im Vergleich zu späteren Jahren war die Zahl derjenigen, die unterschrieben, vergleichsweise hoch ${ }^{333}$. Bei Vorlage des Revers nach Haftverbüßung scheint der Prozentsatz in den Vorkriegsjahren sich in etwa der gleichen Größenordnung bewegt zu haben ${ }^{334}$. Jedenfalls ist der Unterschied zu der sehr niedrigen Zahl von Verpflichtungserklärungen, die in den folgenden Jahren durch Bibelforscher-Häftlinge in den Konzentrationslagern abgegeben wurden, signifikant. Dies läßt sich auf mehrere Gründe zurückführen: Während es sich bei den KZ-Gefangenen um „Aktivisten“ handelte, die in aller Regel bereits mehrfach durch die Ablehnung der Unterschriftsleistung ihre Standhaftigkeit gezeigt hatten, befanden sich in der Gefängnis- oder kurzfristigen Schutzhaft auch viele, die aufgrund der erstmaligen Bekanntschaft mit Gefängnismauern den Schock der Hafterfahrung noch zu verarbeiten hatten. Hinzu kam die Isolierung in den Haftanstalten; in den Einzelzellen oder in der Unterbringung mit Andersgläubigen fehlte jener Rückhalt, den die Gemeinschaft mit den Glaubensgeschwistern in den Lagern zu geben vermochte ${ }^{335}$.

Ein - wenn nicht der wesentliche - Grund ist jedoch darin zu sehen, daß mit der Ende 1938 erfolgten Anordnung eines einheitlichen Formulares der Charakter des Revers sich von einer Wohlverhaltens-, Unterlassungs- und Bereitschaftserklärung zur Denunziation und Kooperation mit der Polizei - und damit insgesamt auf äußere Handlungen bezogenen Angelegenheit zu einer Gesinnungs- bzw. Abschwörungserklärung veränderte. Diese Akzentverschiebung setzte die Zeugen Jehovas außerstande, die geforderte Unterschrift zu leisten.

Noch die Erklärung, die laut Erlaß des Geheimen Staatspolizeiamtes vom 4. Mai 1938 denjenigen Bibelforschern vorgelegt werden mußte, die unter das Amnestiegesetz vom 30. April 1938 fielen $^{336}$, forderte , lediglich' die Abgabe einer Versicherung, ,sich nicht mehr für die IBV zu betätigen und auch kein Zeugnis mehr für die IBV abzulegen“. Zur Ausführung bestimmte das Gestapa: „Unterschreiben die Bibelforscher diese Erklärung, sind sie zu entlassen. Soweit diese Erklärung nicht unterschrieben wird, sind sie vorläufig festzunehmen. Thre Inschutzhaftnahme ist in der üblichen Form zu beantragen."337 Der Staatspolizeistelle München, die zehn Tage später den Gestapa-Erlaß weitergab, schien diese formale Handhabung und eine alleinige Zusicherung der Nicht-Betätigung nicht hinreichend. Sie fügte ver-

$\overline{333}$ Nach den Feststellungen von Christl Wickert, die die Düsseldorfer Gestapo-Akten über Bibelforscherinnen ausgewertet hat, ,unterschrieben die erzwungene Erklärung des Abschwörens von ihrer Religionsgemeinschaft mehr als die Hälfte der Verdächtigten und Angeklagten“" (Wickert, Frauen, S. 218).

334 Anfangs war auch die Zahl der in den Konzentrationslagern abgegebenen Verpflichtungserklärungen im Vergleich zu den späteren Jahren bedeutend höher. So sollen $1935 \mathrm{im} \mathrm{KZ} \mathrm{Ester-}$ wegen 13 von ca. 120 Bibelforscher-Häftlingen unterschrieben haben, d. h. ungefähr jeder Zehnte. Vgl. Erwachet!, 22.11.1992, S. 19.

335 Vgl. Lichtenegger, Wiens Bibelforscherinnen, S. 172. Ob es im Blick auf die vergleichsweise höhere Zahl von Unterschriften ,während der U-Haft" allerdings angemessen ist, von den ,,Schattenseiten “ des Bibelforscherwiderstandes“ (ebenda) zu sprechen, sei dahin gestellt. Diese fragwürdige Sichtweise ist $\mathrm{m}$. E. Folge einer naiv verklärten Retrospektive, die danach trachtet, Widerstandsgeschichte zu einem Heldenepos zu verdichten, und dabei die realen $\mathrm{Be}-$ dingungen menschlichen Handelns außer acht läßt.

336 Gesetz über die Gewährung von Straffreiheit vom 30.4.1938, RGB1. 1938 I, S. 433.

337 BA, Sammlung Schumacher/267 I, Geheimes Staatspolizeiamt, Erlaß vom 4.5.1938, zitiert im RdErl. der Staatspolizeileitstelle München vom 14.5.1938. 
schärfend hinzu, daß „eine Entlassung der unter das Amnestiegesetz fallenden Bibelforscher in den meisten Fällen erst dann möglich ist, wenn sie sich entsprechend umgestellt haben und bei ihrer Freilassung keine Gefährdung der öffentlichen Ordnung und Sicherheit mehr zu befürchten ist. Dies ist insbesondere dann nicht mehr anzunehmen, wenn die Bibelforscher neben der vorerwähnten Erklärung auch zu der Überzeugung gekommen sind, daß eine Einordnung in die Volksgemeinschaft notwendig und sie gewillt sind, ihren staatsbürgerlichen Pflichten wie Teilnahme an Wahlen, Ableistung des Heeresdienstes, Beteiligung am Luftschutzdienst usw. nachzukommen." 338

Indem die Münchener Gestapo über die Unterschriftsleistung zu dem bis dahin üblichen Revers hinaus eine Glaubhaftmachung der Einsicht in und Umstellung auf jene „staatsbürgerlichen Pflichten“ forderte, deren Befolgung den Zeugen Jehovas aufgrund ihres Glaubens nicht möglich war, wurde die Akzentverlagerung bereits eingeleitet.

Mit Runderlaß vom 24. Dezember 1938 übermittelte das Geheime Staatspolizeiamt eine Anordnung des Reichsführers-SS und Chefs der Deutschen Polizei, wonach an Stelle der bislang in ihrem Wortlaut unterschiedlichen und, wie das Gestapa bemängelte, ,inhaltlich und stilistisch zu beanstandenden“ Verpflichtungserklärungen in Zukunft nur noch eine einheitliche Fassung verwendet werden dürfe. Deren ausschließliche Verwendung wurde auch für die Konzentrationslager angeordnet. Für diese ,einheitliche Verpflichtungserklärung der zur Entlassung kommenden Bibelforscher" wurde der folgende Wortlaut verbindlich:

„Erklärung. Ich habe erkannt, daß die Internationale Bibelforscher-Vereinigung eine Irrlehre verbreitet und unter dem Deckmantel der religiösen Betätigung lediglich staatsfeindliche Ziele verfolgt. Ich habe mich deshalb voll und ganz von dieser Organisation abgewandt und mich auch innerlich von der Lehre dieser Sekte freigemacht. Ich versichere hiermit, daß ich mich nie wieder für die Internationale Bibelforschervereinigung betätigen werde. Personen, die für die Irrlehre der Bibelforscher werbend an mich herantreten, werde ich umgehend zur Anzeige bringen. Sollten mir Bibelforscherzeitschriften zugesandt werden, werde ich sie umgehend bei der nächsten Polizeidienststelle abgeben. Ich will künftig die Gesetze des Staates achten und mich voll und ganz in die Volksgemeinschaft eingliedern. Mir ist eröffnet worden, daß ich mit meiner sofortigen erneuten Inschutzhaftnahme zu rechnen habe, wenn ich meiner heute abgegebenen Erklärung zuwider handele."339

In der Übermittlung dieser Textfassung durch die Staatspolizeileitstelle München wurde von dieser unterstrichen, daß eine Schutzhaftaufhebung bei „zur Entlassung vorgeschlagenen bzw. in Aussicht genommenen Bibelforschern" nur bei Unterzeichnung der Erklärung erfolgen könne ${ }^{340}$, da bei Ablehnung der Unterschrift an-

338 BA, Sammlung Schumacher/267 I, Staatspolizeileitstelle München, RdErl. vom 14.5.1938.

339 In der im RSHA bis Ende 1942 geführten „Kurzzusammenstellung in Sektenangelegenheiten ergangener Erlasse“ ist die Gestapa-Verfügung vom 24.12.1938 unter der Ifd. Nr. 25/MBV verzeichnet (BA, R 58/1074, Bl. 30). Der Wortlaut des Gestapa-Runderlasses ist zitiert in der RdV der Staatspolizeistelle Düsseldorf vom 6.1.1939, abgedruckt in: Steinberg, Essen, S. 282.

340 Soweit bekannt, ist es bis zur 1943/44 erfolgten Neuregelung - sieht man einmal von ganz wenigen besonders gelagerten Einzelfällen ab - nur einmal zu Entlassungen von Bibelforscher-Häftlingen aus Konzentrationslagern gekommen, ohne daß diese die geforderte Unter- 
genommen werden müsse, ,daß sich die Bibelforscher innerlich noch nicht umgestellt haben" 341 .

Für die Gestapo stellte fortan allein die Verweigerung der Unterschrift einen hinreichenden Grund für die Einweisung in ein Konzentrationslager dar. So wurde beispielsweise ein Schutzhaftbefehl vom Geheimen Staatspolizeiamt am 15.4.1941 mit der folgenden Begründung erlassen: „Emma S. wird in Schutzhaft genommen. Gründe: Sie gefährdet [...] durch ihr Verhalten den Bestand und die Sicherheit des Volkes und Staates, indem sie auf Grund ihrer fanatischen Einstellung für die IBV, die sie durch Unterschriftsverweigerung unter die Verpflichtungserklärung deutlich zeigt, zu der Befürchtung Anlaß gibt, sie werde ihre Freiheit auch nach Strafverbüßung zu erneuter Betätigung für die Irrlehre der IBV benutzen. “342

Die Forderung, den Bibelforscherglauben als „Irrlehre“ zu verleugnen, nahm den Zeugen Jehovas jeden Spielraum. Eine solche Erklärung zu unterzeichnen, war für sie gänzlich unmöglich, da dies in ihren Augen einem „Verrat“ an dem Gott gegebenen Treueversprechen gleichkam. Viele Zeugen Jehovas waren eher bereit $\mathrm{zu}$ sterben, als sich dazu bereit zu finden.

Mit der Vorlage von Erklärungen zur „Gesinnungsprüfung“ arbeitete im „Dritten Reich“ nicht nur die Gestapo; zuweilen entwickelten auf örtlicher Ebene Parteistellen eigene Initiativen. So schrieb im Frühjahr 1937 der NSDAP-Kreisleiter von Waldenburg alle Personen an, die der Bibelforschervereinigung im Kreis angehört hatten, aber auch jene, von denen nur bekannt war, daß sie ihr früher einmal nahegestanden oder mit ihr ,,sympathisiert“ hatten ${ }^{343}$. Diese Personen wurden aufgefordert, eine beigefügte „Ehrenerklärung“, mit der sie sich förmlich vom Gedankengut der Bibelforscher lossagen könnten, binnen zwei Wochen unterschrieben zurückzureichen. Diesen Weg halte er für angebracht, so erklärte der Kreisleiter im Fürsorge

schrift geleistet hatten. Diese Entlassungen waren auf die Amnestie anläßlich des 50. Geburtstages Hitlers am 20.4.1939 zurückzuführen, zu der letztmalig im größeren Umfang Schutzhäftlinge aller Kategorien aus den KZs entlassen wurden. Wer dafür in Frage kam, bestimmte der Chef der Sicherheitspolizei in Absprache mit den Staatspolizeistellen. In den Richtlinien, die Heydrich mit Runderlaß vom 5.4.1939 den Staatspolizeistellen bekanntgab, wurde unter Punkt 5 verfügt, daß freizulassen seien: „Über 60 Jahre alte Schutzhäftlinge; darunter auch die unbelehrbaren Bibelforscher, die noch heute die Abgabe einer Loyalitätserklärung verweigern, soweit sie kriminell nicht vorbestraft sind.“ (BA, R 58/264, Bl. 376378, Der Chef der Sicherheitspolizei, RdErl. vom 5.4.1939) Im KZ Buchenwald erfolgte am 20./21.4.1939 die Entlassung von 53 Zeugen Jehovas, die höchstwahrscheinlich auf die ,Geburtstags-Amnestie' zurïckzuführen ist. Vgl. BA, NS 4 Bu/vorl. 137, KZ Buchenwald, Tägliche Stärke-Meldungen.

341 BA, Sammlung Schumacher/267 I, Staatspolizeileitstelle München, RdErl. vom 23.1.1939.

342 AfW HH, 260488, BI. 29, Schutzhaftbefehl vom 15.4.1941. Teilweise haben die Staatspolizeistellen bei Verweigerung der Unterschriftsleistung sich dieses von dem oder der Betreffenden bestätigen lassen. So mußte am 3.4.1944 die 36jährige Eleonore Müller, die nach Beendigung einer zweijährigen Gefängnishaft in Polizeihaft genommen worden war und bei der Staatspolizeistelle Düsseldorf die Unterzeichnung der ihr vorgelegten Verpflichtungserklärung verweigert hatte, ihre Ablehnung durch Unterschrift unter die folgende Passage des Vernehmungsprotokolles bekräftigen: „Die von mir gewünschte ,Erklärung [...]' kann ich niemals unterschreiben, weil ich erstens nicht erkannt habe, da $\beta$ die IBV. eine Irrlehre verbreitet, und weil ich zweitens auch innerlich mich nicht von dieser Lehre freigemacht habe. Meiner nunmehrigen Überstellung in ein Konzentrationslager sehe ich mit Ruhe entgegen." (Protokoll vom 3.4.1944, abgedruckt in: Steinberg, Essen, S. 283)

343 Kreisleitung Waldenburg, Schreiben vom 5.4.1937, abgedruckt in: Zürcher, Kreuzzug, o. S. (Abdruck nach S. 192). 
heuchelnden Ton, weil er verhindern wolle, „daß an sich unschuldige und ehrliche Volksgenossen bestraft werden“. Wer die Erklärung jedoch nicht unterzeichne, von dem müsse er annehmen, daß er sich offensichtlich gegen Partei und Staat stelle. Mit entsprechenden „Konsequenzen“ hätten solche dann folglich zu rechnen. Diese „Ehrenerklärung“, in schroffer Diktion verfaßt, nötigte die Unterzeichnenden zu großen Zugeständnissen. Gefordert wurde beispielsweise nicht nur die Versicherung, künftig die Gesetze und Anweisungen von Staat und Partei gewissenhaft zu befolgen, sondern auch ,den Geist des Führers“ in der Familie, und zwar ,besonders im Herzen“ der Kinder aufzurichten.

Erfolgte die Vorlage der Verpflichtungserklärungen durch die Gestapo zunächst nur dann, wenn Zeugen Jehovas sich in ihrer Zuständigkeit und Gewalt befanden (Verhör, Schutzhaft, KZ), so wirkten sich ab etwa 1938 die Absprachen zwischen Justizverwaltung und Gestapo-Führung auch auf diesem Gebiet aus. Zunehmend häufiger wurde es nun üblich, den Revers entweder bereits Wochen vor dem Termin des Vollzugsendes oder am Tage der Entlassung noch im Gefängnis vorzulegen. Auf diese Weise vermied man den Eindruck einer erst erfolgten Entlassung und einer anschließenden polizeilichen Inhaftnahme; der Vorgang nahm nun immer stärker den Charakter einer ,geregelten“ Überstellung an. Zwar erschienen zum Zwecke der Vorlage des Revers zumeist zwei Gestapo-Beamte in der Vollzugsanstalt ${ }^{344}$, doch zumindest indirekt wirkten jetzt auch Justizbedienstete an dieser Gesinnungsprüfung mit dem Ziel der Identitätsbrechung mit.

Handelte es sich für die Gestapo bei den Bibelforschern im Grunde um ,unverbesserliche Elemente“, die es „rücksichtslos auszuschalten" gelte, so waren Gefängnisleiter und andere Justizbeamte doch noch so weit vom Denken in den Kategorien der „Besserung“ und der „Erreichung des Vollzugszweckes“ geprägt, daß sie bei jenen Zeugen Jehovas, die sie für ,gebessert“ hielten - bei den „Unbelehrbaren" plädierten sie in ihren Beurteilungen in Gestapo-Diktion ebenfalls auf „Unterbringung in Konzentrationslagern“ $345_{-}$, nachdrücklich darauf hinzuwirken versuchten, daß diese unterschrieben. Dabei blieb für die Justizbeamten die Unbeugsamkeit der Zeugen Jehovas im Grunde unerklärlich: Wie konnte jemand, obwohl ihm die Möglichkeit zum Weg in die „Freiheit“ offenstand, ,den Weg ins Konzentrationslager wählen"? So kam es, daß für die Zeugen Jehovas bei der Vorlage des Revers oftmals die Justizbeamten die größere Bedrohung ausmachten, mochten diese auch das „Beste“ im Interesse ,,ihrer“ Gefangenen zu erreichen suchen. Der Bericht eines Hamburger Zeugen Jehovas, der eine zweieinhalbjährige Gefängnishaft in Fuhlsbüttel, Wolfenbüttel und den Emslandlagern verbüßt hatte, veranschaulicht dies auf prägnante Weise:

„Für mich kam nun die Zeit heran, wo meine Strafhaft ablief. Es war am 19.4.1940. Da sollte ich entlassen werden, morgens um 9.00 Uhr. Ich wurde aber gleich von Gestapo-Beamten in Emp-

$\overline{344}$ Die Hamburger Staatspolizeileitstelle, aber vermutlich nicht nur diese, ging bereits im Jahre 1939 in einigen Fällen zu einer Art Verwaltungsvereinfachung über. Sie übersandte den Gefängnisleitungen den Vordruck der Verpflichtungserklärung mit der Bitte um weitere Veranlassung (vgl. SLG HH, HSG 11 Js. Sond. 298/38). Der Gestapo bereitete dieser Weg keine Probleme, lag doch die endgültige Entscheidung in jedem Fall weiterhin in ihren Händen. 
fang genommen. In Gegenwart des Justiz-Beamten wurde ich gefragt, wie heute meine Einstellung zu meinem Glauben sei und ob ich weiterhin ein Bibelforscher oder Zeuge Jehovas bleiben wolle. [...] Mir wurde nun gesagt, ich könnte noch heute entlassen werden, wenn ich einwilligen würde, mich nicht mehr für die IBV zu betätigen und auch in meiner Heimat mit niemanden über meine Strafhaft zu sprechen, darüber hinaus mich mit keinem Menschen über meinen Glauben zu unterhalten. Dies hatte ich erwartet; es befremdete mich nicht, daß man so mit uns verfahren würde. Die Gestapo-Beamten verhielten sich noch einigermaßen, aber ich hatte ja noch mit dem JustizBeamten zu tun, der meine Entlassung durchführen sollte. Eine Viertelstunde hielt er einen Vortrag, lobte meine gute Führung während der Strafhaft. Er sagte, ich hätte mich während der ganzen Zeit mustergültig verhalten; jetzt sollte ich aber an meine Zukunft und an meine Familie denken. Es wäre doch nichts dabei, ich könnte doch auf dieses Angebot eingehen und dann wäre ich wieder frei. [...] Ich gab zur Antwort, den Inhalt kenne ich und aus der Unterhaltung ginge hervor, daß man mich unter Druck setzen wolle, daß ich meinen Glauben verleugnete. Ich würde dies nie unterschreiben. Der Justiz-Beamte wurde leichenblaß und tobte und drohte alles mögliche mit mir zu machen. Er stellte mich als einen Verrückten hin. In seiner Raserei hätte ich wohl sonst was von ihm erwarten können, wenn nicht die Gestapo-Beamten dabei gewesen wären. “346

Nach seiner Unterschriftsverweigerung wurde dieser Zeuge Jehovas aus dem emsländischen Strafgefangenenlager Neusustrum vorübergehend zur Zwischenhaft nach Lingen überführt. Die drei dort verbrachten Tage bedeuteten für den 36jährigen Kupferschmied eine harte Prüfung. Seine Gedanken zeigen, welch psychischer Druck in dieser Situation auf den Zeugen Jehovas lastete:

„Man war sehr freundlich zu mir und ließ durchblicken, daß ich doch nachgeben sollte, dann könnte ich zur Entlassung nach Hamburg kommen. Man hielt mir auch vor, daß ich doch an meine Familie denken sollte. Gerade dies tat ich auch, aber ich dachte auch an meine [Glaubens]Brüder. Ich versuchte den ganzen Tag ruhig zu bleiben, aber meine Gedanken arbeiteten ununterbrochen. Einmal erwog ich die Entlassung, dann wieder eine Einlieferung in ein Konzentrations-Lager. [...] Vom Nachmittag bis zum Abend versuchte ich mich zu beherrschen; aber des Nachts' konnte ich dann nicht mehr schlafen. Wie es kam, weiß ich nicht, aber ich habe fast die ganze Nacht bitterlich geweint und hatte ein fürchterliches Heimweh nach zu Hause, zu meiner Familie. Ich habe zu Jehova gefleht, er möge mir dies Heimweh nehmen, er möchte alles so geschehen lassen, wie er es möchte; nur davor möchte er mich bewahren, daß ich nicht in der letzten entscheidenden Stunde noch einen Kompromiß eingehen werde [...]. Gespannt war ich, was der nächste Tag bringen würde, ein Tag den ich nie niemals vergessen werde. Es war der 20. April, der Geburtstag des größten Feindes unseres Glaubens, der sich vorgenommen hatte auch meinen Glauben zu schwächen, wie er es schon mit vielen anderen versuchte. Mir kam die Resolution vom 7. Oktober 1934 in den Sinn und ich sagte mir, es muß sich erweisen, wer stärker ist: Unser Gott Jehova, oder der Gott Hitler.“

Für die Zeugen Jehovas wurde der „Revers“ zum Symbol für die ihnen auferlegte Prüfung; für sie galt es ihre „Loyalität gegenüber Jehova und seiner Organisation“ unter Beweis zu stellen und ihre „Lauterkeit“ zu wahren. Aus diesem Grunde bezeichneten sie diese Befragungen auch als „Treuevernehmung“"347.

346 EB Willi Lehmbecker, 15.4.1971.

347 Vgl. Hartmann, Kriegsdienstverweigerung (1982), S. 93. 
Oftmals erhöhte sich die nervliche Belastung noch dadurch, daß Angehörige auf eine Unterschrift drängten. Die Gestapo machte sich diesen Umstand zunutze und arrangierte kurz vor oder nach dem Haftende Zusammentreffen der unbeugsamen Zeugen Jehovas mit ihren Ehepartnern, Kindern oder Eltern. Das Kalkül, daß jene sich unter dem Flehen ihrer Angehörigen erweichen lassen würden, ging in nicht wenigen Fällen auf. Primäres Ziel bei diesem „Bemühen“ der Gestapo war es allerdings nicht, Entlassungsvoraussetzungen herbeizuführen, sondern es ging um die Brechung der Identität jener Bekenner, die - so wußte auch die Gestapo - nach einer erfolgten Unterschrift nicht selten in eine tiefe Glaubenskrise gerieten ${ }^{348}$.

\section{Justizproteste gegen ,zweckwidrige Schutzhaft"}

Im Gegensatz zum Problemkreis der Inschutzhaftnahme von IBV-Anhängern nach Strafverbüßung war auf der „Chefpräsidentenbesprechung“ vom 18. Juni 1937 eine Klärung hinsichtlich der von den Gerichten heftig kritisierten Verhängung von Schutzhaft bei freisprechendem Urteil weitgehend unterblieben. Diese für das Verhältnis von Gestapo und Justiz noch weit konfliktträchtigere Frage führte auch in den folgenden Jahren immer wieder zu Auseinandersetzungen. Nachdem in Hamburg abermals in mehreren Fällen nach Freispruch oder nach bereits durch die Untersuchungshaft abgegoltenen Strafen Schutzhaftbefehle erlassen worden waren, entschloß sich Dr. Curt Rothenberger, Präsident des Hanseatischen Oberlandesgerichtes und Protagonist einer „nationalsozialistischen Justizreform“, die der „Rechtspflege“ auch im ,totalen Staat" ihre Existenzberechtigung durch entschlossenere und härtere Handhabung der Strafgewalt zu sichern suchte, im Frühjahr $1938 \mathrm{zu}$ einem entschiedenen Protest gegen solche Formen polizeilicher Urteilskorrektur $^{349}$. Den konkreten Anlaß boten die Fälle zweier Zeugen Jehovas. Dabei war der eine vom Hanseatischen Sondergericht mit der Begründung, daß er sich ,anscheinend gewandelt habe", zu der - angesichts einer mittlerweile rapide verschärften Spruchpraxis in Bibelforscherverfahren - verhältnismäßig geringen Strafe von acht Monaten Gefängnis verurteilt worden, die unter Anrechnung der Schutzund Untersuchungshaft als verbüßt erklärt wurde. Das Gericht hatte überdies ausdrücklich betont, es votiere auch deshalb für Freilassung, damit der Angeklagte die Gelegenheit erhalte, ,sein als glaubwürdig erscheinendes Bekenntnis zum Nationalsozialismus durch die Tat zu erhärten“ 350 .

Die Staatspolizei sah dies allerdings anders: Nach Ende des Verfahrens erfolgte die erneute Festnahme des Mannes und seine anschließende Verbringung in das

348 Wie es bei solchen Begegnungen zuging, deutet der folgende Berichtsausschnitt an: „Meine Frau weinte, meine kleine Tochter hing mir am Hals und bat: ,Papa, komm doch nach Haus!' Ich wurde weich und erklärte mich bereit, das Schriftstück am nächsten Tag zu unterzeichnen. Als ich wieder in die Zelle zurückgebracht wurde, kam mir die Tragweite meines Entschlusses zu Bewußtsein. Unter Tränen bereute ich meinen Fehlentschluß und flehte zu Jehova um Vergebung." (Zit. nach Menzinger, Jugend, S. 120)

349 Zu den Protestnoten Rothenbergers gegen „Urteilskorrekturen“ vgl. auch Gruchmann, Justiz, S. 623-626; Johe, Justiz, S. 156-160.

350 StA HH, Hanseatisches Oberlandesgericht Hamburg, Präsidialabteilung, 461-3a/1, Bl. 75. 
Polizeigefängnis Fuhlsbüttel ${ }^{351}$. Die Gestapo hatte also mit der Inschutzhaftnahme, die voraussetzte, daß eine Gefahr für die öffentliche Sicherheit fortbestand, die Begründung des Gerichtes bewußt konterkariert.

Die Richter fühlten sich folglich brüskiert; derartige polizeiliche Eingriffe wurden als totale Infragestellung eigener Kompetenzen empfunden. In einer für Rothenberger angefertigten Stellungnahme heißt es zu diesem Vorgang:

„Was unter diesen Umständen eine Strafzumessung und ihre Begründung für einen Sinn haben soll, ist unklar. [...] Die Richterschaft muß letzten Endes das Gefühl der Sinnlosigkeit ihrer Arbeit bekommen, wenn, wie dies z. B. in dem ganz krassen Fall P. sich zeigt, ihre sorgfältig begründeten und ausgeführten Überlegungen zum Strafmaß praktisch bedeutungslos sind, weil die Dauer der Freiheitsentziehung unter Außerachtlassung all dieser im Urteil ausgeführten Gründe einfach von einem Unterbeamten der Staatspolizei festgesetzt wird. “352

Mit Schreiben vom 25. April 1938 legte Rothenberger beim Leiter der Hamburger Staatspolizeileitstelle, Oberregierungsrat Bruno Streckenbach, Protest gegen die Verfahrensweise der Gestapo ein. Der Einspruch wurde, nachdem zuvor - mit dem Bemerken, daß die Schutzhaft andernorts verfügt worden sei - lediglich ausweichend reagiert worden war, von Streckenbach schließlich am 7. Oktober - also nach nahezu einem halben Jahr - ohne Erörterung des Einzelfalles unter Verweis auf den Gestapa-Erlaß vom 22. April 1937 pauschal zurückgewiesen. Die Art, in der die Gestapo mit seinen ausführlich vorgetragenen Einwänden meinte verfahren zu können, befremdete Oberlandesgerichtspräsident Rothenberger derart, daß er sich fünf Tage später beschwerdeführend an das Reichsjustizministerium wandte.

Der Leiter des dortigen Generalreferates für politische Strafsachen, Dr. Herbert Klemm, erbat daraufhin mit Schreiben vom 13. Dezember vom Chef der Sicherheitspolizei eine Stellungnahme zu den von Rothenberger beklagten Vorgängen ${ }^{353}$. Dabei gab er zu bedenken, daß eine generelle Inschutzhaftnahme von Zeugen Jehovas nach Strafverbüßung einen geradezu gegenteiligen Effekt hervorrufen könne. Dies versuchte er an dem anderen Fall, der Gegenstand von Rothenbergers Beschwerde war, zu verdeutlichen. In besagtem Fall betraf die Schutzhaftverhängung eine Mutter von zwei Kindern, die Bibelforscherin Johanna F., die im Anschluß an die Verbüßung einer 15monatigen Gefängnisstrafe im Januar 1938 in ein KZ überstellt worden war, obgleich die Gefängnishaft von der Justiz bereits als „hart genug“ angesehen wurde. Oberstaatsanwalt Klemm brachte vor, daß in einem derartigen Fall befürchtet werden müsse, daß die übrigen, bisher nicht als Bibelforscher in Erscheinung getretenen Familienmitglieder ,so verbittert werden, daß in Zukunft mit einer staatsfeindlichen Einstellung zu rechnen" sei. Wenn wegen der Betätigung für die IBV Verurteilte sich von der Bibelforscherlehre abwenden, halte das Ministerium eine Freilassung dieser Personen nach der Strafverbüßung für

351 Von Fuhlsbüttel aus wurde der Zeuge Jehovas in das KZ Sachsenhausen überstellt. Nach seiner Entlassung verunglückte der durch die Hafterlebnisse gebrochene Mann tödlich; seine Frau wurde in Auschwitz ermordet. Vgl. Zeitzeugen aus Schleswig-Holstein. Ergänzung zur Ausstellung „Standhaft trotz Verfolgung“, Kiel 1997 (Tafel zu Ruth H.).

352 StA HH, Hanseatisches Oberlandesgericht Hamburg, Präsidialabteilung, 461-3a/1, Bl. 79.

353 BA, R 22/1467, RJM, Schreiben vom 13.12.1938 an den Chef der Sicherheitspolizei. 
angebracht und wünschenswert, ,damit sie allein schon durch das Beispiel weiterhin in ihrem ehemaligen Sektiererkreis zersetzend wirken“.

Am 24. Januar 1939 fand in Berlin eine Zusammenkunft von allen Oberlandesgerichtspräsidenten statt, bei der abermals auch Fragen im Zusammenhang mit Schutzhaftmaßnahmen auf der Tagesordnung standen. Rothenberger hatte zu dieser Zusammenkunft eine Aufstellung erarbeiten lassen, die - obwohl bei weitem nicht vollständig - 23 Fälle polizeilicher Urteilskorrektur durch Inschutzhaftnahme nach Freispruch oder Haftentlassung, die sich im Hamburger Oberlandesgerichtsbezirk zugetragen hatten, auflistete. Zu diesen Fällen gehörten auch solche, die Zeugen Jehovas betrafen. Rothenberger konnte in der Besprechung darauf verweisen, daß die von der Gestapo in den Akten vermerkten Haftgründe zuweilen ganz offen zeigten, daß diese sich als Korrekturinstanz gegenüber den Gerichten berufen fühlte. So hatte ein Kriminalsekretär in einem Fall die Schutzhaft deshalb für nötig erachtet, „um die verbüßte Strafe noch wirksamer zu gestalten“354.

Nach seiner Rückkehr aus Berlin teilte Rothenberger den Hamburger Gerichtspräsidenten mit, das Ministerium vertrete den Standpunkt, „daß Schutzhaftmaßnahmen, soweit sie reinen Präventivcharakter tragen, nicht zu beanstanden sind, daß jedoch Korrekturmaßnahmen, wie sie in verschiedenen Fällen bekannt geworden sind, nicht einreißen dürfen“355. Um zu unterstreichen, daß er weiterhin nicht gewillt sei, Anmaßungen der Polizei widerspruchslos hinzunehmen, bat er um „,sofortige Vorlage“ aller Fälle, in denen davon ausgegangen werden müsse, ,daß die Polizei das Urteil mit ihrer Haftmaßnahme zu korrigieren anstrebe“. Bei etwaigen Verhaftungen im Gerichtssaal sei er umgehend zu verständigen.

Anfang Februar erhielt das Justizministerium die von der Gestapo-Führung erbetene Stellungnahme zu den beiden Hamburger Fällen, die über den Einzelfall hinaus als ein grundlegender Bescheid zur Frage der Inschutzhaftnahme von Bibelforschern zu gelten hat. In diesem von Kriminalrat Heinrich Müller unterzeichneten Schreiben des Reichsführers-SS und Chefs der Deutschen Polizei wurde festgestellt, daß Bibelforscher ,nach Strafverbüßung nur dann in Schutzhaft genommen bzw. in ein Konzentrationslager verbracht werden, wenn sie trotz Verbüßung ihrer Strafhaft hartnäckig an der Irrlehre der Sekte weiterhin festhalten“356. Eine weitere „Verwahrung“ sei in derartigen Fällen ,unbedingt erforderlich, da bei der fanatischen Einstellung der IBV-Anhänger erfahrungsgemäß mit einer erneuten Betätigung für die verbotene Sekte zu rechnen“ sei. Diese Feststellungen unterstrichen - im Einklang mit der seit über einem Jahr allgemein gängigen GestapoPraxis, aber doch gewissermaßen entgegen dem anderslautenden Gestapa-Erlaß vom 22. April 1937 -, daß eine Überstellung von Zeugen Jehovas nach Beendigung der Strafhaft in ein KZ nicht ,grundsätzlich" erfolgen sollte, sondern dann, wenn die Gestapo eine Brechung der gegnerischen Einstellung und damit eine Gewähr für zukünftiges Wohlverhalten bislang noch nicht als gegeben ansah.

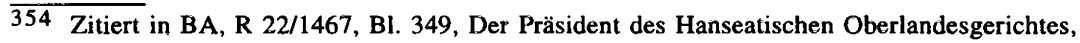
Schreiben vom 30.1.1939.

355 StA HH, Hanseatisches Oberlandesgericht Hamburg, Präsidialabteilung, 461-3a/1, B1. 87, Niederschrift über die Präsidentenbesprechung am 1.2.1939.

356 BA, R 22/1467, Bl. 325-327, RFSS, Schreiben vom 8.2.1939 an das RJM (Hervorhebung im Original). 
Weiter heißt es in der Stellungnahme, daß zur Klärung der Frage, „ob sich der IBV-Anhänger tatsächlich von der Irrlehre der Sekte freigemacht" hat, von der Gestapo in jedem Einzelfall eine ,eingehende Prüfung“ vorgenommen werde:

„Hierbei kann der Erklärung eines Bibelforschers, er habe sich von der Irrlehre freigemacht, allein kein entscheidender Wert beigelegt werden. Denn die Erfahrungen gerade bei der Durchführung dieser Prüfungen haben gezeigt, daß derartige Erklärungen häufig nur abgegeben werden, um die Freiheit zu erlangen. In zahlreichen Fällen wurden Bibelforscher bald nach Entlassung auf Grund derartiger Erklärungen wieder bei illegaler Betätigung für die IBV betroffen. Aus diesem Grunde ist die Glaubwürdigkeit der diese Erklärung abgebenden Bibelforscher besonders zu prüfen.“

Damit stand fest, daß die Unterschrift unter eine Verpflichtungserklärung für die Gestapo noch keinen hinreichenden Beleg für die geforderte Sinnesänderung ergab. Die Unterzeichnung des „Revers“ allein garantierte nicht eine Verschonung von weiterer Haft; sie bedeutete keineswegs automatisch die Freilassung. Vielmehr erfolgte auch bei Abgabe der geforderten Erklärung eine umfassende „Glaubwürdigkeitsprüfung “357.

Zu den Einzelfällen, die der Beschwerde Rothenbergers zugrunde lagen, erklärte die Gestapo, daß im ersten Fall die Inschutzhaftnahme gerechtfertigt gewesen sei, weil der Zeuge Jehovas auch nach dem Prozeß - in dem, wie erwähnt, die Richter durch ihr ,mildes' Strafmaß zum Ausdruck gebracht hatten, daß sie eine Fortführung der Inhaftierung für nicht erforderlich hielten - ,von der Irrlehre der Sekte nicht abließ“". Auch in dem anderen Fall sei die Einweisung in ein Konzentrationslager „unbedingt erforderlich“ gewesen, weil es sich um eine „äußerst gefährliche und von unbelehrbarem Fanatismus erfüllte Anhängerin der IBV“, somit also um

357 Den Zeugen Jehovas war es also weder durch einfache Unterschriftsleistung als „einzigen“ möglich, ,ihre Einlieferung [ins KZ] zu verhindern“, noch waren sie - wie in der Literatur fast durchgängig behauptet wird - in der Lage, „das Ende ihrer Haft mit Bestimmtheit durch eigenes Handeln herbeizuführen" (Pingel, Häftlinge, S. 87). Vielmehr überprüften die Staatspolizeistellen beziehungsweise im Konzentrationslager die „Politischen Abteilungen“ zunächst die „Glaubwürdigkeit“ der Unterschriftsleistung. In einem Runderlaß der Staatspolizeistelle Düsseldorf vom 27.4.1939 wurden die Polizeibehörden ausdrücklich belehrt, daß selbst dann, „wenn Bibelforscher die glaubhafte Erklärung abgegeben haben, sich künftig nicht mehr betätigen zu wollen oder gar die Verpflichtungserklärung unterschrieben haben“", nur auf Anordnung des Gestapa, das sich „, die Entscheidung über die Entlassung nach Strafverbüßung ausschließlich vorbehalten“ habe, eine Entlassung vorgenommen werden dürfe (Der Prozeß gegen die Hauptkriegsverbrecher, Band XXXI, S. 15f., Dokument 084-D). Die Überprüfung erfolgte während einer zumeist mehrere Tage dauernden, an die Entlassung aus der Justizhaft sich unmittelbar anschließenden Polizeihaft bei der für den Zeugen Jehovas örtlich zuständigen Staatspolizeistelle oder durch Einvernahmen während der zwischenzeitlichen vorübergehenden Unterbringung in Polizeigefängnissen oder Verwahrlagern (siehe S. 301f.).

In den Konzentrationslagern wurden Zeugen Jehovas, die den „Revers“ unterschrieben hatten, einer längeren „Beobachtungsphase“ ausgesetzt. Diese Praxis reagierte darauf, daß viele Zeugen Jehovas - da die Unterschrift regelmäßig unter dem augenblicklichen Druck einer extremen Zwangssituation zustande gekommen war - ihren Entschluß später wieder zurücknahmen und sich „,korrigierten“ (siehe S. 428). Das Verfahren der „Glaubwürdigkeitsprüfung“ hatte zur Folge, daß längst nicht alle, die ,unterschrieben“ (selbst jene, die ihre Unterschrift nicht widerriefen), auch tatsächlich entlassen wurden. Erst nach 1942 trat mit der „Besserstellung" der Zeugen Jehovas in den Konzentrationslagern (siehe S. 451ff.) eine Änderung ein. Die Lagerkommandanturen verzichteten fürderhin auf eine spezielle Überprüfung; die Unterschrift konnte nunmehr direkt zur Entlassung führen; gegen Kriegsende wurden Entlassungen zum Teil nach „,bloßer Verpflichtung auf Handschlag“ vollzogen (siehe S. 464-467). 
eine „eingefleischte Bibelforscherin“ handele, die sich in Freiheit „aller Wahrscheinlichkeit nach [...] sofort wieder für die staatsfeindlichen Ziele der IBV einsetzen" würde. Mit dieser Bemerkung sollte zugleich die präventive Funktion der Schutzhaft im Gegensatz zu der eine Straftat ahndenden Funktion der Justizhaft herausgestellt werden, um dem Reichsjustizministerium zu signalisieren, daß es sich weder um eine Kritik am gerichtlich verhängten Strafmaß noch um eine unzulässige Verlängerung der Strafhaft handeln würde. Die Gestapo unterstrich, daß eine Entlassung aus dem $\mathrm{KZ}$ in diesem - und damit zugleich in allen - Bibelforscherfällen solange nicht in Frage komme, wie sie „den sicherheitspolitischen Zweck" noch nicht als erfült ansehen könne.

Nach Eingang dieser Stellungnahme beschloß man im Justizministerium, dem Präsidenten des Hanseatischen Oberlandesgerichtes mitzuteilen, daß die von ihm beanstandeten Fälle ,im Hinblick auf die Ausführung des Reichsführers-SS zu weiteren Maßnahmen keinen Anlaß geben“358.

Das daraufhin gefertigte Antwortschreiben an Rothenberger, datierend auf den 27. März 1939 und unterzeichnet von Ministerialdirektor Crohne, ist ein bezeichnendes Beispiel für die Haltung der Justiz, die sich angesichts der von der Gestapo vorgenommenen Eingriffe in den Bereich justitiabler Angelegenheiten auf die Regelung des ihr jeweils noch verbliebenen Handlungsraumes zurückzog und damit zur „Legalisierung“ der Gestapo-Praktiken beitrug. So wird man es kaum anders als eine Selbstpreisgabe der Justiz bezeichnen können, wenn Crohne gegenüber Rothenberger grundsätzlich darauf verweist, daß es „,der pflichtgemäßen Prüfung der mit Handhabung vorbeugender Maßnahmen betrauten Stellen überlassen bleiben [muß], ob sie von den ihnen obliegenden Mitteln der Verbrecherbekämpfung Gebrauch machen“359.

In Form einer kasuistischen Grenzziehung führt das Schreiben dann jene Fälle an, in denen die Verhängung der Schutzhaft als ,eine vorbeugende polizeiliche Maßnahme" auch nach Tätigwerden der Justizbehörden und Abschluß der entsprechenden juristischen Schritte prinzipiell nicht zu beanstanden sei, gegenüber jenen Fällen, in denen eine Inschutzhaftnahme unter Umständen als unangebracht zu gelten habe. Unter Verweis auf das mit dem Reichsführer-SS in diesen Fragen bestehende Einvernehmen ließ das Reichsjustizministerium den Präsidenten des Hanseatischen Oberlandesgerichtes wissen, daß zum einen ,gegen Bibelforscher auch dann noch Schutzhaftmaßnahmen geboten sind, wenn sie trotz Verbüßung einer gegen sie erkannten Strafe nach wie vor hartnäckig an ihrer Irrlehre festhalten und so auch weiterhin das Staatswohl gefährden“, und daß ferner Schutzhaft ,auch gegen solche Staatsfeinde geboten sein kann, die in einem gerichtlichen Verfahren mangels Beweises freigesprochen worden sind". Erklärte sich das Ministerium mit der Inschutzhaftnahme im Anschluß an eine verbüßte Justizhaft und nach einem Freispruch einverstanden ${ }^{360}$, so erhob es auf der anderen Seite Bedenken gegen die

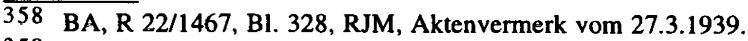

359 BA, R 22/1467, Bl. 329f., RJM, Schreiben vom 27.3.1939 an den Präsidenten des Hanseatischen OLG.

360 In Fällen, in denen ein freisprechendes Urteil nicht aus Mangel an Beweisen, sondern wegen erwiesener Unschuld erging, lehnte das RJM hingegen eine Schutzhaftverhängung kategorisch ab. Vgl. dazu Gruchmann, Justiz, S. $601 f$. 
Verhängung von Schutzhaft nach einem vorangehenden, von den Justizbehörden ausgesprochenen Gnadenerweis, weil ein ,im Gnadenwege“ verfügter Haftnachlaß mit Auflage einer Bewährungsfrist voraussetze, „daß die Gefahr eines Rückfalles für ausgeschlossen erachtet“" werde. Da die Gestapo Schutzhaftbefehle erließ, wenn sie ,die öffentliche Sicherheit und Ordnung unmittelbar gefährdet“" sah, hielt das Ministerium in letzterem Fall eine mögliche Diskrepanz zwischen justitiellen und polizeilichen Maßnahmen anscheinend für so bedenklich, daß man in diesem Punkt gegenüber dem Reichsführer-SS auf einer klaren Festlegung bestanden hatte. Dabei war es sicherlich nicht ohne Bedeutung, daß in dieser Frage Belange des Justizministeriums als Gnadeninstanz selbst berührt waren.

Von dieser Entschiedenheit war im anderen Fall, in dem das Ministerium eine Inschutzhaftnahme unter Umständen für „nicht angebracht“ hielt, nichts mehr zu spüren. Damit waren jene Vorgänge gemeint, bei denen Gerichte ,auf Grund einwandfreier Tatsachenfeststellungen“ zu der Überzeugung gelangten, durch „die bisherigen Zwangsmaßnahmen [...] den Strafzweck erreicht“ zu haben. Schon mit der kurzen Bemerkung ,,sehr häufig werden diese Fälle nicht sein“, deutete Ministerialdirektor Dr. Crohne jedoch an, daß man im Ministerium darin ein Problem von untergeordneter Bedeutung sah. Zudem gab Crohne zu verstehen, daß die Gerichte in den meisten Fällen zu dieser Frage kein kompetentes Urteil fällen könnten, da „,bei der Eigenart der Bibelforscher im allgemeinen eine längere Beobachtung erforderlich sein wird“. So kann es nicht verwundern, wenn Crohne dem Hamburger Oberlandesgerichtspräsidenten abschließend mitteilte, daß er auch in den von diesem angeführten Einzelfällen aufgrund der Sachlage der Verhängung von Schutzhaft „nicht entgegenzutreten“ vermag.

Mit dem vom Reichsjustizministerium - im Grunde seit 1933 - vertretenen Standpunkt, daß gegen die Schutzhaft als „vorbeugende polizeiliche Maßnahme“ grundsätzlich keine Bedenken zu erheben seien, hatte die Justiz sich von vornherein selbst der Kritikmöglichkeit an dem zunehmenden Eindringen der Gestapo in justitiable Angelegenheiten beraubt ${ }^{361}$. Denn damit hatte das Justizministerium zugleich die alleinige Definitionsgewalt in die Hände der Gestapo gelegt. Unter Verweis auf eine angeblich aufgrund polizeilicher Erkenntnisse erworbene Kenntnis von einer weiter bestehenden beziehungsweise erneut zu erwartenden Gefährdung des Staates ließ sich praktisch jede Inschutzhaftnahme als eine aus präventiven Gesichtspunkten heraus erfolgende Maßnahme darstellen.

361 Die alleinige Zuständigkeit der Gestapo für die aus „,staatspolizeilichen Notwendigkeiten“ angeordnete Schutzhaft zu „Präventionszwecken“ stand bei dieser Auseinandersetzung für die Justiz von vornherein außer Frage. Die Schutzhaft galt als eine politische Maßnahme und gehörte damit in den Bereich, der im „Führer-Staat“ von juristischen Reglementierungen und Nachprüfungsmöglichkeiten frei zu bleiben hatte. $\$ 7$ des Preußischen Gesetzes über die Geheime Staatspolizei vom 10.2.1936, mit dem der Rechtsweg gegen Verfügungen der Gestapo grundsätzlich ausgeschlossen wurde, bestimmte: „Verfügungen und Angelegenheiten der Geheimen Staatspolizei unterliegen nicht der Nachprüfung durch die Gerichte." (PrGS 1936, S. 21f.) 


\section{Polizeiliche Urteilskorrekturen durchgesetzt}

Nachdem die Gestapo-Praxis der Schutzhaftverhängung bei Bibelforschern im Prinzip von höchster Stelle gebilligt worden war, versuchten die Gerichte ihre Autorität durch die Zuflucht zu höheren Strafen zu wahren, da sie hofften, auf diese Weise ein mögliches Eingreifen der Gestapo und damit ",herabsetzende“ Urteilskorrekturen vermeiden zu können. Das Hanseatische Sondergericht entwickelte 1938 detaillierte „Richtlinien für die Bestrafung der Angeklagten in den Bibelforscherprozessen“. Diese sahen für „,vorbestrafte höhere Funktionäre“ (Gruppendiener, Hauptgruppendiener) eine Ansatzstrafe von 4 Jahren Gefängnis vor, für bislang „unbestrafte höhere Funktionäre“ 3 Jahre Gefängnis, für Zellendiener 2 Jahre 6 Monate (vorbestraft) bzw. 2 Jahre (unbestraft), für Schriftenverteiler 1 Jahr 3 Monate bzw. 1 Jahr Gefängnis und für ,einfache Mitglieder, die nicht verteilt haben, also nur Bezieher und Leser des ,Wachtturms' waren" 9 Monate bzw. 6 Monate Gefängnis ${ }^{362}$.

$\mathrm{Da}$ die Rechtsprechung der Sondergerichte zunehmend ,einheitlicher und straffer" geworden sei, stellte Ende 1938 der Sicherheitsdienst der SS mit Genugtuung fest und sah von daher kein Grund mehr zur Beanstandung ${ }^{363}$. Die härtere Handhabung der Strafgewalt durch die Gerichte drückte sich jedoch nicht allein in einem höheren Strafmaß aus ${ }^{364}$, sondern auch in einer Ausweitung der Tatbestandsmerkmale, so daß fortan bereits Andachten im Familienkreis oder eine gemeinsame Bibellektüre als eine Betätigung im Sinne der Bibelforschervereinigung gewertet wurden ${ }^{365}$.

Beispielsweise sah das Hanseatische Sondergericht in einer Entscheidung im Mai 1940 im Fall von zwei eng befreundeten Zeugen Jehovas eine Zuwiderhandlung gegen das IBV-Verbot bereits darin begründet, daß die beiden „,bewußt den Zusammenhalt untereinander aufrechterhalten " und sich "trotz Verbotes der IBV weiter über die Bibel unterhalten haben" 366 . Dies erfordere eine harte Strafe, weil die Angeklagten damit, ,wenn auch nur in kleinsten Anfängen, wieder eine

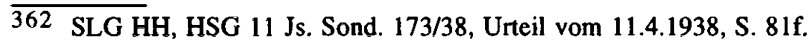

363 Jahreslagebericht 1938 des Sicherheitshauptamtes, Meldungen aus dem Reich, Band 2, S. 7 214 (126).

364 Vgl. die Tabellen über den durchschnittlichen Strafausspruch bei Zipfel, Kirchenkampf, S. 188 (anhand Berliner Entschädigungsakten; Urteile verschiedener Gerichte), und bei Kalous, Bibelforscher, S. 35 und Anhang 4 (Bibelforscherverfahren am SG München 1933 bis 1938).

365 Die Gerichte konnten sich dabei auf eine höchstrichterliche Entscheidung vom 17.2.1938 berufen. Das Reichsgericht sah in der Zusammenkunft zu einer „Familienandacht“ eine verbotene Betätigung, da die Gefahr bestünde, daß auf diese Weise der zwischen den bisherigen Mitgliedern der Glaubensgemeinschaft bestandene Zusammenhang im Rahmen der Familie fortgeführt werde und diese als „, Keimzelle für die künftige Wiedereröffnung der Sekte" nutzbar gemacht werden könne (DJ 100 [1938], S. 829f., RG, 5 D 599/37, Urteil vom 17.2. 1938).

366 SLG HH, HSG 11 Js. Sond. 608/40, Urteil vom 20.5.1940. (Handschriftlich wurde in die Urteilsschrift bei den Worten „über die Bibel unterhalten“ ein „,in ihrem Sinne“ eingefügt.) Im Jahre 1934 hatte das Reichsgericht noch ausdrücklich festgestellt, daß die „Fortsetzung freundschaftlicher Beziehungen zwischen zwei Personen [...] nicht den Begriff der Aufrechterhaltung eines organisatorischen Zusammenhalts" erfülle (JW 63 [1934], S. 767-769, RG, 4 D 244/33, Urteil vom 21.1.1934). 
Keimzelle der verbotenen IBV aufgezogen“" hätten ${ }^{367}$. Im Grunde war für die Verurteilung allein ausschlaggebend gewesen, daß beide Beschuldigten, die jeweils bereits eine lange Haftstrafe verbüßt hatten, sich noch immer unbeugsam zeigten und sich offen zu ihrem Glauben bekannten. Außer den rein privaten Bibelstudien konnte ihnen weder eine Verbindung zu illegal tätigen IBV-Gruppen noch eine Einwirkung auf Außenstehende nachgewiesen werden. Für ihre gemeinsame Bibellektüre wurden sie mit je drei Jahren Gefängnis bestraft. Im Jahr darauf wurde vom gleichen Gericht ein durch seine ehemalige Verlobte denunzierter 49jähriger Hamburger Bibelforscher wegen „Verächtlichmachung der Reichsregierung“ (Vergehen gegen das Heimtückegesetz) zu ebenfalls drei Jahren Gefängnis verurteilt, weil er in einem privaten Gespräch Hitler ,als einen vom Papst in Rom eingesetzten Teufel“" 368 bezeichnet hatte.

Von einzelnen Justizorganen wurde auch die Anregung der Gestapo aufgegriffen und eine Aburteilung von Bibelforschern wegen „Vorbereitung zum Hochverrat“ erwogen. Auf diese Weise beabsichtigte der Generalstaatsanwalt beim Hanseatischen Oberlandesgericht zum Beispiel gegen die an der Flugblattaktion vom Juni 1937 beteiligten Hamburger Zeugen Jehovas vorzugehen. Da die Anklageerhebung für Hochverratsdelikte in die Zuständigkeit des Oberreichsanwaltes gehörte, übergab Generalstaatsanwalt Erich Drescher diesem die Ermittlungsakten des sich gegen 127 Beschuldigte richtenden Verfahrens zur Prüfung. In dem Anschreiben vom 5. Januar 1938 führte Drescher zur Begründung aus: „Bisher wurden die Anhänger der Bibelforscher-Vereinigung wegen ihrer verbotenen Betätigung stets auf Grund des § 4 der Verordnung des Reichspräsidenten zum Schutze von Volk und Staat vom 28.2.33 abgeurteilt. Da nach den [...] Zielen der langsam in ein kommunistisches Fahrwasser abgleitenden IBV der Verdacht einer hochverräterischen Betätigung begründet erscheint, wird die Akte hiermit zur Entscheidung [übergeben], ob und inwieweit die Betätigung der Beschuldigten als Vorbereitung zum Hochverrat anzusehen ist und dementsprechend verfolgt werden soll." ${ }^{369} \mathrm{Um}$ die Aktivitäten der Zeugen Jehovas unter dem Tatbestand eines hochverräterischen Unternehmens subsumieren zu können, hatte Drescher auf das seiner Einschätzung nach „umstürzlerische“ Ziel der Glaubensgemeinschaft verwiesen, das „in der

$\overline{367}$ Das Hanseatische Sondergericht hatte zwei Jahre zuvor die folgende Tatbestandsdefinition über die „Bibelforscherbetätigung“" entwickelt, die auch in diesem Prozeß zugrunde gelegt wurde: „Voraussetzung für die Strafbarkeit ist in objektiver Beziehung lediglich das Bilden oder Aufrechterhalten eines Kontakts zwischen mindestens zwei Personen auf der Grundlage der Lehre der Internationalen Bibelforscher und in subjektiver Beziehung der Wille oder das Bewußtsein, daß durch das eigene Verhalten ein solcher Kontakt gebildet oder aufrechterhalten wird." (FGN-NHS 13-7-3-3, HSG, 11 Js. Sond. 297/38, Urteil vom 23.4.1938, S. 32) Diese Rechtsauffassung vertrat das Gericht in Kenntnis dessen, daß eine Trennung zwischen strafbarer Betätigung und an sich straffreiem persönlichen Glauben bei den Zeugen Jehovas schlechterdings nicht möglich ist, da „die Propaganda für diese Lehre Bestandteil des Glaubens“ sei: „Mit anderen Worten: Jeder Bibelforscher muß , das Königreich verkünden“, wenn er sich nicht mit dem Ausschluß vom Weiterleben im Königreich bestraft sehen will (die Bibelforscher selber sehen das ,verkünden' auch als Bestandteil ihres Glaubens, nicht als Betätigung des Glaubens an)." (SLG HH, HSG 11 Js. Sond. 173/38, Urteil vom 11.4.1938, S. 13)

368 SLG HH, Amtsgericht Hamburg 131 Ds 1432/40, darin: HSG 11 Js. Sond. 956/40, Urteil vom 25.3.1941.

369 DCB, VGH, 8 J 20/38, BI. 1-20 (19), Der Generalstaatsanwalt bei dem Hanseatischen Oberlandesgericht, Schreiben vom 5.1.1938. 
- angeblich gottgewollten - Vernichtung der Regierungen aller Länder und damit auch der nationalsozialistischen" bestehe.

Der oberste Anklagevertreter im Deutschen Reich mochte dieser Lageeinschätzung jedoch nicht folgen. Bereits zwei Wochen nach der Übersendung erhielt der Hamburger Generalstaatsanwalt die eingereichten 139 Einzelakten und Schnellhefter aus Berlin zurück. In der entsprechenden Verfügung vom 19. Januar 1938 stellte der Oberreichsanwalt beim Volksgerichtshof fest, daß sich aus seiner Sicht kein hinreichender Verdacht einer in seine Zuständigkeit gehörenden Straftat ergeben habe: „Insbesondere haben die Ermittlungen keinen ausreichenden Anhalt dafür erbracht, daß die Beschuldigten die gewaltsame Beseitigung der nationalsozialistischen Regierung entweder selbst erstrebt oder in Kenntnis solcher, etwa im Verein mit dem Kommunismus verfolgter Ziele der ausländischen Organisation der IBV sich für diese betätigt haben. "370 Aus diesem Grunde sei „das Erforderliche“" wie bisher in eigener Zuständigkeit zu veranlassen.

Für die beschuldigten Zeugen Jehovas bedeutete dies, daß sie weiterhin ,nur aufgrund eines Vergehens gegen $\S \S 1$ und 4 der Verordnung zum Schutz von Volk und Staat zu einer Strafe von höchstens fünf Jahren Gefängnis verurteilt werden konnten, während bei einem Verfahren wegen Vorbereitung zum Hochverrat das Strafmaß gegebenenfalls bis zur Todesstrafe hätte ausgedehnt werden können.

Als ein Vierteljahr nach der Entscheidung des Oberreichsanwaltes in Hamburg das Hanseatische Sondergericht in dieser Sache verhandelte, nahm es auf diese Frage in der Urteilsschrift kurz Bezug: „Und lediglich der Umstand, daß die Bibelforscher diese Vernichtung nicht selber vornehmen wollen, sondern sie dem Oberbefehlshaber Christus überlassen, unterscheidet sie von Hochverrätern. “371

Damit unterschieden sich in der Sicht des Gerichtes zwar die Handlungen, aber nicht die Ziele der Zeugen Jehovas von denen von Umstürzlern und Hochverrätern. Zum Beleg verwiesen die Richter, die sich ,ausführlich“ mit der Glaubenslehre der Zeugen Jehovas ,beschäftigt“ hatten, auf deren Vorstellungen von der zukünftigen Weltordnung in dem von ihnen proklamierten „Tausendjährigen Reich“. Dazu stellten sie fest, daß ,für das ganze Wirtschaftsleben [...] eine religiös-kommunistische Gemeinschaftsordnung vorgesehen" wäre. Die Ausgestaltung der bibelforscherischen Vorstellung vom Königreich Gottes geschehe nämlich ,in Anlehnung an die Zustände in der Urchristengemeinde (Apostelgeschichte, Kapitel 4,32). Aller Besitz wird gleichmäßig aufgeteilt ${ }^{\star 372}$. Solche urchristlichen Ideale identifizierten die nationalsozialistischen Juristen offenkundig mit den Absichten von Hochverrätern und Umstürzlern.

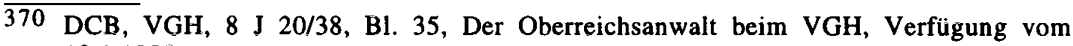
19.1.1938.

371 SLG HH, HSG 11 Js. Sond. 173/38, Urteil vom 11.4.1938, S. 75. In einem anderen, zum gleichen Tatkomplex geführten Verfahren wurde ausdrücklich eingeräumt, daß der Nachweis einer Verbindung zum Kommunismus nicht geführt werden konnte: „Der Schutz des nationalsozialistischen Staates vor den Internationalen Bibelforschern verlangt daher, daß die Angeklagten hart bestraft werden, auch wenn ihre Gefährlichkeit einzelnen nicht völlig zum Bewußtsein gekommen ist und nicht festgestellt wurde, $\mathrm{da}$ einer der Angeklagten früher Kommunist war oder heute mit den Kommunisten Sowjet-Rußlands sympathisiert." (SLG HH, HSG 11 Js. Sond. 179/38, Urteil vom 4.5.1938, S. 32)

372 SLG HH, HSG 11 Js. Sond. 173/38, Urteil vom 11.4.1938. 
Auch andere von Staatsanwaltschaften bei dem Oberreichsanwalt zum Zwecke einer Anklageerhebung wegen „Vorbereitung zum Hochverrat“ eingereichte Bibelforscherverfahren waren nach Ansicht des obersten Anklägers nicht geeignet, diesen Tatvorwurf tatsächlich zu begründen. Im Januar 1940 gingen beispielsweise drei eingereichte Verfahren gegen IBV-Gruppen aus dem Sudetengebiet und aus Österreich an die örtlichen Staatsanwaltschaften mit dem Vermerk zurück, daß bei keinem der Beschuldigten ,ein hochverräterischer Vorsatz hat nachgewiesen werden können“"373. Es scheint während der ganzen zwölf Jahre des Nazi-Regimes, wenn überhaupt, dann nur in besonders gelagerten Einzelfällen zu einer Aburteilung von Bibelforschern unter Anwendung der Strafvorschriften über hochverräterische Betätigung ( $\$ \S 80-84 \mathrm{StGB}$ ) gekommen zu sein ${ }^{374}$. Da diese Strafrechtsnorm auf die Aktivitäten der Bibelforscher als unanwendbar galt, bedurfte es - um über die mit der Reichspräsidentenverordnung ursprünglich gesetzte Grenze hinaus höhere Strafen zu erreichen - der Schaffung von neuen Rechtsvorschriften, wozu es nach Kriegsbeginn mit Erlaß derjenigen Gesetzesbestimmungen auch kam, die für die ,Teilnahme an einer wehrfeindlichen Verbindung“ sowie für ,Zersetzung der Wehrkraft" - in beiden Fällen handelte es sich um neu gebildete Deliktgruppen - schwerste Strafen androhten.

Ebenso wie bei dem polizeilichen Verlangen nach Strafverschärfung kamen die Justizorgane auch beim Gnadenverfahren der Gestapo weit entgegen ${ }^{375}$. Sie holten fortan vor möglichen Begnadigungen erst eine Auskunft der Gestapo ein, ob im Falle einer Strafaussetzung Einwendungen geltend gemacht und eine Inschutzhaftnahme eventuell erfolgen würde, um sich dann an dem jeweiligen GestapoVotum zu orientieren. So wurde auch bei einem Gnadengesuch für einen 63jährigen Gefangenen verfahren, der im Vorjahr wegen Betätigung für die IBV zu zweieinhalb Jahren Gefängnis verurteilt worden war. Nachdem das Gesuch bei der

$\overline{373}$ BA, R 22/3390, B1. 20, Der Oberreichsanwalt beim VGH, Lagebericht vom 31.1.1940.

374 Vgl. den bei Kammler, Kasseler Soldaten, S. 138-141, dokumentierten Fall des Lothar Schirmacher, bei dem die Betätigung für die IBV mit politischer Widerstandsaktivität zusammenfiel. Der 1916 geborene Schirmacher, dessen Eltern seit 1922 der IBV angehörten, hatte sich kurz vor der nationalsozialistischen Machtergreifung dem „Internationalen Sozialistischen Kampfbund“ angeschlossen. Wegen Mitwirkung an der Verbreitung des IBV-Flugblattes ,Resolution" wurde er seinen Angaben zufolge vom Kasseler Sondergericht am 5.5.1937 wegen Vergehens gegen die VOSchVuS in Tateinheit mit „Vorbereitung zum Hochverrat" zu zwei Jahren Gefängnis verurteilt.

375 Es gilt allerdings ausdrücklich festzustellen, daß nicht erst die Beteiligung der Gestapo bei Gnadenverfahren, die teilweise bereits seit 1937 erfolgte, dazu führte, da $\beta$ nur in wenigen Fällen eine Begnadigung ausgesprochen wurde. Vielmehr erwies sich die Praxis der Justizbehörden selbst als ausgesprochen restriktiv. Anhand einer Auswertung von Vollstreckungsund Gnadenheften zu 20 Verfahren, die im Frühjahr 1937 vor dem SG München zur Verurteilung von 103 Zeugen Jehovas zu Zeitstrafen geführt hatten (StA M, Staatsanwaltschaften 8551), stellt sich die Gnadenpraxis wie folgt dar: Bei den 101 Verurteilten, von denen ein Vollstreckungsheft überliefert ist, ist in knapp der Hälfte der Fälle $(47,5 \%)$ ein Gnadengesuch gestellt worden, wobei von diesen 48 Gesuchen 21 von den Verurteilten selbst eingebracht wurden; bei den anderen Bittstellern handelt es sich zumeist um die Ehepartner oder nahe Verwandte, in Einzelfällen auch um die Arbeitgeber oder die Rechtsanwälte. Von diesen 48 Gnadengesuchen wurden 42 abgewiesen, und lediglich sechs Gnadengesuche wurden befürwortet. In 17 Fällen wurde eine Beschwerde gegen die Abweisung eingelegt, denen in acht Gnadenverfahren entsprochen wurde. Somit führten insgesamt 14 Gesuche $(29,2 \%)$ zu einer Begnadigung mit Aussetzung der Reststrafe zur Bewährung. Die anderen 87 Verurteilten mußten ihre Strafe voll verbüßen. 
Justiz eingegangen war, bat diese vier Wochen später die Hamburger Staatspolizeileitstelle um ihre Stellungnahme. Von dort wurde mit Schreiben vom 11. November 1939 mitgeteilt, daß gegen die Gewährung eines Gnadenerweises keine Einwendungen erhoben würden, wenn der Betreffende die beigefügte Verpflichtungserklärung unterschreibe; eine Inschutzhaftnahme sei ,nur beabsichtigt, wenn er die genannte Erklärung nicht unterschreibt“376.

Insoweit entsprach dies jener Praxis, die die Justiz bei Gnadenverfahren zwecks Vermeidung einer Kollision von Begnadigung und Schutzhaft herausgebildet hatte. Doch noch bevor dieses Verfahren abgeschlossen werden konnte, revidierte die Gestapo ihre bisherige Haltung. Am 16. März 1940 übermittelte die Staatspolizeileitstelle Hamburg der Staatsanwaltschaft eine in Berlin getroffene für derartige Fälle allgemeinverbindliche Entscheidung: „Das Reichssicherheitshauptamt hat mitgeteilt, daß es aus grundsätzlichen Erwägungen - insbesondere während der Kriegszeit - Begnadigungen bei Bibelforschern nicht zu befürworten vermag. “377

Danach stand auch für die Justiz ein Gnadenentscheid nicht mehr zur Debatte, zumal die Verzögerung des Gnadenverfahrens dazu geführt hatte, daß nur noch eine kurze Strafzeit zu verbüßen blieb. Da jedoch die Berliner Grundsatzentscheidung zu einer gewissen Verunsicherung der Justizbeamten beigetragen zu haben scheint, fragte man vorsichtshalber noch einmal bei der Gestapo nach, ob mit weiteren polizeilichen Maßnahmen zu rechnen sei. Die Gestapo entkräftete diese Bedenken und teilte mit: „Eine Inschutzhaftnahme nach der Strafverbüßung ist nicht in Aussicht genommen, nachdem F. die Verpflichtungserklärung betreffs Bibelforscher unterschrieben hat.“"378

Die Beteiligung der Gestapo am Gnadenverfahren wie die von ihr gefällten Entscheidungen, die die tatsächliche Haftdauer schließlich bestimmten, sind beredte Beispiele für eine Entwicklung, an deren Ende die Polizei nicht mehr das Hilfsorgan der Justiz, sondern die Justizorgane - teils genötigt, teils im vorauseilenden Gehorsam und teilweise auch aus eigenem Antrieb - Ausführende derjenigen Vorgaben waren, die von den in der Berliner Prinz-Albrecht-Straße residierenden obersten Polizeibehörden ausgegeben wurden. Oder mit anderen Worten: Die Art, wie die beim Vorgehen gegen die Zeugen Jehovas besonders deutlichen Konflikte und Kompetenzfragen ausgetragen und entschieden wurden, ist Ausdruck für die letztlich nahezu vollständige Kapitulation der Justiz vor dem Reichsführer-SS.

$\overline{376}$ SLG HH, HSG 11 Js. Sond. 298/38, GnH 1256/41, B1. 5, Staatspolizeileitstelle Hamburg, Schreiben vom 11.11.1939 an den Generalstaatsanwalt bei dem Hanseatischen OLG.

377 Ebenda, B1. 13, Staatspolizeileitstelle Hamburg, Schreiben vom 16.3.1940.

378 SLG HH, HSG 11 Js. Sond. 298/38, GnH 1256/41, Bl. 15, Staatspolizeileitstelle Hamburg, Schreiben vom 28.3.1940. 